\title{
Uma Contribuição ao Processo de Desenvolvimento e Modelagem de Módulos Educacionais
}

\author{
Ellen Francine Barbosa
}

Tese apresentada ao Instituto de Ciências Matemáticas e de Computação de São Carlos USP, como parte dos requisitos para a obtenção do título de Doutor na Área de Ciências de Computação e Matemática Computacional.

Orientador: Prof. Dr. José Carlos Maldonado

São Carlos/SP

Março/2004 

"Quando ensinares, ensina também a duvidar daquilo que ensinas."

(José Ortega y Gasset) 
A minha mãe. 


\section{Agradecimentos}

A DEUS, pela vida. E pelas alegrias e dificuldades que dela fazem parte, proporcionando-nos aprendizado e amadurecimento. Sem Ele, eu nada seria...

Ao meu orientador, Prof. Dr. José Carlos Maldonado, pela confiança e sobretudo pela amizade conquistada ao longo desses quase oito anos de convívio.

A minha mãe, por simplesmente TUDO!

Aos meus familiares, em especial Angelina e Armando, Nidia, Marcel, Loiane e Gabriel, pelo amor e incentivo.

Ao Pe. José Carlos Frederice, pela amizade e pelo apoio e incentivo constantes.

Ao Luiz Eduardo, pelo amor, incentivo e paciência durante a fase final deste trabalho.

Ao professores do Georgia Tech - Prof. Dr. Richard LeBlanc e Prof. Dr. Mark Guzdial -, e aos professores da University of Florida - Profa. Dra. Sue Legg e Prof. Dr. Terry Morrow -, por me aceitarem em seus grupos de pesquisa durante o estágio nos EUA. À Profa. Dra. Maria da Graça Pimentel e ao Prof. Dr. Ivan Ricarte, pelos “contatos iniciais” que possibilitaram o estágio.

À Eliane, Márcio, Daniel e D. Cida, ao Renato, à Ana e Cláudio, à Janaína e Carlos, pela acolhida e por se tornarem minha "família brasileira" nos EUA.

Aos professores do grupo de Engenharia de Software: Profa. Dra. Rosely Sanches, Profa. Dra. Renata P. M. Fortes e Prof. Dr. Paulo C. Masiero.

Aos colegas do LABES: Simone, Elisa, Mateus, André, Erika, Delamaro, Thaise, Aline, Alê, Gelza, Maris, Marco, Rejane, Rosana, Luciana, KLB, Sandrão (cantina), Tânia, Edilson, Osnete, Bira, Camila, Otávio, André (Clone), Fabiano, Débora, Vartinho, Willie, Sandra e Adenilso.

Aos meus amigos: Tatiana, Ana Cláudia, Sandro, Mayb, Camillo, Rudinei, Flávia, Thelma, Valéria, Júlio. E, é claro, aos "meninos do Oeste Paulista", Sílvio, Rogério, Patão (desculpe, Guilherme!!), Cassio, Klebinho, Reginaldo e Rodrigo. Os momentos que passamos juntos sempre estarão guardados em meu coração.

À Andrea e Evelise, pelas brincadeiras, pelas brigas, pelo convívio de tantos anos...

Com muita saudade, à D. Rosinha e a Ricardo Pelegrini.

Aos professores e funcionários do ICMC, pela disposição e atenção.

À FAPESP pelo apoio financeiro. 

Resumo $\quad$ xiii

$\begin{array}{lll}\text { Abstract } & \text { Xv }\end{array}$

1 Introdução 1

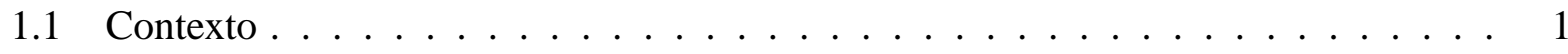

1.2 Motivação . . . . . . . . . . . . . . . . . . . 3

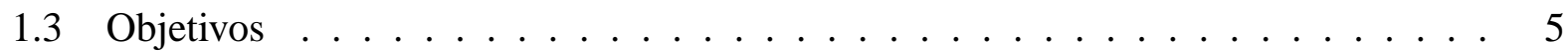

1.4 Organização da Tese . . . . . . . . . . . . . . . . 6

2 Revisão Bibliográfica 9

2.1 Considerações Iniciais . . . . . . . . . . . . . . . . . . . . . . 9

2.2 Mecanismos e Abordagens de Apoio à Modelagem de Conteúdos Educacionais . . 9

2.2.1 Mapas Conceituais . . . . . . . . . . . . . . . . 10

2.2.2 Modelo/Metodologia Daphne . . . . . . . . . . . . . . 11

2.2 .3 Método EHDM . . . . . . . . . . . . . . . . . . . . . 13

2.2 .4 Metodologia MAPHE . . . . . . . . . . . . . . . . . . . . . . . . . 15

2.2 .5 Modelo RMM . . . . . . . . . . . . . . . . . . . 17

2.2 .6 Método OOHDM . . . . . . . . . . . . . . . . . 17

2.2 .7 Modelo EORM . . . . . . . . . . . . . . . . . . . 18

2.2 .8 Modelo Trellis . . . . . . . . . . . . . . . . . . . . . . 19

2.2 .9 Modelo HMBS . . . . . . . . . . . . . . . . . . . . . . . . . . . . . . . . 20

2.2 .10 Modelo MDE . . . . . . . . . . . . . . . . . . . . 24

2.2.11 Síntese dos Mecanismos e Abordagens Consideradas . . . . . . . . . . . . 26

2.3 Ambientes e Sistemas Educacionais . . . . . . . . . . . . . . . . 27

2.3 .1 O Ambiente WebCT . . . . . . . . . . . . . . . 28

2.3 .2 O Ambiente AulaNet . . . . . . . . . . . . . . . . . . . 28

2.3 .3 O Ambiente ATEnA . . . . . . . . . . . . . . . . . . . . . . . 29

2.3.4 O Ambiente Eureka e a Ferramenta WCC . . . . . . . . . . . . . . . . 30

2.3.5 A Ferramenta $\mathrm{CoWeb} \ldots \ldots \ldots \ldots \ldots \ldots \ldots$

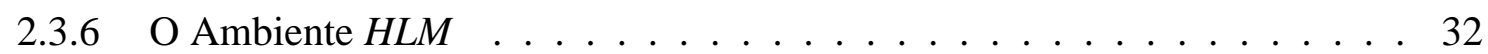

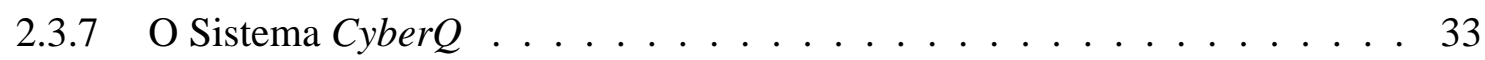

2.3 .8 O Ambiente $e$-Class . . . . . . . . . . . . . . . . 33

2.3.9 Síntese dos Ambientes e Sistemas Considerados . . . . . . . . . . . . . . 34

2.4 Processos de Software . . . . . . . . . . . . . . . . . . . 35 
$2.4 .1 \quad$ A Norma ISO/IEC $12207 \ldots \ldots \ldots \ldots \ldots$

2.4 .2 O Modelo CMM . . . . . . . . . . . . . . . . . . 37

2.4.3 Processo Padrão para Equipes Geograficamente Dispersas . . . . . . . . . . 39

2.5 Teste de Software . . . . . . . . . . . . . . . . . . . . . . 42

2.5.1 Técnicas de Teste . . . . . . . . . . . . . . . . . . . . . . 44

2.5.2 Ferramentas de Teste . . . . . . . . . . . . . . . . . 51

2.5.3 Estudos Teóricos e Empíricos . . . . . . . . . . . . . . . 54

2.6 Considerações Finais . . . . . . . . . . . . . . . . . . . . . . . 61

3 Modelagem de Conteúdos Educacionais $\quad 63$

3.1 Considerações Iniciais . . . . . . . . . . . . . . . . . . . . . 63

3.2 Módulos Educacionais: Definição e Perspectivas de Desenvolvimento . . . . . . . 65

3.2.1 Módulos Educacionais e Objetos de Aprendizado . . . . . . . . . . . . . . 70

3.3 Requisitos para Modelagem de Conteúdos Educacionais: um Conjunto Preliminar . 72

3.4 Modelos Genéricos para Representação de Conteúdos Educacionais ..... . 79

3.4.1 Modelo Conceitual . . . . . . . . . . . . . . . . . . . 80

3.4 .2 Modelo Instrucional $\ldots \ldots \ldots \ldots$. . . . . . . . . . 82

3.4 .3 Modelo Didático . . . . . . . . . . . . . . . . . . . . 84

3.5 Modelos para Representação de Conteúdos Educacionais: Análise e Comparação 86

3.5.1 Abordagens para Construção de Hiperdocumentos Educacionais ..... 87

3.5.2 Abordagens para Construção de Hiperdocumentos Genéricos . . . . . . . . 99

3.6 Abordagem Integrada para Modelagem de Conteúdos Educacionais . . . . . . . . 105

3.7 Mecanismos de Modelagem: Aplicação no Contexto de Objetos de Aprendizado . 112

3.8 Considerações Finais . . . . . . . . . . . . . . . . . 116

4 Padronização de Processos para Elaboração de Módulos Educacionais 119

4.1 Considerações Iniciais . . . . . . . . . . . . . . . . . . . . . . . 119

4.2 Aspectos de Desenvolvimento na Definição do Processo Padrão . . . . . . . . . . 120

4.2 .1 Projeto Instrucional . . . . . . . . . . . . . . . . . . . . 121

4.2.2 Desenvolvimento de Produtos Livres . . . . . . . . . . . . . . . . 121

4.2.3 Desenvolvimento Colaborativo e Distribuído . . . . . . . . . . . . . . . 124

4.3 Visão Geral do Processo Padrão . . . . . . . . . . . . . . . . . . . . . . 125

4.4 Adequação do Processo às Perspectivas de Desenvolvimento de Módulos Educa-

cionais . . . . . . . . . . . . . . . . . . . . . . . . . 129

4.5 Processos do Ciclo de Vida de um Módulo Educacional . . . . . . . . . . . . . . 132

4.5.1 Processos Fundamentais . . . . . . . . . . . . . . . . . 132

4.5.2 Processos de Apoio . . . . . . . . . . . . . . . . . . . . . . . . . . . . . . . . . . . . . . . . . . .

4.5.3 Processos Organizacionais . . . . . . . . . . . . . . . . . . . . . . 148

4.6 Modelo para a Definição de Processos . . . . . . . . . . . . . . . . . . . . 152

4.7 Aspectos de Especialização do Processo Padrão para Módulos Educacionais . . . . 154

4.7.1 Estrutura do Modelo de Maturidade para Módulos Educacionais . . . . . . 154

4.7.2 Especialização do Processo Padrão para os Níveis de Maturidade . . . . . 157

4.8 Instanciação do Processo Padrão para Módulos Educacionais . . . . . . . . . . . . 161

4.8 .1 Recursos Humanos . . . . . . . . . . . . . . . . . . . . . . . 162

4.8.2 Métodos e Técnicas de Desenvolvimento . . . . . . . . . . . . . . . . . . 163

4.8.3 Recursos Tecnológicos e Computacionais . . . . . . . . . . . . . . . . . 164

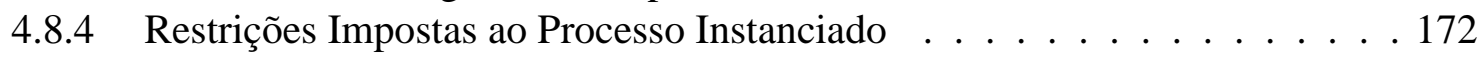

4.9 Considerações Finais . . . . . . . . . . . . . . . . . . . . . 173 
5.1 Considerações Iniciais . . . . . . . . . . . . . . . . . . . . 175

5.2 Aspectos Gerais do Módulo Teste de Software: Teoria e Prática . . . . . . . . . . . 176

5.3 Aplicação do Processo Padrão Instanciado no Domínio de Teste de Software . . . . 178

5.3.1 Determinação da Condição de Aprendizado Atual . . . . . . . . . . . . . . . 178

5.3.2 Definição das Metas de Aprendizado e Habilidades Associadas . . . . . . . . 179

5.3.3 Definição da Estrutura Geral do Módulo . . . . . . . . . . . . . . . . . . . 179

5.3.4 Planejamento da Equipe de Desenvolvimento . . . . . . . . . . . . . . 183

5.3.5 Determinação da Metodologia, Padrões e Ferramentas . . . . . . . . . . . . 183

5.3.6 Análise de Audiência . . . . . . . . . . . . . . . . . . . . . . 184

5.3.7 Modelagem de Conteúdos Educacionais . . . . . . . . . . . . . . . . . . . . . . . 205

5.3 .8 Projeto da Interface . . . . . . . . . . . . . . . . . . . 201

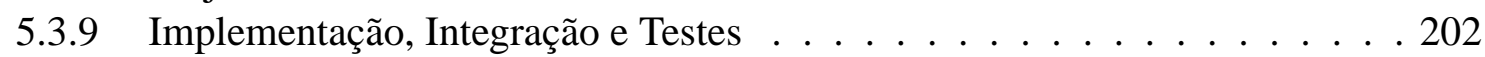

5.3 .10 Disponibilização do Módulo . . . . . . . . . . . . . . . . . . 203

5.3.11 Identificação de Problemas e Melhorias . . . . . . . . . . . . . . . . . 206

5.4 Considerações Finais . . . . . . . . . . . . . . . . . . 206

6 Conclusão $\quad 209$

6.1 Visão Geral da Pesquisa Realizada . . . . . . . . . . . . . . . . . . . . . . . . . . . . . . . . . . . . . . . . .

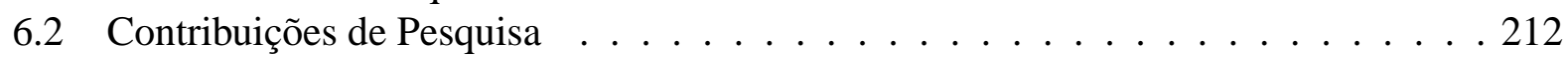

6.3 Trabalhos Futuros . . . . . . . . . . . . . . . . . . 213

6.4 Produção Científica . . . . . . . . . . . . . . . . . . . . . 215

6.4.1 Publicações Relacionadas . . . . . . . . . . . . . . . . . . . . . . . . 215

6.4.2 Publicações Esperadas . . . . . . . . . . . . . . . . 215

$\begin{array}{ll}\text { Referências Bibliográficas } & 217\end{array}$

A Modelo de Maturidade de Processos para Elaboração de Módulos Educacionais 235

A.1 Níveis de Maturidade . . . . . . . . . . . . . . . . . . . . 235

A.1.1 Nível 1 - Inicial (Organizações Caóticas) . . . . . . . . . . . . . . . 236

A.1.2 Nível 2 - Repetível (Organizações Disciplinadas) . . . . . . . . . . . . . 236

A.1.3 Nível 3 - Definido (Organizações Padronizadas) . . . . . . . . . . . . . . . 238

A.1.4 Nível 4 - Gerenciado (Organizações Previsíveis) . . . . . . . . . . . . . . 241

A.1.5 Nível 5 - Otimizado (Organizações com Melhoria Contínua) . . . . . . . . 242

A.2 CMMI para Módulos Educacionais . . . . . . . . . . . . . . . . . . . 243

B Avaliação de Módulos Educacionais: Questionário e Síntese dos Resultados 247

B.1 Usabilidade - Interface . . . . . . . . . . . . . . . . . . . . . . 248

B.2 Conteúdo: Conceitos, Exemplos, Exercícios e Informações Complementares . . . . 249

B.3 Navegação . . . . . . . . . . . . . . . . . . . . . . . . 250

B.4 Aspectos Gerais . . . . . . . . . . . . . . . . . . . . . . . . . . . . . . . . . . . . . . . . . .

B.5 Síntese dos Resultados Obtidos . . . . . . . . . . . . . . . . . . 252 



\section{Lista de Figuras}

2.1 Estrutura de um Mapa Conceitual (Moreira \& Buchweitz, 1987). . . . . . . . . . . 11

2.2 Camadas do Modelo/Metodologia Daphne (Kawasaki \& Fernandes, 1996). . . . . 12

2.3 Fases do Método EHDM (Pansanato \& Nunes, 1999). . . . . . . . . . . . . . . . . 14

2.4 Etapas da Metodologia MAPHE (Pimentel, 1997). . . . . . . . . . . . . . . . 15

2.5 MDE: Estruturação dos Conteúdos de um Hiperdocumento Educacional. . . . . . . 26

2.6 Processos de Ciclo de Vida de Software (da Rocha et al., 2001). . . . . . . . . . . 36

2.7 Correspondência entre CMM e CMMI. . . . . . . . . . . . . . . . . . . . . 40

2.8 Estrutura do Processo Padrão para Equipes Dispersas (Maidantchik, 1999). . . . . 41

3.1 Componentes de um Módulo Educacional. . . . . . . . . . . . . . . . . . . . . 65

3.2 Mapa Conceitual para o Domínio de Harmonia Musical (Kawasaki \& Fernandes, 1996). . . . . . . . . . . . . . . . . . . . 87

3.3 Esquema HDM para Harmonia Musical (Kawasaki \& Fernandes, 1996). . . . . . . 89

3.4 Modelo Conceitual Hierárquico para o Domínio de Movimentos Retilíneos (Pansanato \& Nunes, 1999). . . . . . . . . . . . . . . . . . . . . . . . . . 91

3.5 Exemplo de um Modelo Navegacional de Contextos para o Domínio de Movimentos Retilíneos (Pansanato \& Nunes, 1999). . . . . . . . . . . . . . . . . . . . . 92

3.6 Modelo Orientado a Conceitos para o Domínio de Figura Plana (Pimentel, 1998). . 94

3.7 Mapa Conceitual de um Curso Básico sobre HTML (Leiva, 2003). . . . . . . . . . 96

3.8 Representação Gráfica mais Abstrata do Curso sobre HTML (Leiva, 2003). . . . . 97

3.9 Avaliação Diagnóstica do Curso Básico sobre HTML (Leiva, 2003). . . . . . . . . 97

3.10 Unidade de Estudo Ligações (Leiva, 2003) . . . . . . . . . . . . . . . . . . 98

3.11 AIM-CID: Abordagem Integrada para Modelagem de Conteúdos Educacionais. . 105

3.12 Representação de um Estado DD. . . . . . . . . . . . . . . . . . . . 111

3.13 Mecanismos de Apoio à Geração de Conteúdos Educacionais. . . . . . . . . . . . . 111

3.14 Objeto de Aprendizado: Metáfora do Átomo e Perspectivas de Modelagem. . . . . 113

3.15 Objeto de Aprendizado para o Critério Análise de Mutantes. . . . . . . . . . . . . 114

3.16 Meta-Modelo: Integração das Perspectivas de Modelagem de Conteúdos Educacionais. . . . . . . . . . . . . . . . . . . . . 115

4.1 Estrutura Geral do Processo Padrão para Módulos Educacionais. . . . . . . . . . . . 126

4.2 Norma ISO/IEC 12207 x Processo Padrão para Equipes Geograficamente Dispersas x Processo Padrão para Módulos Educacionais. . . . . . . . . . . . . . . . . 127

4.3 Processo Padrão x Perspectivas de Desenvolvimento de Módulos Educacionais. . 130 
4.4 Modelo para a Definição de Processos de Software (Maidantchik, 1999; da Rocha et al., 2001). . . . . . . . . . . . . . . . . . 153

4.5 Modelo CMM x Modelo de Maturidade para Equipes Geograficamente Dispersas x Modelo CMM/Educacional. . . . . . . . . . . . . . . . . . . . . . 155

4.6 Equipe de Desenvolvimento e Papéis Associados. . . . . . . . . . . . . . . . 163

5.1 Transparência Principal do Módulo Teste de Software: Teoria e Prática: Integração entre Transparências, Documentos-Texto, Ferramentas de Teste e Ferramentas Educacionais. . . . . . . . . . . . . . . . . . . . . . 177

5.2 Estrutura Geral do Módulo Teste de Software: Teoria e Prática. . . . . . . . . . . . 181

5.3 Tópicos do SWEBOK (Área de Teste de Software) x Sub-Módulos. . . . . . . . . . 183

5.4 Critério Análise de Mutantes: Modelo (Mapa) Conceitual. . . . . . . . . . . . . 186

5.5 Requisitos Associados à Perspectiva Conceitual Representados no Modelo. . . . . 187

5.6 Transparências referentes a Mutante Equivalente e Equivalência de Programas. . 188

5.7 Critério Análise de Mutantes: Modelo Instrucional (HMBSS/Instrucional). . . . . . . 189

5.8 Transparências referentes à Análise de Mutantes. . . . . . . . . . . . . . . . . . 191

5.9 Transparências referentes à Aplicação da Análise de Mutantes. . . . . . . . . . . . . 192

5.10 Transparências referentes ao Exercício Proposto para a Aplicação da Análise de Mutantes. . . . . . . . . . . . . . . . . . . . 193

5.11 Critério Análise de Mutantes: Modelo Didático (HMBSS/Didático) - Especificação Aberta. . . . . . . . . . . . . . . . . . . . 195

5.12 Critério Análise de Mutantes: Modelo Didático (HMBSS/Didático) - Especificação Parcialmente Aberta. . . . . . . . . . . . . . . . . . . . . . . . . 197

5.13 Critério Análise de Mutantes: Modelo Didático (HMBBS/Didático) - Especificação Fechada. . . . . . . . . . . . . . . . . . . . . . . . . . . 198

5.14 Transparências referentes a Mutante - Versão Aberta, Parcialmente Aberta e Fechada. . . . . . . . . . . . . . . . . . 200

5.15 ADVs das Transparências do Módulo Teste de Software: Teoria e Prática. . . . . . 201

5.16 ADV Chart Item de Informação. . . . . . . . . . . . . . . . . . . . . 202

5.17 Integração entre Transparências e Páginas HTML. . . . . . . . . . . . . . . . 204

5.18 Página do WebCT referente ao Curso Verificação, Validação e Teste de Software. . 207

A.1 $\quad \mathcal{C M M} /$ Educacional $\mathrm{x}$ CMNI/Educacional. . . . . . . . . . . . . . . . . . 244

B.1 Usabilidade: Alternativas Selecionadas para cada Questão. . . . . . . . . . . . . . 249

B.2 Conteúdo: Alternativas Selecionadas para cada Questão. . . . . . . . . . . . . . . . 250

B.3 Navegação: Alternativas Selecionadas para cada Questão. . . . . . . . . . . . . . . 252 


\section{Lista de Tabelas}

2.1 Síntese dos Mecanismos e Abordagens de Apoio à Modelagem de Conteúdos Educacionais. . . . . . . . . . . . . . . . . . 27

2.2 Síntese dos Principais Recursos Oferecidos pelos Ambientes e Sistemas Educaci-

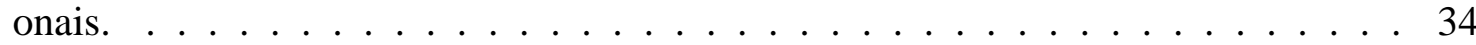

3.1 Requisitos para Modelagem de Conteúdos x Perspectivas de Desenvolvimento de Módulos Educacionais. . . . . . . . . . . . . . . . . . . 78

3.2 Perspectivas e Requisitos para Modelagem de Conteúdos Educacionais. . . . . . . 80

3.3 Síntese das Características do Modelo/Metodologia Daphne. . . . . . . . . . . . . 90

3.4 Síntese das Características do Método EHDM. . . . . . . . . . . . . . . . . . . . 93

3.5 Síntese das Características da Metodologia MAPHE. . . . . . . . . . . . . . . . 95

3.6 Síntese das Características do Modelo MDE. . . . . . . . . . . . . . . . . . . . . 98

3.7 Síntese das Características do HDM, RMM, OOHDM e EORM. . . . . . . . . . . 101

3.8 Síntese das Características do Modelo Trellis. . . . . . . . . . . . . . . . . . . . 102

3.9 Síntese das Características do Modelo HMBS. . . . . . . . . . . . . . . . . . . . . 104

4.1 Correspondência entre as Fases do Modelo ADDIE e os Processos Fundamentais. . 128

4.2 Áreas-Chave (Nível 2) x Processo Padrão. . . . . . . . . . . . . . . . . . . . . . 158

4.3 Áreas-Chave (Nível 3) x Processo Padrão. . . . . . . . . . . . . . . . . . . . . . 159

4.4 Áreas-Chave (Nível 4) x Processo Padrão. . . . . . . . . . . . . . . . . . . . . . . . . . . . . . . . . . . . . . . . . . . .

4.5 Áreas-Chave (Nível 5) x Processo Padrão. . . . . . . . . . . . . . . . . . . . . . 160

4.6 Categorias de Ferramentas de Apoio x Processo Padrão para Módulos Educacionais. 166

4.7 Ferramentas de Apoio x Perspectivas de Desenvolvimento de Módulos Educacionais. 169 

Várias pesquisas têm sido conduzidas no contexto de ensino e treinamento, sendo o desenvolvimento de módulos educacionais uma das atividades relevantes investigada. Neste trabalho são discutidos e estabelecidos mecanismos de apoio à atividade de modelagem de conteúdos e ao processo de desenvolvimento de tais módulos. Requisitos e perspectivas para a modelagem conceitual, instrucional e didática são identificadas. Uma abordagem integrada $(\mathcal{A L M}-\mathcal{C L D})$ envolvendo diferentes aspectos associados à modelagem de conteúdos também é proposta. No nível conceitual, mapas conceituais estendidos são utilizados. No nível instrucional, é estabelecido o modelo $\mathcal{H}$ MBS/Instrucional. No nível didático, propõe-se o modelo $\mathcal{H}$ MBS/Didático. Quanto ao processo de desenvolvimento, atividades e tarefas sistemáticas são estabelecidas no contexto de um processo padrão para a elaboração de módulos educacionais. Investigam-se ainda aspectos associados às atividades de especialização e instanciação do processo padrão definido. Um modelo de maturidade de processos $-\mathcal{C M M} /$ Educacional - é proposto. Além disso, uma instância do processo padrão definido é aplicada no desenvolvimento de um módulo educacional no domínio de Teste de Software. 

Many research have been conducted regarding to education and learning. In this context, one of the relevant activities is the development of educational modules. In this work, we have discussed and investigated mechanisms to support the content modelling activity and the development process of such modules. Requirements and perspectives for conceptual, instructional and didactic modelling are identified. An integrated approach $(\mathcal{I M A}-\mathcal{C D D})$ dealing with different perspectives related to the modelling content activity is also proposed. In the conceptual level, extended conceptual maps are applied. In the instructional level, the $\mathcal{H} M B S /$ Instructional model is established. In the didactic level, the $\mathcal{H} M \mathcal{M S} /$ Didactic model is proposed. Regarding to the development process, systematic activities and tasks are established in the context of a standard process for the development of educational modules. Specialization and instantiation activities are also investigated. A maturity model $-\mathcal{C M M} /$ Educational - is proposed. Also, an instance of the defined standard process is applied on the development of an educational module for Software Testing knowledge domain. 
Este capítulo apresenta o contexto no qual o presente trabalho de doutorado está inserido e os fatores que motivaram sua realização. Definem-se ainda os principais objetivos da pesquisa realizada e apresenta-se sua organização.

\subsection{Contexto}

Nos últimos anos, temas relacionados ao ensino e treinamento têm sido bastante discutidos e investigados pela comunidade científica, nas mais variadas áreas de atuação. De fato, a demanda por formação e capacitação de pessoal remete-nos a alguns aspectos relevantes dentro do contexto educacional: o quê ensinar, como ensinar e como avaliar. Nessa perspectiva, teóricos da educação, professores, educadores, psicólogos, filósofos, projetistas instrucionais, entre outros, têm concentrado esforços no estudo e desenvolvimento de mecanismos que facilitem o processo de aprendizado.

Quanto ao aspecto de $o$ quê ensinar, é fundamental que sejam identificados quais tópicos devem ser abordados, bem como em que nível ensiná-los. Os conteúdos trabalhados pelo aprendiz devem possuir, entre outras características: (1) abrangência, no que diz respeito ao entendimento dos conceitos e teorias que servem como base para o domínio de conhecimento sendo ensinado; (2) profundidade, no sentido de motivar o aprendiz, a partir dos conceitos já abordados, a explorar por si mesmo outros tópicos e sub-áreas relacionadas; e (3) orientação, visando à aplicação prática do conhecimento adquirido.

Com respeito às questões de como ensinar e como avaliar, observa-se um crescente interesse na utilização de recursos computacionais como mecanismos facilitadores no processo educacional. 
A idéia é que, a partir da definição de mecanismos adequados à elaboração e à disponibilização de material didático, criem-se condições para o estabelecimento de ambientes de ensino e treinamento atraentes aos aprendizes e efetivos quanto aos objetivos educacionais.

Além disso, salienta-se que as questões e problemas pertinentes ao ensino e treinamento são relevantes não apenas no ambiente acadêmico, mas também no meio industrial. É fundamental que a organização ofereça programas de profissionalização visando a desenvolver as habilidades pessoais e aumentar o conhecimento dos indivíduos para que os mesmos possam desempenhar seus papéis ou funções de maneira eficiente e com qualidade. Isso envolve identificar as necessidades de aprendizado dentro da organização e desenvolver e/ou contratar treinamento para preencher tais necessidades.

A fim de que as expectativas da indústria em relação a seus profissionais também sejam consideradas no contexto de ensino e aprendizado, uma série de necessidades e requisitos educacionais pode ser identificada. Ênfase deve ser dada, por exemplo, em: (1) habilidades técnicas, as quais possam ser aplicadas na resolução de problemas cotidianos; (2) habilidades cognitivas, que auxiliem no aprendizado, avaliação e incorporação de novas tecnologias; (3) conhecimento do contexto de mercado, permitindo ao profissional entender, de maneira abrangente, as implicações de suas decisões; e (4) habilidades profissionais, as quais favoreçam a cooperação e o trabalho em grupo dentro das organizações. Tais habilidades envolvem áreas multidisciplinares e, quando reunidas, caracterizam um bom profissional, segundo a perspectiva da indústria.

Também é importante destacar que a demanda por pessoal capacitado é observada em vários domínios de conhecimento. Por exemplo, considerando o domínio de Engenharia de Software, um fator fundamental e determinante para que seus objetivos sejam alcançados está relacionado à formação de recursos humanos. Em virtude disso, pode-se observar uma crescente procura por programas de certificação, educação continuada e treinamento na área. Ainda, esforços visando a estabelecer e documentar um corpo de conhecimento relevante associado à Engenharia de Software, tanto no âmbito acadêmico como industrial, também podem ser observados (Dupuis et al., 2001; IEEE Computer Society, 2001; IEEE Computer Society and Association for Computing Machinery, 2003).

Considerando um contexto ainda mais específico, no caso Teste de Software, os mesmos problemas e questões educacionais permanecem válidos. De fato, entre as áreas de conhecimento tidas como essenciais dentro da Engenharia de Software, a atividade de teste desempenha um papel fundamental na temática Qualidade de Software, sendo fundamental para a avaliação e a melhoria dos produtos de software desenvolvidos (Maldonado, 1991; Pressman, 2001).

Ressalta-se, entretanto, que apesar dos avanços e pesquisas na área - definição e estudo de critérios de teste, especificação e implementação de ferramentas de apoio e condução de estudos teóricos e empíricos -, a utilização sistemática de Teste de Software em ambientes de desenvolvimento ainda não é uma prática comum. No contexto nacional, por exemplo, os resultados da quinta edição da pesquisa Qualidade e Produtividade no Setor de Software Brasileiro, realizada 
no período de setembro/2001 a abril/2002 pelo Ministério da Ciência e Tecnologia (DSI/CGSA, 2002), indicaram que apenas parte das empresas desenvolvedoras de software no país utilizam algum tipo de teste como método para detecção de erros. De modo geral, os resultados obtidos demonstram a dificuldade da indústria em incorporar e aplicar em seu processo de desenvolvimento tanto recursos já disponíveis comercialmente como novas tecnologias investigadas no ambiente acadêmico.

Por outro lado, a percepção de que o teste é uma atividade indispensável dentro do processo de desenvolvimento tem provocado um crescimento significativo na demanda por pessoal capacitado, sobretudo no ambiente industrial. No entanto, apesar de algumas iniciativas serem identificadas, o meio acadêmico não tem conseguido atender satisfatoriamente à demanda existente. Como exemplos de universidades que oferecem a seus alunos cursos específicos envolvendo Teste de Software e Garantia de Qualidade podem-se destacar a George Mason University, a Kansas State University e a Purdue University, esta última possuindo dois cursos de graduação em Engenharia de Software abordando teste e confiabilidade (Dustin et al., 1999). No Brasil, embora existam mais de 600 cursos de Computação/Informática no país, poucos deles possuem uma disciplina especificamente voltada ao ensino dos conceitos relacionados à atividade de teste. No caso do ICMC-USP, uma disciplina no domínio de Teste de Software - VV\&T: Verificação, Validação e Teste -, abordando tanto aspectos teóricos como práticos da atividade de teste, é oferecida aos alunos de graduação.

Dentro da perspectiva apresentada, este trabalho procura, basicamente, investigar e definir mecanismos de apoio ao processo de desenvolvimento instrucional, visando a fornecer subsídios para a formação e a capacitação de recursos humanos. Como um estudo de caso, os mecanismos identificados são aplicados no contexto específico de Teste de Software, objetivando o domínio e a disseminação de conhecimentos técnico-científicos na área.

\subsection{Motivação}

Conforme discutido na seção anterior, a preocupação com ensino e treinamento, tanto no ambiente acadêmico, apoiando a pesquisa e o estudo de novas tecnologias, como no meio industrial, oferecendo atividades de complementação curricular e formação continuada na aplicação das tecnologias existentes, requer que vários aspectos sejam levados em consideração. De modo geral, entre os aspectos investigados destacam-se: (1) a autoria de material didático; (2) a apresentação do material, de maneira controlada, aos aprendizes; e (3) o apoio à interação e à colaboração entre os atores do processo (aprendizes, instrutores/mediadores, monitores, etc.).

Procurando abordar os aspectos acima relacionados, uma das linhas que tem sido objeto de intensa pesquisa refere-se ao desenvolvimento e implementação de ambientes e sistemas educacionais que ofereçam suporte à disponibilização de material didático, à condução de atividades práticas, e à avaliação e acompanhamento dos aprendizes (Eberspächer et al., 1999; Goldberg et 
al., 1996; Guzdial et al., 2002; Leiva et al., 2002a; Leiva, 2003; Lucena et al., 1998, 1999; Menasce, 1998; Pacheco et al., 1999b; Pimentel et al., 2001, 2002).

De modo geral, uma grande diversidade de características e funcionalidades associadas aos ambientes e sistemas educacionais, tanto em aspectos pedagógicos como técnicos e administrativos, pode ser observada. Entretanto, apesar dos aspectos apoiados, uma limitação comum à maioria dos trabalhos conduzidos refere-se ao fato dos ambientes e técnicas subjacentes concentrarem-se na criação da estrutura, armazenamento do conteúdo e controle de acesso ao material didático, deixando a tarefa de modelagem do conteúdo educacional inteiramente a cargo do autor do curso, sem qualquer tipo de suporte ou mesmo diretrizes e atividades sistemáticas que apóiem sua elaboração.

Tal limitação direciona-nos à outra linha de pesquisa relevante - a modelagem de conteúdos educacionais. No processo de ensino e treinamento, a modelagem representa uma atividade essencial para a estruturação do conhecimento, apoiando a identificação e a definição de conceitos e informações associadas, possibilitando, em última análise, que os mesmos sejam disponibilizados de modo coerente e ordenado, com base em teorias e princípios educacionais previamente definidos. De fato, a simples utilização de recursos computacionais não garante necessariamente o sucesso e a efetividade do aprendizado. A qualidade do material didático utilizado também constitui um fator determinante nessa perspectiva e, com isso, a modelagem dos conteúdos associados torna-se um aspecto fundamental.

Ressalta-se, no entanto, que apesar de sua importância no processo ensino e treinamento, poucos são os modelos especificamente voltados à modelagem de conteúdos educacionais (Kawasaki \& Fernandes, 1996; Leiva et al., 2002b; Leiva, 2003; Pansanato \& Nunes, 1999; Pimentel, 1997, 1998). Além disso, como não há um conjunto pré-estabelecido de requisitos associados à atividade, cada um dos modelos existentes aborda aspectos distintos, os quais podem ser adequados a um determinado cenário e inadequado para outros.

Evidenciam-se, com isso, alguns pontos importantes a serem considerados no contexto da atividade de modelagem de conteúdos educacionais: (1) a necessidade do estabelecimento de requisitos e perspectivas de modelagem que forneçam subsídios à construção, comparação, avaliação e seleção de modelos para representação de conteúdos; e (2) a necessidade de abordagens integradas, capazes de reunir e aplicar, de forma consistente, os diversos aspectos de modelagem observados.

A modelagem de conteúdos é apenas uma das atividades a serem consideradas no contexto de desenvolvimento de módulos educacionais (conteúdos teóricos e práticos integrados por meio de recursos tecnológicos e computacionais). De fato, o desenvolvimento de tais produtos requer que, além de aspectos essencialmente técnicos, fatores gerenciais e organizacionais também sejam considerados. Adicionalmente, tais módulos podem ser disponibilizados aos aprendizes de diferentes maneiras, evoluídos em função do aprendizado proporcionado a partir de sua utilização, e reutilizados em produtos e domínios de conhecimento correlatos, em diferentes contextos de ensino e treinamento e para aprendizes com perfis distintos. Em virtude da diversidade e comple- 
xidade dos fatores envolvidos, a construção de tais produtos demanda tempo e recursos (humanos, técnico-administrativos e econômicos), não podendo ser considerada uma atividade trivial.

Sob vários aspectos de desenvolvimento, a produção de módulos educacionais assemelha-se à produção de software. No caso de software, métodos, ferramentas e procedimentos têm sido definidos e integrados visando ao estabelecimento de processos sistemáticos que resultem em produtos confiáveis e eficientes (Pressman, 2001; da Rocha et al., 2001). De maneira análoga, o estabelecimento e a aplicação de práticas sistemáticas e disciplinadas que garantam a produtividade do processo de desenvolvimento e a qualidade dos produtos gerados também são necessários no que se refere a módulos educacionais.

Dentro do contexto apresentado, evidencia-se a relevância em se definir e padronizar processos para o desenvolvimento de módulos educacionais, a exemplo do que já ocorre em software. Em linhas gerais, tais processos podem ser apoiados na identificação de aspectos e características similares àquelas observadas na produção de software, incorporando ainda fatores específicos, como práticas de projeto instrucional (Clark, 2003; Kruse, 2003; Lee \& Owens, 2000) e aspectos de modelagem de conteúdos educacionais, entre outros.

Os aspectos e limitações discutidas nesta seção motivaram a que se investigassem mecanismos de apoio específicos dentro do contexto de ensino e treinamento. Tais mecanismos foram caracterizados basicamente em duas linhas de atuação - Modelagem de Conteúdos Educacionais e Padronização de Processos para a Elaboração de Módulos Educacionais -, a partir das quais foram estabelecidos os principais objetivos do trabalho, apresentados a seguir.

\subsection{Objetivos}

O presente trabalho de doutorado visa ao estudo e à definição de mecanismos adequados para a elaboração e a disponibilização de módulos educacionais. Com isso, pretende-se fornecer subsídios para o estabelecimento de um ambiente de ensino e treinamento que seja atraente e efetivo quanto aos objetivos e metas de aprendizado, favorecendo assim o processo de formação e capacitação de pessoal.

Os principais objetivos do trabalho podem ser caracterizados segundo as linhas de atuação em que se enquadram:

- Estudo e definição de mecanismos para a modelagem de conteúdos educacionais, estabelecendo subsídios para a identificação e estruturação das partes relevantes do domínio de conhecimento a serem ensinadas. Parâmetros para comparação e seleção de modelos e abordagens existentes também são estabelecidos a fim de apoiar a modelagem de conteúdos.

- Padronização de processos para a elaboração de módulos educacionais, fornecendo diretrizes para o desenvolvimento sistemático de produtos voltados a ensino e treinamento. Aspectos 
de especialização dos processos definidos e sua instanciação para projetos específicos também são abordados.

Os mecanismos estabelecidos são aplicados no contexto de Teste de Software, a fim de proporcionar o domínio e a disseminação de conhecimentos técnico-científicos na área, visando ao constante aprimoramento de pessoal e dos próprios produtos de software desenvolvidos. Do ponto de vista acadêmico, a idéia é facilitar o aprendizado dos conceitos de teste e motivar novas pesquisas e desenvolvimento. Do ponto de vista industrial, pretende-se (a médio prazo) fornecer recursos para formação e capacitação de pessoal tanto em conceitos já consolidados como em tecnologias emergentes, estimulando o processo de transferência tecnológica entre universidade e indústria.

Com relação aos objetivos principais do trabalho, os aspectos de modelagem investigados são aplicados na estruturação e organização do conhecimento sobre Teste de Software, ao passo que os processos definidos são utilizados como base para o desenvolvimento, integração e disponibilização de módulos educacionais nesse domínio.

É importante observar que, embora os mecanismos investigados sejam explorados essencialmente no domínio de teste, estes também poderão ser utilizados a fim de apoiar, em linhas gerais, o processo de ensino e treinamento em outros domínios de conhecimento, sobretudo aqueles associados à Ciência de Computação.

Por fim, faz-se necessário ressaltar que, apesar de algumas teorias e princípios educacionais terem sido consideradas neste trabalho (por exemplo, as teorias de Ausubel et al. (1978) e de Merril (1983), e aspectos do Projeto Instrucional (Clark, 2003; Kruse, 2003; Lee \& Owens, 2000)), nenhuma abordagem pedagógica específica é enfatizada e/ou adotada. Procura-se, com isso, garantir a independência dos mecanismos investigados em relação a teorias e princípios educacionais existentes, os quais devem ser definidos pelo próprio instrutor/mediador ou responsável pelo módulo educacional a ser desenvolvido.

\subsection{Organização da Tese}

Neste capítulo foram apresentados o contexto do trabalho, as motivações para a sua realização e os principais objetivos da pesquisa conduzida.

O Capítulo 2 contém uma revisão dos trabalhos conduzidos envolvendo a modelagem de conteúdos e o desenvolvimento de ambientes e sistemas educacionais. Ainda, questões pertinentes à padronização e à melhoria de processos são discutidas no contexto de produção de software. Uma visão geral a respeito do domínio de conhecimento sobre Teste de Software também é apresentada, caracterizando a área em termos de definição de critérios de teste, condução de estudos teóricos e empíricos, e desenvolvimento de ferramentas de apoio.

O Capítulo 3 aborda especificamente a atividade de modelagem de conteúdos educacionais, discutindo aspectos voltados ao estabelecimento de requisitos e perspectivas de modelagem e sua 
utilização na construção, comparação, avaliação e seleção de modelos e abordagens associadas. Modelos genéricos envolvendo a representação de conteúdos educacionais e uma abordagem integrada para sua aplicação também são definidos.

No Capítulo 4 são discutidas as atividades de padronização, especialização e instanciação de processos no contexto de ensino e aprendizado. Um processo padrão para módulos educacionais é definido com o propósito de fornecer diretrizes para a elaboração e evolução sistemáticas dos mesmos. Um modelo de maturidade, definido no contexto de processos para a elaboração de módulos educacionais, também é proposto e discutido como apoio à especialização do processo padrão. Além disso, o processo padrão é instanciado, sendo discutidos os métodos e técnicas de desenvolvimento, recursos humanos e ferramentas de apoio adotados.

No Capítulo 5, a aplicação prática do processo instanciado é ilustrada por meio da elaboração de um módulo educacional específico envolvendo o domínio de conhecimento sobre Teste de Software.

No Capítulo 6 estão sintetizados os principais resultados, contribuições e desdobramentos deste trabalho.

O Apêndice A apresenta o modelo de maturidade de processos para módulos educacionais, descrevendo em detalhes os níveis de maturidade e as KPAs associadas.

Finalmente, no Apêndice B é ilustrado o questionário de avaliação aplicado aos aprendizes durante a utilização do módulo educacional sobre Teste de Software. Uma síntese dos resultados obtidos também é apresentada. 



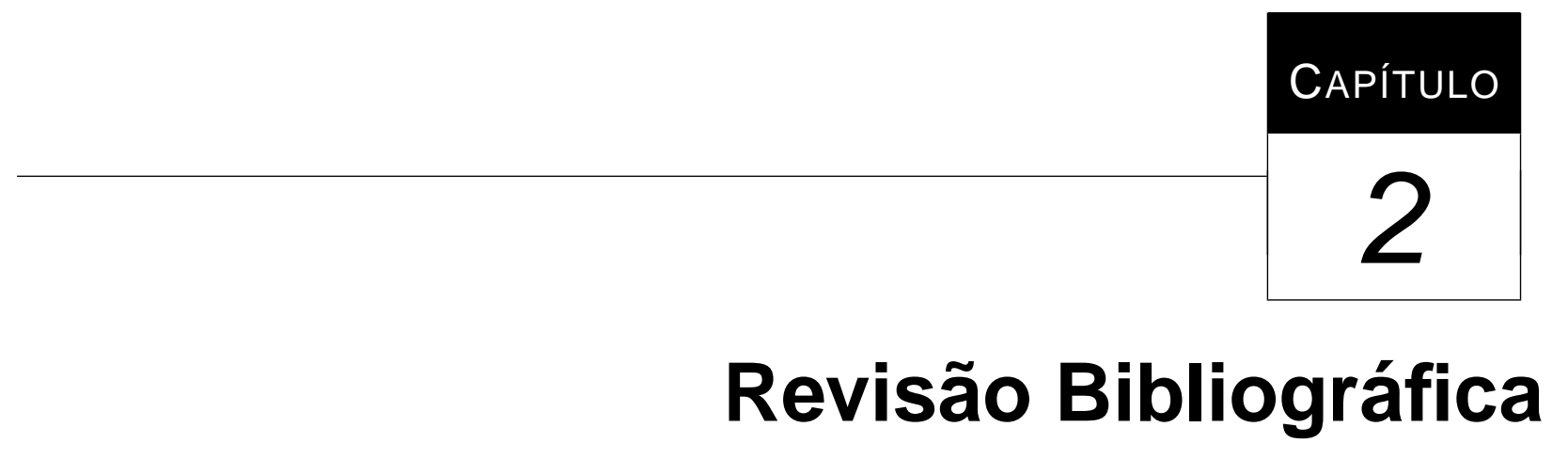

\subsection{Considerações Iniciais}

No presente trabalho de doutorado são investigados e definidos mecanismos de apoio ao processo de desenvolvimento de módulos educacionais, caracterizados essencialmente em duas linhas de pesquisa - Modelagem de Conteúdos Educacionais e Padronização de Processos para a Elaboração de Módulos Educacionais. Ainda, tais mecanismos são aplicados em um domínio de conhecimento específico, apoiando a construção de um módulo educacional na área de Teste de Software.

Neste capítulo é apresentada uma revisão das principais pesquisas conduzidas, sob as quais este trabalho está fundamentado. Na Seção 2.2 são sintetizados alguns dos mecanismos e abordagens de apoio à modelagem de conteúdos educacionais existentes. Experiências envolvendo o desenvolvimento e a implementação de ambientes e sistemas educacionais são caracterizadas na Seção 2.3. Aspectos associados à padronização e melhoria de processos, discutidos no contexto de desenvolvimento de software, são apresentados na Seção 2.4. Por fim, uma visão geral a respeito do domínio de conhecimento sobre Teste de Software é apresentada na Seção 2.5.

\subsection{Mecanismos e Abordagens de Apoio à Modelagem de Conteúdos Educacionais}

A elaboração de material didático envolve, sobretudo, a organização e a estruturação das informações sobre o domínio de conhecimento que se deseja ensinar. Dessa forma, o uso de mecanismos 
e abordagens que apóiem a modelagem dos conteúdos educacionais permite ao autor capturar e organizar a estrutura de um domínio complexo e torná-la clara e acessível aos aprendizes.

As próximas seções discutem alguns mecanismos e abordagens de apoio nessa direção. A Seção 2.2.1 aborda aspectos referentes a Mapas Conceituais - técnica utilizada em várias abordagens como base para a representação do domínio de conhecimento. O modelo/metodologia Daphne (Seção 2.2.2), o método EHDM (Seção 2.2.3), a metodologia MAPHE (Seção 2.2.4) e o modelo MDE (Seção 2.2.10) têm como principal objetivo o projeto e o desenvolvimento de aplicações hipermídia educacionais. Abordagens para o projeto de hiperdocumentos genéricos - o modelo RMM (Seção 2.2.5), o método OOHDM (Seção 2.2.6), o modelo EORM (Seção 2.2.7), o modelo Trellis (Seção 2.2.8) e o modelo HMBS (Seção 2.2.9) também são brevemente apresentadas. Uma síntese dos mecanismos e abordagens consideradas é apresentada na Seção 2.2.11.

\subsubsection{Mapas Conceituais}

Um mapa conceitual consiste na representação de conceitos referentes a um domínio de conhecimento na forma de estruturas hierárquicas ou grafos orientados. Cada nó contém o nome de um conceito e cada arco entre dois conceitos indica o relacionamento existente entre eles.

Os mapas conceituais, inicialmente desenvolvidos por Novak (Moreira \& Buchweitz, 1987; Novak, 1981; Novak \& Gowin, 1984; Novak, 1990), são baseados na teoria da Aprendizagem Significativa (Ausubel et al., 1978) e visam a auxiliar a ordenação e o seqüenciamento hierarquizado de conteúdos educacionais de forma a fornecer ao aprendiz os estímulos adequados. De acordo com Ausubel et al. (1978), o aprendizado se dá, principalmente, por meio de dois princípios:

- Diferenciação Progressiva: Consiste na elaboração hierárquica de conceitos ou proposições, em que as idéias mais inclusivas ocupam uma posição no topo da estrutura cognitiva e abrangem outras idéias, progressivamente menos inclusivas e mais diferenciadas.

- Reconciliação Integrativa: Consiste no delineamento de semelhanças e diferenças entre conceitos relacionados. Este princípio postula que a programação do material a ser apresentado ao aprendiz deve ser feita de modo que haja exploração explícita de semelhanças e diferenças significativas entre idéias relacionadas e a reconciliação de inconsistências reais ou aparentes dessas idéias (Faria, 1989).

Os mapas conceituais foram criados na tentativa de interpretar e ilustrar a teoria de Ausubel et al. (1978). Nesse sentido, seguindo o princípio de diferenciação progressiva, conceitos mais inclusivos situam-se no topo do mapa conceitual, descendo-se até os menos inclusivos. Ressaltase que os relacionamentos entre conceitos é tão importante quanto os próprios conceitos visto que, em muitos assuntos, o objeto de estudo é um fenômeno, um procedimento ou uma transformação em que um conceito atua sobre outro. Esses relacionamentos ficam claramente delineados por meio da reconciliação integrativa. 
A estrutura geral de um mapa conceitual é exemplificada na Figura 2.1. A representação gráfica permite visualizar a distância relativa entre diferentes partes do assunto.

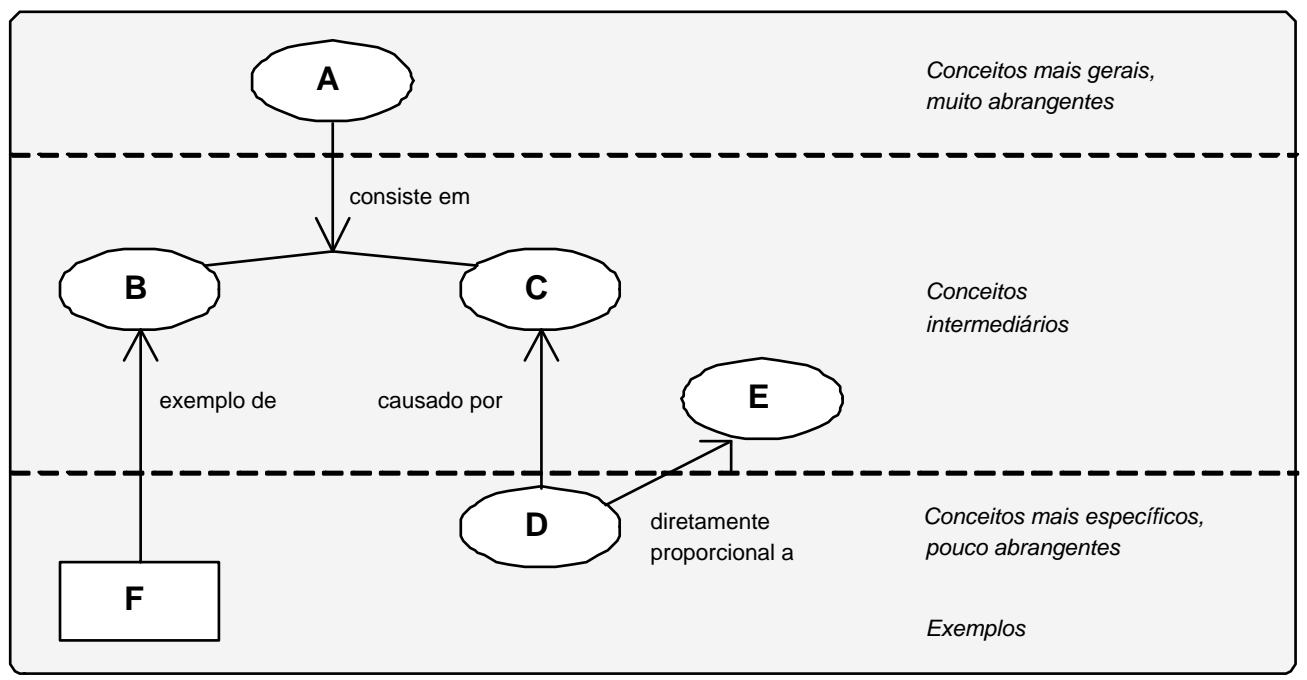

Figura 2.1: Estrutura de um Mapa Conceitual (Moreira \& Buchweitz, 1987).

Mapas conceituais têm sido empregados em diversas atividades associadas a ensino e treinamento. Na construção de hiperdocumentos educacionais, estes foram incorporados por várias abordagens como mecanismos de apoio à modelagem conceitual dos conteúdos (Kawasaki \& Fernandes, 1996; Leiva et al., 2002b; Leiva, 2003; Pansanato \& Nunes, 1999; Pimentel, 1997, 1998). Além disso, trabalhos envolvendo o desenvolvimento de ferramentas de suporte à construção de mapas conceituais também vêm sendo conduzidos. Como exemplos, podem-se citar as ferramentas Inspiration (Inspiration Software Inc., 2003), KMap (Gaines \& Shaw, 2003) e CMap (Coffey et al., 2002), entre outras.

\subsubsection{Modelo/Metodologia Daphne}

O modelo/metodologia Daphne (Definição de Aplicações Hipermídia na Educação) (Kawasaki \& Fernandes, 1996) é voltado ao desenvolvimento de cursos hipermídia, tendo como base o modelo HDM (Hypertext Design Model) (Garzotto et al., 1993), a teoria de Mapas Conceituais (Moreira \& Buchweitz, 1987; Novak, 1981; Novak \& Gowin, 1984; Novak, 1990) e a técnica de Mapeamento de Informações (Horn, 1989). Tanto aspectos pedagógicos como navegacionais são abordados.

Em linhas gerais, o Daphne é constituído por três camadas: Hiperbase, Estruturas de Acesso Direto (EADs) e Estruturas de Acesso Programado (EAPs). Tais camadas são ilustradas esquematicamente na Figura 2.2 e brevemente descritas a seguir.

\section{Hiperbase}

A Hiperbase constitui o corpo principal das informações contidas no curso, organizadas de acordo com uma combinação de Mapas Conceituais, HDM e Mapeamento de Informações. Basicamente, 


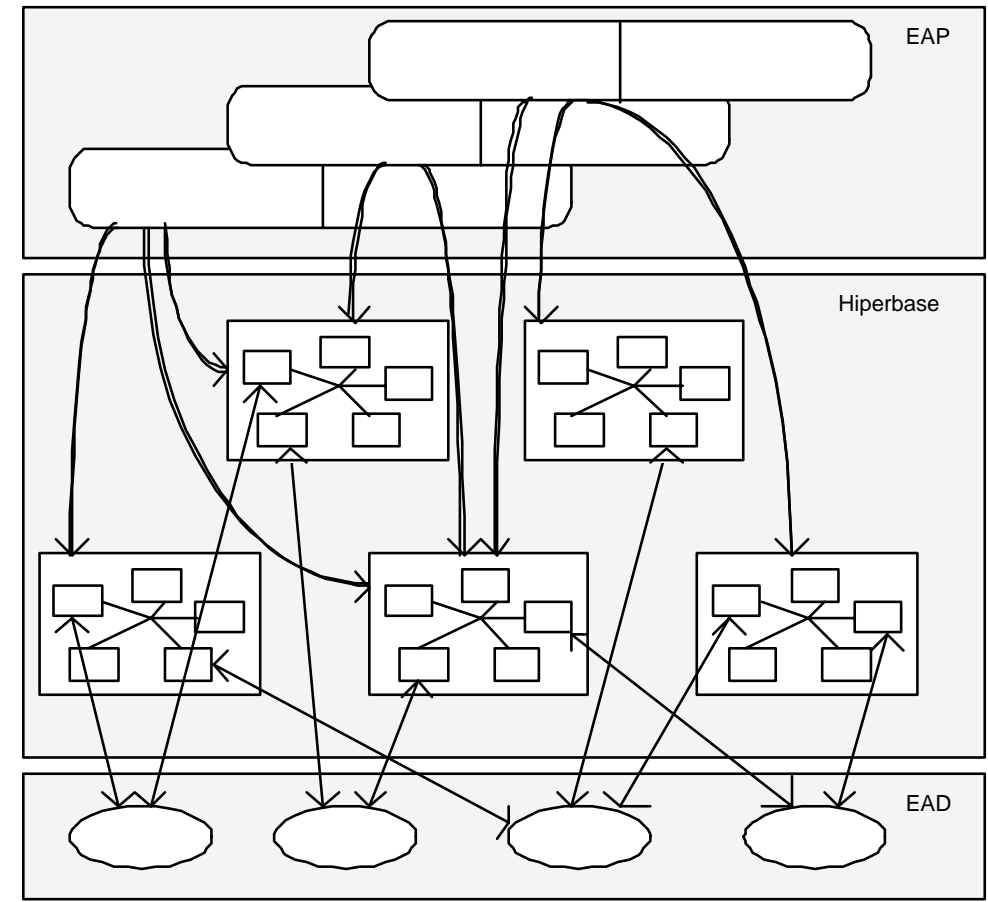

Figura 2.2: Camadas do Modelo/Metodologia Daphne (Kawasaki \& Fernandes, 1996).

um curso é formado por uma ou mais entidades, cada uma delas correspondendo a um conjunto completo de informações sobre um determinado assunto. A estrutura interna de uma entidade é determinada por meio de um mapa conceitual, sendo que cada nó do mapa representa um tópico.

Cada tópico do mapa conceitual é dividido em porções, denominadas mapas de informação. Os mapas, por sua vez, são divididos em partes menores - blocos de informação. Mapas e blocos de informação são derivados a partir da aplicação da técnica de Mapeamento de Informações (Horn, 1989). De acordo com a técnica, sete tipos de mapas de informação são considerados: Conceito, Classificação, Estrutura, Fato, Princípio, Procedimento e Processo. Os blocos podem ser de vários tipos: Definição, Exemplo, Diagrama de Blocos, Lista de Classificação, Fórmula, Regra, Teorema, Sinônimo, Diagrama, entre outros.

Além da construção de mapas conceituais e da definição de mapas e blocos de informação, o Daphne também prevê a elaboração de um esquema HDM (Garzotto et al., 1993) como parte do processo de desenvolvimento de hiperdocumentos educacionais. Em linhas gerais, um esquema HDM é descrito como um conjunto de entidades e elos. As entidades são constituídas por componentes hierarquicamente estruturados. Os elos podem ser de perspectiva, estruturais ou aplicativos. O HDM prevê ainda a definição de estruturas de acesso como, por exemplo, índices e roteiros guiados.

\section{Estruturas de Acesso Direto (EADs)}

As EADs permitem localizar um determinado bloco de informação de forma direta, sem que o aprendiz precise saber em que parte da Hiperbase o bloco se encontra. O uso das EADs possibilita 
a navegação livre através da Hiperbase, permitindo o acesso às informações na ordem que se desejar. Três tipos de EADs são propostos pelo modelo:

- Glossário: Apresenta a definição de todos os termos relevantes do assunto em estudo.

- Índice Analítico: Escolhido um termo, permite o acesso a todos os blocos de informação da Hiperbase nos quais apareça aquele termo.

- Galeria de Tipos: Permite que o aprendiz selecione um tipo de bloco e acesse todos os blocos daquele tipo na Hiperbase.

\section{Estruturas de Acesso Programado (EAPs)}

EAPs permitem o acesso a um tópico de cada vez, em uma seqüência pré-estabelecida. A finalidade das EAPs é promover um estudo dirigido visando a atingir determinado objetivo de aprendizado. Como exemplo, podem-se considerar os seguintes objetivos: introduzir um assunto novo, aprofundar-se em um tema, revisar os conteúdos já estudados, preparar o aprendiz para um exame, atender a aprendizes de diferentes perfis. O autor do curso pode criar várias EAPs sobre a Hiperbase, cada uma atendendo a um desses objetivos. Observa-se que o uso de EAPs caracteriza a navegação dirigida.

\subsubsection{Método EHDM}

O EHDM (Educational Hyperdocuments Design Method - Método para Projeto de Hiperdocumentos para Ensino) (Pansanato \& Nunes, 1999) visa a apoiar o desenvolvimento de aplicações hipermídia para ensino, propondo uma série de etapas de projeto e fornecendo modelos de representação para modelar o domínio de conhecimento e os aspectos navegacionais dessas aplicações. O método é composto por três fases distintas, ilustradas na Figura 2.3: Modelagem Conceitual Hierárquica, Projeto Navegacional de Contextos, e Construção e Teste.

\section{Modelagem Conceitual Hierárquica}

A fase de Modelagem Conceitual Hierárquica visa à estruturação do domínio de conhecimento. $\mathrm{O}$ Modelo Conceitual Hierárquico, construído nesta fase, é responsável pela representação das partes relevantes do domínio de conhecimento e seus relacionamentos.

O modelo tem como base a teoria de Mapas Conceituais (Moreira \& Buchweitz, 1987; Novak, 1981; Novak \& Gowin, 1984; Novak, 1990) e o Modelo de Michener (Michener, 1978). Este último identifica três categorias fundamentais do conhecimento matemático - Conceito, Resultado e Exemplo -, fornecendo uma estrutura para cada categoria e discutindo possíveis associações entre elas. Ressalta-se, entretanto, que as definições dessas categorias procuram extrapolar o domínio matemático com o objetivo de estender a modelagem para outros domínios (Pansanato \& Nunes, 1999). 


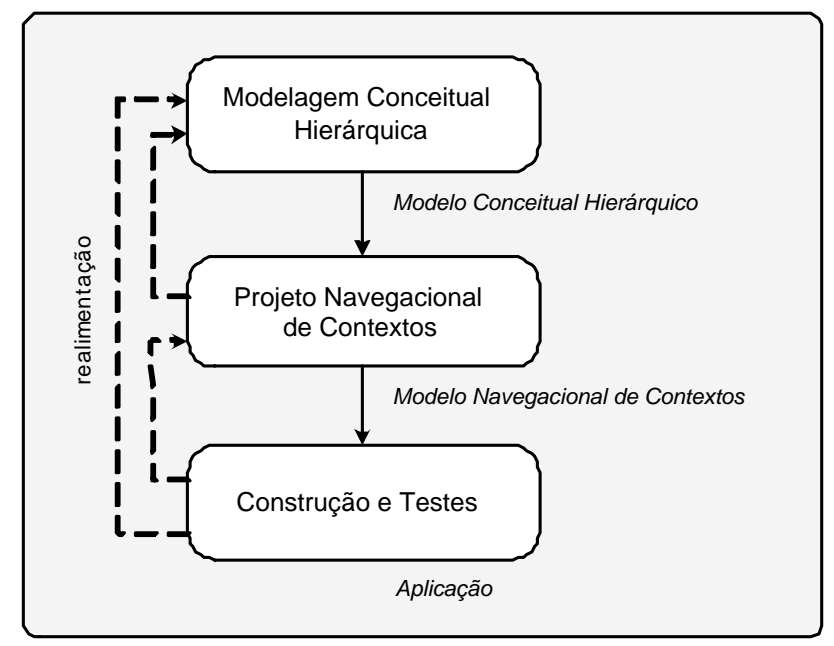

Figura 2.3: Fases do Método EHDM (Pansanato \& Nunes, 1999).

\section{Projeto Navegacional de Contextos}

Na fase de Projeto Navegacional são construídos os Modelos Navegacionais de Contexto. O EHDM permite que vários modelos navegacionais sejam derivados a partir de um mesmo modelo conceitual, enfatizando determinadas partes do domínio de conhecimento, e de acordo com o perfil do aprendiz a que se destina o hiperdocumento.

Segundo Pansanato \& Nunes (1999), essa abordagem é semelhante à proposta pelo método OOHDM (Schwabe \& Rossi, 1995), descrito na Seção 2.2.6, que utiliza visões navegacionais do mesmo modelo conceitual, cada uma delas constituindo um tipo distinto de hiperdocumento. No entanto, enquanto no OOHDM é utilizada uma linguagem de definição de visões orientada a objetos, no EHDM é especificado um mapeamento de elementos conceituais em navegacionais.

Em linhas gerais, o Modelo Navegacional de Contextos define um conjunto de entidades - nós e elos. Os nós são descritos por um grupo de atributos e um conjunto de âncoras. Os atributos representam as informações derivadas das categorias de conhecimento (Conceito, Exemplo ou Resultado) para o nó, e as âncoras correspondem aos elos que partem do nó.

Os elos são responsáveis pela ligação entre os nós, sendo definidos a partir dos relacionamentos do Modelo Conceitual Hierárquico. Observa-se, no entanto, que nem todos os relacionamentos são necessariamente mapeados para elos. Além disso, novos elos podem ser adicionados ao Modelo Navegacional de Contextos sem que sejam mapeados a partir de um relacionamento do Modelo Conceitual Hierárquico. O resultado da navegação por um elo depende da especificação do tipo dos atributos do nó destino.

Os contextos navegacionais constituem mecanismos para definir a estrutura (organização hierárquica) do hiperdocumento. A definição de estruturas de acesso (índices e roteiros) completa o modelo. 


\section{Construção e Testes}

Nesta fase constrói-se o hiperdocumento por meio de um processo de tradução do modelo navegacional para uma plataforma hipermídia. Testes são conduzidos visando a identificar possíveis erros ocorridos durante a construção do hiperdocumento.

\subsubsection{Metodologia MAPHE}

O MAPHE (Metodologia de Apoio a Projetos de Hipertextos Educacionais) (Pimentel, 1997) tem como objetivo apoiar o desenvolvimento de hipertextos educacionais, em particular, os projetos cuja proposta é trabalhar com a formação de conceitos. A metodologia é formada por quatro etapas - Planejamento, Modelagem, Implementação e Testes -, conforme ilustrado na Figura 2.4.

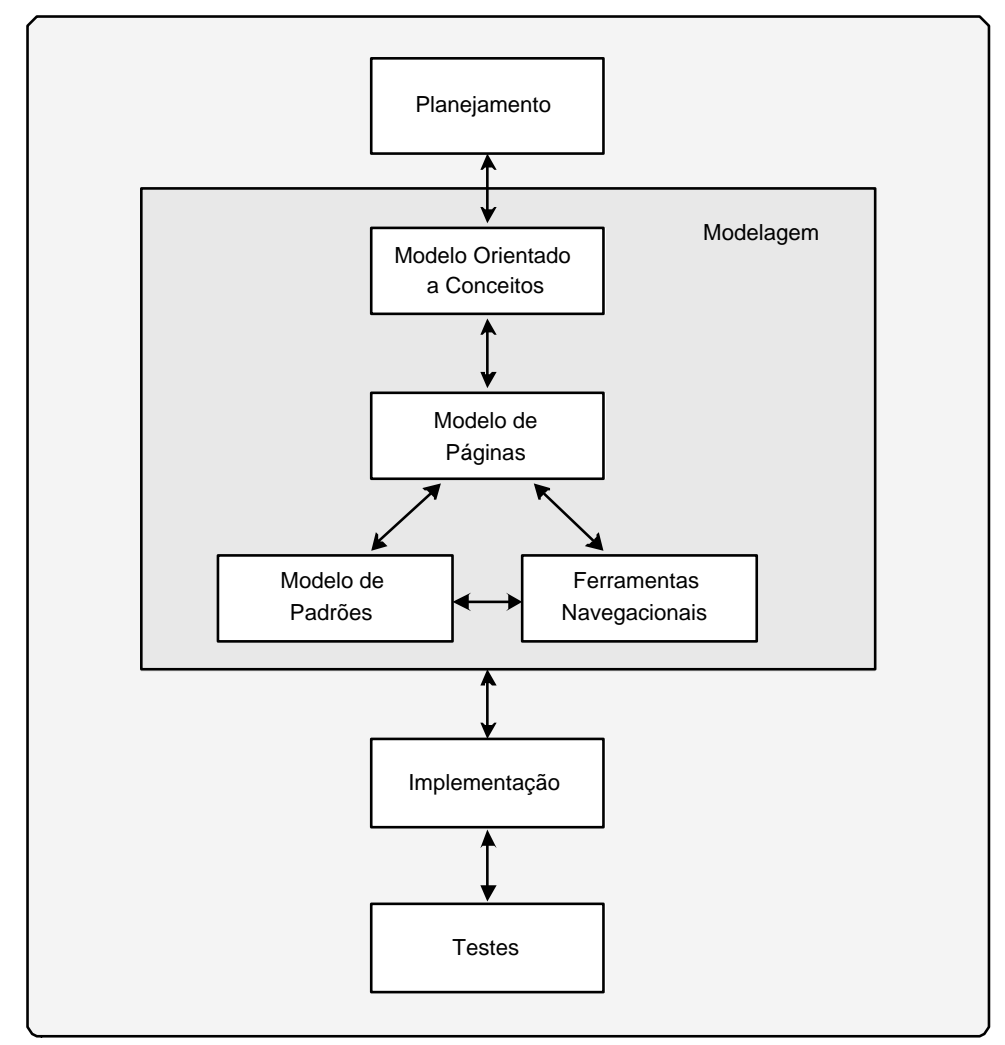

Figura 2.4: Etapas da Metodologia MAPHE (Pimentel, 1997).

\section{Planejamento}

Na etapa de Planejamento são estipuladas as estratégias a serem utilizadas no desenvolvimento do hipertexto educacional. São estabelecidos os objetivos, definindo-se o conteúdo programático e as principais habilidades cognitivas a serem desenvolvidas. Delimita-se, com isso, o universo de informações que o hipertexto deve conter. 


\section{Modelagem}

A Modelagem, foco da metodologia, tem como objetivo estruturar o hipertexto antes de sua implementação. A ênfase nesta etapa visa a permitir a automação do processo de implementação e, sobretudo, desenvolver uma análise adequada para que se possa gerar um hipertexto educacionalmente válido.

Nesta etapa são desenvolvidos quatro modelos, os quais permitem isolar as principais características a serem analisadas em um hiperdocumento educacional. São eles:

- Modelo Orientado a Conceitos (MOC) (Pimentel, 1998): Tem como objetivo elaborar uma estrutura coerente do conteúdo a ser abordado no hipertexto. De acordo com Pimentel (1998), o MOC pode ser visto sob duas perspectivas: (1) como uma extensão da teoria de Mapas Conceituais (Novak, 1990), à qual são incorporados alguns dos relacionamentos mais usuais do Modelo Orientado a Objetos (Rumbaugh et al., 1991); ou (2) como uma modificação do Modelo Orientado a Objetos, voltado à estruturação e sistematização de conceitos em um dado domínio de conhecimento.

- Modelo de Páginas: O conteúdo é mapeado para as páginas do hipertexto, definindo sua granularidade. O modelo é responsável pela representação de todas as páginas do hipertexto propriamente dito e de todos os possíveis caminhos entre elas. Notações específicas para páginas, elos unidirecionais e bidirecionais são estabelecidas. A navegação de uma página para outra (navegação em ponto pequeno) também é definida neste modelo.

- Ferramentas Navegacionais: Estrutura a navegação em ponto grande, acrescentando outras formas de navegação (índices, visitas guiadas, entre outras).

- Modelo de Padrões: Trata da interface gráfica e dos aspectos envolvidos na apresentação das páginas.

De acordo com Pimentel (1997), a ênfase da metodologia na etapa de Modelagem permite antecipar os erros que seriam tardiamente constatados durante o processo de implementação. Assim, é preferível despender esforços intelectuais durante a modelagem para evitar a força bruta na implementação.

\section{Implementação}

Na etapa de Implementação, os modelos construídos durante a fase de Modelagem são convertidos nas páginas do hipertexto propriamente dito, sendo implementados em uma plataforma específica.

\section{Testes}

A etapa de Testes tem como objetivo identificar os erros cometidos durante a implementação e verificar a validade educacional do hipertexto. 


\subsubsection{Modelo RMM}

O RMM (Relationship Management Methodology) (Isakowitz et al., 1995) é uma metodologia de desenvolvimento de aplicações hipermídia baseada nos Modelos de Entidade-Relacionamento (Elmasri \& Navate, 1990) e no HDM (Garzotto et al., 1993).

Em linhas gerais, o RMM estende o HDM acrescentando estruturas de acesso mais ricas, e definindo um modelo metodológico detalhado. Sete etapas são definidas, algumas das quais podem ser conduzidas em paralelo: Projeto de Entidades, Projeto de Relacionamento de Entidades, Projeto de Navegação, Projeto de Protocolo de Conversão, Projeto de Tela de Interface de Usuário, Projeto de Comportamento de Tempo de Execução, e Construção.

Durante o projeto de E-R, um modelo entidade-relacionamento do domínio da aplicação é construído e cada entidade é descrita. A idéia de "fatia" (slice) é usada para dividir uma entidade e determinar como a informação será apresentada aos usuários. Uma entidade pode ser dividida em fatias significativas, sendo que cada fatia pode ser vista como uma janela e conter um ou mais atributos de entidades.

No projeto de navegação, o esquema E-R é enriquecido com estruturas de acesso (índices, roteiros e agrupamentos), tornando viável a navegação.

O RMM é indicado principalmente para aplicações que apresentam uma estrutura regular do domínio e que requerem atualizações freqüentes (catálogos de produtos, por exemplo).

\subsubsection{Método OOHDM}

O OOHDM (Object-Oriented Hypermedia Design Method) (Schwabe \& Rossi, 1995) é um método para construção de aplicações hipermídia que utiliza abstrações orientadas a objetos. Envolve desde a modelagem do domínio de aplicação até o projeto e a implementação do sistema, compreendendo quatro fases de desenvolvimento: Projeto Conceitual, Projeto Navegacional, Projeto da Interface Abstrata e Implementação. Esse processo suporta os estilos de desenvolvimento incremental, iterativo e baseado em protótipo. Cada fase produz ou enriquece um modelo orientado a objetos focalizando um determinado interesse de projeto.

\section{Projeto Conceitual}

Na fase de Projeto Conceitual é realizado o entendimento da semântica do domínio da aplicação, sem a preocupação com o tipo de usuário ou tarefas do produto final. Como produto dessa fase tem-se um modelo do domínio de aplicação (esquema conceitual) representado em uma técnica de modelagem orientada a objetos (Rumbaugh et al., 1991).

$\mathrm{Na}$ construção do modelo são utilizados subsistemas, classes, relacionamentos, atributos, entre outros. Mecanismos de agregação e generalização/especialização podem ser utilizados para especificar as classes conceituais. 


\section{Projeto Navegacional}

Para obter uma aplicação utilizando o OOHDM, é necessário definir um modelo navegacional para o modelo conceitual. Uma aplicação é vista como uma visão navegacional do esquema conceitual. Assim, diferentes modelos navegacionais podem ser construídos para expressar diferentes visões do mesmo domínio, levando-se em conta perfis de usuários e as tarefas desempenhadas pelo sistema.

As diferentes visões navegacionais são representadas por esquemas de classes navegacionais. Em seguida, representam-se os caminhos de navegação disponibilizados pelo sistema por meio de uma estrutura navegacional utilizando nós, âncoras, estruturas de acesso (índices e roteiros), contextos de navegação, transformações navegacionais, entre outros. A estrutura navegacional é definida em termos de contextos de navegação que são induzidos a partir dos esquemas de classes navegacionais.

\section{Projeto de Interface Abstrata}

O Projeto de Interface Abstrata é responsável pela geração do modelo de interface com o usuário. Esse modelo especifica quais objetos de interface serão vistos pelo usuário e, particularmente, quais objetos de interface irão ativar a navegação, a maneira como os objetos de interface serão sincronizados e quais transformações ocorrerão na interface. A separação entre o modelo navegacional e a interface abstrata permite construir interfaces diferentes para a mesma estrutura navegacional. Desse modo, é possível adequar-se às variações de necessidades e preferências dos usuários, ou de tecnologia de interface.

Para especificar a interface das aplicações são construídos ADVs (Abstract Data Views). Os $A D V s$ definem os aspectos estáticos dos objetos da interface, a maneira como esses objetos estão relacionados aos objetos navegacionais e como reagem a eventos externos.

Os aspectos dinâmicos da aplicação são representados por meio de $A D V$ Charts. Os $A D V$ Charts correspondem a uma generalização de Statecharts (Harel, 1987), permitindo representar a associação entre eventos externos e $A D V s$. Além disso, expressam as transformações ocorridas na interface com o usuário e seu impacto nos objetos navegacionais.

\section{Implementação}

Na fase de Implementação, os esquemas de classes navegacionais e os modelos de interface são mapeados para o ambiente de implementação, resultando no sistema hipermídia a ser executado.

\subsubsection{Modelo EORM}

O EORM (Enhanced Object Relationship Model) (Lange, 1994) é uma abordagem orientada a objetos para o projeto de aplicações hipermídia. O modelo tem como base a OMT (Object Mode- 
ling Technique) (Rumbaugh et al., 1991), a qual é estendida com construções específicas a fim de capturar a semântica das interações entre objetos.

A idéia central consiste em representar, explicitamente, os relacionamentos semanticamente ricos no modelo orientado a objetos. Esses relacionamentos são definidos como classes, possuindo estrutura e comportamento próprios. Dessa forma, os relacionamentos são capazes de capturar não apenas as restrições estruturais básicas dos relacionamentos OMT, mas também as propriedades complexas desses relacionamentos como, por exemplo, a semântica de ligações hipermídia. A semântica hipermídia de um relacionamento é modelada definindo as classes e hierarquias de ligações e associando as semânticas dessas ligações aos relacionamentos.

O EORM é bastante similar ao OOHDM no fato de utilizar o modelo de orientação a objetos como filosofia central para a descrição de aplicações hipermídia. Há, no entanto, algumas diferenças importantes entre ambas as abordagens, tais como: (1) o EORM não separa explicitamente o projeto conceitual do navegacional; (2) as agregações não são explicitamente definidas, mas consideradas como um relacionamento possível, definido pelo usuário; (3) a idéia de contextos navegacionais não é tratada no EORM; e (4) tal como outras abordagens, o EORM relega o projeto de interface do usuário para a etapa de implementação, não oferecendo ferramentas formais para a descrição do comportamento da interface de modo independente da implementação.

\subsubsection{Modelo Trellis}

O modelo Trellis (Stotts \& Furuta, 1989, 1991) utiliza o formalismo Redes de Petri (Murata, 1984, 1989; Peterson, 1977, 1981) para especificar a estrutura de nós e ligações do hiperdocumento e sua semântica de navegação. O objetivo do modelo é utilizar as propriedades estáticas de dígrafos para a especificação da estrutura dos documentos e as propriedades dinâmicas de Redes de Petri para a definição da semântica de navegação inerente ao hiperdocumento.

Redes de Petri constitui uma técnica eficiente para especificar e analisar o fluxo de controle em sistemas caracterizados por atividades concorrentes e de sincronização (Turine, 1998). Basicamente, uma Rede de Petri possui dois tipos de nós: os lugares (representados graficamente por círculos) e as transições (representadas por barras). Os nós são conectados por arcos, que são representados por setas direcionadas dos lugares para as transições e vice-versa. A execução de uma Rede de Petri é controlada pela posição e movimentação de marcadores (representados por círculos cheios) nos lugares da rede. Os marcadores estabelecem o comportamento dinâmico da Rede, mostrando os lugares ativos em um dado momento e quais transições podem ser ativadas. $\mathrm{O}$ conjunto de todos os lugares ativos em um instante define uma marcação na Rede de Petri, ou seja, representa um dos estados que o sistema pode alcançar durante a sua execução.

O modelo Trellis foi a primeira proposta reconhecida na literatura utilizando o formalismo Redes de Petri na modelagem de hiperdocumentos (Turine, 1998). Em síntese, um hiperdocumento em Trellis é formado por um conjunto de conteúdos, janelas e botões: conteúdos e janelas são associados a lugares enquanto botões são associados a transições. Um hiperdocumento marcado 
é definido aumentando a Rede de Petri subjacente com uma marcação, representando o estado do hiperdocumento durante o processo de navegação. Além disso, especificam-se quais componentes (conteúdo, janela, botão) são apresentados e quais caminhos de navegação podem ser percorridos. Desse modo, a semântica de navegação do hiperdocumento é definida pela semântica de execução da Rede de Petri subjacente.

Segundo Turine (1998) e Leiva (2003), o modelo Trellis permite separar a estrutura organizacional (representada pela Rede de Petri) dos componentes visíveis ao leitor, permitindo que componentes lógicos sejam representados de diferentes formas. Adicionalmente, o modelo permite resolver vários problemas associados a hipertextos, tais como: análise da complexidade da apresentação, alcançabilidade de um nó, caminhos concorrentes de navegação, sincronização, controle de acesso a certas porções de informação e versões personalizadas de hiperdocumentos (Stotts \& Furuta, 1989).

Por outro lado, conforme observado por Leiva (2003), o Trellis não dispõe de recursos satisfatórios para a estruturação hierárquica, dificultando a especificação de controle de sincronização entre os diferentes níveis das estruturas hierárquicas. A decomposição sucessiva de estados também não é realizada facilmente, visto que um estado decomposto não é uma Rede de Petri, mas sim um conjunto de vários subestados. Além disso, mecanismos para especificar a sincronização entre estados decompostos não são tratados.

\subsubsection{Modelo HMBS}

O HMBS (Turine et al., 1997; Turine, 1998; Turine et al., 1998) consiste em um modelo para a especificação da estrutura e da semântica navegacional de hiperdocumentos, utilizando a técnica Statecharts (Harel, 1987) como modelo de especificação formal subjacente.

De acordo com o HMBS, um hiperdocumento é composto por três tipos de objetos: estruturais, navegacionais e de apresentação. Objetos estruturais - estados, transições e eventos - são especificados a partir da estrutura organizacional do hiperdocumento, definida pelo statechart subjacente. Objetos navegacionais - páginas, ligações (ainda que não explicitamente formalizadas no modelo) e âncoras - definem a estrutura navegacional. Objetos de apresentação são definidos por meio de canais de apresentação, que correspondem a abstrações de dispositivos pelos quais é possível especificar os requisitos associados à apresentação do hiperdocumento. Os canais são invocados para visualizar as informações contidas nas páginas durante a navegação, atuando como interpretadores da página.

Nesse sentido, um hiperdocumento é definido no HMBS segundo uma organização hierárquica dos estados do statechart que representa a sua estrutura organizacional e navegacional, os quais são associados a porções de informação ou páginas. Os eventos contidos nos rótulos das transições representam as âncoras que disparam as possíveis ligações entre as páginas, definindo assim os caminhos de navegação disponíveis ao usuário. 


\section{Definição Formal}

Segundo Turine (1998) e Turine et al. (1998), um hiperdocumento $H$ é formalmente definido como uma 7-tupla $H=<S T, P, m, L, p l, a e, N>$, na qual:

- $S T$ representa o statechart subjacente ao hiperdocumento, definido como uma 11-tupla $S T=<S, \rho, \psi, \gamma, \delta, V, C, E, A, R, T>$ representando, respectivamente, estados, função de hierarquia, função tipo de decomposição, função história, função default, conjunto de expressões, conjunto de condições, conjunto de eventos, conjunto de ações, conjunto de rótulos e conjunto de transições.

- $P$ é o conjunto finito de páginas de informação que define o conteúdo do hiperdocumento. Cada página $p \in P$ é definida conceitualmente pela tripla $\left\langle c, t, A n c_{p}\right\rangle$, tal que:

- $c$ representa a porção de informação, que pode ser composta por mídias estáticas (texto, gráfico ou imagem) ou dinâmicas (vídeo, áudio ou animação);

- $t$ representa o título associado à página; e

- $A n c_{p}$ define uma coleção de âncoras contidas na página.

O conjunto de páginas pode incluir uma página nula especial $(P \lambda)$, sem qualquer conteúdo, título e/ou âncora, a qual pode ser associada a estados que não modelam a apresentação da informação.

- $m: S_{S} \rightarrow P$ é uma função que mapeia estados compostos do tipo $O R$ e estados atômicos do statechart em páginas. Estados $A N D$ não são mapeados em páginas, sendo utilizados unicamente para especificar concorrência de informações na apresentação.

- L define o conjunto de canais de apresentação invocados para interpretar e visualizar as informações contidas nas páginas durante a navegação.

- $p l: P \rightarrow L$ é a função de visualização que associa cada página $p \in P$ a um único canal $l \in L$ capaz de interpretá-la.

- ae : Anc $c_{p} \rightarrow E$ é a função que associa âncoras de uma página a eventos do statechart que, por sua vez, definem as transições a serem disparadas.

- $N$ define o nível navegacional, ou de visibilidade, do hiperdocumento. Por exemplo, se $N=$ 0, são exibidas todas as páginas associadas aos estados atômicos ativos durante a navegação; com $N=1$, as páginas apresentadas são aquelas definidas por $N=0$ mais as associadas aos estados $O R$ ancestrais imediatos da configuração atual; e assim por diante. Pode-se utilizar o valor de $N$ para definir a profundidade hierárquica a ser apresentada durante a navegação. 


\section{Semântica de Navegação}

De acordo com Turine (1998), a semântica de navegação adotada no HMBS fornece mecanismos que realçam a estrutura hierárquica típica de muitas aplicações. São definidas as páginas a serem apresentadas durante a navegação, quais âncoras serão habilitadas e quais as transformações navegacionais que irão ocorrer durante a interação com o usuário. O comportamento dinâmico do hiperdocumento é baseado na semântica operacional de Statecharts a partir de alguma configuração de estados.

Para visualizar as informações do hiperdocumento, os canais são invocados para interpretar um número arbitrário de páginas durante a navegação, sendo que diversas páginas podem ser exibidas concorrentemente. O conjunto de páginas exibidas é determinado pela configuração de estados corrente do statechart subjacente e pelo nível de visibilidade $N$. Um hiperdocumento cujo nível de visibilidade foi definido em zero $(N=0)$ tem exibidas, em um determinado momento durante a navegação, todas as páginas associadas aos estados atômicos que estiverem ativos na configuração válida de estados do statechart. Para $N=1$, são apresentadas as mesmas páginas para $N=0$, além daquelas associadas aos estados ancestrais (do tipo $O R$ ) imediatos da configuração de estados atual, e assim por sucessivamente para $N>1$. Desse modo, o conjunto de páginas apresentadas estabelece uma configuração de contexto do hiperdocumento, formada pelas páginas associadas aos estados da configuração de estados corrente do statechart, além das páginas que satisfazem o nível de visibilidade especificado pelo autor.

No HMBS, quando o usuário seleciona uma âncora, as seguintes ações devem ser executadas pelo hiperdocumento (Turine, 1998):

- Gerar o evento correspondente à âncora, disparando a ligação correspondente, interpretada internamente pela transição do statechart à qual o evento está associado.

- Ativar todos os estados que fazem parte do conjunto destino da transição disparada, gerando a próxima configuração de estados e desabilitando a configuração anterior.

- Definir a nova configuração de contexto do hiperdocumento, composta pelas páginas associadas aos estados da nova configuração de estados, além das páginas que obedecem ao escopo estabelecido pelo nível de visibilidade. Invocar, em seguida, os respectivos canais de apresentação para cada página da configuração de contexto.

Como limitações do HMBS, destacam-se (Turine, 1998; Turine et al., 1998):

- O modelo impõe sobrecarga associada à abordagem formal, uma vez que a notação e a gramática de Statecharts requerem familiaridade com matemática discreta e lógica simbólica.

- A modelagem conceitual do domínio de conhecimento não é apoiada pelo HMBS. Desse modo, para projetar um hiperdocumento, a utilização do HMBS não é suficiente por si só. 
Essa limitação, no entanto, é facilmente solucionada incorporando-se ao modelo mecanismos de apoio à modelagem conceitual (modelos E-R, modelos OO).

Ressalta-se que o método HMBS/M (Carvalho, 1998; Carvalho et al., 1999), brevemente descrito no final desta seção, é uma iniciativa a fim de incorporar ao HMBS, entre outros aspectos, questões referentes à modelagem conceitual.

\section{Ambiente HySCharts}

A criação, execução e validação de especificações de aplicações hipermídia segundo o modelo HMBS é apoiada pelo ambiente HySCharts (Hyperdocument System Based on StateCharts) (Turine et al., 1998), que oferece facilidades de prototipação rápida e simulação interativa da estrutura navegacional subjacente ao hiperdocumento.

A arquitetura do ambiente é composta por três camadas principais: camada de aplicação, camada de estruturação e camada de armazenamento. A camada de aplicação está subdividida nos módulos de autoria e de navegação, em adição a um ambiente de edição e simulação de Statecharts. A camada de estruturação é o núcleo do sistema, pois define a estrutura interna do hiperdocumento por intermédio dos objetos estruturais, navegacionais e de apresentação do HMBS. Todos esses objetos são armazenados em bases de dados gerenciadas por funções da camada de armazenamento.

Segundo (Turine et al., 1998), o HySCharts foi projetado e desenvolvido com o propósito de provar e validar a aplicação prática do HMBS em um contexto real, permitindo ao autor especificar um hiperdocumento e visualizar rapidamente o resultado obtido. Permite-se ainda a análise das propriedades do modelo, possibilitando que alterações na estrutura e no conteúdo do hiperdocumento sejam realizadas rapidamente.

Informações detalhadas sobre o HMBS e o ambiente HySCharts, incluindo características, limitações e exemplos de aplicação, estão disponíveis em (Turine et al., 1997; Turine, 1998; Turine et al., 1998).

\section{Método HMBS/M}

A fim de permitir a utilização do HMBS em um processo completo de construção de hiperdocumentos, apoiando tanto o projeto como o desenvolvimento estruturado das aplicações hipermídia, foi definido o método HMBS/M (Hypertext Model Based on Statecharts/Method) (Carvalho, 1998; Carvalho et al., 1999).

O método é composto por quatro fases - Modelagem Conceitual, Modelagem Navegacional, Modelagem da Interface e Implementação e Teste -, em que o produto de cada fase é incrementado ou melhorado na fase posterior. As melhorias introduzidas no modelo de uma certa fase devem ser especificadas nos modelos das fases anteriores, possibilitando o desenvolvimento interativo. $\mathrm{O}$ método também permite a prototipação dos modelos obtidos a cada fase a fim de facilitar a 
verificação dos requisitos. Assim como o OOHDM, o HMBS/M utiliza abstrações orientadas a objetos.

A fase de Modelagem Conceitual tem como propósito analisar o domínio da aplicação, representando-a em modelos que ajudem a identificar as informações relevantes associadas. Dois modelos são construídos nessa fase: o modelo de objetos (permite modelar as informações do domínio da aplicação e os relacionamentos entre elas) e o modelo de fatias (permite modelar somente as informações e os relacionamentos que serão efetivamente implementados).

Na fase de Modelagem Navegacional, o objetivo é reorganizar os modelos da fase anterior, considerando o perfil do usuário e as tarefas que o autor pretende apoiar. São especificados os contextos de navegação (permitem reunir informações do domínio da aplicação que estão relacionadas segundo algum critério), o modelo navegacional de tipos (permite modelar vários tipos de contextos de navegação definidos por estruturas de acesso) e o modelo navegacional de instâncias (modela as instâncias das classes e dos relacionamentos representadas no Modelo Navegacional de Tipos em termos de estados e transições). De fato, o HMBS/M destaca-se por fornecer uma tradução efetiva do Modelo Navegacional de Tipos para uma especificação segundo o modelo HMBS.

A fase de Modelagem de Interface visa a especificar a interface do sistema, definindo apenas suas características genéricas, ou seja, que independem do ambiente de implementação.

Finalmente, na fase de Implementação e Teste, o objetivo é mapear os modelos navegacional e de interface em objetos concretos de um determinado ambiente, cujo resultado é a aplicação hipermídia propriamente dita.

\subsubsection{Modelo MDE}

O MDE (Model for Distance Education - Modelo para Documentos Educacionais) (Leiva et al., 2002b; Leiva, 2003) estende o modelo HMBS (Turine, 1998) para a modelagem de um domínio específico - ensino à distância -, dando ênfase a aspectos de avaliação contínua e acompanhamento do aprendiz. Aspectos referentes à técnica de Mapas Conceituais (Novak, 1990) também são incorporados ao modelo.

Em linhas gerais, o MDE pressupõe que o conteúdo de um curso seja organizado em uma estrutura hierárquica, a qual define um mapa conceitual simplificado. Os conceitos fundamentais associados ao conteúdo são organizados em uma sequiência de unidades de estudo que, por sua vez, são compostas por tópicos. Desse modo, os mapas conceituais são estruturados em três níveis hierárquicos: Curso, Unidades de Estudo (UEs) e Tópicos.

A navegação pelo curso respeita a organização hierárquica do conteúdo, podendo ser controlada pelo desempenho do aprendiz nas avaliações. Três tipos de avaliação são formalizados no modelo: diagnóstica, formativa e somativa. Antes de iniciar uma unidade de estudo, o aprendiz pode ser submetido a uma avaliação diagnóstica (AD). Após estudar cada tópico, seu domínio sobre esse tópico pode ser medido por meio de uma avaliação formativa (AF), cujo propósito é 
identificar se o aprendiz compreendeu o conceito apresentado e pode prosseguir o estudo. Ao terminar a última unidade de estudo do curso, o aprendiz responde a uma avaliação somativa (AS), abrangendo todo o conteúdo explorado. A avaliação somativa pode ser utilizada, de forma isolada ou combinada às demais avaliações, na determinação da nota final do aprendiz.

O MDE adota como modelo formal subjacente uma variante da técnica Statecharts (Harel, 1987), cuja estrutura e a semântica operacional possibilitam especificar a estrutura organizacional e a semântica de navegação de hiperdocumentos complexos. Nesse sentido, uma série de extensões no modelo HMBS original é introduzida a fim permitir a modelagem dos hiperdocumentos educacionais (Leiva et al., 2002b; Leiva, 2003):

- Notação de estados parametrizados, procurando reduzir a repetição de alguns elementos e tornar os modelos mais concisos.

- Condição avaliável por uma expressão lógica, visando a descrever critérios de aprovação em avaliações e determinar a progressão do usuário na navegação pelo conteúdo.

- Associação de um único tipo (unidade de estudo, tópico, questão, etc.) a cada página.

- Associação de atributos estruturados às páginas, os quais variam conforme o tipo da página.

- Comportamento e semântica navegacional associados ao tipo da página.

- Mapa conceitual associado à estrutura de cursos, apoiando a organização lógica dos principais conceitos abordados no hiperdocumento educacional.

- Associação de múltiplas páginas a um mesmo estado.

A Figura 2.5 apresenta a estruturação dos conteúdos de um hiperdocumento educacional, segundo a formalização proposta no modelo MDE: a Figura 2.5(a) refere-se à estrutura de um curso; a Figura 2.5(b) apresenta a estrutura de uma unidade de estudo; a Figura 2.5(c) apresenta a notação parametrizada para os estados $A D$ (avaliação diagnóstica), $A F$ (avaliação formativa) e $A S$ (avaliação somativa); e a figura 2.5(d) ilustra a organização de referências bibliográficas.

Por questões de espaço, os modelos ilustrados não serão discutidos nesta seção. A aplicação do MDE na estruturação de um curso básico sobre HTML é brevemente apresentada e analisada no Capítulo 3.

Segundo Leiva (2003), uma característica importante do modelo, obtida a partir da formalização baseada em Statecharts, consiste na possibilidade de coletar informações relevantes sobre a navegação e o comportamento do aprendiz durante o estudo do material disponível. Tais dados são disponibilizados ao instrutor, constituindo um mecanismo de apoio à avaliação formativa. Além disso, o MDE permite que o autor do curso estabeleça os parâmetros de avaliação e o fluxo de estudo do material didático segundo critérios e interesses pedagógicos pertinentes. 


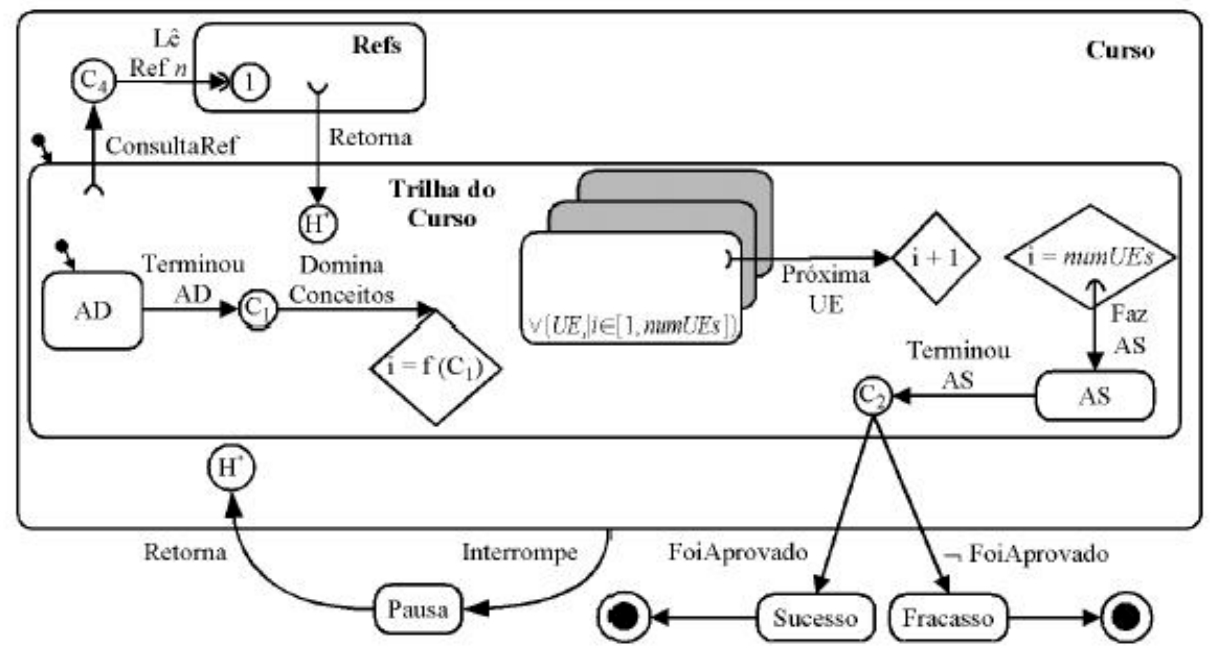

(a) Estrutura de um Curso (Leiva, 2003).

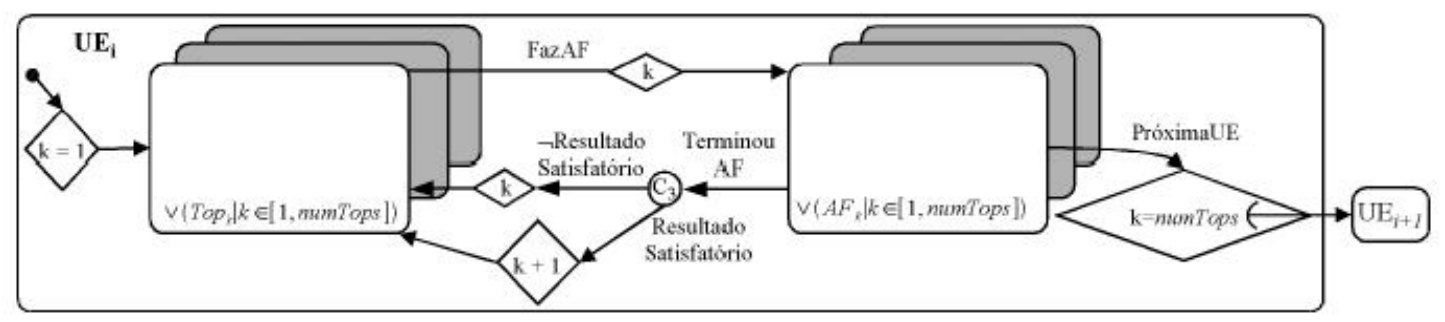

(b) Statechart Parametrizado de uma Unidade de Estudo (Leiva, 2003).

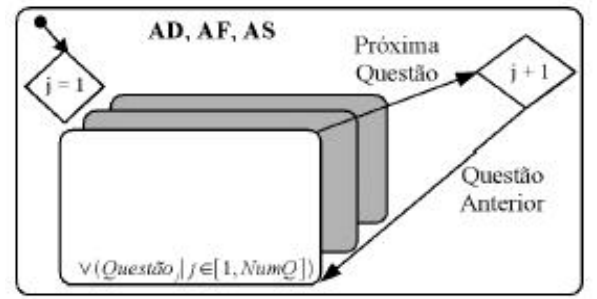

(c) Statechart Parametrizado de Avaliações (Leiva, 2003).

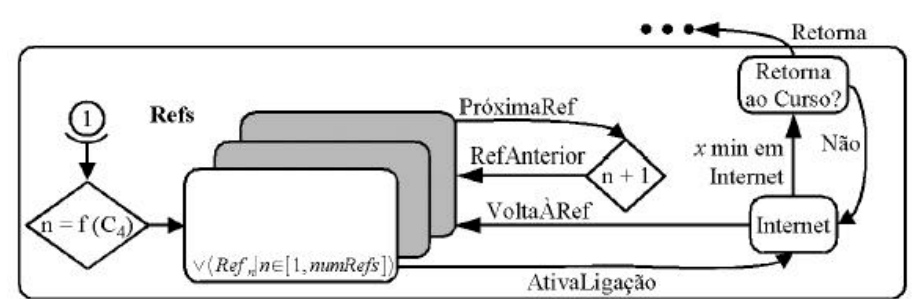

(d) Statechart Parametrizado para Referências (Leiva, 2003).

Figura 2.5: MDE: Estruturação dos Conteúdos de um Hiperdocumento Educacional.

A viabilidade de aplicação do MDE foi verificada a partir da implementação dos principais aspectos do modelo no ambiente ATEnA (Leiva et al., 2002a; Leiva, 2003), apresentado na Seção 2.3.3.

\subsubsection{Síntese dos Mecanismos e Abordagens Consideradas}

A Tabela 2.1 sintetiza os principais aspectos observados com respeito aos mecanismos e abordagens para modelagem de conteúdos educacionais consideradas nas seções anteriores.

De modo geral, é possível observar que as abordagens voltadas ao desenvolvimento de aplicações educacionais - Daphne, EHDM, MAPHE e MDE - tratam, no nível estrutural, de aspectos 
Tabela 2.1: Síntese dos Mecanismos e Abordagens de Apoio à Modelagem de Conteúdos Educacionais.

\begin{tabular}{|c|c|c|c|c|}
\hline $\begin{array}{l}\text { Mecanismo } \\
\text { Abordagem }\end{array}$ & Aplicação & Fundamentação & Objetos Estruturais & $\begin{array}{l}\text { Objetos } \\
\text { Navegacionais }\end{array}$ \\
\hline $\begin{array}{l}\text { Mapas } \\
\text { Conceituais }\end{array}$ & Educacional & $\begin{array}{l}\text { Teoria da } \\
\text { Aprendizagem } \\
\text { Significativa }\end{array}$ & $\begin{array}{l}\text { Conceitos, Exem- } \\
\text { plos, Relaciona- } \\
\text { mento }\end{array}$ & - \\
\hline Daphne & Educacional & $\begin{array}{l}\text { Mapas Conceituais, } \\
\text { HDM, Mapeamento } \\
\text { de Informações }\end{array}$ & $\begin{array}{l}\text { Conceitos, } \\
\text { Relacionamentos }\end{array}$ & $\begin{array}{l}\text { Entidades (Nós), Elos, } \\
\text { Estruturas de Acesso }\end{array}$ \\
\hline EHDM & Educacional & $\begin{array}{l}\text { Mapas Conceituais, } \\
\text { Modelo de Michener }\end{array}$ & $\begin{array}{l}\text { Conceitos, Resulta- } \\
\text { dos, Exemplos, Rela- } \\
\text { cionamentos }\end{array}$ & $\begin{array}{l}\text { Nós, Elos, Estruturas de } \\
\text { Acesso, Contextos Na- } \\
\text { vegacionais }\end{array}$ \\
\hline MAPHE & Educacional & $\begin{array}{l}\text { Mapas Conceituais, } \\
\text { Modelo OO }\end{array}$ & Conceitos & $\begin{array}{l}\text { Nós,Elos, Estruturas de } \\
\text { Acesso }\end{array}$ \\
\hline RMM & Genérica & Modelo E-R & $\begin{array}{l}\text { Entidades, Relacio- } \\
\text { namentos }\end{array}$ & $\begin{array}{l}\text { Entidades (Nós), Elos, } \\
\text { Estruturas de Acesso }\end{array}$ \\
\hline OOHDM & Genérica & Modelo OO & $\begin{array}{l}\text { Subsistemas, } \\
\text { Classes, } \\
\text { Relacionamentos, } \\
\text { Atributos }\end{array}$ & $\begin{array}{l}\text { Nós, Âncoras, Estruturas } \\
\text { de Acesso, Contextos de } \\
\text { Navegação, Transforma- } \\
\text { ções Navegacionais }\end{array}$ \\
\hline EORM & Genérica & Modelo OO & $\begin{array}{l}\text { Classes, Relaciona- } \\
\text { mentos, Atributos }\end{array}$ & $\begin{array}{l}\text { Nós, Elos, Estruturas de } \\
\text { Acesso }\end{array}$ \\
\hline Trellis & Genérica & Redes de Petri & $\begin{array}{l}\text { Lugares, Transições, } \\
\text { Marcações }\end{array}$ & $\begin{array}{l}\text { Conteúdo, Janelas, Bo- } \\
\text { tões }\end{array}$ \\
\hline HMBS & Genérica & Statecharts & $\begin{array}{l}\text { Estados, Transições, } \\
\text { Eventos }\end{array}$ & $\begin{array}{l}\text { Páginas, Ligações e Ân- } \\
\text { coras }\end{array}$ \\
\hline MDE & Educacional & $\begin{array}{l}\text { Mapas Conceituais, } \\
\text { HMBS, Statecharts }\end{array}$ & $\begin{array}{l}\text { Estados, Transições, } \\
\text { Eventos }\end{array}$ & $\begin{array}{l}\text { Páginas, Ligações e Ân- } \\
\text { coras }\end{array}$ \\
\hline
\end{tabular}

específicos associados ao domínio do conhecimento, sobretudo por meio da representação de conceitos e seus relacionamentos associados. No caso do MDE, os conceitos estão associados aos estados do statechart, que podem corresponder a um curso, unidades de estudo, tópicos, avaliações, questões e referências bibliográficas. Por outro lado, abordagens tais como RMM, OOHDM e EORM procuram a generalização do domínio, sem enfatizar características e aspectos específicos do mesmo.

Quanto aos aspectos navegacionais, certos objetos, tais como nós, elos e estruturas de acesso, são comuns tanto nas abordagens genéricas como em abordagens específicas para o projeto de hiperdocumentos educacionais. Ainda, algumas abordagens - Trellis, HMBS e MDE - utilizamse de recursos e técnicas formais como apoio à modelagem dos aspectos de navegação.

\subsection{Ambientes e Sistemas Educacionais}

O desenvolvimento e a implementação de ambientes e sistemas educacionais têm sido uma das linhas de intensa pesquisa pela comunidade científica dentro do contexto de ensino e treinamento. De modo geral, tais ambientes visam a oferecer suporte à disponibilização de material didático, 
à condução de atividades colaborativas, e à avaliação e acompanhamento dos aprendizes, constituindo mecanismos relevantes no que se refere ao desenvolvimento instrucional.

A seguir, são descritos alguns dos principais ambientes e sistemas educacionais existentes. $\mathrm{O}$ objetivo é fornecer uma visão geral a respeito da pesquisa conduzida na área. Tais ferramentas constituem, em sua maioria, trabalhos consolidados e que vêm sendo efetivamente aplicados e avaliados pela comunidade acadêmica ao longo dos últimos anos. É importante ressaltar, entretanto, que várias outras experiências no desenvolvimento e implementação de ambientes e sistemas educacionais podem ser identificadas, além das apresentadas nas próximas seções.

\subsubsection{O Ambiente WebCT}

O WebCT (Web Course Tools) (Goldberg et al., 1996), desenvolvido na University of British Columbia, consiste em uma iniciativa internacional utilizada em programas educacionais de várias universidades, em diferentes países. Basicamente, o ambiente fornece um conjunto de ferramentas que facilitam a criação de cursos baseados na web, podendo ainda ser utilizado como ferramenta complementar de um curso já existente, na disponibilização de material didático.

A principal vantagem associada ao WebCT está na possibilidade de se estabelecer um ambiente de ensino e treinamento integrado, contendo uma série de ferramentas educacionais tais como sistema de conferência, chat, correio eletrônico, acompanhamento do aprendiz ${ }^{1}$, suporte à projetos colaborativos, auto-avaliação, questionários, distribuição e controle de notas, glossário, controle de acesso, calendário do curso, geração automática de índices e pesquisa, entre outras.

Toda interação com o WebCT é baseada na web, não sendo necessário criar versões especiais do software para diferentes plataformas. Ainda, o software é executado a partir de um servidor central, podendo ser acessado de qualquer local onde um computador conectado à Internet esteja disponível.

Além de ferramentas educacionais que auxiliam o aprendizado, a comunicação e a colaboração, o WebCT também fornece um conjunto de ferramentas administrativas para auxiliar no gerenciamento do curso.

\subsubsection{O Ambiente AulaNet}

O AulaNet (Fuks, 2000; Lucena et al., 1998, 1999, 2000), desenvolvido no Laboratório de Engenharia de Software (LES) do Departamento de Informática da Pontifícia Universidade Católica do Rio de Janeiro (PUC/RJ), consiste em um ambiente de aprendizado cooperativo baseado na web, com suporte à administração, criação, manutenção e assistência de cursos à distância.

\footnotetext{
${ }^{1}$ Cada ambiente estabelece uma denominação própria para os atores do processo educacional. Por exemplo, enquanto em alguns ambientes são utilizados os termos professor e aluno, em outros são adotados os termos autor e aprendiz. Nesta seção optou-se por manter a terminologia adotada em cada um dos ambientes considerados.
} 
A fim de que o professor possa elaborar seu curso conforme os objetivos de aprendizado, o ambiente oferece um conjunto de mecanismos de comunicação, coordenação e cooperação. Mecanismos de comunicação fornecem meios para a troca de informações entre professores e alunos. Tais mecanismos incluem ferramentas de correio eletrônico e lista de discussão, ferramenta de conferência assíncrona textual (newsgroup), ferramenta de conferência síncrona textual (chat) e ferramenta de videoconferência $(C U$-SeeMe).

Os mecanismos de coordenação oferecem suporte às atividades de acompanhamento do curso. Incluem ferramentas para o planejamento de tarefas (agenda, quadro de avisos) e para avaliação do aprendizado (provas, trabalhos, exercícios).

Mecanismos de cooperação correspondem ao instrumental pedagógico que deverá ser utilizado no decorrer do curso. No AulaNet, cooperação deve ser entendida como a preparação do material ao qual os alunos terão acesso e, sob uma perspectiva construtivista, como a permissão para que outras pessoas (outros professores e alunos) possam preparar materiais que poderão ser incorporados ao curso. Como mecanismos de cooperação têm-se: transparência, apresentação gravada, texto de aula, livro-texto, bibliografia, demonstração, co-autoria de professor e co-autoria de aluno.

Ao aluno é oferecido um menu de serviços, configurado pela seleção dos mecanismos de comunicação, coordenação e cooperação, realizada previamente pelo professor. O menu de serviços proporciona ao aluno facilidades de navegação de alto nível, que ajudam a minimizar o problema de desorientação. Ainda, os cursos oferecidos usando o ambiente são estruturalmente parecidos, aumentando o sentido de orientação do aluno.

Ressalta-se, por fim, que o AulaNet deliberadamente não oferece meios de sincronização entre os diferentes materiais em virtude da concepção de que o aluno é quem deve ter o controle (Lucena et al., 1998). Desse modo, o aluno pode colocar o vídeo em segundo plano e simplesmente ouvilo, retroceder ou avançar o vídeo, mover a divisão entre as transparências e o texto de aula, entre outras opções para otimizar a área de sua tela.

\subsubsection{O Ambiente ATEnA}

O ATEnA (Adaptative Training Environment with Support for Assessment - Ambiente de Treinamento, Ensino e Aprendizagem) (Casagrande, 2001; Leiva et al., 2002a; Leiva, 2003), desenvolvido no Laboratório de Engenharia de Software (LABES) do ICMC-USP, consiste em um ambiente de autoria e disponibilização de cursos.

Três módulos compõem o sistema: módulo de administração, módulo de autoria e módulo de ensino. O módulo de administração foi construído para registrar e controlar as informações a respeito do oferecimento de cursos. Além de gerenciar cursos, departamentos, unidades, instrutores, aprendizes, funcionários, etc., o módulo também inclui a elaboração de propostas de cursos, inscrições e aprovações dos candidatos, e acompanhamento da freqüência e dos resultados das avaliações dos aprendizes para posterior certificação. 
No módulo de autoria é definida a estrutura do curso, associando-a ao conteúdo. Tal estrutura é baseada no modelo MDE (Leiva et al., 2002b; Leiva, 2003), discutido na Seção 2.2.10. O MDE é especialmente voltado à formalização, baseada em Statecharts, dos aspectos de avaliação do aprendiz, incorporando ainda aspectos pertinentes à técnica de Mapas Conceituais (Novak, 1990). Em linhas gerais, o modelo pressupõe que o conteúdo de um curso seja organizado hierarquicamente em uma seqüência de unidades de estudo e tópicos pertinentes. O ATEnA permite a edição de mapas conceituais bem como de questões pertinentes à avaliação do aprendiz por meio de formulários HTML.

É importante observar que os mapas conceituais elaborados de acordo com o MDE referem-se à estrutura geral do curso, visando à compreensão das idéias fundamentais abordadas no hiperdocumento. Entretanto, detalhes e relacionamentos específicos associados aos conceitos não são modelados.

O módulo de ensino é responsável pela disponibilização dos cursos criados no módulo anterior. A partir das questões, armazenadas em uma base de dados, são elaboradas as avaliações (diagnóstica, formativa ou somativa), de forma manual ou automática, utilizadas para verificar o desempenho do aprendiz. Na forma manual, escolhem-se as questões a partir de uma lista. Na avaliação automática, especifica-se a quantidade de questões sobre cada conceito, de acordo com um nível de dificuldade, cabendo ao sistema selecionar dinamicamente as questões que irão compor a avaliação. O conteúdo é disponibilizado ao aprendiz de modo controlado e adaptado, com base no conhecimento do mesmo em relação aos conceitos abordados. Por exemplo, o aprendiz pode ser dispensado de uma ou mais unidades de estudo, caso a avaliação diagnóstica indique que o mesmo já domina os conceitos daquela unidade.

Leiva (2003) ressalta que o $A T E n A$ poderia ser integrado a um ambiente mais geral, proporcionando outros recursos tais como uma maior interação entre os participantes por meio de fóruns, chat, listas de discussão, etc. Tais aspectos, no entanto, não são abordados na versão atual do ambiente.

\subsubsection{O Ambiente Eureka e a Ferramenta WCC}

O Eureka (Eberspächer et al., 1999) é um projeto de pesquisa desenvolvido no Laboratório de Mídias Interativas (LAMI) da Pontifícia Universidade Católica do Paraná, tendo como propósito implementar um ambiente baseado na web para o aprendizado cooperativo.

$\mathrm{O}$ ambiente integra um conjunto de ferramentas de comunicação, administrativas e de suporte ao conteúdo, objetivando possibilitar interatividade entre o grupo de participantes de um curso ou atividade, de modo que o conhecimento possa ser construído conjuntamente (Eberspächer et al., 1999).

Como principais módulos que compõem o Eureka, destacam-se: módulo de informações sobre o curso, chat, correio eletrônico, módulo de conteúdo, módulo de estatísticas, fórum de discussão, módulos de perfil dos participantes, funções administrativas, entre outros. 
Em outro projeto paralelo ao Eureka, foi construído um sistema de apoio à geração de conteúdo, na forma de uma ferramenta de autoria que ajuda o professor a elaborar seu material hipertexto sem o conhecimento explícito de HTML - o sistema WCC (Web Course Creator) (Pacheco et al., 1999a,b).

Basicamente, o WCC é composto por cinco assistentes (Pacheco et al., 1999a,b): assistente de formatação, assistente de edição, assistente de geração de hipermídia, assistente de aprendizagem e assistente de estatísticas.

Em especial, os assistentes de edição e de geração de hipermídia possibilitam ao professor a criação do conteúdo hipermídia, com a inserção de texto, hiperlinks e outras mídias (como som, imagens, animações, etc.), bem como a criação de exercícios. Durante a edição, o WCC sugere a criação de links, metodologias de passagem e a inserção de exercícios em pontos estratégicos, assistindo o professor, de forma inteligente, na criação do material. Técnicas de Inteligência Artificial, sobretudo frames, são utilizadas pelo sistema para a gerência do conhecimento.

\subsubsection{A Ferramenta CoWeb}

A CoWeb (Collaborative Website) (Guzdial, 1997; Guzdial \& Kehoe, 1998; Guzdial, 1999, 2001; Guzdial et al., 2002) é uma ferramenta de edição colaborativa baseada na web, desenvolvida no Georgia Institute of Technology.

Sob a perspectiva de ensino e aprendizado, a CoWeb fornece um espaço colaborativo no qual os aprendizes podem trabalhar juntos, ajudando-se mutuamente na articulação do conhecimento para a realização das tarefas e projetos propostos. Segundo Guzdial et al. (2002), o desenvolvimento e o uso da $C o W e b$ no contexto educacional estão baseados na idéia de que novas oportunidades de aprendizado são criadas quando os aprendizes são motivados a articular seu conhecimento por meio da elaboração de documentos multimídia, quando revisam seus trabalhos e quando recebem comentários e críticas sobre aquilo que fizeram.

De modo geral, os usos da ferramenta podem ser caracterizados em três perspectivas:

- Distribuição da informação: Professores e aprendizes compartilham informações referentes aos tópicos discutidos durante a disciplina, utilizando a CoWeb como mecanismo de integração e distribuição dessas informações. Nesse caso, a CoWeb atua como um site da disciplina.

- Criação colaborativa de artefatos: Os aprendizes trabalham colaborativamente na elaboração de documentos (resumos, monografias, glossários) e na realização de projetos, utilizando a CoWeb como um espaço comum para reunir e integrar as diferentes partes do documento/projeto sendo desenvolvido ou, simplesmente, para coordenar as atividades envolvidas.

- Discussão e revisão: A CoWeb atua como um espaço para revisar documentos, idéias e projetos, os quais são criticados e discutidos tanto pelos professores como pelos aprendizes. 
Um aspecto interessante associado ao uso da CoWeb é a possibilidade de disponibilizar material didático, discussões e resultados de projetos para as turmas futuras de uma mesma disciplina cross-term communication. Disciplinas que enfocam o mesmo assunto, porém em diferentes níveis de detalhamento (por exemplo, aspectos de Engenharia de Software nos contextos de graduação e de pós-graduação), também podem ser integradas via CoWeb. Além disso, alunos de diferentes disciplinas (ou mesmo diferentes cursos) podem ser envolvidos no desenvolvimento de projetos em comum - cross-class projects. É possível, por exemplo, promover a integração entre alunos de Ciências de Computação e Estatística por meio de projetos envolvendo coleta e análise de dados referentes à produção de software.

Destaca-se ainda a possibilidade de integração entre a CoWeb e o ambiente de captura $e$-Class, (discutido na Seção 2.3.8), apoiando aspectos pertinentes à evolução e reuso do conhecimento. A motivação para tal integração vem do fato de que, uma vez capturadas, as aulas tornam-se "mortas", isto é, material estático. Nesse sentido, a integração com a CoWeb permite que as aulas capturadas sejam armazenadas e estendidas por meio de discussão e links para recursos externos. Detalhes sobre a integração entre $C o W e b$ e $e$-Class podem ser encontrados em (Pimentel et al., 2001).

\subsubsection{O Ambiente $H L M$}

Desenvolvido na George Mason University, o HLM (HyperLearning Meter) (Menasce, 1998) é um ambiente de auto-avaliação e certificação baseado na web, destinado a profissionais que desejam desenvolver e certificar sua competência em determinado domínio.

O ambiente apresenta questões individualizadas para cada aprendiz, elaboradas a partir de templates preparados pelos professores. O HLM permite ainda que o aprendiz realize testes de auto-avaliação, obtendo versões preliminares de certificações; e apresenta ao aprendiz seus pontos fracos, indicando os links para módulos que podem auxiliá-los. Também são obtidas amostras e medidas estatísticas a respeito do desempenho do aprendiz, contrastando-o com um mapa conceitual do domínio. Nesse mapa todos os termos ou rótulos são conceitos inter-relacionados, cujas ligações contêm pesos representando a importância dos conceitos-filhos em relação aos conceitospai.

O HLM oferece uma série de ferramentas aos instrutores, entre elas: editor de mapas conceituais, autoria de gabaritos de avaliação paramétrica (permite a criação de templates de questões), construtor de testes (os templates são utilizados na construção de testes de auto-avaliações ou certificações), monitor de desempenho, e serviço de mensagens.

Aos aprendizes estão disponíveis ferramentas para resolução de testes, certificação e visualização dos resultados dos testes. Um relatório de testes apresenta os resultados do teste atual, ligações para os materiais de apoio, histórico de resultados de tentativas anteriores e resultados gerais da classe.

Como ressalta Menasce (1998), avaliações dos próprios aprendizes têm demonstrado que o ambiente é bastante útil, ajudando-os a identificar quais aspectos da aula não foram bem com- 
preendidos. Além disso, existe uma forte correlação entre os resultados dos exames e as notas (escores) obtidas quanto ao número de vezes que os aprendizes utilizaram o ambiente com o propósito de auto-avaliação.

\subsubsection{O Sistema CyberQ}

O CyberQ (Tucker, 1995) é um sistema de avaliação a partir do qual é possível automatizar a administração de questões para avaliar a estrutura acadêmica, conteúdo, processo e resultados. O sistema é formado por uma série de componentes funcionais, com destaque ao software de monitoramento de transações e ao software de avaliação adaptável.

O software de monitoramento de transações é responsável por controlar o movimento das informações, registrando a proporção da entrada e saída de bytes no sentido do instrutor ao aprendiz, do aprendiz ao instrutor, e do aprendiz ao grupo de trabalho. A partir da quantidade de informações trocadas, podem ser extraídas informações tais como o tempo de resposta em consultas, o quanto um aprendiz está participando das aulas, etc.

O software de avaliação adaptável obtém medidas de desempenho a partir de perguntas feitas aos aprendizes durante o decorrer do curso. O aprendiz pode, em muitos casos, "passar" a questão, sabendo que isso aumentará o peso da avaliação nas questões subseqüentes. Entretanto, algumas questões tem que ser respondidas na hora e sem consulta, enquanto outras permitem consulta ao material.

Ainda, por meio dos componentes de análise sintática, análise de comentário e análise de predicado, o $C y b e r Q$ procura fornecer feedback ao aprendiz, mesmo para as questões discursivas.

\subsubsection{O Ambiente e-Class}

O e-Class (Abowd et al., 1996, 1998b,a; Abowd, 1999; Abowd et al., 1999; Brotherton \& Abowd, 1998; Brotherton et al., 1998; Pimentel et al., 2002) consiste em um ambiente instrumentado com recursos computacionais visando à captura de material multimídia em salas de aula convencionais e sua posterior integração aos conteúdos educacionais previamente elaborados. O ambiente foi desenvolvido no Georgia Institute of Technology, dentro do escopo do projeto e-Class. Em linhas gerais, esse projeto trata de aspectos relacionados à captura de material multimídia em aulas presenciais, investigando ainda mecanismos para disponibilização e acesso a esse material via web (Pimentel, 2001).

O desenvolvimento de material didático no e-Class é dividido em três fases (Abowd et al., 1996):

- Pré-Produção: Consiste na preparação do material a ser utilizado na aula: transparências, transparências, textos, entre outros. É importante observar, entretanto, que o e-Class não dispõe de mecanismos que apóiem a pré-produção do material. 
- Captura (Live-Recording): Consiste na captura e armazenamento das discussões e experiências ocorridas durante a aula. Para isso utilizam-se microfones, câmeras de vídeo, projetores e lousas eletrônicas, os quais são adaptados na sala de aula de forma pouco intrusiva. Um conjunto de aplicações cliente-servidor fornece suporte aos equipamentos de captura e é responsável pela integração e sincronização dos vários fluxos de informação capturados (áudio, vídeo, anotações), gerando um conjunto de hiperdocumentos disponibilizados automaticamente na web (Pimentel, 2001). Ressalta-se que a atividade de captura é um aspecto-chave dentro do $e$-Class e seu diferencial em relação aos demais ambientes e sistemas existentes, os quais oferecem recursos para o tratamento do material didático antes e depois das aulas, mas não "durante" as mesmas.

- Pós-Produção: Consiste em associar as informações capturadas em aula ao material previamente desenvolvido. Conforme destacado anteriormente, a ferramenta CoWeb (Guzdial et al., 2002) pode ser integrada ao $e$-Class, sendo que as informações resultantes de atividades colaborativas envolvendo professores e aprendizes são incorporadas ao material nessa fase.

A partir das experiências adquiridas com o projeto $e$-Class foi estabelecida uma parceria entre o ICMC/USP e o Georgia Tech - o projeto InCA-SERVE (Development and understanding of automated capture environments to support long-term use). Esse projeto tem como objetivo o desenvolvimento de novas infra-estruturas para captura e disponibilização de informações - InCA (Infrastructure for Capture and Access) e SERVE (Store, Extend, Retrieve, and Visualize Evolutionary Information) -, e conta com o apoio do ProTeM-CC/CNPq (Brasil) e do NSF (USA).

\subsubsection{Síntese dos Ambientes e Sistemas Considerados}

A Tabela 2.2 apresenta uma síntese dos principais recursos oferecidos pelos ambientes e sistemas educacionais descritos nas seções anteriores.

Tabela 2.2: Síntese dos Principais Recursos Oferecidos pelos Ambientes e Sistemas Educacionais.

\begin{tabular}{||l|l|l|l|l||}
\hline \hline $\begin{array}{l}\text { Ambientes e } \\
\text { Sistemas Educa- } \\
\text { cionais }\end{array}$ & $\begin{array}{l}\text { Estruturação e } \\
\text { Gerenciamento } \\
\text { de Cursos }\end{array}$ & $\begin{array}{l}\text { Modelagem } \\
\text { de Conteúdos } \\
\text { Educacionais }\end{array}$ & $\begin{array}{l}\text { Comunicação e } \\
\text { Colaboração }\end{array}$ & $\begin{array}{l}\text { Avaliação e } \\
\text { Acompanha- } \\
\text { mento }\end{array}$ \\
\hline \hline WebCT & Sim & Não & Sim & Sim \\
\hline AulaNet & Sim & Não & Sim & Sim \\
\hline$A T E n A$ & Sim & Sim & Não & Sim \\
\hline Eureka/WCC & Sim & Não & Sim & Sim \\
\hline CoWeb & Não & Não & Sim & Não \\
\hline$H L M$ & Não & Parcial & Parcial & Sim \\
\hline$C y b e r Q$ & Sim & Não & Não & Sim \\
\hline$e$-Class & Não & Parcial & Não \\
\hline \hline
\end{tabular}

De modo geral, é possível observar uma grande diversidade de características e funcionalidades associadas aos ambientes e sistemas educacionais, tanto em aspectos pedagógicos como técnicos 
e administrativos. Uma limitação comum identificada refere-se ao fato de que a maioria dos ambientes e sistemas existentes concentram-se na criação da estrutura do curso, armazenamento e controle de acesso ao conteúdo e monitoração do aprendiz, deixando a tarefa de modelagem do conteúdo educacional inteiramente a cargo do autor do curso, sem quaisquer diretrizes ou mesmo um processo sistemático que apóie sua realização.

É importante salientar que, embora o ATEnA e o HLM possibilitem a criação de mapas conceituais como parte do processo de autoria, os mapas elaborados, no entanto, referem-se essencialmente à estrutura geral do curso, não abordando aspectos específicos de modelagem do conteúdo propriamente dito. Ainda com respeito ao ATEnA, o ambiente permite a modelagem de conteúdos por meio da incorporação do MDE. Ressalta-se que tal modelagem enfatiza os aspectos de avaliação do aprendiz. Já o sistema $W C C$, integrado ao Eureka, segue a linha de tutores inteligentes, utilizando técnicas de IA na representação e gerência do conhecimento e oferecendo ao autor "assistência inteligente" na criação do conteúdo. Apesar disso, aspectos de modelagem não são explicitamente tratados ou apoiados pelo sistema.

\subsection{Processos de Software}

Sob vários aspectos de desenvolvimento, a construção de produtos educacionais assemelha-se à construção de software. No caso de software, métodos, ferramentas e procedimentos têm sido definidos e integrados visando ao estabelecimento de processos sistemáticos que resultem em produtos confiáveis e eficientes (Pressman, 2001; da Rocha et al., 2001). A norma ISO/IEC 12207 (International Organization for Standardization, 1995), o modelo CMM (Paulk, 1993; Paulk et al., 1995) e o processo padrão para equipes geograficamente dispersas (Maidantchik, 1999) são exemplos de iniciativas nessa direção.

De maneira análoga, o estabelecimento e a aplicação de práticas sistemáticas e disciplinadas que garantam a produtividade do processo de desenvolvimento e a qualidade dos produtos gerados também se fazem fundamentais no contexto de desenvolvimento instrucional. Nesse sentido, alguns aspectos pertinentes ao desenvolvimento de software foram utilizados como base para a definição dos processos, atividades e tarefas associadas à produção de módulos educacionais, que constitui um dos objetivos do presente trabalho.

Dentro desse contexto, a seguir são discutidos alguns trabalhos relevantes no que se refere à produção de software. Na Seção 2.4.1 é dada uma visão geral a respeito da norma ISO/IEC 12207. A Seção 2.4.2 aborda aspectos referentes ao modelo CMM. Finalmente, o processo padrão para equipes geograficamente dispersas é discutido na Seção 2.4.3.

\subsubsection{A Norma ISO/IEC 12207}

A norma internacional ISO/IEC 12207 - (Information Technology - Software Life Cycle Processes) (International Organization for Standardization, 1995) e sua correspondente em português, a 
NBR ISO/IEC 12207 (Tecnologia da Informação - Processos de Ciclo de Vida de Software) (Associação Brasileira de Normas Técnicas, 1998), têm por objetivo auxiliar os envolvidos na produção de software a definir seus papéis, por meio de processos bem definidos, possibilitando às organizações que a utilizam um melhor entendimento das atividades a serem executadas nas operações que envolvem, de alguma forma, o software (da Rocha et al., 2001).

A ISO/IEC 12207 cobre todo o ciclo de vida de desenvolvimento de software, desde a concepção das idéias iniciais sobre o produto até o mesmo ser retirado de execução. Além disso, processos para a aquisição e o fornecimento de produtos e serviços, bem como mecanismos para o controle e a melhoria dos processos envolvidos no ciclo de vida do software também são estabelecidos.

De acordo com a norma, os processos que envolvem o ciclo de vida do software são agrupados em três classes, representando sua natureza: Processos Fundamentais, Processos de Apoio e Processos Organizacionais. Cada processo é definido em função de suas próprias atividades, as quais, por sua vez, são definidas em termos de suas tarefas. A Figura 2.6 ilustra a estrutura da norma, de acordo com os processos que a compõem.

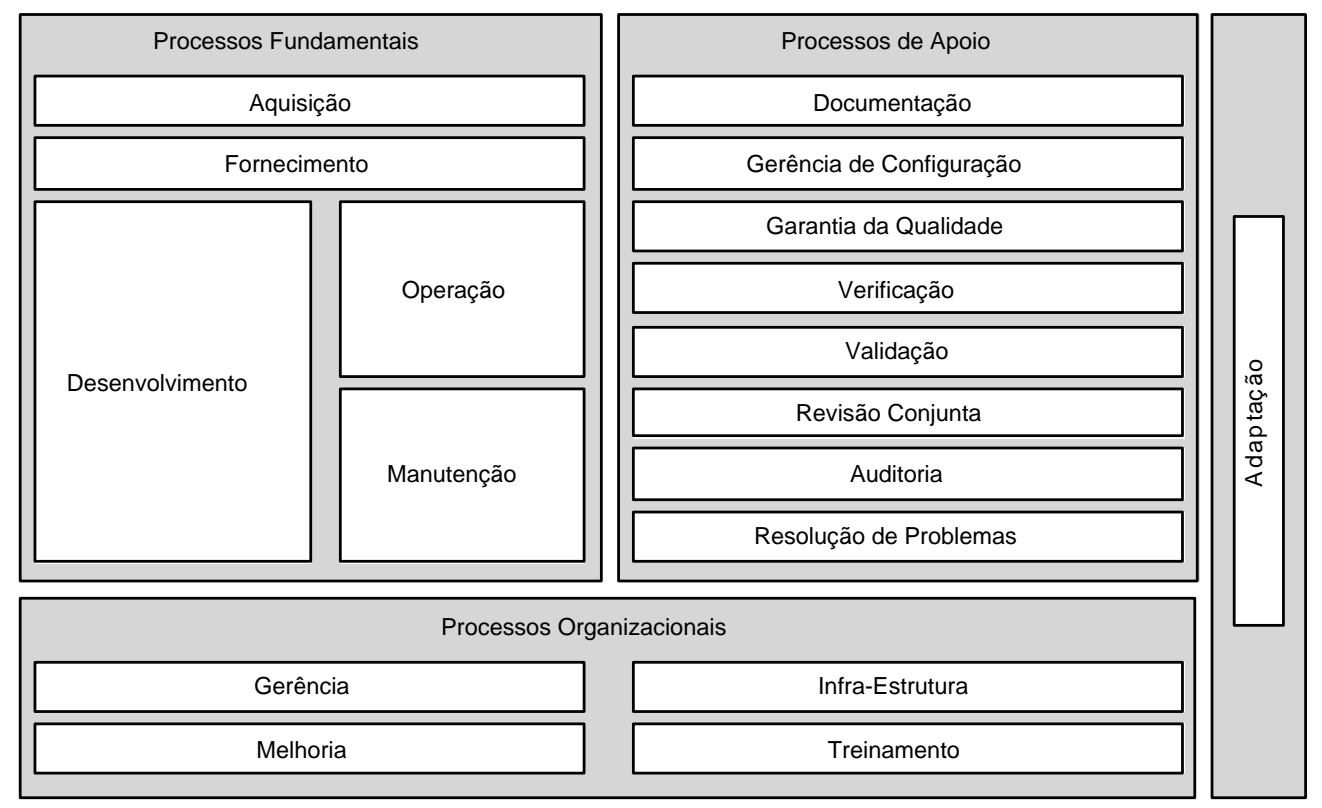

Figura 2.6: Processos de Ciclo de Vida de Software (da Rocha et al., 2001).

A classe de Processos Fundamentais, também referenciados como Processos Primários (Maidantchik, 1999), consiste em um conjunto de cinco processos, no qual são abordadas atividades referentes ao contrato entre o cliente e o fornecedor, ao desenvolvimento, à operação e à manutenção do software. São eles: Processo de Aquisição, Processo de Fornecimento, Processo de Desenvolvimento, Processo de Manutenção e Processo de Operação.

Os Processos de Apoio auxiliam outros processos como parte integrante dos mesmos, contribuindo para o sucesso e a qualidade do projeto de software. São eles: Processo de Documentação, Processo de Gerência de Configuração, Processo de Garantia da Qualidade, Processo de Verifica- 
ção, Processo de Validação, Processo de Revisão Conjunta, Processo de Auditoria e Processo de Resolução de Problemas.

A classe de Processos Organizacionais é utilizada pela organização para estabelecer e implementar uma estrutura subjacente, constituída pelos processos de ciclo de vida e pelo pessoal envolvido no desenvolvimento de software, e para melhorar continuamente a estrutura e os processos. São eles: Processo de Gerência, Processo de Infra-Estrutura, Processo de Melhoria e Processo de Treinamento.

Ainda como parte da norma, o Processo de Adaptação define as atividades necessárias para sua adaptação a organizações ou projetos específicos. A adaptação deve ser executada com base em fatores que diferenciam uma organização ou projeto de outros. Devem-se considerar, por exemplo, estratégias, procedimentos, políticas e cultura organizacional, tamanho, criticalidade e tipo de sistema, modelos de ciclo de vida de projeto, características do sistema, riscos, custos e pessoal envolvidos.

Finalmente, é importante salientar a flexibilidade da norma quanto às abordagens de Engenharia de Software envolvidas. Nesse sentido, é possível utilizá-la com qualquer modelo de ciclo de vida (cascata, incremental, evolutivo, etc.), com qualquer método ou técnica de Engenharia de Software (projeto orientado a objetos, técnicas estruturadas, prototipação, etc.) e com quaisquer linguagens de programação. Tais escolhas dependem do projeto e do estado da arte da tecnologia, sendo deixadas a critério dos usuários da norma (da Rocha et al., 2001).

\subsubsection{O Modelo CMM}

O modelo CMM (Capability Maturity Model - Modelo de Maturidade da Capacidade) (Paulk, 1993; Paulk et al., 1995), desenvolvido pelo SEI (Software Engineering Institute), tem como objetivo avaliar a maturidade da capacidade dos processos de software das organizações, identificando ainda as práticas requeridas para melhorar a maturidade desses processos. Entende-se por capacidade do processo de software a habilidade inerente de um processo em produzir os resultados planejados (Paulk et al., 1995).

O modelo estabelece níveis de maturidade nos quais as organizações podem ser categorizadas. Segundo Paulk et al. (1995), um nível de maturidade representa um patamar evolucionário bem definido em direção a um processo de software maduro.

Cada nível de maturidade compreende um conjunto de metas a serem satisfeitas e está dividido em áreas-chave de processo (KPAs - Key Process Areas). Cada área-chave aborda um determinado tema, sendo detalhada em práticas-chave, que correspondem aos quesitos a serem cumpridos para a melhoria de processos. As práticas-chave especificam o que deve ser cumprido, exigindo documentos, treinamentos ou políticas definidas para as atividades, sem no entanto especificar como essas devem ser implementadas (da Rocha et al., 2001).

No total, o CMM apresenta cinco níveis de maturidade, 18 áreas-chaves e 316 práticas-chave. Os níveis de maturidade são os seguintes (Paulk, 1993; Paulk et al., 1995): 
- Inicial: As organizações no Nível 1 apresentam um processo de software caracterizado como ad hoc e mesmo como caótico. O sucesso depende essencialmente das habilidades e esforços individuais dos desenvolvedores. Não existem áreas-chave associadas a este nível.

- Repetível: As organizações no Nível 2 estabelecem políticas de gerenciamento e procedimentos para orientar os projetos. Funções de garantia de qualidade asseguram que as políticas e procedimentos sejam praticados, possibilitando que o processo seja repetido em projetos similares. Neste nível, seis áreas-chave são definidas: (a) gerência de requisitos; (b) planejamento de projeto de software; (c) acompanhamento e supervisão de projeto de software; (d) gerência de subcontratação de software; (e) garantia da qualidade de software; e (f) gerência de configuração do software.

- Definido: Nas organizações que estão no Nível 3, o processo de software é documentado, padronizado e integrado em um processo de software padrão. Todos os projetos da organização utilizam-se desse processo para desenvolver e manter o software. Sete áreas-chave são definidas: (a) foco no processo organizacional; (b) definição do processo organizacional; (c) programa de treinamento; (d) gerência integrada de software; (e) engenharia de produto de software; (f) coordenação intergrupos; e (g) revisões (peer reviews).

- Gerenciado: No Nível 4, a qualidade do processo e do produto são medidos. O processo de software e os produtos são quantitativamente entendidos e controlados. Duas áreas-chave são estabelecidas: (a) gerência quantitativa do processo; e (b) gerência da qualidade de software.

- Otimizado: Nas organizações que estão no Nível 5, o processo é continuamente melhorado por meio da avaliação quantitativa de processos anteriores e pela facilidade de introdução de novas idéias e tecnologias. Neste nível, três áreas-chave são definidas: (a) prevenção de defeitos; (b) gerência de mudança tecnológica; e (c) gerência de mudança no processo.

O CMM tem sido considerado e utilizado em muitas organizações, tornado-se um padrão na avaliação e melhoria de processos de software (da Rocha et al., 2001). Salienta-se, entretanto, que a aplicação do modelo na implementação da melhoria de processos é uma tarefa de longo prazo, envolvendo aspectos de mudança cultural dentro da organização e, especialmente, interesse e apoio efetivos da alta administração. Além disso, para sua aplicação em projetos pequenos, é necessário um trabalho cuidadoso de interpretação e adequação à realidade da organização (da Rocha et al., 2001).

\section{O Modelo CMMI}

Atualmente, o SEI tem trabalhado no estabelecimento do CMMI (Capability Maturity Model Integration - Modelo Integrado de Maturidade da Capacidade) (Ahern et al., 2001; Chrissis et al., 2003; Software Engineering Institute, 2003), visando à evolução e à integração do modelo CMM. 
O principal objetivo do CMMI é a redução do custo de implementação de melhoria de processo multidisciplinar baseada em modelo. Nesse sentido, procura-se eliminar inconsistências, reduzir duplicações, e melhorar a clareza e o entendimento do modelo CMM. Além disso, são apoiadas a utilização de uma terminologia comum e estilo consistente, e o estabelecimento de regras de construção uniformes. Ressalta-se ainda que o CMMI é consistente e compatível com a norma ISO/IEC 15504 (International Organization for Standardization, 1998).

Ao invés de áreas-chave de processo (KPAs), o CMMI estabelece áreas de processo (APs Area Process). Ao todo, 22 APs são estabelecidas, as quais podem ser representadas de duas formas: representação por estágio e representação contínua.

A representação por estágio assemelha-se à representação utilizada no CMM, fornecendo uma direção pré-determinada na implementação da melhoria de processos. As áreas de processo são agrupadas em 5 níveis de maturidade: (1) Inicial, (2) Gerenciado, (3) Definido, (4) Gerenciado Quantitativamente, e (5) Em Otimização.

A representação contínua, por sua vez, fornece uma abordagem mais flexível para a melhoria, permitindo que as organizações utilizem apenas um subconjunto de áreas de processo, selecionadas com base em seus próprios problemas e objetivos de negócio específicos. As áreas de processo são agrupadas em quatro categorias - Gerenciamento de Processo, Gerenciamento de Projeto, Engenharia e Apoio -, e seis níveis de capacidade - Incompleto, Executado, Gerenciado, Estabelecido, Previsível e Em Otimização.

A Figura 2.7 ilustra os modelos CMM e CMMI, procurando estabelecer uma correspondência entre as áreas-chave do CMM e áreas de processo do CMMI. Informações detalhadas a respeito do CMMI podem ser encontradas em (Ahern et al., 2001; Chrissis et al., 2003; Software Engineering Institute, 2003).

\subsubsection{Processo Padrão para Equipes Geograficamente Dispersas}

Diversos são os problemas que permeiam o desenvolvimento distribuído de software, entre eles a coordenação das equipes e das atividades, a comunicação entre as equipes e o controle de artefatos. De acordo com Maidantchik (1999), tais problemas podem ser minimizados a partir do estabelecimento e adoção de um processo de software bem definido, adequado às especificidades dos ambientes distribuídos.

Dentro desse contexto, Maidantchik (1999) estabeleceu um processo padrão para o desenvolvimento de software, no qual as equipes de trabalho encontram-se geograficamente dispersas, muitas vezes utilizando equipamentos, métodos, técnicas, ferramentas e padrões distintos.

A Figura 2.8 ilustra a estrutura do processo padrão para equipes geograficamente dispersas. $\mathrm{O}$ processo define uma estrutura única a ser seguida por todas as equipes distribuídas envolvidas em um projeto de software, cobrindo todo o ciclo de vida do software, desde a concepção inicial, determinação de requisitos, construção, entrega, manutenção, até finalizar sua utilização (Maidantchik, 1999). 


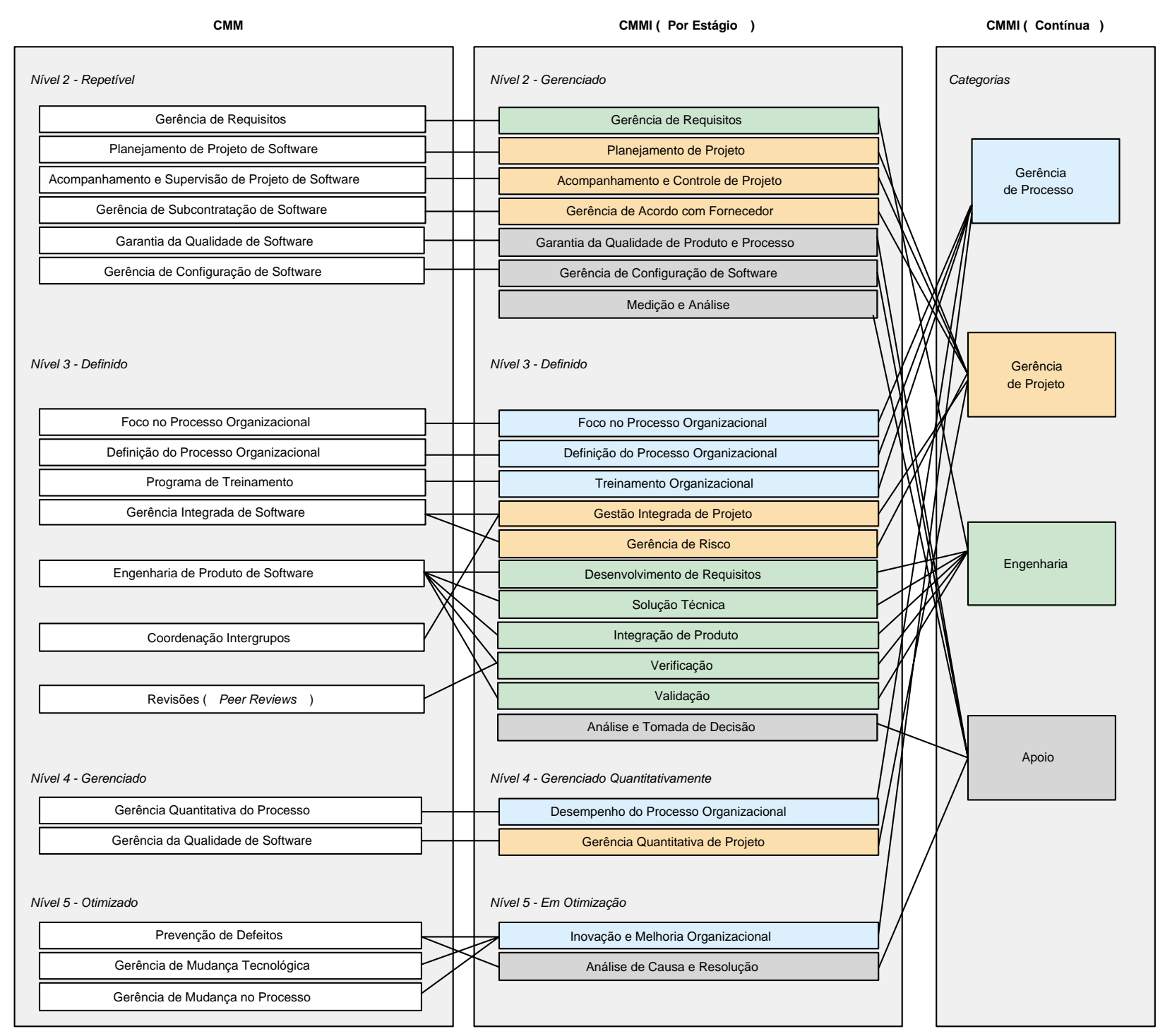

Figura 2.7: Correspondência entre CMM e CMMI.

A definição do processo padrão teve como base a norma ISO/IEC 12207 (International Organization for Standardization, 1995). Os processos originalmente pertencentes à norma foram redefinidos, sendo introduzidos outros processos e atividades específicas para atender às necessidades de equipes de trabalho dispersas. De modo geral, processos não adequados ao desenvolvimento distribuído, tais como os processos de Aquisição e de Fornecimento, não foram considerados. Por outro lado, processos abordando aspectos específicos do desenvolvimento envolvendo equipes dispersas, tais como os processos de Comunicação, de Coordenação e de Controle de Artefatos, foram acrescentados.

Conforme observado por Nakagawa (2002), o processo padrão para equipes geograficamente dispersas retrata, em alguns aspectos, a forma como ocorre o processo de desenvolvimento de software livre. Em ambas as situações, os desenvolvedores encontram-se, muitas vezes, distribuídos por diversos países, utilizando diferentes tecnologias, ferramentas e métodos. Tais considerações 


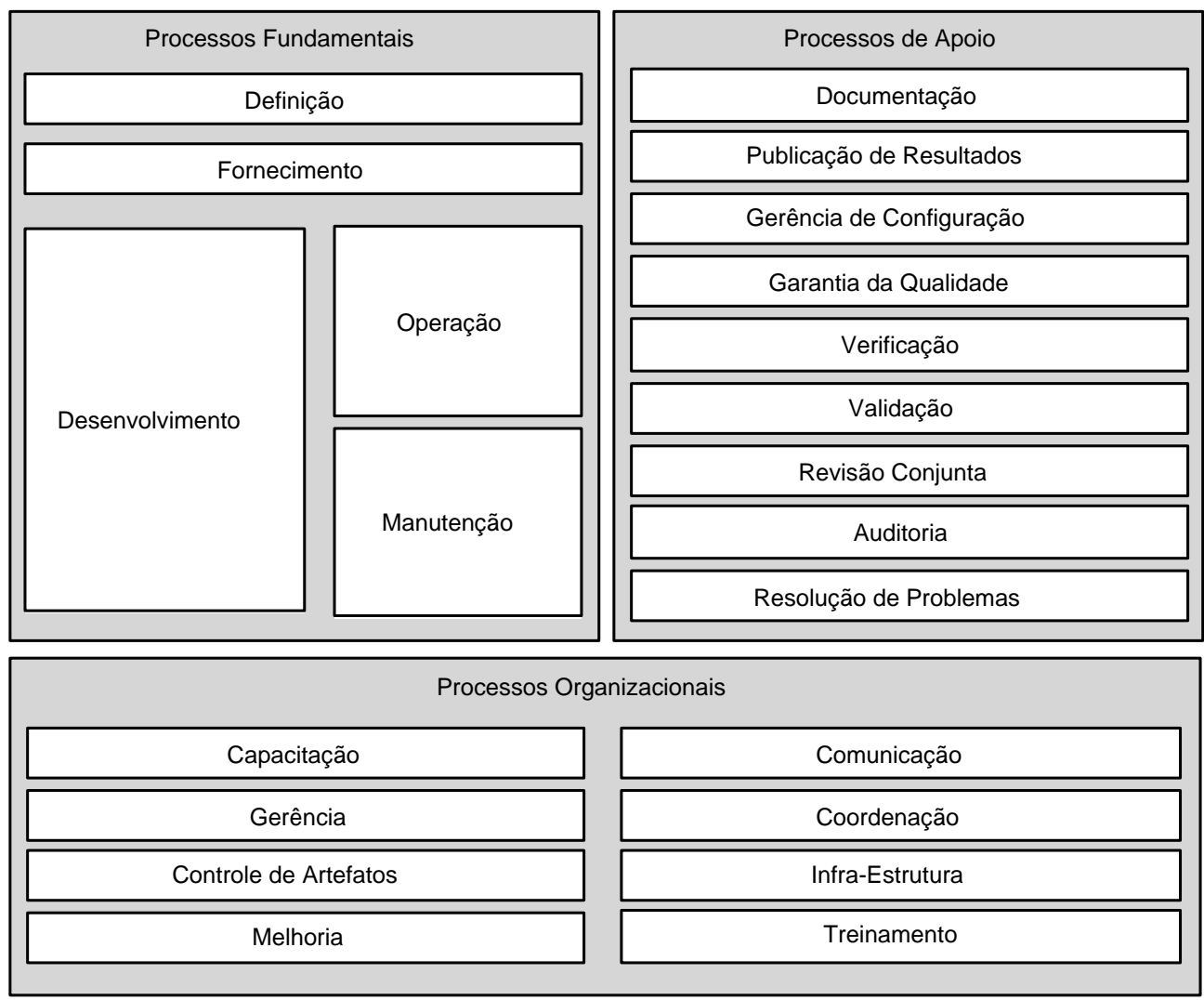

Figura 2.8: Estrutura do Processo Padrão para Equipes Dispersas (Maidantchik, 1999).

são relevantes no contexto de desenvolvimento de módulos educacionais livres, sendo retomadas no Capítulo 4.

Ainda como parte do trabalho de Maidantchik (1999), foi definido um modelo de gerência de processos de software para equipes geograficamente dispersas. O modelo tem como principais objetivos: (1) garantir que projetos distribuídos tenham êxito e possam ser realizados por equipes em diferentes níveis de maturidade; (2) melhorar a capacidade de cada equipe de trabalho; e (3) aprimorar o processo de software da organização como um todo.

Dentro dessa perspectiva, o processo padrão definido foi especializado em quatro outros processos, cada qual correspondendo a um nível de maturidade. A especialização do processo utilizou um modelo de maturidade de referência, obtido a partir da adaptação do CMM às necessidades do desenvolvimento de software geograficamente distribuído. Segundo Maidantchik (1999), a correspondência entre os diferentes aspectos do processo padrão e as áreas-chave do modelo de maturidade permite identificar quais categorias do processo requerem maior atenção. Desse modo, o processo de software de uma organização pode ser aprimorado com base na experiência de sua utilização.

Alguns dos aspectos investigados no trabalho de Maidantchik (1999) são retomados no Capítulo 4. Maiores informações sobre o processo padrão para equipes geograficamente dispersas e sobre o modelo de gerência de processos de software estão disponíveis em (Maidantchik, 1999) e (da Rocha et al., 2001). 


\subsection{Teste de Software}

O processo de desenvolvimento de software envolve uma série de atividades nas quais, apesar das técnicas, métodos e ferramentas empregadas, $\operatorname{erros}^{2}$ no produto ainda podem ocorrer. Para que o produto de software atinja um grau de qualidade aceitável, atividades agregadas sob o nome de Garantia de Qualidade de Software, entre elas atividades de V\&V - Verificação e Validação - têm sido introduzidas ao longo de todo o processo de desenvolvimento. Dentre as técnicas de verificação e validação, a atividade de teste é uma das mais utilizadas, constituindo um dos elementos para fornecer evidências da confiabilidade do software (Maldonado, 1991; Pressman, 2001).

A atividade de teste consiste em uma análise dinâmica do produto, sendo relevante para a identificação e eliminação dos erros que persistem, representando a última revisão da especificação, projeto e codificação (Harrold, 2000; Maldonado, 1991; Pressman, 2001; Zhu, 1996). Segundo Myers (1979), o objetivo principal do Teste de Software é revelar a presença de erros ou defeitos no produto. Nesse sentido, o teste bem sucedido é aquele que consegue determinar casos de teste para os quais o programa sendo testado falhe. Salienta-se, entretanto, que a atividade de teste tem sido apontada entre as mais onerosas no desenvolvimento de software, podendo, em alguns casos, consumir grande parte dos custos de desenvolvimento (Pressman, 2001).

Apesar de não ser possível, por meio de testes, provar que um programa está correto, estes contribuem para aumentar a confiança de que o software desempenha as funções especificadas. Além disso, apesar das limitações próprias da atividade de teste, sua aplicação de maneira sistemática e bem planejada pode garantir ao software algumas características mínimas, importantes tanto para o estabelecimento da qualidade do produto como para o seu processo de evolução.

O teste de produtos de software envolve basicamente quatro etapas: planejamento de testes, projeto de casos de teste, execução e avaliação dos resultados dos testes (Maldonado, 1991; Pressman, 2001). Tais atividades devem ser desenvolvidas ao longo do processo de desenvolvimento de software e, em geral, concretizam-se em três fases. A primeira delas é o teste de unidade, na qual cada módulo do software é testado individualmente, buscando revelar erros de lógica e fornecer evidências de que o módulo funciona adequadamente. A próxima fase, o teste de integração, é uma técnica sistemática para integrar os módulos componentes da estrutura do software, visando a identificar erros de interface entre tais módulos. Finalizando, o teste de sistema verifica se todos os elementos do sistema combinam-se adequadamente e se a função/desempenho global do mesmo é atingida na perspectiva dos requisitos do usuário (Pressman, 2001).

\footnotetext{
${ }^{2}$ A IEEE tem realizado vários esforços na tentativa de padronizar a terminologia utilizada no contexto de Engenharia de Software. O padrão IEEE 610.12-1990 (IEEE, 1990) diferencia os seguintes termos: engano (mistake) ação humana que produz um resultado incorreto (por exemplo, uma ação incorreta tomada pelo programador); defeito (fault) - passo, processo ou definição de dados incorreta (por exemplo, uma instrução ou comando incorreto); erro (error ) - diferença entre o valor obtido e o valor esperado, ou seja, qualquer estado intermediário incorreto ou resultado inesperado na execução do programa; e falha (failure) - produção de uma saída incorreta com relação à especificação. Neste texto os termos engano, defeito e erro são referenciados como erro (causa) e o termo falha (conseqüência) a um comportamento incorreto do programa.
} 
Um dos pontos críticos da atividade de teste é o projeto e/ou avaliação dos casos de teste a serem utilizados. O programa, em princípio, deveria ser exercitado com todos os valores do domínio de entrada. Sabe-se, entretanto, que o teste exaustivo é impraticável por razões de custo e tempo. Dessa forma, por questões de produtividade, o objetivo é utilizarem-se casos de teste que tenham alta probabilidade de revelar a presença da maioria dos erros existentes com o mínimo de tempo e esforço.

Dentro dessa perspectiva, para que a atividade de teste possa ser conduzida de forma sistemática e teoricamente fundamentada, faz-se necessária a aplicação de técnicas e critérios que indiquem como testar o software, quando parar os testes e que, se possível, forneçam uma medida objetiva do nível de confiança e de qualidade alcançados com os testes realizados (Demillo, 1980).

Além disso, é importante ressaltar o aspecto complementar entre as técnicas e critérios existentes. De fato, a questão que se coloca está em como utilizá-las de forma que as vantagens de cada uma sejam melhor exploradas em uma estratégia que leve a um teste de boa qualidade, ou seja, eficaz em revelar a presença de erros e de baixo custo (Maldonado, 1991). Estudos teóricos e empíricos visando à comparação de critérios de teste bem como o estabelecimento de estratégias para sua aplicação têm sido conduzidos nessa direção (Barbosa et al., 2001; Frankl \& Weyuker, 1993a; Jorge et al., 2001; Mathur \& Wong, 1993; Maldonado et al., 2000a; Mresa \& Bottaci, 1999; Ntafos, 1988; Offutt et al., 1996; Rapps \& Weyuker, 1982, 1985; Vincenzi et al., 2001; Weyuker, 1990; Zhu, 1996).

Outro aspecto relevante associado à atividade de teste refere-se ao desenvolvimento de ferramentas que automatizem a aplicação das técnicas e critérios associados. De fato, sem a utilização de ferramentas automatizadas como mecanismos de apoio, a atividade de teste tende a ser extremamente trabalhosa, propensa a erros e limitada a programas muito simples (Horgan \& Mathur, 1992). Além de contribuir para a qualidade e a produtividade dos testes, a existência de ferramentas automatizadas viabiliza ainda a realização de estudos empíricos, auxilia a condução dos testes de regressão e apóia o processo de ensino e aprendizado envolvendo a aplicação prática dos conceitos de teste.

Salienta-se, por fim, que o teste é apenas uma das atividades de Garantia de Qualidade de Software e, em geral, sua utilização isolada não é suficiente para alcançar um produto de boa qualidade. Nesse sentido, é fundamental que a atividade de teste seja utilizada em complemento a outras atividades da Engenharia de Software, tais como inspeções, revisões, técnicas formais e rigorosas de especificação e de verificação, walkthrough, entre outras (Maldonado, 1991; Pressman, 2001).

De modo geral, os aspectos discutidos nesta seção caracterizam o domínio de conhecimento associado ao Teste de Software - definição de técnicas e critérios de teste, automatização da atividade de teste, e condução de estudos teóricos e empíricos. Nas próximas seções, tais aspectos são abordados mais detalhadamente ${ }^{3}$. Na Seção 2.5.1, uma visão geral a respeito das principais

\footnotetext{
${ }^{3}$ Os aspectos discutidos foram extraídos essencialmente de (Maldonado et al., 1998), (Maldonado et al., 2003) e (Vincenzi et al., 2003a).
} 
técnicas e critérios de teste é apresentada. Aspectos de automatização e exemplos de ferramentas de teste são discutidos e ilustrados na Seção 2.5.2. Uma síntese dos principais estudos teóricos e empíricos conduzidos é apresentada na Seção 2.5.3.

\subsubsection{Técnicas de Teste}

Em geral, critérios de teste são estabelecidos a partir de três técnicas: funcional, estrutural e baseada em erros. Tais técnicas diferenciam-se pela origem da informação utilizada na avaliação e construção dos conjuntos de casos de teste. Na técnica funcional, os critérios e requisitos de teste são estabelecidos a partir da especificação funcional do software; na técnica estrutural, os critérios e requisitos são derivados essencialmente a partir das características de uma particular implementação em teste; e, na técnica baseada em erros, os critérios e requisitos de teste são oriundos do conhecimento sobre erros típicos cometidos durante o processo de desenvolvimento de software (Maldonado, 1991). É importante destacar que os critérios de teste podem ser utilizados para auxiliar tanto na geração de conjuntos de casos de teste como na avaliação da adequação desses conjuntos.

\section{Técnica Funcional}

O teste funcional, também conhecido como teste caixa preta, trata o software como uma caixa cujo conteúdo é desconhecido e da qual só é possível visualizar o lado externo, ou seja, os dados de entrada fornecidos e as respostas produzidas como saída (Beizer, 1990; Myers, 1979).

A técnica de teste funcional envolve dois passos principais: (1) identificar as funções que o software deve realizar; e (2) projetar casos de teste capazes de checar se essas funções estão sendo realizadas pelo software (Pressman, 2001). As funções que o software possui são identificadas a partir da especificação de requisitos do sistema, sem se preocupar com detalhes de implementação. Assim, uma especificação correta e de acordo com os requisitos do usuário é de fundamental importância para apoiar a aplicação dos critérios relacionados a essa técnica (Beizer, 1990; Demillo, 1987).

Como exemplos de critérios de teste funcional podem-se destacar (Pressman, 2001):

- Particionamento em Classes de Equivalência: A partir das condições de entrada de dados identificadas na especificação, o domínio de entrada de um programa é dividido em classes de equivalência válidas e inválidas. Em seguida, seleciona-se o menor número possível de casos de teste, baseando-se na hipótese de que um elemento de uma dada classe seria representativo da classe toda, sendo que para cada uma das classes inválidas deve ser gerado um caso de teste distinto. O uso de particionamento permite examinar os requisitos de forma mais sistemática e restringir o número de casos de teste existentes. Alguns autores também consideram o domínio de saída do programa para estabelecer as classes de equivalência. 
- Análise do Valor Limite: É um complemento ao critério Particionamento em Classes de Equivalência, sendo que os limites associados às condições de entrada são exercitados de forma mais rigorosa. Ao invés de selecionar-se qualquer elemento de uma classe, os casos de teste são escolhidos nas fronteiras das classes, visto que são nesses pontos que se concentra um grande número de erros. O espaço de saída do programa também é particionado e são exigidos casos de teste que produzam resultados nos limites dessas classes de saída.

- Grafo de Causa-Efeito: Os critérios anteriores não exploram combinações das condições de entrada. Esse critério estabelece requisitos de teste baseados nas possíveis combinações das condições de entrada. Primeiramente, são levantadas as possíveis condições de entrada (causas) e as possíveis ações (efeitos) do programa. A seguir, constrói-se um grafo relacionando as causas e efeitos levantados. Esse grafo é convertido em uma tabela de decisão a partir da qual são derivados os casos de teste.

Um dos problemas relacionados à técnica funcional é que muitas vezes a especificação do programa é feita de modo descritivo e não formal. Dessa maneira, os requisitos de teste derivados de tais especificações são também, de certa forma, imprecisos e informais. Como conseqüência, tem-se dificuldade em automatizar a aplicação de tais critérios, que ficam, em geral, restritos à aplicação manual. Outro problema refere-se à dificuldade em quantificar a atividade de teste, uma vez que é difícil garantir que partes essenciais ou críticas do programa foram executadas.

Por outro lado, a aplicação de critérios funcionais requer apenas que se identifiquem as entradas, a função a ser computada e a saída do programa, o que os tornam aplicáveis praticamente em todas as fases de teste (unidade, integração e sistema) e em programas construídos sob diferentes paradigmas de desenvolvimento (procedimental, orientado a objetos).

\section{Técnica Estrutural}

O teste estrutural, também conhecido como teste caixa branca (em oposição ao nome caixa preta), baseia-se no conhecimento da estrutura interna da implementação. Em geral, a maioria dos critérios dessa técnica utiliza uma representação de programa conhecida como grafo de fluxo de controle (ou grafo de programa). Um grafo de fluxo de controle é um grafo orientado, com um único nó de entrada e um único nó de saída. Cada vértice representa um bloco de comandos que são sempre executados seqüencialmente e cada arco representa uma transferência de controle entre esses blocos. A representação de um programa $P$ como um grafo de fluxo de controle consiste em estabelecer uma correspondência entre nós e blocos e em indicar possíveis fluxos de controle entre blocos através dos arcos. A partir do grafo de programa podem ser escolhidos os elementos que devem ser exercitados, caracterizando assim o teste estrutural.

A técnica estrutural apresenta uma série de limitações e desvantagens decorrentes das limitações inerentes à própria atividade de teste enquanto estratégia de validação (Frankl, 1987; Howden, 1987; Ntafos, 1988; Rapps \& Weyuker, 1985). Esses aspectos introduzem sérios problemas 
na automatização do processo de validação de software (Maldonado, 1991). Independentemente dessas desvantagens, a técnica estrutural é vista como complementar à técnica funcional, sendo que as informações obtidas pela aplicação de critérios estruturais são consideradas relevantes para as atividades de manutenção, depuração e confiabilidade de software (Ostrand \& Weyuker, 1988; Pressman, 2001; Maldonado, 1991).

Os primeiros critérios estruturais eram baseados unicamente no fluxo de controle dos programas. Os critérios Todos-Nós, Todos-Arcos e Todos-Caminhos são os mais conhecidos dessa classe e exigem, respectivamente, que cada nó, cada arco e cada caminho do grafo de programa seja executado pelo menos uma vez (Myers, 1979). Observa-se que, apesar de desejável, executar todos os caminhos de um programa é, na maioria das vezes, uma tarefa impraticável. O número de caminhos de um programa pode ser muito grande e até mesmo infinito (quando laços estão presentes).

Em meados da década de 70 surgiram os critérios baseados em fluxo de dados (Herman, 1976). Tais critérios requerem que sejam testadas as interações envolvendo definições de variáveis e subseqüentes referências a essas definições, ou seja, exigem a execução de caminhos do ponto onde uma variável foi definida, até o ponto em que ela foi utilizada (Laski \& Korel, 1983; Maldonado, 1991; Ntafos, 1984; Rapps \& Weyuker, 1985; Ural \& Yang, 1988).

Uma motivação para a introdução dos critérios baseados em fluxo de dados foi a indicação de que, mesmo para programas pequenos, o teste baseado unicamente no fluxo de controle não era eficaz para revelar a presença até mesmo de erros simples e triviais. A introdução dessa classe de critérios procurou estabelecer uma hierarquia entre os critérios Todos-Arcos e Todos-Caminhos, visando a tornar o teste mais rigoroso.

Dentre os critérios baseados em fluxo de dados destacam-se os critérios de Rapps e Weyuker (Rapps \& Weyuker, 1982, 1985), introduzidos na década de 80: Todas-Definições, Todos-Usos, Todos-Du-Caminhos, Todos-P-Usos, Todos-P-Usos/Alguns-C-Usos e Todos-C-Usos/Alguns-PUsos. Desses, o critério mais básico é o critério Todas-Definições; entre os mais utilizados e investigados está o critério Todos-Usos:

- Todas-Definições: Requer que cada definição de variável seja exercitada pelo menos uma vez, não importa se por um uso computacional ou por um uso predicativo.

- Todos-Usos: Requer que todas as associações entre uma definição de variável e seus subseqüentes usos sejam exercitadas pelos casos de teste, através de pelo menos um caminho livre de definição, ou seja, um caminho no qual a variável não é redefinida.

É importante ressaltar, no entanto, que a maioria dos critérios baseados em fluxo de dados, para requerer um determinado elemento (caminho, associação etc.), exige a ocorrência explícita de um uso de variável e não garante, necessariamente, a inclusão do critério Todos-Arcos na presença de caminhos não executáveis, presentes na maioria dos programas.

Com a introdução do conceito de potencial-uso, nos início dos anos 90, Maldonado (1991) definiu a família de critérios Potenciais-Usos e a correspondente família de critérios executáveis, 
obtida pela eliminação dos caminhos e associações não executáveis. Os critérios Potenciais-Usos requerem associações independentemente da ocorrência explícita de uma referência (um uso) a uma definição de variável, ou seja, requerem que caminhos livres de definição a partir da definição de uma determinada variável sejam executados, independentemente de ocorrer um uso dessa variável nesse caminho.

Os critérios básicos que fazem parte dessa família de critérios são:

- Todos-Potenciais-Usos: Requer que pelo menos um caminho livre de definição de uma variável definida em um nó $i$ para todo nó e todo arco possível de ser alcançado a partir de $i$ seja exercitado.

- Todos-Potenciais-Usos/Du: Requer que pelo menos um potencial-du-caminho ${ }^{4}$ com relação a uma variável $x$ definida em $i$ para todo nó e para todo arco possível de ser alcançado a partir de $i$ seja exercitado.

- Todos-Potenciais-Du-Caminhos: Requer que todos os potenciais-du-caminhos com relação a todas as variáveis $x$ definidas e todos os nós e arcos possíveis de serem alcançados a partir dessa definição sejam exercitados.

Visto que os requisitos de teste exigidos pelos critérios estruturais limitam-se ao escopo da unidade, tais critérios têm sido utilizados principalmente no teste de unidade. Na tentativa de estender o uso de critérios estruturais para o teste de integração, alguns esforços podem ser identificados. Haley \& Zweben (1984) propuseram um critério para selecionar caminhos em um módulo que deveria ser testado novamente na fase de integração com base em sua interface. Linnenkugel \& Müllerburg (1990) apresentaram uma série de critérios que estendem os critérios baseados em fluxo de controle e em fluxo de dados para o teste de integração. Harrold \& Soffa (1991) propuseram uma técnica para determinar as estruturas de definição-uso interprocedurais permitindo a aplicação dos critérios baseados em análise de fluxo de dados em nível de integração. Jin \& Offut (1995) definiram alguns critérios baseados em uma classificação de acoplamento entre módulos. Vilela (1998), com base no conceito de potencial-uso, estendeu os critérios Potenciais-Usos para o teste de integração.

\section{Técnica Baseada em Erros}

A técnica de teste baseada em erros utiliza informações sobre os tipos de erros mais freqüentes no processo de desenvolvimento de software para derivar os requisitos de teste. A ênfase da técnica está nos erros que o programador ou projetista pode cometer durante o desenvolvimento e nas abordagens que podem ser usadas para detectar a sua ocorrência. Semeadura de Erros (Budd,

\footnotetext{
${ }^{4}$ Um potencial-du-caminho em relação à variável $x$ é um caminho livre de definição $\left(n_{1}, \ldots, n_{j}, n_{k}\right)$ com relação a $x$ do nó $n_{1}$ para o nó $n_{k}$ e para o arco $\left(n_{j}, n_{k}\right)$, onde o caminho $\left(n_{1}, \ldots, n_{j}\right)$ é um caminho livre de laço e no nó $n_{1}$ ocorre uma definição de $x$.
} 
1981) e Análise de Mutantes (DeMillo et al., 1978) são critérios típicos que se concentram em erros.

No critério Semeadura de Erros, introduzido nos anos 80, uma quantidade conhecida de defeitos é semeada artificialmente no programa. Após o teste, do total de defeitos encontrados, verificam-se quais são naturais e quais são artificiais. Usando estimativas de probabilidade, o número de defeitos naturais ainda existentes no programa pode ser estimado. Entre os problemas associados à aplicação do critério destacam-se: (1) os defeitos artificiais podem interagir com os naturais fazendo com que os defeitos naturais sejam "mascarados" pelos defeitos semeados; (2) para obter um resultado estatístico não questionável é necessário o uso de programas capazes de conter 10.000 defeitos ou mais; (3) é preciso assumir que os defeitos estão uniformemente distribuídos pelo programa, o que, em geral, não é verdade. Programas reais apresentam longos trechos de código simples e com poucos defeitos, e pequenos trechos de grande complexidade e alta concentração de defeitos (Budd, 1981).

O critério Análise de Mutantes surgiu na década de 70, na Yale University e Georgia Institute of Technology, possuindo um forte relacionamento com um método clássico para detecção de erros lógicos em circuitos digitais - o modelo de teste de falha única (Friedman, 1975).

Um dos primeiros artigos que descrevem o teste de mutantes foi publicado em 1978 (DeMillo et al., 1978). A idéia básica apresentada por DeMillo, conhecida como hipótese do programador competente (competent programmer hypothesis), assume que programadores experientes escrevem programas corretos ou muito próximos do correto. Considerando a validade desta hipótese, pode-se afirmar que erros são introduzidos no programa por meio de pequenos desvios sintáticos que, embora não causem erros sintáticos, alteram sua semântica e, conseqüentemente, o programa pode apresentar um comportamento incorreto. Para revelar a presença de tais erros, a Análise de Mutantes identifica os desvios sintáticos mais comuns e, por meio da aplicação de pequenas transformações sobre o programa em teste, encoraja o testador a construir casos de testes que mostrem que tais transformações levam a um programa incorreto (Agrawal et al., 1989).

Outra hipótese explorada na aplicação do critério Análise de Mutantes é o efeito de acoplamento (coupling effect) (DeMillo et al., 1978), que assume que erros complexos estão relacionados a erros simples. Assim, espera-se, e alguns estudos empíricos confirmaram essa hipótese (Acree et al., 1979; Budd et al., 1980), que conjuntos de casos de teste capazes de revelar a presença de erros simples são também capazes de revelar a presença de erros complexos.

Partindo-se da hipótese do programador competente e do efeito de acoplamento, a princípio, deve-se fornecer um programa $P$ a ser testado e um conjunto de casos de teste $T$ cuja adequação deseja-se avaliar. O programa $P$ é executado com $T$ e se apresentar resultados incorretos então um erro foi revelado e o teste termina. Do contrário, $P$ ainda pode conter erros que o conjunto $T$ não conseguiu revelar. O programa $P$ sofre então pequenas alterações, a partir da aplicação de um conjunto de operadores de mutação (mutant operators), dando origem aos programas $P_{1}, P_{2}, \ldots$, 
$P_{n}$, denominados mutantes de $P$, diferindo de $P$ apenas pela ocorrência de erros simples, ou seja, aplica-se uma mutação (transformação sintática) de cada vez no programa $P$ em teste.

Entende-se por operador de mutação as regras que definem as alterações que devem ser aplicadas no programa original $P$. Os operadores de mutação são construídos para satisfazer a um entre dois propósitos (Offutt \& Hayes, 1996): (1) induzir mudanças sintáticas simples com base nos erros típicos cometidos pelos programadores (como trocar o nome de uma variável); ou (2) forçar determinados objetivos de teste (como executar cada arco do programa).

Gerados os mutantes, estes são executados com o mesmo conjunto de casos de teste $T$. $\mathrm{O}$ objetivo é obter um conjunto de casos de teste $T$ que resulte apenas em mutantes mortos (para algum caso de teste o resultado do mutante e do programa original diferem entre si) e equivalentes (o mutante e o programa original apresentam sempre o mesmo resultado, para qualquer item de dado pertencente ao domínio de entrada). Neste caso, $T$ é adequado ao teste de $P$, no sentido de que, ou $P$ está correto, ou possui erros pouco prováveis de ocorrerem (DeMillo et al., 1978).

Ressalta-se que, em geral, a equivalência de programas é uma questão indecidível e requer a intervenção do testador. Essa limitação, no entanto, não significa que o problema deva ser abandonado por não apresentar solução. Na verdade, alguns métodos e heurísticas foram propostos para determinar a equivalência de programas em uma grande parte dos casos de interesse (Budd, 1981).

Um ponto importante destacado por Demillo (1980) é que a Análise de Mutantes fornece uma medida objetiva do nível de confiança da adequação dos casos de teste analisados por meio da definição de um escore de mutação (mutation score), o qual relaciona o número de mutantes mortos com o número de mutantes não equivalentes gerados. O escore de mutação é calculado da seguinte forma:

$$
m s(P, T)=\frac{D M(P, T)}{M(P)-E M(P)}
$$

sendo:

$D M(P, T)$ : número de mutantes mortos pelos casos de teste em $T$.

$M(P)$ : número total de mutantes gerados.

$E M(P)$ : número de mutantes gerados equivalentes a $P$.

O escore de mutação varia no intervalo entre 0 e 1 sendo que, quanto maior o escore mais adequado é o conjunto de casos de teste para o programa sendo testado. Percebe-se com essa fórmula que apenas $D M(P, T)$ depende do conjunto de casos de teste utilizado, e que $E M(P)$ é obtido à medida que o testador, manualmente ou com o apoio de heurísticas, decide que determinado mutante vivo é equivalente (Souza, 1996).

Um dos maiores problemas para a aplicação do critério Análise de Mutantes está relacionado ao seu alto custo, uma vez que o número de mutantes gerados, mesmo para pequenos programas, pode ser muito grande, exigindo um tempo de execução muito alto. 
Várias soluções têm sido propostas para fazer com que a Análise de Mutantes possa ser utilizada de modo mais eficiente, dentro de limites economicamente viáveis. A utilização de arquiteturas de hardware avançadas para diminuir o tempo de execução dos mutantes (Choi et al., 1989b; Choi \& Mathur, 1993; Krauser et al., 1991; Mathur \& Krauser, 1988) e o uso da análise estática de anomalias de fluxo de dados para reduzir o número de mutantes gerados (Marshall et al., 1990) são algumas dessas soluções.

Outra solução, bastante explorada pela comunidade de teste, procura diminuir o custo de aplicação da Análise de Mutantes por meio da redução do número de mutantes a serem executados e analisados. Seguindo esta perspectiva, algumas abordagens derivadas da Análise de Mutantes foram propostas: Mutação Aleatória (Randomly Selected Mutation) (Acree et al., 1979), Mutação Restrita (Constrained Mutation) (Mathur, 1991) e Mutação Seletiva (Selective Mutation) (Offutt et al., 1993). Tais abordagens procuram selecionar apenas um subconjunto do total de mutantes gerados.

Na Mutação Aleatória, embora sejam utilizados todos os operadores de mutação, apenas uma porcentagem dos mutantes gerados a partir de cada operador é considerada. Na Mutação Restrita são selecionados alguns operadores de mutação específicos para serem utilizados na geração dos mutantes. É importante observar que a Mutação Restrita não define um método para a seleção dos operadores a serem utilizados; em geral, os operadores são selecionados "intuitivamente", com base na experiência dos testadores. A Mutação Seletiva é similar à Mutação Restrita, exceto pelo fato de que o método de seleção dos operadores a serem utilizados está relacionado à quantidade de mutantes que cada operador gera: os operadores de mutação responsáveis pelo maior número de mutantes não são aplicados. Desse modo, na Mutação- $N$-Seletiva aplicam-se todos os operadores de mutação exceto os $N$ operadores que tendem a gerar mais mutantes. Vários estudos empíricos têm sido conduzidos visando a investigar a aplicação tais abordagens.

Assim como os critérios baseados em análise de fluxo de dados, o critério Análise de Mutantes também tem sido essencialmente utilizado no teste de unidade. Na tentativa de estender sua aplicação para o teste de integração, Delamaro \& Maldonado $(1996,1997)$ propuseram o critério Mutação de Interface (Interface Mutation) - um critério para o teste de integração baseado no conceito de mutação, neste caso, mutação de interface entre os módulos componentes do software. A idéia básica é viabilizar o teste da interface entre as unidades que compõem o software, ao contrário da Análise de Mutantes, que explora somente as características das unidades separadamente (Delamaro et al., 2000, 2001a). As abordagens de Mutação Aleatória, Mutação Restrita e Mutação Seletiva também foram estendidas de modo a permitir sua aplicação no teste de integração.

É importante observar que o Teste de Software é uma atividade abrangente, não estando suas linhas de pesquisa restritas aos aspectos discutidos neste texto. Nesse sentido, os conceitos e mecanismos de apoio à atividade de teste vêm sendo investigados em outros contextos, introduzindo com isso novos desafios e considerações no teste de produtos. 
Conforme destacado por Weyuker (1998), faz-se necessário o desenvolvimento de novos métodos para testar e manter componentes de software a fim de torná-los confiáveis e reutilizáveis em uma grande diversidade de projetos, produtos e ambientes de software. Harrold (2000) reafirma que o teste de sistemas baseado em componentes de software, o qual inclui o teste de programas OO, o desenvolvimento de processos de teste efetivos e a demonstração da eficácia de critérios e estratégias de teste, constituem algumas das principais direções para a área de Teste de Software, as quais devem ser inevitavelmente exploradas nos próximos anos. Harrold comenta ainda que, para atingir tais objetivos, é de fundamental importância o desenvolvimento de métodos e ferramentas de teste que dêem suporte à realização de estudos empíricos, bem como favoreçam a transferência tecnológica e a capacitação do parque tecnológico industrial.

Embora as direções levantadas por Harrold (2000) tenham sido caracterizadas em meados de 2000, tais aspectos continuam válidos no contexto das pesquisas atuais. O teste de programas OO e o teste de componentes, por exemplo, abordam novos problemas introduzidos pelas características das linguagens OO. Encapsulamento, herança, polimorfismo e acoplamento dinâmico, embora tragam benefícios para o projeto e codificação, acarretam problemas quanto à maneira com que os requisitos e critérios de teste devem ser estabelecidos e aplicados. Pesquisas buscando soluções nessa direção vêm sendo conduzidas pela comunidade científica (Bieman et al., 2001; Binder, 1996, 1999; Doong \& Frankl, 1994; Harrold, 2000; Kim et al., 1999, 2000a,b; Ma et al., 2002; Sridhanan et al., 2000; Vincenzi, 2000; Vincenzi et al., 2003a).

Dentro dessa perspectiva, o Grupo de Engenharia de Software do ICMC-USP tem atuado em várias linhas, apresentando contribuições em diferentes contextos de teste, entre eles o desenvolvimento orientado a objetos (Vincenzi, 2000; Vincenzi et al., 2003b) e o desenvolvimento baseado em componentes (Delamaro et al., 2001b; Vincenzi et al., 2003a).

Outra linha de pesquisa investigada pelo grupo refere-se ao teste de especificações (specification testing), com ênfase no teste e validação de aspectos comportamentais de sistemas reativos e validação de protocolos. Nesse sentido, extensões ao critério Análise de Mutantes têm sido propostas para o teste de especificações em Redes de Petri (Fabbri et al., 1995; Simão \& Maldonado, 2000), Statecharts (Fabbri, 1996; Sugeta, 1999), Máquinas de Estado Finito (Fabbri et al., 1993, 1994) e Estelle (Probert \& Guo, 1991; Souza et al., 2000).

\subsubsection{Ferramentas de Teste}

A qualidade e produtividade da atividade de teste dependem, entre outros fatores, do critério de teste utilizado e da existência de ferramentas de teste que o apóiem. De fato, sem o suporte de uma ferramenta automatizada, a aplicação de um critério torna-se uma atividade propensa a erros e limitada a programas muito simples.

A disponibilidade de ferramentas de teste permite ainda a transferência tecnológica entre universidade e indústria, e contribui para a contínua evolução de tais ambientes, fatores indispensáveis 
para a produção de software de alta qualidade. Além disso, estas são de fundamental importância no apoio à condução de estudos empíricos, possibilitando avaliar o aspecto complementar das técnicas e critérios de teste.

Outro fator importante é o suporte oferecido aos testes de regressão. Os casos de teste utilizados durante a atividade de teste podem ser facilmente obtidos para revalidação do software após uma modificação. Com isso, é possível checar se a funcionalidade do software foi alterada, reduzir o custo para gerar os testes de regressão e comparar os resultados obtidos nos testes de regressão com os resultados do teste original (Souza, 1996).

Ressalta-se, por fim, que a existência de ferramentas automatizadas auxilia pesquisadores e alunos de Engenharia de Software a adquirirem os conceitos básicos e experiência na comparação, seleção e estabelecimento de estratégias de teste. Nesse sentido, ferramentas de teste desempenham um papel relevante no processo de ensino e treinamento de conceitos, técnicas e critérios de teste, contribuindo para a formação e capacitação de pessoal na área.

Dentro do contexto apresentado, uma série de ferramentas de teste pode ser identificada. No apoio à aplicação dos critérios baseados em fluxo de dados, uma das primeiras iniciativas de automatização foi a ferramenta Asset (A System to Select and Evaluate Tests) (Frankl \& Weyuker, 1985). A ferramenta foi desenvolvida na New York University, apoiando a aplicação dos critérios definidos por Rapps \& Weyuker $(1982,1985)$ no teste de programas Pascal.

Um dos esforços mais significativos no contexto de ferramentas de teste foi o desenvolvimento da Atac (Automatic Test Analysis for C), pela Telcordia Technologies (Horgan \& Mathur, 1992). A ferramenta apóia a aplicação de critérios de fluxo de controle e de dados no teste de programas escritos nas linguagens $\mathrm{C}$ e $\mathrm{C}++$. Basicamente, é possível verificar a adequação de um conjunto de casos de teste, visualizar o código não coberto pelos casos de teste, auxiliar na geração de casos de teste e reduzir o tamanho do conjunto de teste, por meio da eliminação de casos de teste redundantes.

Atualmente a Atac está integrada ao ambiente xSuds (Telcordia Software Visualization and Analysis Toolsuite) (Agrawal et al., 1998), que oferece suporte às atividades de teste, análise e depuração. O ambiente vem sendo comercializado pela IBM, sendo uma forte evidência de que o uso de critérios baseados em fluxo de dados constituirá, em um futuro próximo, o estado da prática no que diz respeito ao Teste de Software.

Com respeito ao teste de especificações, Wong et al. (2003) investigaram como os critérios baseados em fluxo de controle e em fluxo de dados poderiam ser utilizados no teste de especificações em SDL. Para auxiliar as atividades de teste e validação de especificações, foi desenvolvida a ferramenta $C A T_{S D L}$ (Coverage Analysis Tool - SDL), que permite a análise de cobertura de teste para especificações baseadas em SDL e fornece dicas ao testador que auxiliam na geração de casos de teste. De modo geral, a cobertura dos casos de teste é avaliada em relação a cinco critérios de teste: Todos-Blocos, Todas-Decisões, Todos-Usos, Todos-P-Usos e Todos-C-Usos. 
Como apoio à aplicação do critério Análise de Mutantes, tem-se a ferramenta Mothra (Choi et al., 1989b; DeMillo et al., 1988). Desenvolvida na Purdue University e no Georgia Institute of Technology, a ferramenta apóia a aplicação do critério no teste de programas na linguagem Fortran, contando com 22 operadores de mutação implementados. A Mothra apresenta interface baseada em janelas, facilitando a visualização das informações, e permite a incorporação de outras ferramentas (tais como gerador de casos de teste, verificador de equivalência e oráculo).

Especificamente no contexto dos trabalhos conduzidos pelo Grupo de Engenharia de Software do ICMC-USP, várias são as iniciativas de pesquisa relacionadas à especificação e implementação de ferramentas de teste. Podem-se destacar, por exemplo, as ferramentas:

- PokeTool (Potential Uses Criteria Tool for Program Testing) (Chaim, 1991): Desenvolvida na FEEC/UNICAMP em colaboração com o ICMC-USP, apóia a aplicação dos critérios Potenciais-Usos (Maldonado, 1991) e também outros critérios estruturais como Todos-Nós e Todos-Arcos.

- Proteum (Program Testing Using Mutants) (Delamaro, 1993): Apóia a aplicação do critério Análise de Mutantes (DeMillo et al., 1978), em nível de unidade, no teste de programas C.

- PROTEM/IM (Delamaro et al., 2000): Apóia a aplicação do critério Mutação de Interface (Delamaro \& Maldonado, 1996, 1997; Delamaro et al., 2001a) no teste de programas C, em nível de integração. A ferramenta é uma extensão da Proteum, possuindo arquitetura e implementação similares a esta. O que diferencia ambas as ferramentas é o conjunto de operadores de mutação utilizados em cada uma e o fato de que a $\mathcal{P R O T E M} M / \mathcal{I M}$ oferece características para testar a conexão entre as unidades do software.

- PROTEM/IM2.0 (Maldonado et al., 2000b): Ambiente de teste integrado que viabiliza a aplicação do teste de mutação tanto em nível de unidade como de integração. A PROTEM M/IM2.0 é resultado da integração das ferramentas Proteum e $\mathcal{P R O T E M} / \mathcal{I M}$.

Além disso, mecanismos e ferramentas para automatizar a aplicação do critério Análise de Mutantes no contexto de especificações formais também têm sido explorados. Utilizando a ferramenta Proteum como base, foram definidas as ferramentas:

- Proteum-RS/FSM (Fabbri et al., 1999): Apóia o teste de especificações baseadas em Máquinas de Estado Finito.

- Proteum-RS/ST (Sugeta, 1999): Apóia o teste de especificações baseadas em Statecharts.

- Proteum-RS/PN (Simão et al., 2000): Apóia o teste de especificações baseadas em Redes de Petri. 
O Grupo de Engenharia de Software do ICMC-USP também tem atuado no contexto de orientação a objetos e, nesse sentido, atualmente vem sendo desenvolvida a ferramenta JaBUTi (Java Bytecode Understanding and Testing) (Vincenzi et al., 2003b). Basicamente, a ferramenta apóia aplicação do teste estrutural intra-método em programas e componentes Java.

Finalmente, ressalta-se que as ferramentas desenvolvidas pelo grupo também vêm sendo evoluídas de modo a permitir sua utilização via web, tornando seu acesso independente de plataforma (Bianchini et al., 2003). A primeira iniciativa nesse sentido foi o desenvolvimento da interface web para a ferramenta $\mathcal{P R O T E M} / I_{M}$ 2.0. Como resultado correlato destaca-se ainda o desenvolvimento da estrutura gráfica de um framework para a geração de ferramentas de teste disponibilizadas via web. Em curto prazo, pretende-se que o framework seja instanciado na construção de interfaces web para as demais ferramentas de teste desenvolvidas pelo grupo.

Com a disponibilização via web, a idéia é que tais ferramentas possam ser mais facilmente integradas aos ambientes e sistemas educacionais existentes, sendo utilizadas como mecanismos de apoio ao aprendizado e revisão de conceitos de teste tanto por alunos do ICMC-USP como por alunos de outras instituições e por profissionais da indústria. Trabalhos preliminares (Barbosa et al., 2000) envolvendo a integração de ferramentas de teste no contexto de ambientes educacionais já foram conduzidos no escopo da ferramenta PokeTool (Chaim, 1991) e do ambiente CALM (Adriano et al., 1999).

\subsubsection{Estudos Teóricos e Empíricos}

Em virtude da diversidade de critérios de teste existente e dado o caráter complementar entre eles, saber qual critério utilizar a fim de obter a melhor relação custo/benefício é uma questão complicada. A realização de estudos teóricos e empíricos procura, por meio de comparações entre os critérios, obter uma estratégia que seja eficaz para revelar a presença de erros no programa, ao mesmo tempo em que apresente baixo custo de aplicação.

Para entender a importância desses estudos, considere a seguinte situação (Mathur \& Wong, 1994): é preciso testar um programa $P$ que será usado em um ambiente de segurança crítica e o funcionamento desse sistema depende de que $P$ tenha sido bem testado. O testador deve testar $P$ tanto quanto for possível e, para isso, decide usar vários critérios de teste a fim de verificar a adequação dos casos de teste desenvolvidos. Inicialmente, os casos de teste são gerados de modo a satisfazerem um determinado critério $C_{1}$. De posse disso, coloca-se a seguinte questão: Tendo obtido um conjunto de casos de teste adequado ao critério $C_{1}$ e, utilizando agora o critério $C_{2}$, consegue-se melhorar o conjunto de casos de teste?

Com o propósito de responder a esta e demais questões que surgem diante da dificuldade em decidir quando um programa está suficientemente testado, estudos teóricos e empíricos têm sido conduzidos.

Do ponto de vista teórico, procura-se estabelecer propriedades e características dos critérios de teste, tais como sua complexidade (número máximo de casos de teste requeridos no pior caso) 
ou uma relação de hierarquia entre os mesmos (relação de inclusão (Rapps \& Weyuker, 1982, 1985)). Do ponto de vista empírico, dados e estatísticas são coletados, registrando, por exemplo, a freqüência com que diferentes estratégias de teste revelam a presença de erros em um determinado conjunto de programas (Howden, 1978).

Tanto a abordagem teórica como a empírica buscam avaliar critérios de teste por meio de três fatores básicos:

- Custo: Refere-se ao esforço necessário para a utilização de um critério. Pode ser medido por meio do número de casos de teste requeridos para satisfazer o critério ou por outras métricas dependentes do critério (por exemplo, quantidade de mutantes gerados, tempo gasto para identificar mutantes equivalentes, caminhos e associações não executáveis).

- Eficácia: Refere-se à capacidade de um dado critério em revelar a presença de um maior número de erros em relação a outro.

- Dificuldade de Satisfação (Strength): Refere-se à probabilidade de satisfazer um dado critério tendo satisfeito outro.

Utilizando tais fatores comparativos, estudos empíricos e teóricos são conduzidos com o objetivo de encontrar formas econômicas e produtivas para a realização dos testes. A seguir, são ilustrados alguns dos principais estudos realizados. São considerados os critérios baseados em fluxo de dados e baseados em mutação. Avaliam-se aspectos de custo, eficácia e dificuldade de satisfação. Em linhas gerais, os estudos conduzidos têm comprovado a aplicabilidade e evidenciado o enfoque promissor desses critérios no teste de programas.

\section{Aspectos Teóricos}

Estudos teóricos de critérios de teste têm sido conduzidos com base principalmente na complexidade e na relação de inclusão (Rapps \& Weyuker, 1982, 1985). A complexidade é dada pelo número de casos de teste necessários para satisfazer o critério, no pior caso, para qualquer programa $P$.

Quanto à relação de inclusão, um critério $C_{1}$ inclui um critério $C_{2}$ se, para qualquer programa, todo conjunto de casos de teste $T$ que satisfaz $C_{1}$ ( $T$ é $C_{1}$-adequado) também satisfaz $C_{2}$ ( $T$ é $C_{2}$-adequado). Dois critérios, $C_{1}$ e $C_{2}$, são ditos incomparáveis se $C_{1}$ não incluir $C_{2}$ e nem $C_{2}$ incluir $C_{1}$. A relação de inclusão é importante no que diz respeito ao estabelecimento de novos critérios de teste, além de estabelecer certas propriedades e requisitos mínimos que os critérios devem preencher.

\section{Critérios Baseados em Fluxo de Dados}

Do ponto de vista da relação de inclusão, o critério Todos-Arcos, por exemplo, inclui o critério Todos-Nós, ou seja, qualquer conjunto de casos de teste que satisfaz o critério Todos-Arcos 
também satisfaz o critério Todos-Nós, necessariamente. Já os critérios Todas-Definições e TodosArcos são ditos incomparáveis, visto que não é possível estabelecer uma ordem de inclusão entre eles (Rapps \& Weyuker, 1985). De modo geral, os critérios baseados em fluxo de dados são mais exigentes que os baseados em fluxo de controle e "bridge the gap" entre os critérios Todos-Arcos e Todos-Caminhos (Frankl \& Weyuker, 1988; Maldonado, 1991).

Ainda, pode-se observar que os critérios Potenciais-Usos são os únicos critérios baseados em fluxo de dados que satisfazem, mesmo na presença de caminhos não executáveis, as propriedades mínimas esperadas de um critério de teste $C$, e que nenhum outro critério baseado em fluxo de dados os inclui (Maldonado, 1991):

1. Incluir o critério Todos-Arcos, ou seja, um conjunto de casos de teste que exercite os elementos requeridos pelo critério $C$ deve exercitar todos os ramos do programa.

2. Requerer, do ponto de vista de fluxo de dados, ao menos um uso de todo resultado computacional; isto equivale ao critério $C$ incluir o critério Todas-Definições.

3. Requerer um conjunto de casos de teste finito.

Um aspecto relevante é que alguns dos critérios Potenciais-Usos "bridge the gap" entre os critérios Todos-Arcos e Todos-Caminhos mesmo na presença de caminhos não executáveis, o que não ocorre para os demais critérios baseados em fluxo de dados.

Os critérios baseados em fluxo de dados também foram avaliados quanto ao custo de aplicação, em termos do número de casos de teste requeridos (Maldonado, 1991). Do ponto de vista teórico, tais critérios apresentaram complexidade de ordem exponencial em relação ao número de comandos de decisão. No entanto, com a condução de estudos empíricos pode-se observar que, na prática, o número de casos de teste requeridos é de ordem linear em relação ao número de comandos de decisão.

A relação de inclusão tem sido bastante utilizada para comparar os critérios quanto aos fatores custo e strength. Quanto à eficácia em revelar erros, entretanto, alguns autores questionam sua utilização na comparação entre critérios de teste.

Hamlet \& Taylor (1998) argumentam que é possível um critério $C_{1}$ incluir um critério $C_{2}$ e, ainda assim, que um conjunto de casos de teste $T_{2}\left(C_{2}\right.$-adequado) revele erros não revelados por um conjunto de casos de teste $T_{1}\left(C_{1}\right.$-adequado). Isso se deve ao fato de que a eficácia de $T_{1} \mathrm{e}$ $T_{2}$ irá depender da estratégia utilizada para gerá-los. Para Weyuker \& Jeng (1991), a relação de inclusão é útil para comparar o custo entre critérios, mas não diz nada sobre a eficácia destes em revelar erros.

Frankl \& Weyuker (1993a,b) exploraram a relação de inclusão entre critérios e concluíram que o fato de $C_{1}$ incluir $C_{2}$ não garante que $C_{2}$ seja melhor em revelar erros que $C_{1}$. Nesse contexto, foram definidas outras relações para a comparação de critérios de teste de modo que, se um determinado critério $C_{1}$ satisfaz uma dada relação com respeito a um critério $C_{2}$, é possível 
afirmar que $C_{1}$ é melhor que $C_{2}$ em revelar a presença de erros. As autoras definiram cinco novas relações (restringe, cobre, particiona, cobre propriamente, particiona propriamente) identificando a capacidade em revelar a presença de erros dos critérios de teste de acordo com três medidas probabilísticas $\left(M_{1}, M_{2}\right.$ e $\left.M_{3}\right)$. Salienta-se, entretanto, que as próprias autoras consideram difícil a aplicação de tais relações na avaliação teórica de critérios mais elaborados, apontando que outros trabalhos analíticos e experimentais devem ser conduzidos até que se possam transpor para o estado da prática os resultados obtidos (Frankl \& Weyuker, 1993b).

O trabalho conduzido por Zhu (1996) contesta os resultados obtidos por Frankl \& Weyuker (1993a) de que a relação de inclusão não reflete a capacidade em revelar erros dos critérios. Em seu trabalho, dois cenários de teste são explorados: um cenário em que os casos de teste são construídos com base no critério de adequação utilizado, e outro em que os casos de teste são gerados sem que se tenha conhecimento sobre qual critério está sendo considerado. De acordo com Zhu (1996), os resultados obtidos por Frankl \& Weyuker (1993a,b) são válidos para o primeiro cenário de teste. No entanto, considerando o segundo cenário, observou-se que a relação de inclusão reflete também a capacidade em revelar erros dos critérios.

Frankl \& Weyuker (2000) também estenderam os resultados obtidos em (Frankl \& Weyuker, 1993a,b) por meio da definição de medidas de eficácia relacionadas ao risco do programa em teste. Duas métricas, relacionadas ao risco detectado e à redução dos riscos em virtude da utilização de um dado critério de teste, foram introduzidas e utilizadas para comparar, analiticamente, a eficácia dos critérios. Demonstrou-se que, se um critério $C_{1}$ cobre apropriadamente um critério $C_{2}$ para um dado programa $P$ e uma especificação $S$, e se os casos de teste são selecionados a partir de cada subdomínio de acordo com uma distribuição normal, garante-se que $C_{1}$ é, no mínimo, tão bom quanto $C_{2}$ segundo as métricas de risco definidas. Conforme ressaltado pelas autoras, tais resultados podem ser úteis na escolha do critério mais apropriado para o teste de um programa quando se tem como objetivo a minimização dos riscos.

\section{Critérios Baseados em Mutação}

Um dos maiores problemas relacionado ao critério Análise de Mutantes é o grande número de mutantes que podem ser gerados, mesmo para pequenos programas. Como cada um dos mutantes deve ser executado com pelo menos um e potencialmente com todos os elementos do conjunto de teste para que seu comportamento seja comparado ao do programa original, o custo computacional para a aplicação do critério pode tornar-se muito elevado (Delamaro, 1997).

O custo de aplicação da Análise de Mutantes, do ponto de vista teórico, é $O$ (vals*refs), onde vals é o número de variáveis do programa e refs é o número de referências a dados. Com a condução de estudos empíricos, no entanto, alguns autores têm determinado uma relação linear em relação a refs (Budd et al., 1980).

Quanto ao critério Mutação de Interface, duas análises teóricas foram realizadas (Delamaro, 1997). A primeira análise comparou o critério Mutação de Interface e o critério baseado em fluxo 
de dados interprocedimental de Harrold \& Soffa (1991). A exemplo do que ocorre em nível de unidade, observou-se que tais critérios são incomparáveis. Segundo Delamaro (1997), esse resultado aponta para aspectos complementares, já ressaltados em nível de unidade, entre os critérios baseados em fluxo de dados e critérios baseados em mutação, sugerindo a utilização conjunta desses critérios na atividade de teste tanto em nível de unidade como de integração.

A segunda análise refere-se à complexidade do critério. Observou-se que o número de mutantes gerados pelos operadores propostos é determinado, principalmente, pelo número de variáveis vezes o número de referências a essas variáveis, assim como ocorre com o critério Análise de Mutantes, e pelo número de parâmetros formais da função chamada. Como ressalta Delamaro (1997), apesar dos pontos de aplicação dos operadores de Mutação de Interface serem limitados a pontos relacionados com uma conexão, a quantidade de mutantes gerados pode ser elevada, revelando a necessidade de adoção de abordagens alternativas que restrinjam o número de mutantes.

\section{Aspectos Empíricos}

O desenvolvimento de experimentos requer a elaboração de um framework composto, basicamente, pelas seguintes atividades (Wong, 1993): seleção e preparação dos programas, seleção das ferramentas de teste, geração de conjuntos de casos de teste, execução dos programas com os casos de teste gerados, e análise dos resultados do experimento.

A geração dos conjuntos de casos de teste é feita, em geral, aleatoriamente. Além de ser facilmente automatizada e de gerar grandes conjuntos de casos de teste a um baixo custo, a geração aleatória também elimina possíveis influências do testador em conduzir a geração dos casos de teste de acordo com o conhecimento dos programas utilizados. Normalmente, define-se o domínio de entrada de cada programa para a geração aleatória e, quando não se consegue satisfazer o critério, casos de teste criados manualmente são adicionados ao conjunto (Souza, 1996).

Além dessas atividades, conforme o tipo de experimento a ser realizado, são necessárias atividades adicionais, tais como identificar caminhos não-executáveis e programas equivalentes. Alguns estudos vêm sendo realizados nessa direção, visando a a facilitar a condução de tais atividades (Jorge, 2000; Offutt \& Hayes, 1996; Vergílio et al., 1992; Vergilio, 1997).

Conforme discutido anteriormente, os critérios baseados em fluxo de dados e em mutação, do ponto de vista teórico, têm complexidade exponencial. Tal fato motiva a condução de estudos empíricos para determinar o custo de aplicação desses critérios em termos práticos. Alguns desses estudos são discutidos a seguir.

\section{Critérios Baseados em Fluxo de Dados}

Weyuker (1990) conduziu uma avaliação empírica a fim de definir uma forma para estimar o número de casos de teste necessários para satisfazer um dado critério para um programa $P$ a ser testado. Observou-se que o número de casos de teste requeridos para satisfazer os critérios 
definidos por Rapps \& Weyuker $(1982,1985)$ pode ser visto como linear em função do número de comandos de decisão do programa. Outro ponto relevante é a caracterização do pior caso empírico, denominado complexidade empírica: o máximo valor obtido dividindo-se o número de casos de teste pelo número de comandos de decisão. Segundo Weyuker (1990), isso é uma boa indicação de que os critérios baseados em fluxo de dados são aplicáveis do ponto de vista prático, uma vez que podem ser vistos como lineares no número de comandos de decisão, até mesmo no pior caso empírico.

O mesmo benchmark utilizado por Weyuker também foi aplicado por Maldonado (1991) em uma primeira avaliação empírica dos critérios Potenciais-Usos. Modelos relacionando o número de casos de teste e várias características de programa (tais como número de definições, número de variáveis, número de nós, complexidade, etc.) foram obtidos. Em geral, pode-se dizer que os critérios Potenciais-Usos, do ponto de vista prático, são factíveis e demandam um número de casos de teste relativamente pequeno.

\section{Critérios Baseados em Mutação}

Mathur \& Wong (1993) compararam a Mutação Aleatória (no caso, foi utilizado o critério 10\%-Aleatório) e a Mutação Restrita a fim de determinar qual dessas abordagens apresentava melhor relação custo/eficácia. Segundo os autores, ambas mostraram-se igualmente eficazes, obtendo-se uma sensível redução no número de mutantes gerados sem perda significativa na eficácia em revelar a presença de erros.

Nos trabalhos de Wong et al. (1994) e Souza (1996), seis diferentes categorias de mutação restrita, obtidas a partir dos operadores de mutação da ferramenta Proteum, foram comparadas em termos de custo e eficácia. Com base nas comparações realizadas foi possível o estabelecimento de uma ordem incremental para o emprego dessas categorias: os conjuntos de casos de testes podem ser construídos inicialmente de forma a serem adequados à categoria com menor relação custo/eficácia e, na sequiência, quando as restrições de custo permitirem, esse conjunto pode ser melhorado de modo a satisfazer as categorias cuja relação custo/eficácia é maior.

Offutt et al. (1996) determinaram um conjunto essencial de operadores de mutação para a linguagem Fortran, a partir dos operadores da ferramenta Mothra (Choi et al., 1989a; DeMillo et al., 1988). Entende-se por conjunto essencial de operadores aquele formado por um subconjunto do total de operadores de mutação, capaz de modelar a maioria dos erros que se objetivam revelar durante a atividade de teste. A utilização desse conjunto deve proporcionar sensível redução de custo, em termos do número de mutantes gerados, preservando alto escore de mutação em relação ao critério Análise de Mutantes. A aplicação do conjunto essencial obtido por Offutt et al. (1996) proporcionou uma redução de custo da ordem de $77.5 \%$, mantendo um escore de mutação de 0.995 em relação à Análise de Mutantes.

Wong et al. (1997) conduziram um estudo em que a Mutação Restrita foi comparada no contexto das linguagens $\mathrm{C}$ e Fortran. Esse estudo resultou na seleção de um subconjunto de operadores 
de mutação da ferramenta Proteum, constituindo a base para a determinação do conjunto essencial de operadores da linguagem C. A aplicação deste subconjunto de operadores possibilitou reduzir o número de mutantes gerados, mantendo a eficácia do critério em revelar a presença de erros. A seleção dos operadores foi realizada de forma intuitiva, de acordo com a experiência dos próprios autores. De um modo geral, esse estudo forneceu indícios de que a utilização de um subconjunto de operadores de mutação, selecionados de maneira mais sistemática, pode ser uma boa heurística para a construção e avaliação de conjuntos de casos de teste na prática.

Os resultados obtidos por Offutt et al. (1996) e Wong et al. (1997) motivaram a realização dos trabalhos (Barbosa, 1998; Barbosa et al., 1998, 2001), os quais resultaram na proposição de um procedimento para a determinação de um conjunto essencial de operadores de mutação. O procedimento proposto foi aplicado em dois diferentes grupos de programas $\mathrm{C}$, sendo que para cada grupo foi determinado um conjunto essencial de operadores de mutação, a partir dos operadores implementados na ferramenta Proteum. De um modo geral, ambos os conjuntos essenciais obtidos apresentaram um alto grau de adequação em relação ao critério Análise de Mutantes, com escores de mutação acima de 0.995 , proporcionando, em média, reduções de custo superiores a $65 \%$. Observou-se ainda que os conjuntos essenciais obtidos foram bastante semelhantes em termos dos operadores selecionados.

A mesma linha de estudos empíricos investigando o critério Análise de Mutantes foi aplicada no âmbito do teste de integração, visando a avaliar empiricamente o critério Mutação de Interface ( (Delamaro, 1997; Vincenzi, 1998; Vincenzi et al., 1999, 2001)).

Maldonado et al. (2000a) conduziram um estudo investigando a aplicação da Mutação Seletiva no teste de programas $\mathrm{C}$, tanto em nível de unidade quanto de integração. De modo geral, para os conjuntos de programas utilizados, observou-se que com uma redução próxima a $80 \%$ no número de mutantes gerados, ainda assim seriam obtidos escores de mutação bastante significativos, em torno de 0.980 .

Dada a existência de um conjunto de operadores de mutação definido para a linguagem $\mathrm{C}$ para o teste em nível de unidade e em nível de integração, Vincenzi (2000) identificou, para o teste de métodos, quais operadores de unidade da linguagem $\mathrm{C}$ poderiam ser aplicados no contexto de pro-

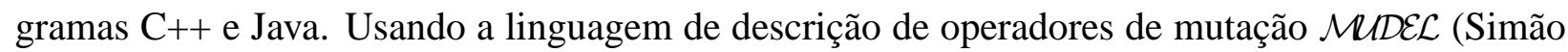
\& Maldonado, 2001), todos os 80 operadores de mutação de unidade foram implementados. Em seguida, devido às similaridades das gramáticas das linguagens de $\mathrm{C}, \mathrm{C}++$ e Java em determinadas construções, foram avaliadas tanto a possibilidade de aproveitar a mesma descrição do operador de mutação em $\mathcal{M R D E L}$ nas três linguagens, como a concepção do operador em si.

Considerando o total de 80 operadores de mutação implementados, observou-se que 31 operadores $(38,75 \%)$ foram comuns às três linguagens de programação. A maioria deles, 34 (42,50\%), foram comuns às linguagens $\mathrm{C}$ e $\mathrm{C}++$. Além disso, para a linguagem $\mathrm{C}$, outros 15 operadores $(18,75 \%)$ puderam ser aplicados. O mesmo foi observado para a linguagem $\mathrm{C}++$. No caso da linguagem Java, além dos operadores comuns, 31 (38,75\%), mais 28 (35,00\%) puderam ser ins- 
tanciados por caracterizarem erros típicos ocorridos quando se programa em Java. Os demais, por serem de características intrínsecas de $\mathrm{C}$ e $\mathrm{C}++$, tais como ponteiros, não foram implementados. Observou-se entretanto que, embora existam operadores específicos para estruturas sintáticas de C e C++ que não existem em Java, a idéia do operador pode ser aproveitada no contexto de Java.

\section{Comparação entre Critérios Baseados em Fluxo de Dados e em Mutação}

Mathur \& Wong (1994) compararam os critérios Análise de Mutantes e Todos-Usos. O objetivo do experimento foi verificar o strength e o custo entre os dois critérios, uma vez que estes são incomparáveis do ponto de vista teórico. Os conjuntos de casos de teste adequados ao critério Análise de Mutantes também se mostraram adequados ao critério Todos-Usos; no entanto, os conjuntos de casos de teste adequados ao critério Todos-Usos não se mostraram, em muitos dos casos, adequados à Análise de Mutantes. Segundo os autores, esses resultados demonstram que é mais difícil satisfazer o critério Análise de Mutantes do que o critério Todos-Usos, podendo-se dizer, na prática, que Análise de Mutantes inclui Todos-Usos.

Souza (1996) realizou um estudo empírico com a finalidade de avaliar o strength e o custo do critério Análise de Mutantes empregando, para efeito comparativo, os critérios Potenciais-Usos, os quais incluem o critério Todos-Usos. Os resultados demonstraram que o custo de aplicação da Análise de Mutantes, estimado pelo número de casos de teste necessário para satisfazer o critério, apresentou-se maior do que o custo dos critérios Potenciais-Usos. Em relação ao strength observou-se que, de maneira geral, os critérios Análise de Mutantes e Todos-Potenciais-Usos não possuem grandes diferenças entre si e podem ser vistos como equivalentes do ponto de vista da relação de inclusão. Já os critérios Todos-Potenciais-Usos/Du e Todos-Potenciais-Du-Caminhos apresentaram maior strength que o critério Todos-Potenciais-Usos em relação à Análise de Mutantes, o que motiva a se investigar o aspecto complementar desses critérios quanto à eficácia.

\subsection{Considerações Finais}

Neste capítulo foi apresentada uma síntese das principais pesquisas que serviram como base para a condução das atividades referentes ao presente trabalho de doutorado. Abordagens para a representação de conteúdos educacionais, ambientes e sistemas de apoio desenvolvidos no contexto de ensino e treinamento, e aspectos de padronização e melhoria de processos de software foram abordados. Ainda, uma visão geral sobre a área de Teste de Software foi apresentada.

Com respeito às abordagens para a modelagem de conteúdos educacionais discutidas, observou-se que, apesar de características em comum, cada uma delas apresenta aspectos distintos, os quais podem ser adequados a um determinado cenário educacional e inadequado para outros. Quanto aos ambientes e sistemas educacionais apresentados, salienta-se o pouco (ou quase nenhum) apoio dado à tarefa de modelagem de conteúdos educacionais, deixando-a inteiramente 
a cargo do autor do curso, sem quaisquer diretrizes ou mesmo um processo sistemático que apóie sua realização.

As limitações observadas no contexto da atividade de modelagem serviram como motivação para que se identificassem requisitos para construção, análise e seleção de modelos para a representação de conteúdos educacionais, bem como a proposição de uma abordagem integrada, reunindo diferentes perspectivas de modelagem. Tais aspectos são discutidos detalhadamente no Capítulo 3 .

Considerando ainda que a elaboração de módulos educacionais apresenta características semelhantes à produção de software, os aspectos pertinentes à padronização e melhoria de processos de software discutidos também se mostram adequados ao estabelecimento de processos sistemáticos no contexto de desenvolvimento de tais módulos. A definição de um processo padrão para a construção de módulos educacionais é discutida no Capítulo 4.

Ressalta-se que, além dos aspectos comuns em relação ao desenvolvimento de software, aspectos específicos tais como práticas de projeto instrucional e modelagem de conteúdos educacionais também foram incorporados como parte das atividades do processo padrão estabelecido. Além disso, tendo em vista que ambientes e sistemas educacionais constituem mecanismos de apoio ao desenvolvimento instrucional, tanto no que se refere à automatização de processos e atividades associadas quanto à sua integração como parte dos módulos educacionais desenvolvidos, estes também foram considerados no estabelecimento do processo.

Finalmente, a caracterização do domínio de conhecimento sobre Teste de Software apresentada neste capítulo evidencia alguns aspectos relevantes no processo de desenvolvimento de módulos educacionais. Por exemplo, a condução de estudos teóricos e empíricos ilustra o aspecto dinâmico e evolutivo do conhecimento. Ferramentas de teste, por sua vez, evidenciam a necessidade de mecanismos de apoio à condução de atividades práticas, que possibilitem a aplicação dos conceitos e informações teóricas apresentadas. O desenvolvimento de um módulo educacional no domínio de Teste de Software é ilustrado no Capítulo 5.

O próximo capítulo discute aspectos especificamente voltados à atividade de modelagem de conteúdos educacionais. 


\subsection{Considerações Iniciais}

Módulos educacionais são compostos essencialmente por conteúdos teóricos e práticos, integrados e disponibilizados aos aprendizes por meio de recursos tecnológicos e computacionais. Mecanismos de apoio ao desenvolvimento sistemático de tais módulos constituem o foco de pesquisa deste trabalho, sendo a modelagem dos conteúdos relacionados uma das linhas principais investigada.

De modo geral, a modelagem de conteúdos educacionais apóia o autor na identificação e definição de conceitos e informações associadas, possibilitando, em última análise, que os mesmos sejam disponibilizados de modo coerente e ordenado, com base em teorias e princípios didáticopedagógicos previamente estabelecidos. Desse modo, a atividade de modelagem desempenha um papel relevante dentro do contexto de ensino e treinamento, sendo essencial para a estruturação do domínio de conhecimento que se deseja ensinar.

A construção de modelos para a representação de conteúdos educacionais requer que uma série de características associadas à atividade de modelagem seja considerada, envolvendo desde a determinação de aspectos específicos do domínio de conhecimento, passando pela definição de atividades práticas e mecanismos para a avaliação do aprendiz, até o estabelecimento de uma ordem pedagógica para a apresentação das informações modeladas. Diante da diversidade de características e aspectos a serem considerados, requisitos e perspectivas de modelagem, atuando como mecanismos de apoio à construção, análise e seleção de modelos para a representação de conteúdos educacionais, tornam-se fundamentais. Além disso, evidencia-se a necessidade de abordagens 
integradas, capazes de reunir, de forma consistente, os diferentes aspectos de modelagem relacionados.

Este capítulo discute aspectos pertinentes à atividade de modelagem de conteúdos educacionais, procurando enfatizar questões relativas ao estabelecimento de requisitos e perspectivas de modelagem e sua utilização na construção e análise de modelos para representação de conteúdos. A aplicação integrada dos mecanismos e aspectos de modelagem investigados também é discutida.

Inicialmente, na Seção 3.2 a idéia de módulos educacionais é apresentada, sendo abordadas algumas perspectivas relevantes que permeiam seu processo de desenvolvimento. Além disso, a caracterização de tais módulos na forma de Objetos de Aprendizado (Learning Objects) (IEEE Learning Technology Standards Committee, 2002; Wiley, 2000, 2001) também é discutida.

Na Seção 3.3 é apresentado e discutido um conjunto preliminar de requisitos para a modelagem de conteúdos educacionais, identificado com o propósito de apoiar a construção, comparação, avaliação e seleção de modelos para a representação de conteúdos. Perspectivas de modelagem são discutidas na Seção 3.4, sendo caracterizadas em três linhas: (1) a perspectiva conceitual trata da modelagem dos conceitos e relacionamentos relevantes ao domínio de conhecimento; (2) a perspectiva instrucional aborda a modelagem de informações adicionais e elementos complementares sobre o domínio; e (3) a perspectiva didática é responsável pelo estabelecimento de sequiências de apresentação envolvendo os objetos anteriormente modelados. Tais perspectivas são investigadas em termos de modelos genéricos envolvendo a representação de conteúdos educacionais - Modelo Conceitual, Modelo Instrucional e Modelo Didático.

Com base nos requisitos e perspectivas identificadas, na Seção 3.5 algumas abordagens para a modelagem de conteúdos educacionais são analisadas e avaliadas com respeito às suas características principais. De modo geral, tanto aspectos positivos como fatores limitantes que comprometem a utilização de determinado modelo segundo uma dada perspectiva de modelagem são identificados. A partir das comparações realizadas, é proposta na Seção 3.6 uma abordagem integrada para modelagem de conteúdos educacionais, procurando ressaltar os pontos fortes e minimizar as limitações observadas em cada uma das abordagens analisadas. Por fim, na Seção 3.7 alguns aspectos pertinentes à integração dos mecanismos de modelagem investigados são discutidos sob um ponto de vista específico, relacionado à construção de Objetos de Aprendizado.

Ressalta-se que a modelagem de conteúdos educacionais é apenas uma das atividades a serem consideradas no contexto de desenvolvimento de módulos educacinais, tendo sido incorporada e discutida como parte de processo padrão para a elaboração de tais módulos, apresentado no Capítulo 4. 


\subsection{Módulos Educacionais: Definição e Perspectivas de Desenvolvimento}

Antes de discutir aspectos especificamente relacionados à atividade de modelagem de conteúdos educacionais, faz-se necessário caracterizar os produtos aos quais esses conteúdos são integrados e disponibilizados - os módulos educacionais.

Por módulos educacionais entendem-se unidades concisas de estudo, compostas basicamente por conteúdos teóricos integrados a atividades práticas e avaliações, cuja disponibilização aos aprendizes é apoiada por recursos tecnológicos e computacionais (Barbosa et al., 2003c).

A Figura 3.1 ilustra um módulo educacional em termos de seus componentes principais: o material didático associado, envolvendo os conteúdos referentes ao domínio de conhecimento que se deseja ensinar; e os ambientes educacionais e mecanismos de apoio, representando a infraestrutura necessária à utilização do módulo.

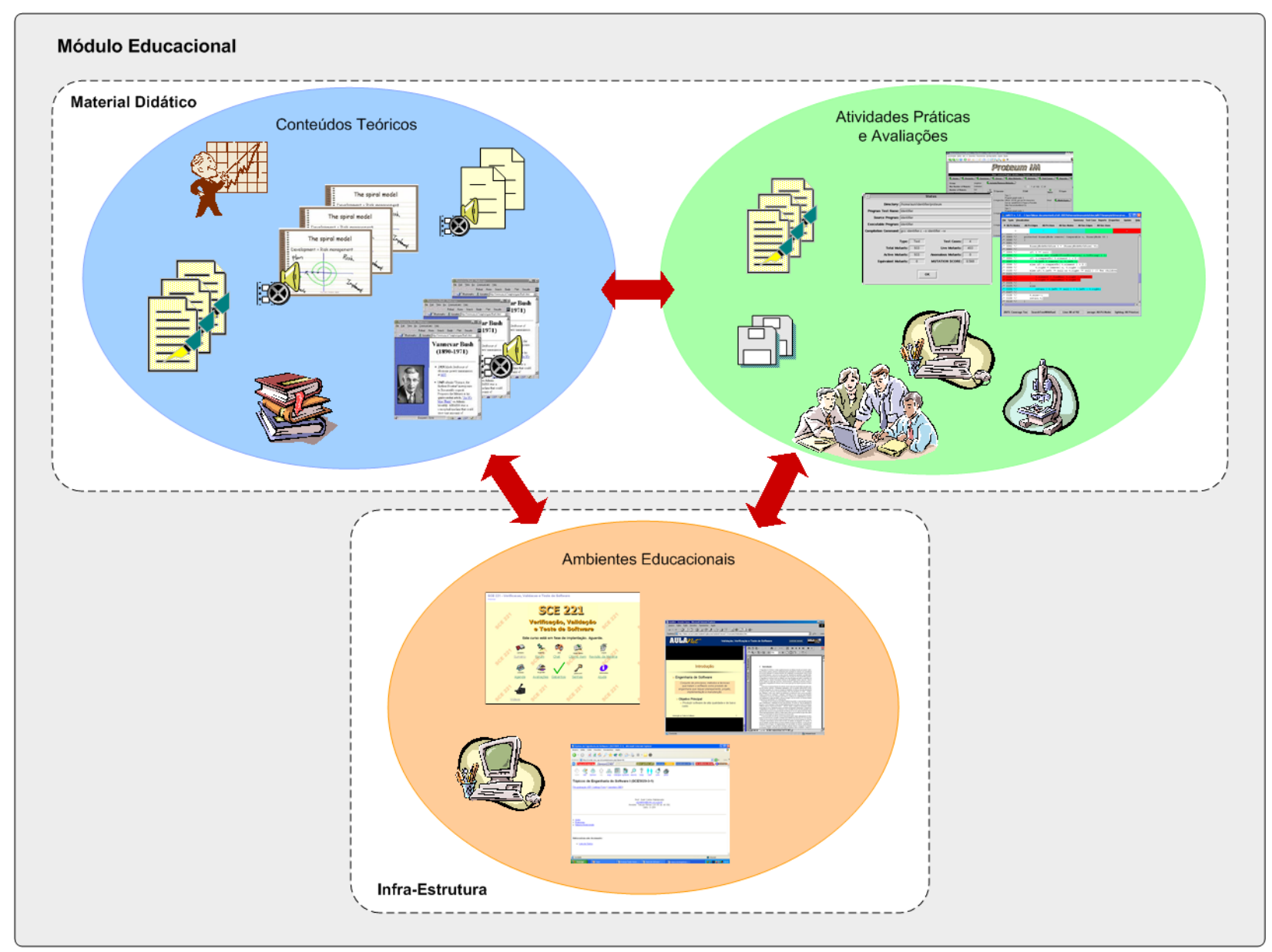

Figura 3.1: Componentes de um Módulo Educacional.

De acordo com a figura, o material didático é constituído por conteúdos teóricos e conteúdos práticos. Conteúdos teóricos podem ser vistos como livros, artigos, informações e referências na web, transparências, anotações de aula, áudio e vídeo associados, entre outros. Conteúdos práticos, 
por sua vez, são caracterizados em função das atividades e avaliações conduzidas e de seus produtos resultantes (documentos, códigos-fonte, programas executáveis, discussões, experimentos). Ferramentas específicas pertinentes ao domínio de conhecimento bem como os resultados obtidos a partir de sua utilização também são considerados conteúdos práticos.

Conteúdos teóricos e práticos são integrados e disponibilizados aos aprendizes por meio de ambientes e sistemas educacionais. Recursos computacionais e tecnológicos (mecanismos para captura de aulas presenciais, mecanismos de apoio à comunicação e à colaboração, entre outros) também são caracterizados como parte da infra-estrutura necessária à integração do material didático e à conseqüente disponibilização do módulo educacional.

A construção de módulos educacionais pode ser investigada sob quatro perspectivas correlatas: estruturação, transferência, evolução e reuso do conhecimento.

\section{- Estruturação do Conhecimento}

A estruturação do conhecimento envolve a agregação adequada das informações do domínio e a criação de uma estrutura para organizá-las. De fato, é fundamental que durante a construção de um módulo educacional os desenvolvedores consigam depreender com clareza o domínio de conhecimento em questão, identificando e organizando conceitos e informações relevantes, especificando ainda atividades práticas e avaliações pertinentes.

Conforme salientado no início deste capítulo, a modelagem de conteúdos educacionais, sejam eles teóricos ou práticos, representa uma atividade essencial para a estruturação do conhecimento, apoiando a identificação e a definição das partes relevantes do domínio a serem tratadas, estabelecendo ainda seqüências de apresentação entre elas com base em teorias e princípios educacionais previamente definidos.

A preocupação da comunidade científica no que se refere à estruturação do conhecimento pode ser evidenciada por meio das abordagens propostas para a construção de hiperdocumentos educacionais, as quais incluem aspectos de modelagem de conteúdos como parte do processo de desenvolvimento. Como exemplos, podem-se destacar as abordagens Daphne (Kawasaki \& Fernandes, 1996), EHDM (Pansanato \& Nunes, 1999), MAPHE (Pimentel, 1997) e MDE (Leiva et al., 2002b; Leiva, 2003). Além disso, estudos envolvendo mecanismos para aquisição e representação do conhecimento, tais como Mapas Conceituais (Moreira \& Buchweitz, 1987; Novak, 1981; Novak \& Gowin, 1984; Novak, 1990) e Ontologias (Falbo, 1998; Gruber, 1995; Guarino, 1997; Guizzardi et al., 2002), incluindo ainda o desenvolvimento de ferramentas de apoio à sua aplicação prática (Beck, 2003; Coffey et al., 2002; Inspiration Software Inc., 2003; Gaines \& Shaw, 2003; Grosso, 1999; Mian \& Falbo, 2002; Knowledge Systems Laboratory, 2003), também evidenciam a relevância do tema. 


\section{- Evolução do Conhecimento}

O desenvolvimento de módulos educacionais também deve levar em consideração o caráter dinâmico e evolutivo do conhecimento, a partir do qual novos conhecimentos são constantemente produzidos e referenciados como resultado de experiências anteriores de aprendizado. A cada aula, seja ela presencial ou à distância, uma série de conteúdos é produzida a partir da disponibilização do módulo educacional aos aprendizes: transparências, anotações, documentos-texto, sub-produtos associados à condução das tarefas práticas, entre outros. De fato, o material didático é continuamente expandido em decorrência das contribuições de todos os participantes do curso. Além disso, esse mesmo material é freqüentemente referenciado, visando tanto a consolidar os conhecimentos prévios adquiridos como a motivar o aprendizado de novos conhecimentos inter-relacionados. Conforme destacado por Pimentel et al. (2001, 2002), o material didático referente a um curso apresenta como características:

- Expansão Progressiva (Active Growth): Os conteúdos são continuamente expandidos (evoluídos) em função das contribuições de instrutores e aprendizes.

- Referência Intrínseca (Intrinsic Reference): Os conteúdos são freqüentemente referenciados, consolidando conhecimentos prévios e motivando o estudo de novos conhecimentos associados.

No domínio de Teste de Software, por exemplo, atividades práticas envolvendo a condução de estudos teóricos e empíricos resultam em novos conhecimentos a respeito das técnicas e critérios de teste considerados. Tais conhecimentos devem ser incorporados ao conteúdo teórico previamente definido e, nesse sentido, mecanismos de apoio à evolução do conhecimento devem ser considerados no processo de desenvolvimento dos módulos.

Em cursos presenciais, a evolução do conhecimento pode ser apoiada a partir de mecanismos para a captura das discussões e interações ocorridas em aula e sua posterior integração aos conteúdos já desenvolvidos. Ambientes instrumentados com recursos computacionais visando à captura de material multimídia em salas de aula convencionais, a exemplo do $e$ Class (Abowd et al., 1996, 1998a,b; Abowd, 1999; Abowd et al., 1999; Brotherton \& Abowd, 1998; Brotherton et al., 1998; Pimentel et al., 2002), têm sido investigados sob essa perspectiva. Ressalta-se ainda a possibilidade de integração de infra-estruturas de captura a ambientes e ferramentas colaborativas. A idéia é associar as discussões ocorridas diretamente aos conteúdos de interesse dos aprendizes. Segundo Guzdial (1997), discussões "ancoradas" mostram-se relevantes para a condução das atividades dos aprendizes e, em particular, tendem a ser mais sustentáveis em comparação a espaços de discussão menos conexos, tais como newsgroups, os quais podem se tornar descontextualizados das atividades propostas. Um trabalho conduzido nessa linha refere-se à integração da ferramenta CoWeb (Guzdial et al., 2002) e o ambiente e-Class. Detalhes podem ser encontrados em (Pimentel et al., 2001, 2002). 
No caso de cursos à distância, ainda que não seja possível a captura de aulas presenciais, atenção deve ser dada às discussões ocorridas entre aprendizes e entre aprendizes/mediador (por meio de sessões de chat, newsgroups, correio eletrônico, etc.) e aos produtos resultantes de condução das atividades práticas e avaliações. Tais elementos constituem, na verdade, conteúdos relevantes a serem integrados àqueles já desenvolvidos. Nesse cenário, ferramentas de apoio à comunicação e à colaboração entre seus participantes são essenciais como suporte à evolução do conhecimento.

Outro mecanismo relevante quanto ao aspecto de evolução do conhecimento são os repositórios de informação, construídos com o objetivo de gerenciar o grande volume de informações produzido durante um curso. A idéia básica é fornecer facilidades de armazenamento, busca e recuperação das informações produzidas, as quais são constantemente alteradas e evoluídas (Pimentel, 2001). Um dos resultados obtidos a partir da realização do presente trabalho refere-se à construção de uma base conceitual, nos moldes de um repositório de informações, para o domínio de Teste de Software. Posteriormente, na Seção 3.7, discutem-se alguns aspectos pertinentes à base conceitual sendo desenvolvida.

\section{- Transferência do Conhecimento}

A transferência de conhecimento refere-se à forma como este é transmitido aos aprendizes, estando associada sobretudo à infra-estrutura necessária para: (1) a disponibilização e apresentação dos conteúdos elaborados; (2) a condução de atividades práticas; e (3) a condução de avaliações pertinentes e acompanhamento do desempenho do aprendiz.

Recursos tecnológicos e computacionais representam mecanismos relevantes a serem explorados na perspectiva de transferência do conehcimento. A web, por exemplo, pode atuar como infra-estrutura de apoio sob diversas maneiras, desde a publicação de informações gerenciais sobre o curso (descrição e objetivos do curso, calendário, regras de avaliação), até a distribuição dos conteúdos teóricos e práticos aos aprendizes.

A diversidade de ambientes e sistemas educacionais existente, tais como WebCT (Goldberg et al., 1996), AulaNet (Lucena et al., 1998), ATEnA (Leiva, 2003), CoWeb (Guzdial et al., 2002), Eureka (Eberspächer et al., 1999), Hyperlearning Meter (Menasce, 1998) e CyberQ (Tucker, 1995), entre outros, também evidencia o esforço da comunidade científica em estabelecer recursos e mecanismos de apoio à transferência do conhecimento. Além disso, a definição e a utilização de ambientes integrados para o aprendizado, envolvendo ferramentas colaborativas e mecanismos de captura (Pimentel et al., 2001, 2002) representam contribuições significativas visando à distribuição dos materiais pertinentes e à discussão dos tópicos que compõem o módulo desenvolvido.

O desenvolvimento e a integração de ferramentas específicas associadas ao domínio de conhecimento também devem ser investigados no contexto de transferência do conhecimento. De fato, tais ferramentas desempenham um papel relevante na consolidação do conheci- 
mento, fornecendo subsídios para a aplicação prática dos conteúdos teóricos previamente estudados. Ferramentas de teste, por exemplo, são essenciais para a compreensão dos conceitos básicos pertinentes a esse domínio, contribuindo ainda para a condução de atividades práticas associadas. Conforme destacado anteriormente, ferramentas específicas ao domínio de conhecimento podem ser vistas como parte dos conteúdos práticos relacionados ao material didático.

Finalmente, é importante ressaltar que, apesar da relevância dos aspectos associados à transferência do conhecimento dentro do processo de construção dos módulos educacionais, a simples utilização de recursos tecnológicos e computacionais não garante necessariamente o sucesso e a efetividade do aprendizado. A qualidade dos conteúdos disponibilizados bem como a motivação para a realização das atividades e avaliações propostas também constituem fatores fundamentais a serem considerados.

\section{- Reuso do Conhecimento}

Módulos educacionais também podem ser caracterizados como unidades independentes, passíveis de reutilização em diferentes cenários e contextos de ensino e treinamento, atendendo a aprendizes com perfis e objetivos de aprendizado distintos.

Considere, por exemplo, um módulo sobre Movimentos (teoria de Mecânica, da Física), aplicado aos seguintes tipos de aprendizes: alunos de ensino médio, universitário e de pósgraduação. Tais usuários necessitam de abordagens de ensino diferenciadas e, possivelmente, de formas distintas de estruturação e diferentes mídias e ferramentas para apresentar os conteúdos associados. Enquanto para alunos de ensino médio pode ser necessária uma abordagem mais intuitiva da teoria, com exemplos na forma de vídeos e/ou animações, para alunos universitários ou de pós-graduação pode-se abordar a teoria de uma maneira mais formal, com discussões e exemplos mais abstratos (Pansanato \& Nunes, 1999). De fato, tal cenário requer a adaptação e a reestruturação do conteúdo em função dos objetivos e expectativas de aprendizado de cada público-alvo.

É interessante observar que as perspectivas de desenvolvimento discutidas nesta seção estão relacionadas entre si: a estruturação dos conteúdos é fundamental para garantir a transferência, reuso e evolução do conhecimento; a evolução, por sua vez, é decorrente da transferência e do reuso, podendo ainda resultar na reestruturação do conhecimento; o reuso, além de conteúdos estruturados, requer mecanismos de transferência bem definidos.

Além das perspectivas discutidas, aspectos de aquisição, integração e compartilhamento de conhecimento também podem ser considerados no processo de desenvolvimento instrucional. Nesse sentido, ontologias podem ser utilizadas como mecanismos de apoio à elaboração dos módulos pertinentes. Basicamente, ontologias consistem em uma representação formal e declarativa que estabelece o vocabulário para os elementos do domínio, as declarações lógicas que descrevem o que são esses elementos e o modo com que os mesmos podem ou não estar relacionados uns com 
os outros (Falbo et al., 1998; Guarino, 1997; Gruber, 1995). No contexto de Inteligência Artificial, ontologias têm sido aplicadas sobretudo na descrição de domínios como Medicina, Engenharia e Direito. No âmbito de Engenharia de Software, alguns trabalhos foram conduzidos visando à definição de ontologias para apoiar a aquisição, organização, reuso e compartilhamento de conhecimento sobre processos de software (Falbo et al., 1998; Falbo, 1998; Guizzardi et al., 2002; Oliveira et al., 1999).

O desenvolvimento de ferramentas de apoio à construção de ontologias (Beck, 2003; Grosso, 1999; Mian \& Falbo, 2002; Knowledge Systems Laboratory, 2003) evidencia a relevância dada pela comunidade científica ao tema e motiva a que se investigue sua utilização no contexto de desenvolvimento instrucional. Neste trabalho não foram abordados aspectos da aplicação prática de ontologias e ferramentas associadas na elaboração dos módulos educacionais, sendo esta uma das linhas de pesquisa futura a ser conduzida.

\subsubsection{Módulos Educacionais e Objetos de Aprendizado}

Conforme ressaltado por Melo et al. (2003), módulos educacionais podem ser desenvolvidos como uma combinação de "blocos de conteúdo", os quais podem ser utilizados mais de uma vez, por mais de um autor, em seqüências e com objetivos possivelmente diferentes. Essas unidades instrucionais “auto-suficientes", reutilizáveis em diferentes contextos formativos, têm sido chamadas de Objetos de Aprendizado (Learning Objects - LOs) (Downes, 2001; Hamel \& Ryan-Jones, 2002; Hodgins, 2000; IEEE Learning Technology Standards Committee, 2002; Longmire, 2000; Martinez, 2000; Merrill, 2000; Muzio et al., 2002; Sosteric \& Hesemeier, 2002; Wiley, 2000, 2001).

Por ser uma linha de pesquisa relativamente nova, o conceito de objetos de aprendizado ainda é considerado vago, não havendo uma definição que seja universalmente aceita. Segundo Muzio et al. (2002), várias definições diferentes para objetos de aprendizado são encontradas e muito outros termos também são utilizados (por exemplo, objetos de ensino, objetos educacionais, componentes de ensino, objetos de comunicação, entre outros).

Segundo o IEEE LSTC (Learning Technology Standards Committee) (IEEE Learning Technology Standards Committee, 2002), um objeto de aprendizado corresponde à qualquer entidade, digital ou não digital, que possa ser usada, reutilizada ou referenciada pelas tecnologias que apóiem o aprendizado. Exemplos de tecnologias de apoio ao aprendizado incluem sistemas CBT (computer-based training), sistemas para aprendizado interativo, sistemas para ensino à distância, ambientes colaborativos, sistemas tutores inteligentes, entre outros. Exemplos de objetos de aprendizado incluem conteúdos multimídia, objetivos de aprendizado, ferramentas de software específicas ao domínio de conhecimento e, ainda, pessoas e organizações ou outras entidades que se utilizem das tecnologias citadas durante o processo de aprendizado. Baseado na definição do IEEE LSTC, Wiley (2001) propõe uma definição pouco menos abrangente na qual um objeto de aprendizado consiste em qualquer recurso digital que possa ser reutilizado como suporte ao ensino. 
Independentemente da definição utilizada, a idéia central por trás dos objetos de aprendizado é permitir que o conteúdo educacional seja "quebrado em pequenos pedaços", os quais possam ser reutilizados em diferentes contextos e cenários de ensino e treinamento. Nesse sentido, como características associadas destacam-se a reusabilidade, a interoperabilidade, a acessibilidade e extensibilidade dos objetos desenvolvidos (Downes, 2001; Longmire, 2000; Wiley, 2001).

Além dos problemas associados à definição e à terminologia adotada, o estabelecimento de abordagens sistemáticas para a construção de objetos de aprendizado também se mostra incipiente. Embora padrões internacionais como IMS (IMS Global Learning Consortium, 2004) e SCORM (Advanced Distributed Learning Initiative, 2004) venham sendo utilizados na tentativa de resolver o problema de interoperabilidade entre as diversas plataformas de ensino à distância, a construção de objetos de aprendizado eficazes e verdadeiramente reutilizáveis vai além de problemas tecnológicos (Melo et al., 2003). De fato, faz-se necessário o estabelecimento de uma metodologia de projeto e implementação, a qual possibilite desenvolver, em tempo rápido e a custos razoáveis, objetos de aprendizado de alta qualidade. Iniciativas nessa direção podem ser identificadas (Baruque et al., 2003; Cisco Systems, Inc., 2000, 2001; Hamel \& Ryan-Jones, 2002; Martinez, 2000).

$\mathrm{Na}$ tentativa de caracterizar os objetos de aprendizado bem como seu processo de desenvolvimento, Wiley (2001) também propõe a metáfora do átomo: átomos correspondem a combinações de bits menores (nêutrons, prótons e elétrons) que, por sua vez, são combinações de bits ainda menores (bárions e mésons), e assim sucessivamente. A maneira com que os bits são combinados em um átomo determina com que outros átomos este pode ser associado. Aplicando essas idéias no contexto de objetos de aprendizado, objetos de menor granularidade são combinados em estruturas maiores, as quais permitem que o objeto resultante (objeto A, por exemplo) seja combinado com um segundo objeto (objeto B), ao mesmo tempo em que previnem sua combinação com um terceiro objeto (objeto $\mathrm{C}$ ).

Dentro dessa perspectiva, questões relevantes podem ser identificadas. Uma delas refere-se à granularidade dos objetos: Qual é o tamanho de um objeto de aprendizado? De fato, tanto elementos básicos (mídias) como unidades de estudo sobre um tópico específico ou ainda um curso completo envolvendo vários tópicos inter-relacionados podem ser abordados como objetos de aprendizado.

Outra questão fundamental refere-se à combinação e ao seqüenciamento dos objetos (e seus componentes internos): Como combinar os objetos de modo a estabelecer um "propósito didático" aos mesmos? Ou seja, é necessário que se estabeleçam ordens de apresentação coerentes, fundamentadas em teorias e princípios didático-pedagógicos, capazes de satisfazer as metas de aprendizado almejadas.

Ainda como aspecto decorrente da combinação dos objetos, surge a necessidade de estabelecimento de metadados - informações descritivas sobre o objeto. A idéia é que, inspecionando os metadados associados, seja possível obter informações gerais a respeito das características do 
objeto e decidir pela sua adequação ou não aos propósitos de um determinado contexto de aprendizado. Vários esforços de padronização têm sido observados no estabelecimento de metadados. O mais significativo deles - IEEE LTSC LOM (Learning Objects Metadata) (IEEE Learning Technology Standards Committee, 2002) - tem sido conduzido pelo IEEE LSTC, em conjunto com outras organizações de padronização.

Em síntese, as questões levantadas nesta seção evidenciam a necessidade de processos e atividades bem definidas que apóiem a construção sistemática de objetos de aprendizado, em especial tratando de aspectos referentes à estruturação do conteúdo do objeto propriamente dito e ao estabelecimento de um conjunto de metadados associado (Downes, 2001).

Partindo-se da idéia que módulos educacionais podem ser caracterizados na forma de objetos de aprendizado, as atividades conduzidas no decorrer deste trabalho também se mostram relevantes na definição de mecanismos de apoio à construção de tais objetos. De fato, os aspectos de modelagem de conteúdos (investigados neste capítulo) e a padronização de processos para o desenvolvimento instrucional (discutida no Capítulo 4) podem ser adaptados e utilizados com esse propósito.

É importante ressaltar, entretanto, que as preocupações deste trabalho residem na estruturação do conteúdo educacional e na sistematização das principais atividades associadas ao desenvolvimento de módulos educacionais. Questões essencialmente técnicas envolvendo, por exemplo, a interoperabilidade e a comunicação entre objetos de aprendizado (ou módulos educacionais), não fazem parte das linhas de pesquisa aqui investigadas e, desse modo, não serão abordadas.

\subsection{Requisitos para Modelagem de Conteúdos Educaci- onais: um Conjunto Preliminar}

A elaboração de material didático de qualidade, capaz de motivar os aprendizes e contribuir efetivamente em seu processo de construção do conhecimento, representa um aspecto essencial no contexto de desenvolvimento de módulos educacionais. Conforme ilustrado na Figura 3.1, o material didático pode ser visto como uma composição de conteúdos teóricos e práticos e, nesse sentido, a modelagem de tais conteúdos desempenha um papel importante na elaboração do material, auxiliando o autor na captura de partes relevantes do assunto que se deseja ensinar bem como na estruturação adequada dessas informações.

Tendo em vista a diversidade de características e perspectivas as quais podem ser consideradas no contexto de modelos para a representação de conteúdos educacionais, o estabelecimento de requisitos de modelagem que forneçam subsídios e parâmetros para a construção, comparação, avaliação e seleção desses modelos torna-se fundamental. No entanto, apesar de sua relevância dentro do contexto de elaboração de material didático, a maioria dos trabalhos envolvendo a identificação de requisitos para o desenvolvimento instrucional concentra-se em aspectos gerais, não abordando especificamente a atividade de modelagem. 
No estudo desenvolvido por Campos (Campos, 1994; Campos et al., 1999), por exemplo, são propostos requisitos genéricos para avaliação da qualidade de sistemas hipertexto/hipermídia educacionais. Características associadas a ambientes educacionais também são consideradas. Nessa mesma linha, Britain (1999) identifica uma série de requisitos para avaliação e comparação de ambientes educacionais, propondo uma metodologia de avaliação pedagógica para ambientes de aprendizado virtual. Papatheodorou et al. (1998) propõem um framework para avaliação de sistemas de gerenciamento e desenvolvimento de aplicações hipermídia. Paiva (2001), por sua vez, estabelece um conjunto de requisitos para sistemas de autoria hipermídia educacional dos quais fazem parte aspectos associados à geração de material didático. Tais aspectos, entretanto, também não abordam questões pertinentes à modelagem de conteúdos.

Dentro do contexto apresentado, duas questões podem ser levantadas: (1) que requisitos devem ser considerados na modelagem de conteúdos educacionais; e (2) como avaliar a adequação de um dado modelo no tratamento de aspectos associados à modelagem de tais conteúdos. A fim de investigar essas questões, nesta seção é proposto um conjunto de nove requisitos especificamente voltados à atividade de modelagem: taxonomia de conceitos, composição de conceitos, relacionamentos específicos, decomposição hierárquica, diferenciação entre categorias do conhecimento, ordem pedagógica, contextos de aprendizado, história, e propagação de eventos.

Os requisitos são definidos procurando levar em consideração as perpectivas de desenvolvimento de módulos educacionais discutidas na Seção 3.2 e têm como principal objetivo fornecer apoio na análise de modelos para representação de conteúdos educacionais. Ressalta-se ainda que o conjunto de requisitos proposto constitui uma das contribuições decorrentes do presente trabalho de doutorado. Os requisitos identificados são brevemente descritos a seguir.

\section{- Taxonomia de Conceitos}

De acordo com a Teoria da Aprendizagem Significativa, proposta por Ausubel et al. (1978), o aprendizado ocorre, principalmente, por meio de dois princípios: diferenciação progressiva e reconciliação integrativa. Na diferenciação progressiva, um conceito genérico é progressivamente diferenciado em termos de detalhe e especificidade. Na reconciliação integrativa, conceitos previamente estudados são percebidos como elementos de um conceito mais amplo, mais inclusivo, sendo então integrados por um conceito mais genérico.

Conforme observado por Novak (1981), tais princípios estabelecem uma estrutura conceitual hierárquica, a qual pode ser empregada como base para a definição e organização das informações relevantes do domínio de conhecimento. Mapas Conceituais (Moreira \& Buchweitz, 1987; Novak, 1981; Novak \& Gowin, 1984; Novak, 1990), vistos como ferramentas importantes na estruturação do conhecimento, estão fundamentados sob a noção de representação hierárquica do conhecimento, tendo sido criados na tentativa de interpretar e ilustrar a teoria proposta por Ausubel.

Dada a importância do estabelecimento de representações hierárquicas envolvendo os conceitos pertinentes ao domínio de conhecimento, um dos requisitos associados à modelagem 
refere-se à taxonomia de conceitos, representada por meio de relacionamentos de classificação (type-of). De fato, tais relacionamentos são responsáveis por associar conceitos genéricos a conceitos mais específicos, sendo considerados como um dos recursos mais utilizados para estruturar cientificamente o conhecimento (Pimentel, 1997).

\section{- Composição de Conceitos}

Alguns conceitos são melhor compreendidos quando analisados em função de suas partes (Pimentel, 1997). Desse modo, relacionamentos de composição (part-of), responsáveis por indicar que um dado conceito é composto por outros, também constituem mecanismos de apoio à estruturação e representação das informações relevantes do domínio de conhecimento.

\section{- Relacionamentos Específicos}

Além dos relacionamentos de classificação (taxonomia) e de composição, aplicáveis em quaisquer domínios de conhecimento, relacionamentos específicos, com semântica própria e dependente do domínio sendo modelado, também são essenciais na representação do conhecimento, facilitando a compreensão do assunto que se deseja ensinar.

É importante observar que a utilização de relacionamentos específicos, sem uma semântica pré-definida, faz com que os modelos construídos sejam bastante flexíveis na representação do domínio de conhecimento. Embora tal flexibilidade seja relevante na representação e compreensão do domínio, esta também pode levar a ambigüidades e inconsistências. Nesse sentido, é fundamental que relacionamentos específicos sejam definidos de forma clara e concisa, tomando os devidos cuidados para que sua utilização não resulte em modelos obscuros, de difícil compreensão.

\section{- Decomposição Hierárquica (Modularização)}

A representação de diversos conceitos e relacionamentos em um único espaço pode tornar a representação do domínio de conhecimento praticamente ilegível. Nessa perspectiva, o agrupamento de conceitos em módulos possibilita a quebra do modelo, permitindo que o conhecimento seja analisado em partes, facilitando sua leitura e compreensão.

Módulos são construídos a partir da utilização de mecanismos de decomposição hierárquica: partes do domínio que correspondem a elementos mais gerais, mais inclusivos, são decompostas em elementos mais específicos, criando assim uma hierarquia entre eles. Observa-se que, da mesma forma que a taxonomia de conceitos, a decomposição hierárquica também é baseada nos princípios propostos por Ausubel et al. (1978). A principal diferença está no fato de que a idéia de taxonomia é aplicável no nível de conceitos isolados enquanto a decomposição hierárquica envolve conjuntos (grupos) de conceitos.

A decomposição hierárquica permite abordar o domínio de conhecimento em vários níveis de abstração (profundidade) e granularidade. À medida em que os níveis de abstração au- 
mentam, podem-se explorar os diferentes níveis de granularidade, tanto no que se refere à estruturação das informações como no que diz respeito à definição das seqüências de apresentação entre elas. No último caso, a decomposição hierárquica é utilizada como apoio na especificação de diferentes contextos de aprendizado, relevantes para o reuso do conhecimento.

\section{- Diferenciação entre Categorias do Conhecimento}

Além de conceitos, outros tipos de informação podem ser tratados como parte do conteúdo educacional. Várias teorias e técnicas discutem a categorização do conhecimento, classificando a informação sob diferentes perspectivas (Merril, 1983; Michener, 1978; Horn, 1989). Merril (1983), por exemplo, propõe a teoria Component Display Theory, a qual estabelece que o aprendizado pode ser classificado em duas dimensões - conteúdo e desempenho (performance -, sendo o conteúdo caracterizado nos seguintes tipos de informação:

- Fato: Partes de informação logicamente associadas. Nomes, datas e eventos são exemplos de fatos.

- Conceito: Símbolos, eventos e objetos que compartilham características e são identificados pelo mesmo nome. Constituem grande parte da linguagem e seu entendimento é essencial para a comunicação.

- Procedimento: Conjunto ordenado de passos, que visam a resolver um problema ou atingir um objetivo.

- Princípio: Explicações e deduções sobre o porquê de determinados acontecimentos e das maneiras específicas com que os mesmos ocorrem.

A diferenciação entre categorias de conhecimento também é discutida no Modelo de Michener (Michener, 1978). Em seu trabalho, Michener identifica três categorias fundamentais do conhecimento matemático, fornecendo ainda uma estrutura para cada categoria e discutindo as associações entre elas:

- Conceito: Refere-se às definições e aos princípios matemáticos.

- Resultado: Refere-se aos aspectos lógicos tradicionais da Matemática, isto é, aos teoremas e suas provas.

- Exemplo: Contém o material ilustrativo.

Embora o Modelo de Michener tenha sido proposto originalmente para representar o conhecimento matemático, é importante salientar que suas idéias podem ser estendidas para diferentes domínios (Pansanato \& Nunes, 1999).

Ainda, a técnica de Mapeamento de Informações (Horn, 1989) também aborda aspectos pertinentes à diferenciação entre categorias de conhecimento. Em linhas gerais, a técnica 
consiste em dividir um determinado assunto em porções menores, que sejam facilmente entendidas pelo aprendiz, denominadas mapas de informação. Cada mapa trata de um único aspecto do tópico ao qual pertence. Sete mapas de informação são estabelecidos: Conceito, Classificação, Estrutura, Fato, Princípio, Procedimento, e Processo.

Um mapa, por sua vez, é formado por unidades indivisíveis chamadas blocos. Um bloco corresponde à menor porção de informação que se pode ter acesso individualmente e contém informação de apenas um tipo. Como exemplos de blocos de informação têm-se: Definição, Exemplo, Diagrama de Blocos, Lista de Classificação, Fórmula, Regra, Teorema, Sinônimo, Diagrama, entre outros.

De acordo com Horn (1989), o Mapeamento de Informações possibilita a criação de conteúdos livres de redundância, nos quais cada informação é criteriosamente classificada e armazenada em seu devido lugar.

Independentemente da teoria ou técnica utilizada, é importante que as categorias de conhecimento sejam bem diferenciadas, sendo representadas sem ambigüidades.

A diferenciação entre categorias do conhecimento pode ser vista como um tipo particular de requisito envolvendo a qualificação dos componentes do material didático (Paiva, 2001). Nesse caso, os componentes são diferenciados (qualificados) a partir da função instrucional que desempenham (conceito, exemplo, exercício, avaliação, complemento, etc.). Outros critérios para qualificação, tais como grau de dificuldade (fácil, médio, difícil) e tipo de mídia (texto, áudio, vídeo, animação), também poderiam ser incorporados às categorias de conhecimento estabelecidas.

Ressalta-se que a categorização do conhecimento aborda as perspectivas de estruturação, evolução, transferência e reuso. De fato, a diferenciação das categorias de conhecimento: (1) possibilita maior compreensão do domínio; (2) facilita a identificação dos elementos passíveis de evolução; (3) fornece suporte à criação de contextos de aprendizado; e (4) permite que ferramentas educacionais também sejam consideradas e representadas durante a modelagem.

\section{- Ordem Pedagógica}

A sequiência em que as informações devem ser apresentadas constitui um aspecto fundamental na elaboração dos conteúdos educacionais. A idéia de ordem pedagógica refere-se ao estabelecimento de precedências e relacionamentos didáticos entre as informações, podendo representar simplesmente uma preferência na seqüência de apresentação das mesmas ou, ainda, que a seqüência é pedagogicamente necessária para o aprendizado, estabelecendo assim a idéia de pré-requisitos entre as informações (Pansanato \& Nunes, 1999).

Relacionamentos de ordem pedagógica devem ser definidos com base em aspectos tais como o perfil dos aprendizes, objetivos de aprendizado e estratégia pedagógica adotada. Nessa perspectiva, o estabelecimento de seqüências de apresentação das informações é importante 
não apenas para a estruturação do conhecimento, mas também no que se refere ao reuso, sendo utilizado como apoio no estabelecimento de contextos de ensino e treinamento diferenciados.

É importante observar, entretanto, que tais sequiências devem ser definidas de modo a não comprometer a liberdade do aprendiz na exploração das informações. Em outras palavras, a natureza exploratória, própria aos conteúdos educacionais, deve ser levada em consideração na especificação das relações de ordem pedagógica.

\section{- Contextos de Aprendizado}

Contextos de aprendizado são especificados a fim de permitir que aprendizes com perfis e objetivos distintos tenham acesso ao mesmo material didático por meio de perspectivas de ensino e treinamento diferenciadas.

É importante observar que os requisitos de ordem pedagógica e contextos de aprendizado estão intrinsicamente relacionados. De fato, cada seqüência de apresentação estabelecida entre os elementos do domínio de conhecimento pode ser vista como um contexto de aprendizado específico.

Ressalta-se, ainda, que estruturas de acesso (tais como índices, roteiros e visitas guiadas), representando maneiras alternativas de acesso às informações, também constituem mecanismos de apoio no estabelecimento de contextos de aprendizado. Nesse sentido, é interessante que tais recursos estejam disponíveis nos modelos utilizados.

\section{- História}

Existem situações nas quais os contextos de aprendizado anteriormente visitados precisam ser recuperados. Por exemplo, suponha que o aprendiz esteja navegando por conteúdos teóricos e, em determinado ponto, seja possível exercitar os conhecimentos até então adquiridos por meio da resolução de um problema. Nesse caso pode haver uma mudança de contexto, fazendo com que o aprendiz passe a navegar não através de conceitos e informações teóricas, mas por exercícios e problemas. Resolvido o problema proposto, o aprendiz deve retomar seu contexto original, dando continuidade à exploração da teoria associada ao domínio de conhecimento. Mecanismos de história, tais como os definidos por Harel (1987) na técnica Statecharts, podem ser explorados visando a modelar esse tipo de situação.

Recursos de história também são úteis quando se deseja "lembrar" (armazenar) os caminhos percorridos pelo aprendiz durante a utilização do material. Como conseqüência, aspectos referentes à avaliação e acompanhamento do aprendiz podem ser beneficiados a partir de tais mecanismos (Leiva, 2003).

Por fim, o uso de história permite uma considerável diminuição do número de transições na especificação dos modelos, possibilitando reduzir a complexidade na representação do domínio de conhecimento (Turine et al., 1997; Turine, 1998). No caso de hiperdocumentos 
educacionais em que, geralmente, a quantidade de conceitos e informações complementares inter-relacionadas é grande, a ausência de mecanismos de história pode levar à explosão do número de transições (relacionamentos) representadas nos modelos pertinentes.

\section{- Propagação de Eventos (Broadcast)}

Conforme discutido anteriormente, conteúdos educacionais podem ser constituídos por diferentes tipos de mídia: texto, áudio, vídeo, animação, entre outros. Um problema típico associado à diversidade de mídias e que pode causar impactos negativos na qualidade do material e no próprio desempenho dos aprendizes é a falta/perda de sincronismo entre as mídias.

Mecanismos de propagação de eventos (broadcast) podem ser explorados, potencialmente, para fornecer suporte à sincronização em diversos tipos de aplicações multimídia (Turine, 1998). Por exemplo, um vídeo que termina antes de seu áudio pode gerar um sinal para finalizar a apresentação do áudio e avançar para outras partes do conteúdo. Nesse sentido, aspectos referentes à concorrência e sincronização de mídias, incluindo mecanismos de propagação de eventos, mostram-se relevantes no contexto da modelagem de conteúdos educacionais, devendo ser considerados na comparação e seleção dos modelos.

A Tabela 3.1 sintetiza os requisitos para modelagem de conteúdos propostos, ilustrando sua adequação em relação às perspectivas de desenvolvimento de módulos educacionais discutidas na Seção 3.2. É interessante observar que, embora a maioria dos requisitos identificados enfatizem a estruturação e o reuso do conhecimento, as perspectivas de evolução e transferência, por estarem intrinsicamente relacionadas, também podem ser indiretamente beneficiadas.

Tabela 3.1: Requisitos para Modelagem de Conteúdos x Perspectivas de Desenvolvimento de Módulos Educacionais.

\begin{tabular}{||l||l||}
\hline \hline \multicolumn{1}{|l||}{ Requisitos de Modelagem } & Perspectivas de Desenvolvimento \\
\hline \hline Taxonomia de Conceitos & Estruturação \\
\hline Composição de Conceitos & Estruturação \\
\hline Relacionamentos Específicos & Estruturação \\
\hline Decomposição Hierárquica & Estruturacão, Reuso \\
\hline Diferenciação entre Categorias do Conhecimento & Estruturação, Evolução, Transferência, Reuso \\
\hline Ordem Pedagógica & Estruturação, Reuso \\
\hline Contextos de Aprendizado & Estruturação, Reuso \\
\hline História & Estruturação, Reuso \\
\hline Propagação de Eventos & Evolução, Reuso \\
\hline \hline
\end{tabular}

Ressalta-se que os requisitos identificados também podem ser investigados no escopo de requisitos mais genéricos, os quais tratam a construção de material didático de maneira ampla e abrangente. Por exemplo, no trabalho de Paiva (2001) foi proposta uma série de requisitos para sistemas de autoria hipermídia educacional. Tais requisitos foram agrupados em categorias, havendo uma categoria exclusivamente voltada à geração de material didático. Os requisitos dessa 
categoria abordam aspectos genéricos (recursos que possibilitam a prototipação do material, recursos que permitem o uso de abordagens de desenvolvimento bottom up e top down, entre outros), sem tratar de atividades específicas como a modelagem de conteúdos. De fato, os requisitos de modelagem identificados nesta seção podem ser investigados no contexto dessa categoria de requisitos, possibilitando que aspectos gerais referentes à geração de material didático também sejam tratados.

Além dos requisitos apresentados, perspectivas de modelagem também foram identificadas e investigadas visando a caracterizar os modelos para representação de conteúdos educacionais. Na próxima seção, tais perspectivas são ilustradas e discutidas em termos de modelos genéricos envolvendo a representação de conteúdos.

\subsection{Modelos Genéricos para Representação de Conteú- dos Educacionais}

Assim como requisitos de modelagem auxiliam na construção, comparação, avaliação e seleção de modelos para representação de conteúdos educacionais, perspectivas de modelagem apóiam a caracterização dos modelos a serem utilizados.

De modo geral, conteúdos educacionais podem ser caracterizados a partir da descrição de conceitos e informações relevantes sobre o domínio de conhecimento, somadas a exemplos, explicações adicionais, exercícios, problemas, sugestões de estudo, avaliações, entre outros elementos complementares associados (Barbosa et al., 2002; Mayorga et al., 1999). A partir dessa definição, três perspectivas correlatas de modelagem de conteúdos foram identificadas neste trabalho:

- Perspectiva Conceitual: Trata especificamente da modelagem dos conceitos relevantes do domínio de conhecimento e da forma com que tais conceitos se inter-relacionam nesse domínio.

- Perspectiva Instrucional: Aborda a modelagem de informações adicionais (fatos, princípios, procedimentos) e elementos complementares (exemplos, exercícios, avaliações, etc.) sobre o domínio. Juntamente com os conceitos, tratados na perspectiva conceitual, informações adicionais e elementos complementares compõem o conteúdo educacional.

- Perspectiva Didática: É responsável por associar os objetos anteriormente modelados, estabelecendo uma sequiência de apresentação entre eles. Para isso, devem ser considerados aspectos tais como a estratégia pedagógica adotada pelo instrutor/mediador, os objetivos de aprendizado e o perfil dos aprendizes, entre outros.

A Tabela 3.2 ilustra a relação entre as perspectivas de modelagem definidas e os requisitos propostos. 
Tabela 3.2: Perspectivas e Requisitos para Modelagem de Conteúdos Educacionais.

\begin{tabular}{||l||l||}
\hline \hline Perspectivas de Modelagem & Requisitos de Modelagem \\
\hline \hline \multirow{4}{*}{ Conceitual } & Taxonomia de Conceitos \\
\cline { 2 - 3 } & Composição de Conceitos \\
\cline { 2 - 3 } & Relacionamentos Específicos \\
\cline { 2 - 3 } & Decomposição Hierárquica \\
\hline \hline Instrucional & Diferenciação entre Categorias do Conhecimento \\
\hline \hline \multirow{4}{*}{ Didática } & Ordem Pedagógica \\
\cline { 2 - 3 } & Contextos de Aprendizado \\
\cline { 2 - 3 } & História \\
\cline { 2 - 2 } & Propagação de Eventos \\
\hline \hline
\end{tabular}

A partir das perspectivas identificadas e levando em consideração os requisitos de modelagem estabelecidos anteriormente, um conjunto de modelos genéricos para a representação de conteúdos educacionais foi caracterizado - Modelo Conceitual, Modelo Instrucional e Modelo Didático. Cada modelo aborda questões específicas do processo de desenvolvimento de módulos educacionais, devendo ser construído de maneira integrada e iterativa em relação aos demais.

Ressalta-se que os modelos genéricos propostos podem ser aplicados diretamente na construção de representações sobre o conteúdo educacional ou, ainda, atuarem como parâmetros de comparação para as abordagens de modelagem existentes. A seguir, uma visão geral de cada um desses modelos é apresentada.

\subsubsection{Modelo Conceitual}

O modelo conceitual consiste em uma descrição de alto-nível do domínio que se deseja ensinar, tratando basicamente de aspectos relativos à estruturação do conhecimento. Em linhas gerais, sua construção envolve a definição dos conceitos relevantes para a compreensão do domínio e a forma com que estes se inter-relacionam, e o estabelecimento de uma estrutura para a representação desses elementos.

No modelo conceitual, os elementos do domínio de conhecimento são caracterizados essencialmente em termos de conceitos. Relacionamentos entre conceitos também devem ser especificados, sendo divididos em duas classes distintas:

- Relacionamentos Estruturais: Possibilitam a realização de inferências a respeito do domínio de conhecimento. Representam uma categoria genérica de relacionamentos, independentes de domínio, podendo ainda ser pré-definidos de acordo com o modelo conceitual utilizado. Relacionamentos de classificação (type-of) e de composição (part-of) são exemplos representativos dessa classe.

- Relacionamentos Específicos do Domínio: Têm seu significado associado a um particular domínio de conhecimento, carregando semântica própria. Em outras palavras, representam relações específicas, cuja interpretação é dependente do domínio sendo modelado. 
Definidos os conceitos e os relacionamentos entre eles, esses devem ser organizados e representados de forma estruturada no modelo, visando a facilitar a compreensão e o entendimento do domínio.

Vários tipos de estruturas podem ser utilizadas na organização de informações (Turine, 1998): hierárquica, linear, rede (grafo). No contexto educacional, atenção especial é dada à estruturação hierárquica do conhecimento. Evidências nesse sentido podem ser observadas na definição dos princípios que fundamentam a Teoria da Aprendizagem Significativa (Ausubel et al., 1978), na definição e construção de Mapas Conceituais (Moreira \& Buchweitz, 1987; Gaines \& Shaw, 2003; Novak, 1981; Novak \& Gowin, 1984; Novak, 1990), e em sua ampla aceitação e utilização nas abordagens para o desenvolvimento de aplicações educacionais existentes (Kawasaki \& Fernandes, 1996; Leiva et al., 2002b; Leiva, 2003; Pansanato \& Nunes, 1999; Pimentel, 1997, 1998). Tais evidências motivaram a que o modelo conceitual genérico proposto neste trabalho enfatizasse aspectos de estruturação hierárquica como mecanismos básicos para a representação do domínio de conhecimento.

Dentro do contexto apresentado, a construção e/ou avaliação de um modelo conceitual deve levar em consideração os seguintes requisitos de modelagem:

- Taxonomia de Conceitos: O modelo deve fornecer primitivas que permitam representar relacionamentos de classificação.

- Composição de Conceitos: O modelo deve fornecer primitivas que permitam representar relacionamentos de composição.

- Relacionamentos Específicos: O modelo deve fornecer primitivas que permitam representar relacionamentos específicos, com semântica dependente do domínio.

- Decomposição Hierárquica: O modelo deve fornecer mecanismos que permitam representar a decomposição do domínio de conhecimento em hierarquias.

\section{Guidelines para Construção de Modelos Conceituais}

Como guidelines associadas ao processo de construção dos modelos conceituais têm-se:

1. Identificar, de maneira genérica, os principais tópicos (assuntos) do domínio de conhecimento que se deseja ensinar, caracterizando unidades coesivas de estudo (módulos).

2. Para cada módulo:

(a) Identificar o conceito principal referente ao módulo.

(b) Identificar os conceitos diretamente relacionados ao conceito principal. Substantivos utilizados na descrição do domínio de conhecimento podem auxiliar na identificação dos conceitos. 
(c) Identificar relacionamentos estruturais entre os conceitos selecionados.

i. Identificar relações de taxonomia (classificação). Verbos e expressões tais como é classificado em e é um tipo de associando dois conceitos podem auxiliar na determinação das relações da taxonomia.

ii. Identificar relações de composição. Verbos e expressões tais como é formado por, é composto de e pertence a associando dois conceitos podem auxiliar na identificação de tais relações.

(d) Identificar relacionamentos específicos entre os conceitos selecionados. Verbos e expressões tais como implica em, é conseqüência de, utiliza, assume, entre outras, podem auxiliar na identificação de relacionamentos específicos.

(e) Repetir os passos (2b), (2c) e (2d) até que todos os conceitos relevantes para o módulo em questão tenham sido representados.

\subsubsection{Modelo Instrucional}

Além de conceitos, uma diversidade de informações adicionais e elementos complementares também pode ser representada no contexto do domínio de conhecimento sendo modelado. O modelo instrucional tem como objetivo definir tais informações e elementos, associando-os aos conceitos previamente identificados. Nesse sentido, a construção do modelo instrucional envolve duas etapas relacionadas: (1) o refinamento do modelo conceitual; e (2) a definição de elementos instrucionais.

$\mathrm{Na}$ primeira etapa, a partir dos conceitos representados no modelo conceitual, informações adicionais associadas ao domínio de conhecimento são identificadas e especificadas no modelo instrucional. Tais informações serão referenciadas pelo termo item de informação ${ }^{1}$. Várias teorias e técnicas podem ser utilizadas a fim de apoiar o refinamento do modelo conceitual (Horn (1989); Merril (1983); Michener (1978)). Por exemplo, considerando a teoria proposta por Merril (1983), são especificados no modelo instrucional os seguintes itens de informação: conceitos (já representados no modelo conceitual), fatos, procedimentos e princípios.

A segunda etapa consiste em definir os elementos instrucionais a serem utilizados como complemento aos itens de informação previamente identificados. Tais elementos são representados a fim de melhor compreender e assimilar o domínio de conhecimento em questão. Basicamente, três categorias de elementos instrucionais foram definidas (Barbosa et al., 2002; Mayorga et al., 1999):

- Elementos Explanatórios: Correspondem a informações complementares utilizadas na explicação de um dado item de informação (exemplos, dicas, sugestões de estudo, referências).

\footnotetext{
${ }^{1}$ Neste texto, o termo item de informação será utilizado para tratar, de maneira genérica, tanto conceitos como os demais tipos de informação adicionais associadas. Tais termos apenas serão diferenciados quando tal distinção se fizer necessária.
} 
- Elementos Exploratórios: Permitem que o aprendiz "navegue" pelo domínio de conhecimento, praticando os itens de informação relacionados (exercícios guiados, simulações, hands-on de ferramentas).

- Elementos de Avaliação: Permitem que se avalie tanto o aprendiz como a efetividade do aprendizado ocorrido (avaliações diagnósticas, formativas ou somativas, na forma questões objetivas e/ou subjetivas).

Itens de informação e elementos instrucionais diferem entre si no sentido que, enquanto aqueles correspondem a partes essenciais do conteúdo educacional, estes representam elementos complementares, os quais podem ser incorporados ou não ao conteúdo, dependendo do contexto didático em que se inserem.

O modo com que os itens de informação se associam entre si, sobretudo com respeito à sua estruturação hierárquica, deve estar representado no modelo instrucional, assim como as associações entre elementos instrucionais também devem ser especificadas. Além disso, as associações entre elementos instrucionais e itens de informação também podem ser estabelecidas. É importante observar, entretanto, que tais associações são definidas de forma genérica, sem a necessidade de explicitar, nesse nível da modelagem, os relacionamentos didáticos pertinentes.

A construção e/ou avaliação de modelos instrucionais incorpora, em especial, o requisito de Diferenciação entre Categorias do Conhecimento. De fato, o modelo instrucional deve fornecer primitivas que permitam representar os diferentes tipos de informação associados ao domínio de conhecimento. Observa-se ainda que o requisito de Decomposição Hierárquica também deve ser considerado de modo a preservar a estruturação hierárquica das informações estabelecida no modelo conceitual.

\section{Guidelines para Construção de Modelos Instrucionais}

O processo de construção de modelos instrucionais pode ser realizado com o apoio das seguintes guidelines:

1. Para cada conceito representado no modelo conceitual, identificar as informações adicionais relevantes que possam ser associadas ao mesmo. Expressões associadas ao conceito caracterizando nomes, datas, eventos, conjunto de passos, etapas, deduções, entre outros elementos, podem auxiliar na identificação dos itens de informação.

2. Associar os itens de informação entre si, preservando/estabelecendo a estruturação hierárquica entre eles.

3. Para cada conceito representado no modelo conceitual, definir elementos instrucionais que possam ser associados ao mesmo. 
(a) Definir elementos explanatórios. Concentrar-se em aspectos que exemplifiquem e complementem os conceitos pertinentes ao domínio de conhecimento.

(b) Definir elementos exploratórios. Concentrar-se em aspectos que permitam explorar o domínio de conhecimento de maneira prática.

(c) Definir elementos de avaliação. Concentrar-se em aspectos que permitam avaliar o aprendizado ocorrido tanto em termos gerais, envolvendo o domínio de conhecimento como um todo, como específicos, envolvendo assuntos pontuais pertinentes ao domínio.

4. Associar os elementos instrucionais entre si, preservando/estabelecendo a estruturação hierárquica entre eles.

5. Associar, de forma genérica, os elementos instrucionais aos itens de informação pertinentes. As associações estabelecidas não precisam ser rotuladas.

\subsubsection{Modelo Didático}

A partir de um mesmo modelo instrucional, diferentes modelos didáticos podem ser derivados, sendo possível estabelecer maneiras distintas de utilização e disponibilização do mesmo conteúdo educacional. De fato, modelos didáticos correspondem a visões do modelo instrucional, representando como seus elementos serão utilizados em um dado cenário de ensino e treinamento. Nesse sentido, tais modelos permitem que o conteúdo educacional seja adaptado e reutilizado em contextos distintos, com propósitos e objetivos de aprendizado variados.

Basicamente, os modelos didáticos são responsáveis pelo estabelecimento de relações de precedência (pré-requisitos) e relacionamentos didáticos, definindo seqüências de apresentação entre os objetos caracterizados no modelo instrucional (itens de informação e elementos instrucionais). Por relacionamentos didáticos entendem-se relações tais como complementa, exemplifica, ilustra, motiva, exercita e avalia, entre outras. Estruturas de acesso, tais como índices, roteiros e visitas guiadas, também podem ser utilizadas.

Aspectos comportamentais também podem ser especificados no modelo didático. Transformações didáticas ilustram a dinâmica do conteúdo educacional, representando a forma com que o espaço didático é modificado à medida em que é percorrido pelo aprendiz, ou seja, quais informações tornam-se ativas e quais são desativadas quando um dado relacionamento é percorrido. Além disso, a especificação dos aspectos comportamentais pode auxiliar no estabelecimento de contextos dinâmicos de aprendizado, em que os elementos do contexto podem variar conforme o desempenho dos aprendizes (observado por meio de avaliações diagnósticas, formativas e somativas) (Leiva, 2003).

A partir das características discutidas é possível fazer uma analogia entre os modelos didáticos e os modelos navegacionais utilizados no projeto e desenvolvimento de aplicações hipermídia (Garzotto et al., 1993; Isakowitz et al., 1995; Pansanato \& Nunes, 1999; Pimentel, 1997; 
Schwabe \& Rossi, 1995; Turine, 1998). De fato, vários aspectos abordados nos modelos navegacionais são igualmente válidos no escopo de modelos didáticos. Por exemplo: (1) contextos de navegação correspondem a contextos de aprendizado; (2) transformações navegacionais representam a transformações didáticas; (3) nós e elos (links) correspondem às informações do domínio de conhecimento e aos relacionamentos entre elas, respectivamente; e (4) estruturas de acesso estão presentes em ambos os modelos, tendo propósitos similares.

Os modelos didáticos incorporam em sua construção os seguintes requisitos de modelagem:

- Ordem Pedagógica: O modelo deve fornecer primitivas que permitam representar relacionamentos de precedência entre as informações do domínio.

- Contextos de Aprendizado: O modelo deve dispor de recursos e mecanismos que permitam especificar diferentes contextos de aprendizado.

- História: O modelo deve fornecer primitivas que permitam recuperar contextos de aprendizado anteriormente visitados, bem como armazenar os caminhos percorridos pelo aprendiz durante a exploração do conteúdo.

- Propagação de Eventos: O modelo deve fornecer mecanismos que permitam tratar aspectos de concorrência e sincronização entre as diferentes mídias que compõem o conteúdo.

Os requisitos de Diferenciação entre Categorias do Conhecimento e Decomposição Hierárquica também devem ser considerados no modelo didático de modo a preservar a consistência e a uniformidade em relação aos modelos instrucional e conceitual previamente definidos.

Por fim, é importante ressaltar que, neste trabalho, nenhuma abordagem pedagógica específica é enfatizada ou considerada na construção e/ou avaliação dos modelos didáticos. O que se deseja, na verdade, é que o modelo didático construído e/ou avaliado disponha dos recursos necessários para representar as seqüências de apresentação estabelecidas, sendo sua aplicação conduzida de modo independente da estratégia adotada. Nesse sentido, aspectos pedagógicos envolvendo questões pertinentes a paradigmas educacionais (comportamentalismo, cognitivismo, construtivismo) (Seels \& Glasgow, 1998), domínios de aprendizado (cognitivo, afetivo, psicomotor) (Bloom et al., 1964), entre outras, devem ser estabelecidos pelo próprio instrutor/mediador e transpostos para o modelo didático por meio das seqüências de apresentação (ordem pedagógica) especificadas.

\section{Guidelines para Construção de Modelos Didáticos}

A construção de modelos didáticos pode ser apoiada pelas seguintes guidelines:

1. Definir seqüências de apresentação entre os objetos modelados. 
(a) Definir relações de precedência entre itens de informação. Concentrar-se em quais elementos constituem pré-requisitos para a compreensão das demais informações associadas. Aspectos de precedência preferencial (pré-requisitos desejáveis) e precedência necessária (pré-requisitos obrigatórios) também podem ser considerados.

(b) Definir relacionamentos didáticos entre itens de informação e elementos instrucionais. Expressões tais como complementa, exemplifica, ilustra, motiva, exercita e avalia podem auxiliar na definição dos relacionamentos didáticos.

2. A partir das seqüências de apresentação definidas nos passos (1a) e (1b), estabelecer contextos de aprendizado. Concentrar-se nos objetivos de aprendizado e no perfil dos aprendizes. Incorporar mecanismos de história e propagação de eventos, quando pertinente.

Cabe ressaltar que informações referentes às perspectivas de modelagem, aos modelos genéricos a elas associados (conceitual, instrucional e didático) e às guidelines estabelecidas para sua construção estão sintetizadas no artigo Learning Materials: Towards the Establishment of Guidelines for Domain Modeling (Barbosa et al., 2002), apresentado no ICTEM 2002 - IFIP WG 3.2 Working Conference on Informatics Curricula, Teaching Methods and Best Practice.

A seguir, os requisitos e as perspectivas identificadas são utilizados na avaliação de alguns dos modelos para representação de conteúdos educacionais existentes.

\subsection{Modelos para Representação de Conteúdos Educa- cionais: Análise e Comparação}

Nesta seção, abordagens de desenvolvimento são analisadas e comparadas com respeito à sua adequação na modelagem e representação de conteúdos educacionais. Os requisitos e perspectivas de modelagem investigados nas seções 3.3 e 3.4 constituem a base sob a qual tais avaliações são conduzidas.

Inicialmente, quatro abordagens específicas ao projeto e desenvolvimento de aplicações hipermídia educacionais são analisadas: Daphne, EHDM, MAPHE e MDE. Em seguida, são consideradas abordagens para a construção de hiperdocumentos genéricos: HDM, RMM, OOHDM, Trellis e HMBS.

É importante ressaltar que o fato das abordagens analisadas serem aplicadas no contexto de desenvolvimento de aplicações hipermídia não significa que os aspectos discutidos e investigados neste capítulo estejam restritos à modelagem de conteúdos educacionais na forma de hiperdocumentos. De fato, outros tipos de conteúdo poderiam ser tratados. Por exemplo, ao invés de hiperdocumentos, poderia ser considerado um conjunto de transparências, incluindo ligações para outros documentos-texto e incorporando vários tipos distintos de mídia. Nesse sentido, os requisitos e perspectivas de modelagem investigadas são independentes do tipo de conteúdo modelado/desenvolvido. 


\subsubsection{Abordagens para Construção de Hiperdocumentos Educacio- nais}

Apesar de sua relevância no processo de desenvolvimento instrucional, poucas são as abordagens especificamente voltadas à modelagem de conteúdos educacionais. Como exemplos de abordagens que incorporam em sua aplicação aspectos pertinentes à modelagem de conteúdos podem-se destacar: o modelo/metodologia Daphne (Kawasaki \& Fernandes, 1996), o método EHDM (Pansanato \& Nunes, 1999), a metodologia MAPHE (Pimentel, 1997, 1998) e o modelo MDE (Leiva et al., 2002b; Leiva, 2003). No Daphne, o conhecimento associado ao conteúdo educacional é modelado basicamente por meio da elaboração de Mapas Conceituais (Moreira \& Buchweitz, 1987; Novak, 1981; Novak \& Gowin, 1984; Novak, 1990). O EHDM e o MAPHE propõem um conjunto de fases e modelos, alguns deles abordando aspectos específicos de modelagem, também apoiados na construção de Mapas Conceituais, e outros associados a detalhes do projeto navegacional do hiperdocumento. O MDE incorpora aspectos de mapeamento conceitual e estabelece mecanismos de modelagem com ênfase à avaliação e ao acompanhamento do aprendiz.

\section{Modelo/Metodologia Daphne}

$\mathrm{Na}$ análise do Daphne foi considerado o domínio de conhecimento de Harmonia Musical. A Figura 3.2 ilustra o mapa conceitual elaborado a partir da aplicação do modelo/metodologia nesse domínio.

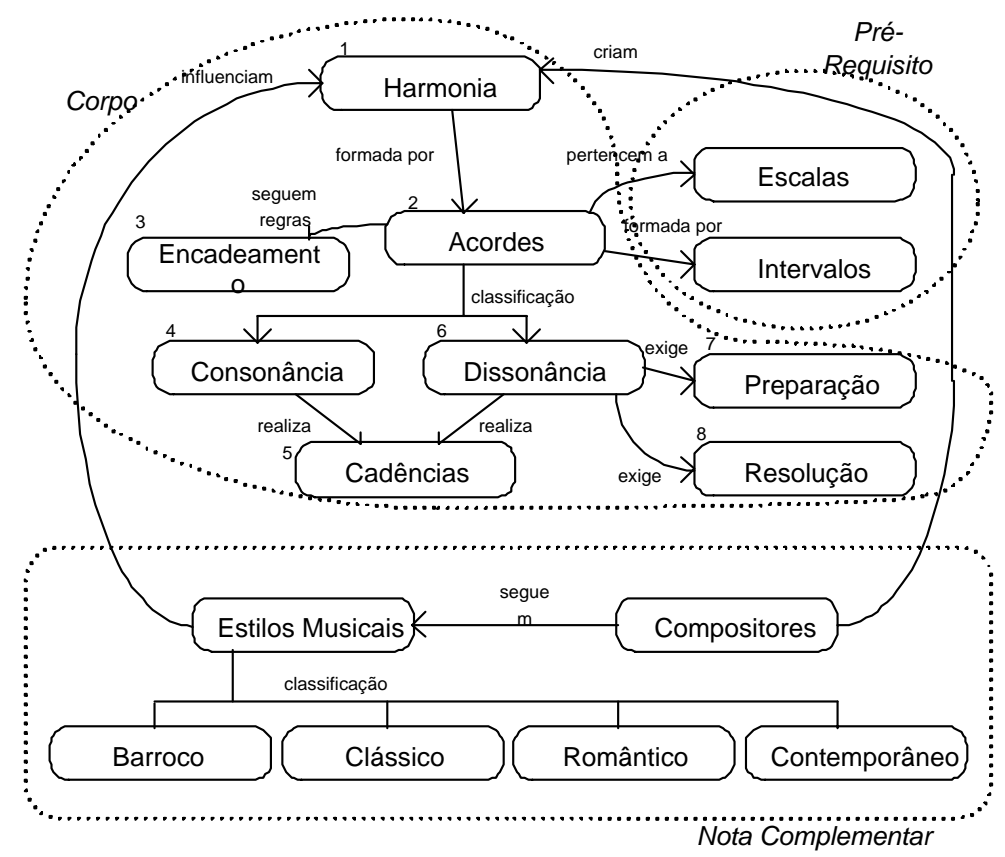

Figura 3.2: Mapa Conceitual para o Domínio de Harmonia Musical (Kawasaki \& Fernandes, 1996). 
Com respeito ao tipo de informação representada, todos os elementos presentes nos mapas conceituais definidos pelo Daphne devem ser vistos como conceitos. Observa-se, entretanto, que essa é uma restrição imposta pelo modelo. De fato, na concepção original de Mapas Conceituais (Novak, 1981) permite-se a representação tanto de conceitos como de exemplos.

No que se refere aos relacionamentos entre conceitos, o Daphne fornece ao autor total liberdade para representar e interpretar tais relações da forma que melhor lhe convier. Todos os relacionamentos são genéricos, sendo possível definir quaisquer tipos de relações entre conceitos e incorporar a elas a semântica necessária para sua compreensão, com base em características específicas do domínio sendo modelado. Nesse sentido, embora não existam relacionamentos pré-estabelecidos que correspondam às idéias de taxonomia e composição de conceitos, estas podem ser representadas definindo-se relacionamentos específicos: "classificado em" e "formado por". Por exemplo, no mapa da Figura 3.2 é possível inferir uma taxonomia para Acordes, os quais são classificados em Consonantes ou Dissonantes. O mesmo ocorre para Estilos Musicais, classificados em Barroco, Clássico, Românt ico e Contemporâneo. Já a relação formada por, estabelecida entre os conceitos Acordes e Intervalos, é utilizada para inferir idéia de composição. De fato, Acordes são compostos por um conjunto de Intervalos.

Apesar de relacionamentos específicos serem uma alternativa à representação de relacionamentos que não tenham sido pré-definidos pelo modelo, sua utilização indiscriminada pode levar a ambigüidades e insconsistências. Por exemplo, o relacionamento formada por entre os conceitos Harmonia e Acordes visa a representar que Harmonia envolve o estudo de vários outros conceitos, dentre eles o conceito de Acordes, não devendo ser interpretado com a idéia de composição.

O Daphne também não define, explicitamente, relações de ordem pedagógica entre os elementos representados em seus mapas conceituais. Alternativamente, no entanto, pode-se aplicar a linearização dos tópicos ${ }^{2}$ visando a definir uma seqüência preliminar para a apresentação dos conceitos relacionados. Seqüências de apresentação são definidas de modo específico no esquema HDM da aplicação, conforme discutido posteriormente nesta seção.

Ainda que graficamente apenas conceitos possam ser representados nos mapas conceituais do Daphne, a utilização da técnica de Mapeamento de Informações (Horn, 1989) possibilita que, em etapas posteriores da aplicação do modelo, os conceitos sejam refinados em termos de sua estrutura interna (mapas e blocos de informação). Nesse sentido, a incorporação do Mapeamento de Informações às etapas do Daphne garante que aspectos pertinentes à diferenciação entre categorias do conhecimento sejam implicitamente tratados.

É interessante observar que o mapa conceitual para Harmonia Musical foi construído a partir do refinamento de outro mapa, de nível mais abstrato - Música Clássica. De forma análoga, alguns

\footnotetext{
${ }^{2}$ Processo a partir do qual são associados números a cada conceito representado no mapa. Esse processo tem como principais objetivos: (1) indicar uma possível seqüência para elaboração dos conteúdos dos mapas de informação; e (2) proporcionar uma identificação para os mesmos à medida que forem confeccionados (Kawasaki \& Fernandes, 1996).
} 
dos conceitos de Harmonia Musical também poderiam ser detalhados em mapas mais específicos, se necessário. Na verdade, para evitar que os mapas conceituais tornem-se muitos grandes e complexos, o Daphne prevê, inicialmente, a elaboração de um mapa conceitual geral para o domínio sendo modelado e, a partir deste, mapas conceituais detalhados para cada uma de suas entidades devem ser construídos. O refinamento de mapas conceituais representa uma forma simplificada de decomposição hierárquica, constituindo um mecanismo de apoio à modularização do domínio de conhecimento sendo modelado.

Aspectos pertinentes ao estabelecimento de seqüências de apresentação e às formas de navegação (livre ou dirigida) são tratados segundo um esquema HDM. O esquema HDM da aplicação Harmonia Musical é ilustrado na Figura 3.3.

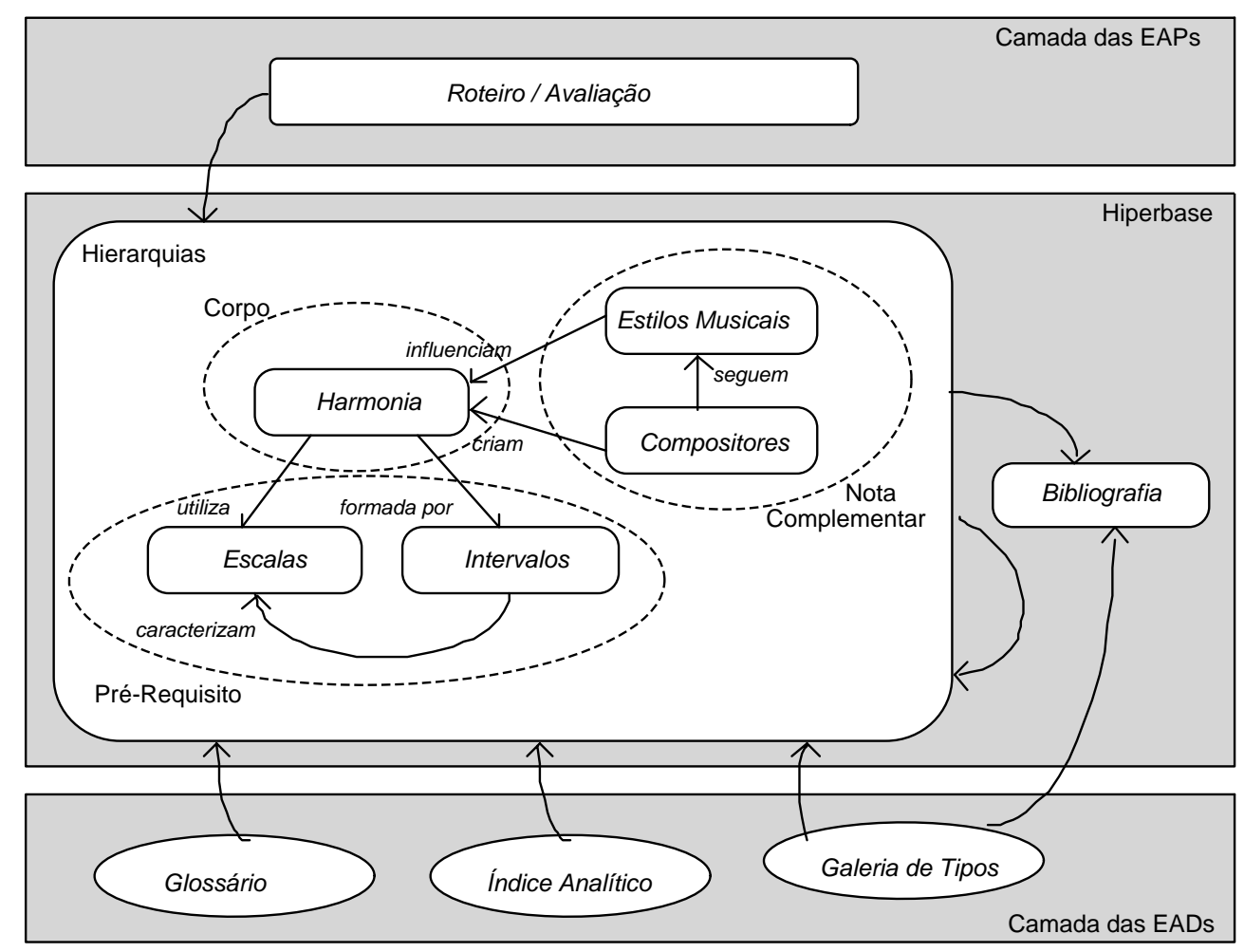

Figura 3.3: Esquema HDM para Harmonia Musical (Kawasaki \& Fernandes, 1996).

Analisado de maneira simplificada, é possível observar que, embora o HDM preserve a estruturação hierárquica das informações, defina uma semântica de navegação para o hiperdocumento, e estabeleça estruturas alternativas de acesso às informações (índices e roteiros), mecanismos de história, variáveis de controle, concorrência, sincronização e propagação de eventos não são abordados. Na verdade, os aspectos comportamentais do hiperdocumento, significativos sob a perspectiva didática das aplicações educacionais, não são enfatizados.

Além da confecção de mapas conceituais, dos mapas e blocos de informação e do esquema HDM, o Daphne também estabelece outras atividades, tais como a construção de storyboards, o projeto de EADs e o projeto de EAPs. A análise detalhada das atividades pertinentes ao modelo/metodologia vai além dos objetivos deste trabalho. Detalhes sobre a aplicação completa do 
Daphne no domínio de Harmonia Musical podem ser encontrados em (Kawasaki \& Fernandes, 1996).

A Tabela 3.3 sintetiza as principais características do modelo/metodologia Daphne, consideradas segundo os requisitos e as perspectivas para modelagem de conteúdos educacionais identificadas nas seções 3.3 e 3.4 .

Tabela 3.3: Síntese das Características do Modelo/Metodologia Daphne.

\begin{tabular}{||l|l|l|l||}
\hline \hline Perspectiva & Requisito & Adequação & Mecanismo \\
\hline \hline \multirow{3}{*}{ Conceitual } & Taxonomia de Conceitos & Adequado & Relacionamento “Classificado em” \\
\cline { 2 - 4 } & Composição de Conceitos & Adequado & Relacionamento "Formada por" \\
\cline { 2 - 4 } & Relacionamentos Específicos & Adequado & Total liberdade, sem notações específicas \\
\cline { 2 - 4 } & Decomposição Hierárquica & Adequado & Mapas Conceituais Gerais/Específicos \\
\hline \hline \multirow{2}{*}{ Instrucional } & $\begin{array}{l}\text { Diferenciação entre Categorias } \\
\text { do Conhecimento }\end{array}$ & Satisfatório & Mapas e Blocos de Informação \\
\hline \hline \multirow{3}{*}{ Didática } & Ordem Pedagógica & Satisfatório & Esquema HDM, Linearização dos Tópicos \\
\cline { 2 - 4 } & Contextos de Aprendizado & Satisfatório & Estruturas de Acesso \\
\cline { 2 - 4 } & História & Não Aborda & - \\
\cline { 2 - 4 } & Propagação de Eventos & Não Aborda & - \\
\hline \hline
\end{tabular}

Analisando a adequação do modelo/metodologia Daphne em relação às perspectivas conceitual, instrucional e didática observa-se que:

- Os mapas conceituais do Daphne correspondem essencialmente ao modelo conceitual, satisfazendo grande parte dos requisitos associados a essa perspectiva.

- O Daphne não possui correspondentes ao modelo instrucional. No entanto, a técnica de Mapeamento de Informações trata alguns aspectos associados à essa perspectiva, ainda que de forma simplificada.

- O esquema HDM corresponde ao modelo didático. Entretanto, o HDM não satisfaz completamente os requisitos identificados na perspectiva didática, sobretudo no que se refere à modelagem de aspectos comportamentais.

\section{Método EHDM}

$\mathrm{Na}$ análise do método EHDM foram considerados o Modelo Conceitual Hierárquico e o Modelo Navegacional de Contextos, ambos construídos para o domínio de conhecimento relativo à Movimentos Retilíneos.

O Modelo Conceitual Hierárquico é apresentado na Figura 3.4. Basicamente, três categorias de conhecimento são representadas: Conceito, Resultado e Exemplo. Os elementos Movimento uniforme, Velocidade, Movimento uniformemente variado e Aceleração pertencem à categoria de conceitos; os elementos Movimento da tartaruga, Carro em movimento e Carro freando pertencem à categoria de exemplos; e os elementos Equação 
horária do MU, Equações do MUV e Equação de Torricelli representam a categoria de resultados.

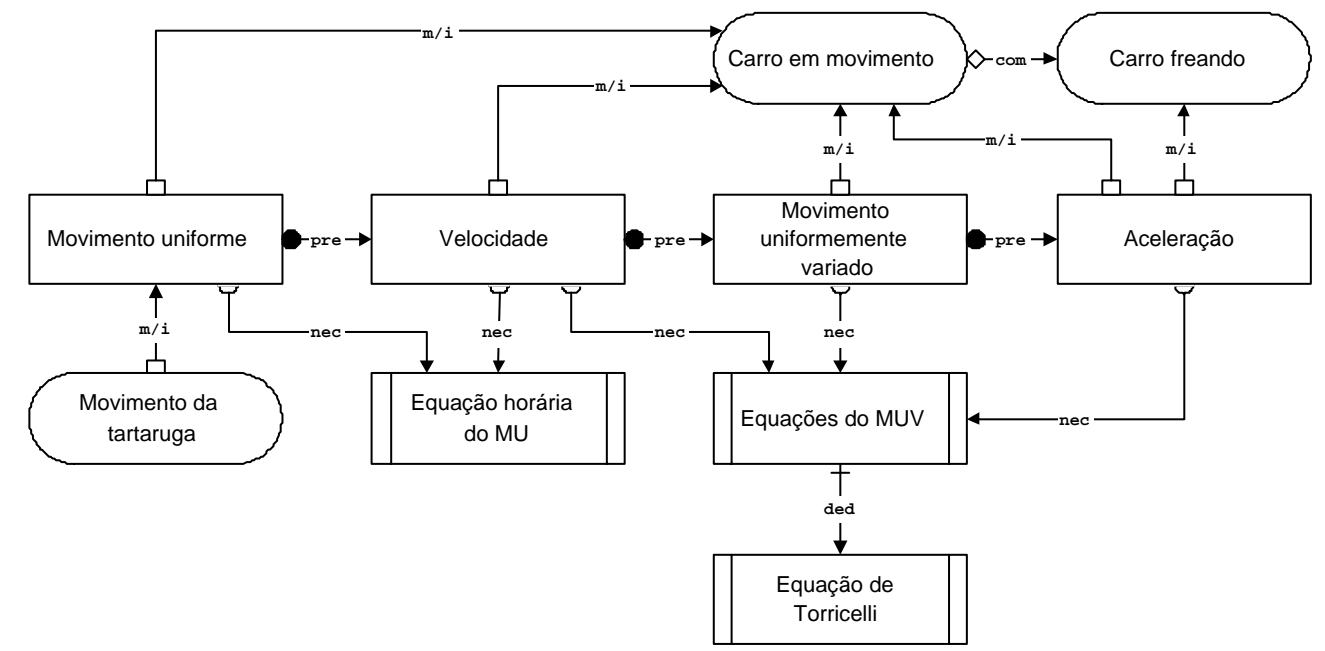

Figura 3.4: Modelo Conceitual Hierárquico para o Domínio de Movimentos Retilíneos (Pansanato \& Nunes, 1999).

Embora o Modelo Conceitual Hierárquico esteja baseado em mapas conceituais, os relacionamentos entre as categorias do conhecimento são representados por meio de um conjunto de notações mais rígidas a fim de evitar ambigüidades. Desse modo, as categorias de conhecimento são associadas segundo um número pré-determinado de relacionamentos: Precedência (Preferencial ou Necessária), Dedução, Complexidade, Motivação/Ilustração, Necessidade e Utilização.

Considerando a Figura 3.4 tem-se, por exemplo, que Movimento uniforme, Velocidade, Movimento uniformemente variado e Aceleração associam-se por meio de relações de Precedência Necessária, devendo ser apresentados nessa seqüência. Ilustra-se com isso a ordem pedagógica entre tais conceitos. Velocidade, Movimento uniformemente variado e Aceleração são conceitos necessários (relação de Necessidade) para descrever (ou provar) o resultado Equações do MUV, a partir do qual pode-se deduzir (relação de Dedução) outro resultado: Equação de Torricelli. O exemplo Carro freando é utilizado para ilustrar (relação de Ilustração) o conceito Aceleração e é mais complexo (relação de Complexidade) que o exemplo Carro em movimento.

É importante observar que o Modelo Conceitual Hierárquico não dispõe de mecanismos para representar relacionamentos de classificação e de composição entre as categorias de conhecimento.

Ainda com respeito ao Modelo Conceitual Hierárquico, ressalta-se que o EHDM também fornece um mecanismo de decomposição hierárquica, baseado no princípio da diferenciação progressiva utilizado pelos mapas conceituais. Assim, o modelo da Figura 3.4 pode ser visto como uma decomposição do domínio de Movimentos Retilíneos que, juntamente com os domínios de Movimentos de Projéteis e Movimento Circular, constituem a Teoria de Movimentos.

A Figura 3.5 ilustra o mapeamento do Modelo Conceitual Hierárquico da Figura 3.4 para um Modelo Navegacional de Contextos. Com exceção do exemplo Carro em movimento, 
cada elemento conceitual foi mapeado para um nó com um atributo. O exemplo Carro em movimento foi mapeado para um atributo nos nós correspondentes aos conceitos ou resultados aos quais ele está relacionado.
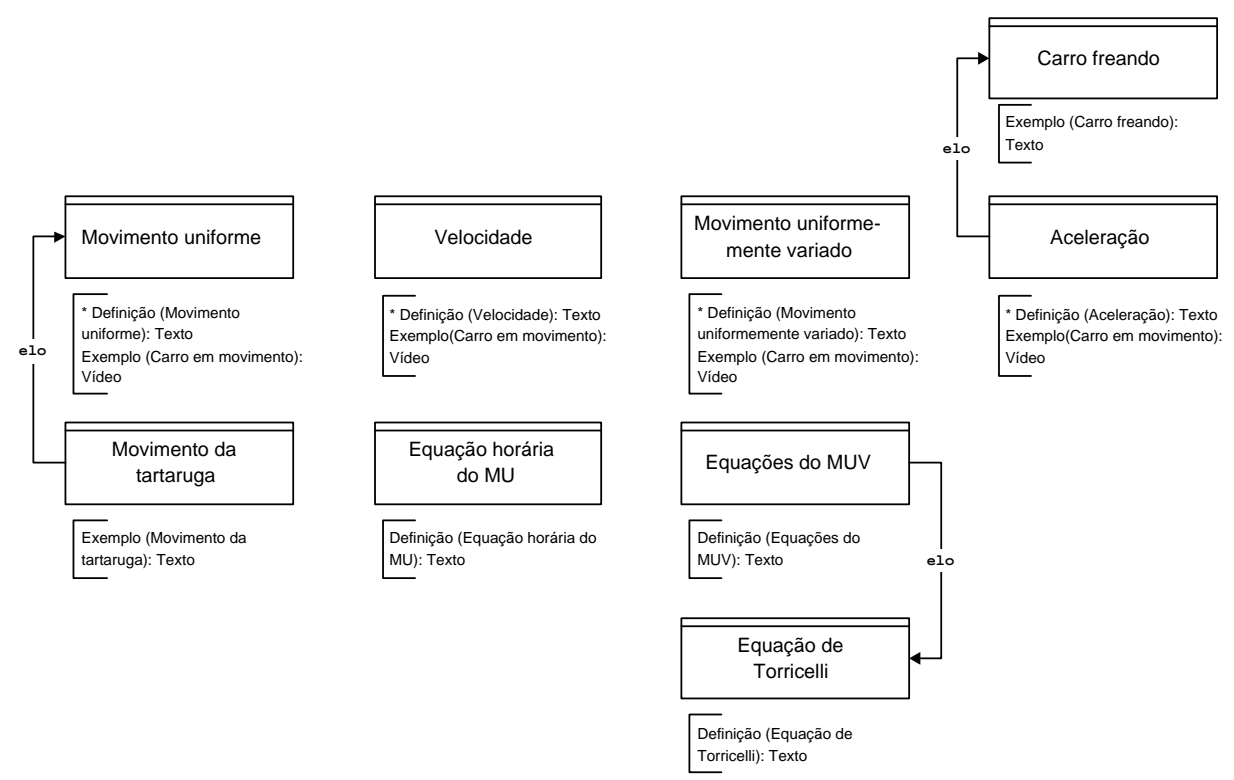

Figura 3.5: Exemplo de um Modelo Navegacional de Contextos para o Domínio de Movimentos Retilíneos (Pansanato \& Nunes, 1999).

Um aspecto importante do EHDM consiste na possibilidade de acrescentar informações adicionais ao modelo navegacional, além das representadas no modelo conceitual (Pansanato \& Nunes, 1999). Por exemplo, um elemento da categoria conceito pode ser mapeado para um nó com três atributos: o primeiro pode corresponder a uma apresentação da teoria, o segundo a um exemplo, e o último a um exercício. Além disso, cada atributo pode ser associado a um tipo (texto, imagem, áudio, vídeo, etc.), indicando a forma de apresentação da informação correspondente ao atributo.

Os atributos de um nó também podem ser divididos em duas classes: Núcleo e Satélite. Atributos da classe Núcleo representam as informações que são apresentadas quando o nó é visitado. Atributos da classe Satélite correspondem às informações que podem ser obtidas a partir das informações relativas aos atributos da classe Núcleo. Tal classificação permite especificar tanto informações essenciais para a apresentação do conteúdo como informações complementares, as quais podem ser apresentadas ou não, dependendo da necessidade do aprendiz.

Por fim, os contextos navegacionais estabelecidos pelo modelo navegacional podem conter outros contextos (aninhados), constituindo mecanismos para definir a estrutura hierárquica do hiperdocumento. Ressalta-se, ainda, que os espaços de navegação representados pelos contextos navegacionais também podem ser explorados utilizando as estruturas de acesso. De fato, as estruturas de acesso são utilizadas para proporcionar uma navegação adicional à realizada através dos elos. Assim como no Daphne, dois tipos de estrutura de acesso são fornecidos: índice e roteiro.

A aplicação completa do EHDM no domínio de Movimentos Retilíneos é discutida em (Pansanato \& Nunes, 1999). 
Na Tabela 3.4 estão sintetizadas as principais características do EHDM.

Tabela 3.4: Síntese das Características do Método EHDM.

\begin{tabular}{||c|l|l|l||}
\hline \hline Perspectiva & Requisito & Adequação & Mecanismo \\
\hline \hline \multirow{4}{*}{ Conceitual } & Taxonomia de Conceitos & Não Aborda & - \\
\cline { 2 - 4 } & Composição de Conceitos & Não Aborda & - \\
\cline { 2 - 4 } & Relacionamentos Específicos & Não Aborda & - \\
\cline { 2 - 4 } Instrucional & Decomposição Hierárquica & Adequado & Modelos Conceituais Gerais/Específicos \\
\hline \hline \multirow{3}{*}{ Didática } & $\begin{array}{l}\text { Diferenciação entre Categorias } \\
\text { do Conhecimento }\end{array}$ & Adequado & $\begin{array}{l}\text { Modelo de Michener (Conceitos, Resulta- } \\
\text { dos, Exemplos), Atributos de um Nó (Nú- } \\
\text { cleo e Satélite) }\end{array}$ \\
\hline \hline \multirow{3}{*}{} & Ordem Pedagógica & Adequado & Precedência Necessária e Preferencial \\
\cline { 2 - 4 } & Contextos de Aprendizado & Adequado & $\begin{array}{l}\text { Contextos Navegacionais, Estruturas de } \\
\text { Acesso }\end{array}$ \\
\cline { 2 - 4 } & História & Não Aborda & - \\
\cline { 2 - 4 } & Propagação de Eventos & Não Aborda & - \\
\hline \hline
\end{tabular}

Analisando o método EHDM sob as perspectivas conceitual, instrucional e didática tem-se que:

- O Modelo Conceitual Hierárquico pode ser visto como uma combinação dos modelos conceitual e instrucional. Ressalta-se, entretanto, que aspectos relevantes em termos conceituais, tais como a taxonomia e a composição de conceitos e a representação de relacionamentos específicos ao domínio, não são considerados. Por outro lado, ênfase é dada às questões instrucionais, sendo este o ponto forte do modelo.

- O Modelo Navegacional de Contextos corresponde ao modelo didático, enfatizando o estabelecimento de precedências entre conceitos e a definição de contextos navegacionais e estruturas de acesso. Aspectos comportamentais não são tratados.

\section{Metodologia MAPHE}

Na análise do MAPHE foi considerada a etapa de modelagem, dando-se ênfase à construção do Modelo Orientado a Conceitos (MOC). O domínio de conhecimento modelado foi o de Figura Plana, dentro da área de Geometria. A Figura 3.6 ilustra o MOC construído nesse domínio (Pimentel, 1998).

Todos os elementos representados no MOC são vistos como conceitos, os quais podem ser comparados às classes em orientação a objetos. A maneira pela qual dois conceitos se relacionam é representada por meio de relacionamentos pré-definidos: Classificação, Agregação, Posse, Igualdade, Diferença e Associação.

Os relacionamentos de Classificação correspondem aos relacionamentos de Herança em OO e podem ser agrupados de acordo com um dado critério, permitindo a diferenciação do conceito genérico em seus conceitos específicos. Herança múltipla, presente em OO, não é permitida no MOC. Considerando o MOC da Figura 3.6, o conceito Círculo é classificado como 


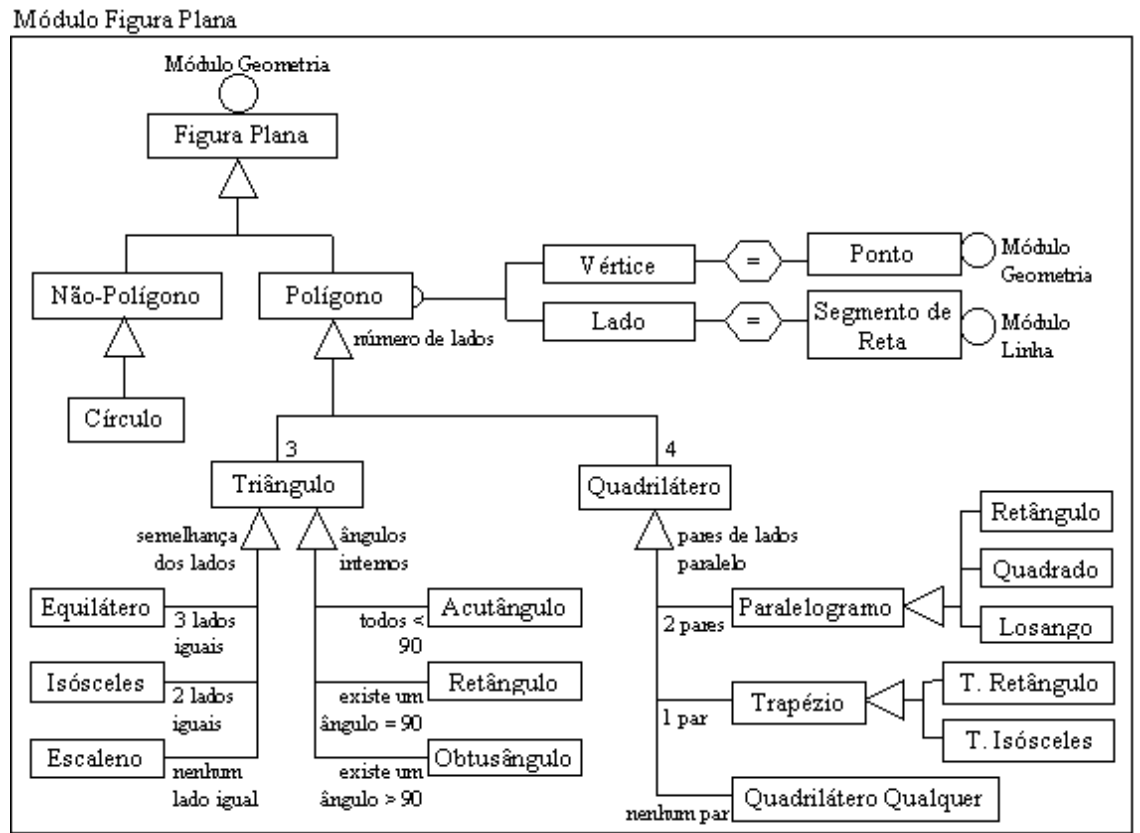

Figura 3.6: Modelo Orientado a Conceitos para o Domínio de Figura Plana (Pimentel, 1998).

um Não-Polígono enquanto os conceitos Triângulo e Quadrilátero são classificados como Polígonos. Triângulo, por sua vez, é classificado segundo dois critérios distintos: semelhança dos lados e ângulos internos. Quadri látero é classificado conforme o número de pares paralelos.

Os relacionamentos de Igualdade e Diferença não possuem correspondentes em OO. Os relacionamentos de Agregação, Posse e Associação são idênticos aos existentes em $\mathrm{OO}$ e utilizados da mesma forma. Este último trata-se de um relacionamento de uso genérico no qual, por não haver uma interpretação pré-estabelecida, explicita-se a hipótese considerada, garantindo com isso uma certa flexibilidade na representação das relações entre conceitos. Segundo Pimentel Pimentel (1997), no entanto, o relacionamento de associação é considerado fraco na estruturação do conhecimento, devendo, sempre que possível, ser substituído por outro mais forte.

Ainda de acordo com a Figura 3.6, os conceitos Ponto e Segmento de Reta, embora sejam referenciados em Figura Plana, não pertencem a esse módulo, devendo ser estudados nos módulos Geometria e Linha, respectivamente. Na verdade, o MAPHE permite o agrupamento de conceitos em módulos, fornecendo uma primitiva gráfica específica no MOC para representar, dentro de cada módulo, o relacionamento deste com os demais módulos do domínio. Considerando o domínio de Geometria, outros módulos existentes, além de Figura Plana, seriam Linha e Sólido Geométrico.

O Modelo de Páginas, também construído na etapa de modelagem, define a navegação em ponto pequeno do hiperdocumento, podendo ter correspondência direta ou não com o MOC (Pimentel, 1997). No último caso, embora as páginas não resultem diretamente do MOC, este serve para organizá-las, permitindo que o autor/desenvolvedor reflita a respeito da complexidade con- 
ceitual do domínio de conhecimento em questão. A liberdade de mapeamento do MOC para o Modelo de Páginas possibilita que diferentes contextos de aprendizado sejam estabelecidos a partir do mesmo modelo conceitual.

O MAPHE também permite estruturar a navegação em ponto grande por meio da implementação de índices e visitas guiadas. Tais aspectos são tratados no modelo de Ferramentas Navegacionais.

A modelagem completa do domínio de conhecimento associado à Geometria, incluindo os conceitos referentes a Ponto, Linha, Figura Plana e Sólido Geométrico, é apresentada em (Pimentel, 1998).

Na Tabela 3.5 são sintetizadas as principais características do MAPHE (etapa de modelagem).

Tabela 3.5: Síntese das Características da Metodologia MAPHE.

\begin{tabular}{||l|l|l|l||}
\hline \hline Perspectiva & Requisito & Adequação & Mecanismo \\
\hline \hline \multirow{4}{*}{ Conceitual } & Taxonomia de Conceitos & Adequado & Relacionamento de Classificação \\
\cline { 2 - 4 } & Composição de Conceitos & Adequado & Relacionamento de Agregação \\
\cline { 2 - 4 } & Relacionamentos Específicos & Adequado & Relacionamento de Associação \\
\cline { 2 - 4 } & Decomposição Hierárquica & Adequado & $\begin{array}{l}\text { Mapas Conceituais Gerais/Específicos, } \\
\text { Notação para Módulos }\end{array}$ \\
\hline \hline \multirow{3}{*}{ Instrucional } & $\begin{array}{l}\text { Diferenciação entre Categorias } \\
\text { de Conhecimento }\end{array}$ & Não Aborda & - \\
\hline \hline \multirow{3}{*}{ Didática } & Ordem Pedagógica & Não Aborda & - \\
\cline { 2 - 4 } & Contextos de Aprendizado & Satisfatório & Estruturas de Navegação \\
\cline { 2 - 4 } & História & Não Aborda & - \\
\cline { 2 - 4 } & Propagação de Eventos & Não Aborda & - \\
\hline
\end{tabular}

Analisando o MAPHE sob as perspectivas conceitual, instrucional e didática observa-se que:

- O Modelo Orientado a Conceitos corresponde ao modelo conceitual, satisfazendo adequadamente os requisitos dessa perspectiva. Ressalta-se, entretanto, que o excesso de relacionamentos pré-definidos pode sobrecarregar o modelo.

- O MAPHE não estabelece modelos específicos que tratem de aspectos referentes à perspectiva instrucional.

- O Modelo de Páginas e Ferramentas Navegacionais correspondem ao modelo didático. No entanto, os requisitos associados à essa perspectiva são satisfeitos de maneira pouco satisfatória tendo em vista que relações de ordem pedagógica e aspectos comportamentais não são abordados.

\section{Modelo MDE}

O MDE foi analisado com respeito à modelagem e estruturação de um curso básico sobre HTML. A Figura ilustra 3.7 um possível mapa conceitual para o curso (Leiva, 2003). 


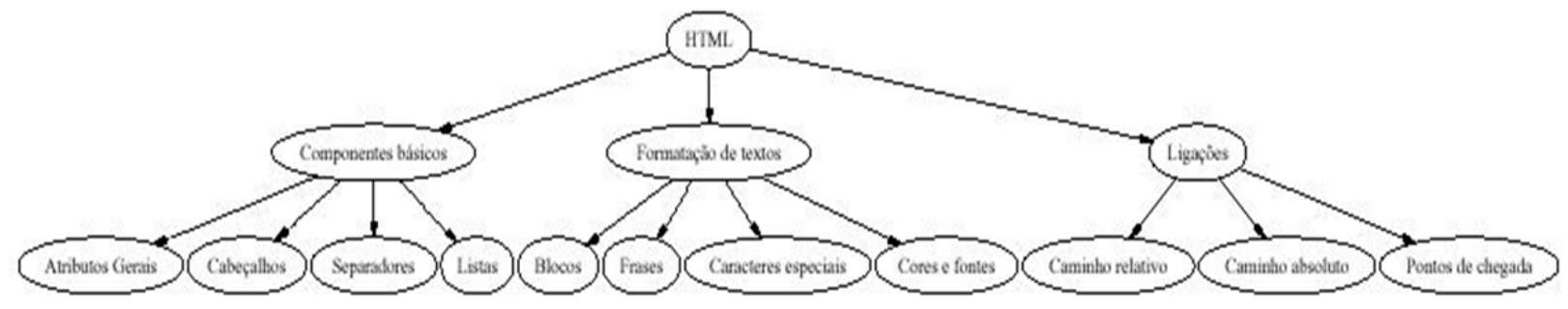

Figura 3.7: Mapa Conceitual de um Curso Básico sobre HTML (Leiva, 2003).

Todos os nós representados nos mapas conceituais definidos pelo MDE correspondem a conceitos, sendo que uma aresta entre dois nós indica que o conceito do nó-origem é mais abrangente e inclusivo do que o conceito do nó-destino. Observa-se que não são utilizados rótulos nas arestas. Isso deve-se ao fato de que no MDE todas as arestas denotam relacionamentos de composição entre conceitos. Nesse sentido, relacionamentos de classificação e relacionamentos específicos do domínio não são tratados no modelo.

Além disso, os conceitos abordados são organizados em três níveis hierárquicos - Curso, Unidades de Estudo e Tópicos -, resultando em mapas conceituais estruturados como árvores de altura igual a três. De acordo com Leiva (2003), essa simplificação na representação dos mapas justificase pela pressuposição de que é possível organizar o conteúdo de qualquer curso de maneira que seus conceitos sejam horizontalizados conforme uma estrutura de árvore em três níveis. Os autores ressaltam, entretanto, que o MDE poderia ser generalizado de modo a permitir que os mapas conceituais fossem descritos por árvores de altura superior a três.

É importante observar que os mapas conceituais elaborados de acordo com o MDE referem-se à estrutura geral do curso, visando à compreensão das idéias fundamentais abordadas no hiperdocumento. Detalhes específicos associados aos conceitos não são modelados nesse nível do modelo.

O conteúdo do curso é detalhado por meio de um modelo HMBS, cujo statechart subjacente é representado parcialmente nas figuras 3.8, 3.9 e 3.10. A Figura 3.8 representa a estrutura do curso em um nível de abstração mais alto. Ao terminar a avaliação diagnóstica (estado $A D$ ), o resultado da condição $C_{1}$ determina a partir de qual unidade de estudo (UE) o aprendiz deve iniciar o curso (Componentes Básicos, Formatação de Textos ou Ligações). Tendo finalizado a última UE do curso, o aprendiz deve realizar uma avaliação somativa (estado AS). Terminada a avaliação somativa, o resultado da condição $C_{2}$ estipula se o aprendiz foi aprovado ou não.

Em qualquer estado, exceto $A D$ e $A S$, o aprendiz pode encerrar a sessão do curso, fazendo com que o sistema ative o estado Pausa, salvando o contexto (dado pela configuração atual do statechart) no perfil do aprendiz. Além disso, o acesso às referências citadas no conteúdo do curso é habilitado pelo evento ConsultaRef, disparado quando o aprendiz seleciona uma citação bibliográfica incluída em alguma página do hiperdocumento.

A Figura 3.9 ilustra a estrutura organizacional e o conteúdo de uma possível avaliação diagnóstica do curso. Basicamente, o aprendiz inicia a avaliação pela primeira questão e, enquanto não 


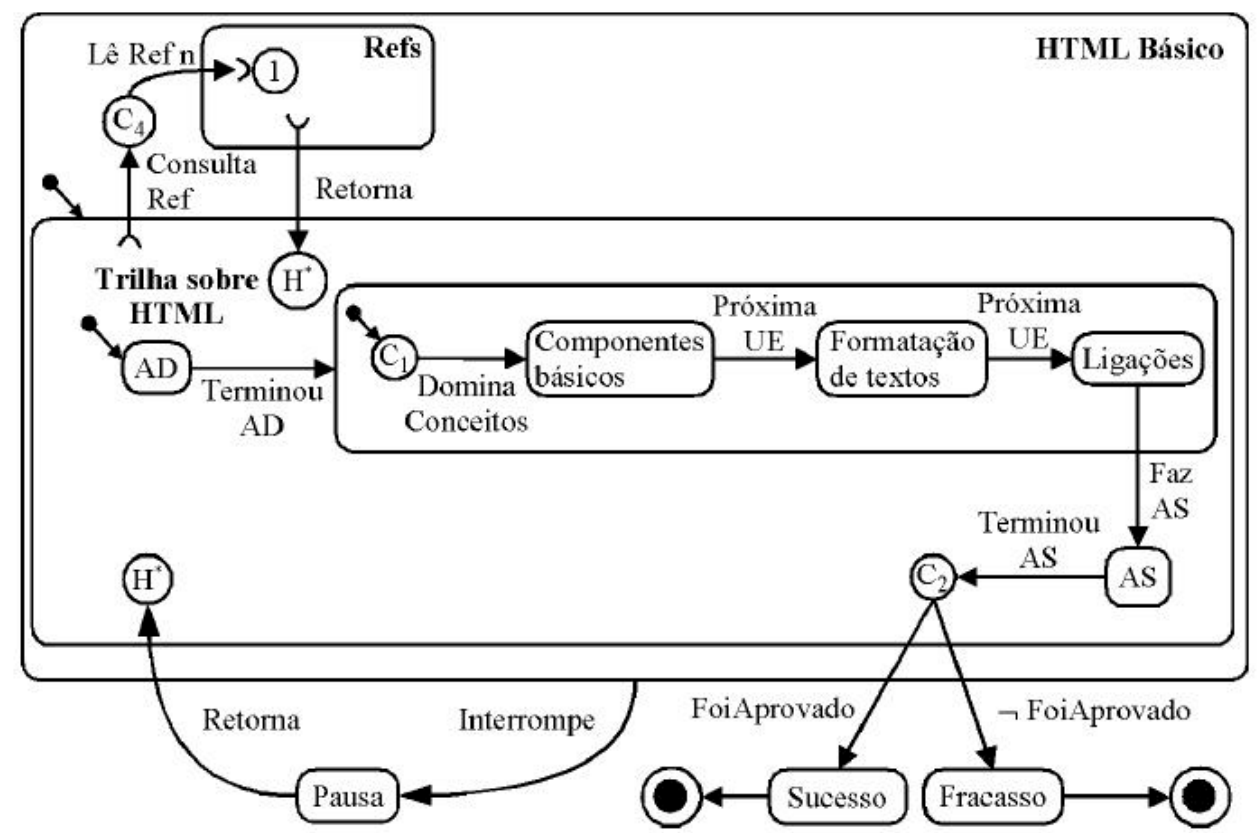

Figura 3.8: Representação Gráfica mais Abstrata do Curso sobre HTML (Leiva, 2003).

sinalizar que terminou a avaliação, pode a qualquer momento avançar para uma próxima questão ou retornar à anterior. A sinalização do término da avaliação é especificada pelo evento Terminou $A D$, representado na Figura 3.8.

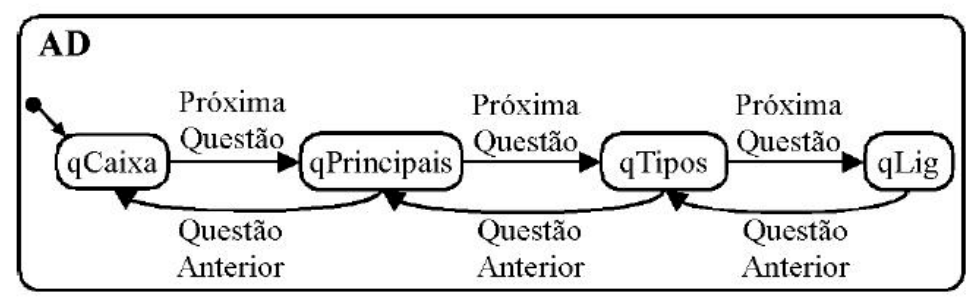

Figura 3.9: Avaliação Diagnóstica do Curso Básico sobre HTML (Leiva, 2003).

Na Figura 3.10 são ilustradas a estrutura e o conteúdo da UE Li gações. O estudo da UE começa pelo tópico inicial Caminho relativo. Terminado o estudo do tópico, o aprendiz realiza uma avaliação formativa (estado $A F_{1}$ ) associada ao mesmo. Encerrada a avaliação, o resultado da condição $C_{C R E L}$ determina se o aprendiz pode estudar o próximo tópico (Caminho absoluto) ou deve reestudar o mesmo tópico. Ao finalizar com sucesso o último tópico (Pontos de chegada) da UE, o aprendiz pode passar à UE seguinte.

De modo geral, pode-se observar que o modelo HMBS estendido pelo MDE permite a especificação de detalhes associados aos elementos de avaliação. No entanto, outras categorias importantes do conhecimento, tais como exemplos e exercícios (visando à prática dos conceitos, sem a idéia de aprovação inerente às avaliações), não são representadas. 


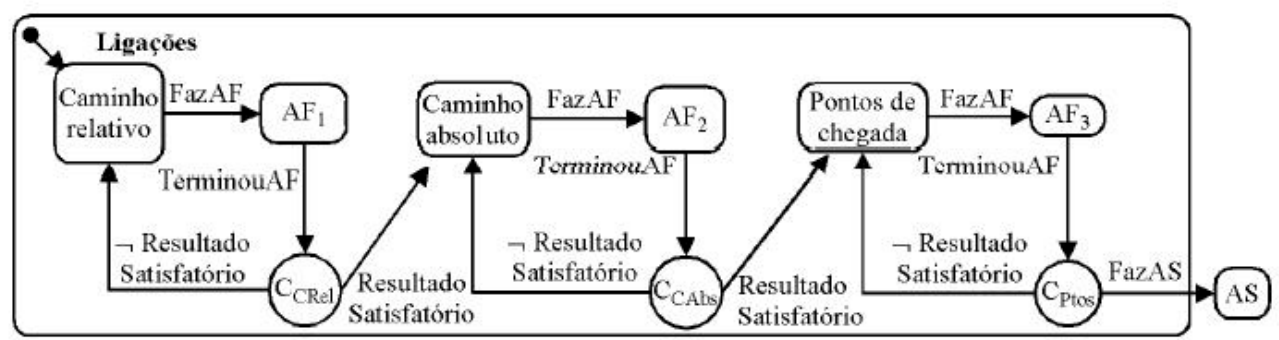

Figura 3.10: Unidade de Estudo Ligações (Leiva, 2003).

Aspectos referentes ao estabelecimento de seqüências de apresentação envolvendo unidades de estudo, tópicos, avaliações e referências bibliográficas também são especificadas por meio do modelo HMBS estendido. Além disso, a ordem das questões que compõem uma dada avaliação também pode ser modelada. É importante observar, no entanto, que as sequiências estabelecidas para as unidades de estudo e seus tópicos associados estão fortemente condicionadas aos resultados das avaliações conduzidas.

Por fim, visto que o MDE apóia-se nos formalismos da técnica de Statecharts, mecanismos de história, propagação de eventos, sincronização e concorrência estão automaticamente incorporados ao modelo.

Detalhes referentes à aplicação completa do MDE na estruturação do curso sobre HTML estão disponíveis em (Leiva et al., 2002b; Leiva, 2003).

A Tabela 3.6 sintetiza as principais características do MDE, analisadas segundo as perspectivas conceitual, instrucional e didática.

Tabela 3.6: Síntese das Características do Modelo MDE.

\begin{tabular}{||c|l|l|l||}
\hline \hline Perspectiva & Requisito & Adequação & Mecanismo \\
\hline \hline \multirow{5}{*}{ Conceitual } & Taxonomia de Conceitos & Não Aborda & - \\
\cline { 2 - 4 } & Composição de Conceitos & Adequado & $\begin{array}{l}\text { Relacionamento de Composição (implí- } \\
\text { cito) }\end{array}$ \\
\cline { 2 - 4 } & Relacionamentos Específicos & Não Aborda & - \\
\cline { 2 - 4 } & Decomposição Hierárquica & Adequado & $\begin{array}{l}\text { Mapas Conceituais (Curso, UEs, Tópicos), } \\
\text { Modelo HMBS (Estados, Mecanismos de } \\
\text { Aninhamento) }\end{array}$ \\
\hline \hline \multirow{3}{*}{ Instrucional } & $\begin{array}{l}\text { Diferenciação entre Categorias } \\
\text { de Conhecimento }\end{array}$ & Satisfatório & $\begin{array}{l}\text { Conceitos, Avaliações (Diagnóstica, So- } \\
\text { mativa, Formativa), Referências Bibliográ- } \\
\text { ficas }\end{array}$ \\
\hline \hline \multirow{3}{*}{ Didática } & Ordem Pedagógica & Satisfatório & Transições de Statecharts \\
\cline { 2 - 4 } & Contextos de Aprendizado & Satisfatório & Navegação Dirigida \\
\cline { 2 - 4 } & História & Adequado & Estabelecido pela Técnica Statecharts \\
\cline { 2 - 4 } & Propagação de Eventos & Adequado & Estabelecido pela Técnica Statecharts \\
\hline \hline
\end{tabular}

Analisando a adequação do modelo em relação às perspectivas conceitual, instrucional e didática observa-se que: 
- Os Mapas Conceituais estabelecidos pelo MDE, embora sejam adequados à estruturação geral do curso, são bastante limitados na representação de conceitos específicos e seus interrelacionamentos. O modelo HMBS referente à modelagem das unidades de estudo, apesar de representar os conceitos com maior riqueza de detalhes, especifica somente a seqüência de apresentação entre eles, sem especificar de modo explícito os relacionamentos pertinentes.

- O MDE não estabelece modelos específicos que tratem separadamente aspectos instrucionais e aspectos didáticos. Apesar disso, a representação detalhada do elementos de avaliação e sua associação às unidades de estudo e tópicos do curso aborda, de certa forma, a diferenciação entre categorias de conhecimento.

- Os aspectos didáticos são abordados no MDE por meio do estabelecimento de seqüências de apresentação, mecanismos de história e propagação de eventos. Ressalta-se, entretanto, que a forma com que as seqüências de apresentação são especificadas fazem com que a navegação pelos elementos que compõem o curso seja completamente fixa, vinculada a interesses pedagógicos previamente estabelecidos. De fato, mecanismos que possibilitem flexibilidade à navegação pelo conteúdo do curso não são abordados.

\subsubsection{Abordagens para Construção de Hiperdocumentos Genéricos}

Além das abordagens especificamente voltadas à construção de hiperdocumentos educacionais, analisadas na seção anterior, uma série de abordagens para o projeto e desenvolvimento de aplicações hipermídia genéricas pode ser identificada: HDM (Garzotto et al., 1993), RMM (Isakowitz et al., 1995), OOHDM (Schwabe \& Rossi, 1995), EORM Lange (1994), Trellis (Stotts \& Furuta, 1989), HMBS (Turine, 1998), entre outras.

A seguir, tais abordagens são brevemente analisadas sob as perspectivas e requisitos de modelagem identificados neste trabalho, com o propósito de investigar a adequação das mesmas na representação de conteúdos educacionais.

\section{HDM, RMM, OOHDM e EORM}

De modo geral, HDM, RMM, OOHDM e EORM incorporam fases e elementos específicos associados à modelagem do domínio da aplicação a ser construída. Tanto o HDM como o RMM são baseados no modelo entidade-relacionamento para representar as informações do domínio. Já no OOHDM e no EORM, o modelo de domínio é construído de acordo com os princípios de orientação a objetos. O resultado da modelagem é um esquema composto por subsistemas, classes e relacionamentos. Mecanismos de agregação e generalização/especialização podem ser usados para especificar classes conceituais.

Embora as abordagens aqui discutidas, à primeira vista, pareçam ser adequadas com respeito aos aspectos considerados na perspectiva conceitual da modelagem de conteúdos educacionais, alguns pontos importantes devem ser ponderados. 
A primeira consideração refere-se à utilização de modelos de objetos e modelos de entidaderelacionamento na representação de domínios de conhecimento. Falbo et al. (1998) discutem algumas questões interessantes quanto ao uso desses modelos na construção de ontologias. Tais questões também são válidas no contexto de modelagem de conteúdos educacionais.

De acordo com (Falbo et al., 1998), em um modelo de objetos, objetos representam abstrações do mundo real que possuem estado (dado por seus atributos), comportamento (dado por seus métodos) e identidade própria. Classes, por sua vez, agrupam objetos que possuem os mesmos atributos e relacionamentos e exibem o mesmo comportamento. Em se tratando de uma ontologia (ou mesmo de conteúdos educacionais), a preocupação está em descrever uma conceituação e, portanto, trabalha-se essencialmente com conceitos e relações. Nesse sentido, ainda que seja possível argumentar que conceitos poderiam ser descritos como classes em um modelo de objetos, existem diferenças fundamentais a serem consideradas. Por exemplo, objetos em uma classe exibem um comportamento dado pelos métodos da classe, o que não faz muito sentido para conceitos. Além disso, geralmente as classes em um modelo orientado a objetos possuem atributos, o que não é uma característica obrigatória para conceitos. Este também é um aspecto negativo na adoção de um modelo entidade-relacionamento para descrever ontologias (e conteúdos educacionais). Por fim, a utilização de modelos de objetos ou de entidade-relacionamento pode tornar-se muito específica e pouco intuitiva caso a modelagem conceitual seja conduzida por professores e/ou especialistas de domínio com pouca ou nenhuma familiaridade com tais técnicas.

Ainda com respeito à modelagem conceitual, a segunda questão, destacada por Pansanato \& Nunes (1999), é que tais abordagens procuram a generalização de domínio, perdendo informações importantes sobre as características de um domínio mais específico que, no contexto de ensino e treinamento, é de fundamental importância. De fato, os modelos conceituais do HDM, RMM, OOHDM e EORM são voltados para a modelagem da aplicação hipermídia. O conteúdo educacional, por sua vez, está em um nível de abstração diferente, o que requer que a modelagem conceitual aborde elementos mais específicos, em termos de conceitos e informações associadas. Nesse sentido, embora os modelos/métodos discutidos nesta seção disponham de mecanismos de apoio à modelagem conceitual da aplicação hipermídia educacional, ainda assim é necessário que mecanismos adequados à modelagem conceitual do conteúdo dessas aplicações também sejam incorporados.

Quanto aos aspectos instrucionais, nenhuma das abordagens analisada inclui modelos correspondentes em sua definição. De fato, a ausência de modelos instrucionais evidencia a limitação dessas abordagens na representação e modelagem de elementos importantes do contexto educacional, tais como exemplos, exercícios, avaliações, entre outros.

Os aspectos didáticos, por sua vez, poderiam ser tratados nos modelos de navegação associados às abordagens. De fato, os modelos navegacionais propostos pelo HDM, pelo RMM e pelo OOHDM dispõem de alguns recursos e mecanismos que podem ser utilizados como apoio à modelagem de tais aspectos, satisfazendo parte dos requisitos associados à perspectiva didática. $\mathrm{O}$ HDM e o RMM, por exemplo, baseiam-se na definição de estruturas de acesso (índices e roteiros). 
No OOHDM, o modelo navegacional representa uma visão do modelo conceitual, sendo que diferentes modelos navegacionais podem ser construídos para expressar diferentes visões do mesmo domínio. Nesse sentido, além de estruturas de acesso, o OOHDM também define primitivas de alto nível, que correspondem aos contextos navegacionais. O EORM, em especial, não separa explicitamente o projeto conceitual do navegacional, nem incorpora a idéia de contextos navegacionais no desenvolvimento dos hiperdocumentos.

Embora os recursos apresentados pelos modelos navegacionais utilizados no projeto de hiperdocumentos genéricos possam ser considerados como apoio ao estabelecimento de contextos de aprendizado, tais modelos não abordam nem incorporam mecanismos específicos associados à idéia de ordem pedagógica entre os objetos modelados. Novamente, tais os modelos enfatizam a aplicação e não o conteúdo sendo desenvolvido. Além disso, pouca ênfase é dada à modelagem dos aspectos comportamentais da navegação. De fato, nenhuma das abordagens dispõe de recursos adequados à especificação de tais aspectos. No caso do OOHDM, embora exista a preocupação com os aspectos dinâmicos da aplicação, esses são considerados no contexto de projeto da interface do hiperdocumento.

A Tabela 3.7 sintetiza as características gerais das abordagens HDM, RMM, OOHDM e EORM, consideradas segundo os requisitos e as perspectivas para modelagem de conteúdos educacionais.

Tabela 3.7: Síntese das Características do HDM, RMM, OOHDM e EORM.

\begin{tabular}{||c|l|l|l||}
\hline \hline Perspectiva & Requisito & Adequação & Mecanismo \\
\hline \hline \multirow{3}{*}{ Conceitual } & Taxonomia de Conceitos & Inadequado em Nível Conceitual & - \\
\cline { 2 - 4 } & Composição de Conceitos & Inadequado em Nível Conceitual & - \\
\cline { 2 - 4 } & Relacionamentos Específicos & Inadequado em Nível Conceitual & - \\
\cline { 2 - 4 } & Decomposição Hierárquica & Inadequado em Nível Conceitual & - \\
\hline \hline \multirow{2}{*}{ Instrucional } & $\begin{array}{l}\text { Diferenciação entre Categorias } \\
\text { do Conhecimento }\end{array}$ & Não aborda & - \\
\hline \hline \multirow{3}{*}{ Didática } & Ordem Pedagógica & Não aborda & - \\
\cline { 2 - 4 } & Contextos de Aprendizado & Satisfatório & Estruturas de Acesso \\
\cline { 2 - 4 } & História & Não Aborda & - \\
\cline { 2 - 4 } & Propagação de Eventos & Não Aborda & - \\
\hline \hline
\end{tabular}

\section{Modelo Trellis}

Conforme discutido na Seção 2.2.8, o modelo Trellis explora as propriedades dinâmicas de Redes de Petri (Stotts \& Furuta, 1989) na definição da semântica de navegação e na especificação dos aspectos comportamentais associados. Em linhas gerais, o modelo aborda vários problemas inerentes a hiperdocumentos, dentre eles (Leiva, 2003): análise da complexidade da apresentação, alcançabilidade de um nó, caminhos concorrentes de navegação, sincronização, controle de acesso a informações e versões personalizadas de hiperdocumentos. 
No entanto, embora o Trellis possibilite computar diferentes propriedades da aplicação pela análise da Rede de Petri correspondente, perde-se alguma força de modelagem devido à natureza das redes. Por exemplo, o modelo não dispõe de recursos satisfatórios para estruturação hierárquica, dificultando a especificação de controle de sincronização entre níveis diferentes das estruturas hierárquicas (Leiva, 2003). A decomposição sucessiva de estados não é realizada facilmente, visto que um estado decomposto não é uma Rede de Petri, mas sim um conjunto de vários subestados. Além disso, não existem mecanismos para especificar a sincronização entre estados decompostos.

De modo geral, ressalta-se que os problemas identificados no modelo Trellis, sobretudo com respeito à estruturação hierárquica dos conceitos (e informações associadas), podem dificultar sua aplicação na modelagem de conteúdos educacionais.

A Tabela 3.8 sintetiza as principais características do Trellis em relação aos requisitos e perspectivas de modelagem identificadas neste capítulo.

Tabela 3.8: Síntese das Características do Modelo Trellis.

\begin{tabular}{||l|l|l|l||}
\hline \hline Perspectiva & Requisito & Adequação & Mecanismo \\
\hline \hline \multirow{4}{*}{ Conceitual } & Taxonomia de Conceitos & Não aborda & - \\
\cline { 2 - 4 } & Composição de Conceitos & Não aborda & - \\
\cline { 2 - 4 } & Relacionamentos Específicos & Não aborda & - \\
\cline { 2 - 4 } & Decomposição Hierárquica & Não Aborda & - \\
\hline \hline \multirow{3}{*}{ Instrucional } & $\begin{array}{l}\text { Diferenciação entre Categorias } \\
\text { do Conhecimento }\end{array}$ & Não aborda & \\
\hline \hline \multirow{3}{*}{\begin{tabular}{l} 
Didática \\
\cline { 2 - 4 }
\end{tabular}} & Ordem Pedagógica & Aborda Indiretamente & $\begin{array}{l}\text { Setas direcionadas entre Lu- } \\
\text { gares e Transições }\end{array}$ \\
\cline { 2 - 4 } & Contextos de Aprendizado & Pouco Satisfatório & Marcações \\
\cline { 2 - 4 } & História & Não Aborda & - \\
\cline { 2 - 4 } & Propagação de Eventos & Aborda Indiretamente & Marcadores \\
\hline \hline
\end{tabular}

\section{Modelo HMBS}

Conforme discutido na Seção 2.2.9, o modelo HMBS pode ser aplicado no projeto e desenvolvimento de hiperdocumentos por meio do método HMBS/M. Analisado em termos de método e sob a perspectiva de uma aplicação hipermídia educacional, a maioria das considerações feitas para o HDM, o RMM, o OOHDM e o EORM também se mostram válidas para o HMBS/M.

No entanto, analisado separadamente (como modelo, desvinculado da noção de método) e sob a perspectiva de conteúdo educacional, o HMBS apresenta uma série de mecanismos e características que pode ser explorada no contexto de ensino e treinamento, em especial no que se refere à modelagem didática e, particularmente, na especificação e validação dos aspectos comportamentais associados.

O primeiro desses mecanismos refere-se ao estabelecimento de visões hierárquicas. De acordo com Thüring et al. (1995), uma representação visual da estrutura do hiperdocumento, fornecendo 
uma visão geral do mesmo, pode auxiliar o leitor na identificação dos tópicos de interesse e, conseqüentemente, na sua orientação. Nesse sentido, mecanismos para navegar de forma estruturada na hierarquia do hiperdocumento são altamente desejáveis. De acordo com Turine (1998), esse tipo de "navegação estruturada" é fortemente apoiado pelo HMBS por meio de visões hierárquicas, permitindo obter uma visão geral adequada do hiperdocumento no nível de abstração desejado.

Adicionalmente, a representação visual do statechart pode auxiliar na orientação do leitor, indicando sua posição atual, o caminho percorrido até essa posição e as possíveis opções de navegação que podem ser escolhidas (Turine, 1998).) Em HMBS, a estrutura navegacional do hiperdocumento pode ser apresentada durante a navegação como um mapa para orientar os leitores, ajudando-os a encontrar o caminho desejado no hiperdocumento, exibindo futuras opções de navegação e também ajudando a construir uma representação mental coerente da estrutura organizacional do hiperdocumento.

Outra característica relevante associada ao HMBS refere-se ao estabelecimento de contextos de informação, definidos a partir do conceito de superestados de Statecharts. Um estado-pai determina o contexto dos seus subestados e inter-relacionamentos entre eles, definindo assim os nós (ou páginas) de composição que admitem aninhamento (Turine et al., 1997, 1998; Turine, 1998).

O conceito de contextos de navegação, propostos por Schwabe \& Rossi (1995), podem ser especificados no HMBS como um conjunto de páginas e ligações constituindo um subgrafo do hiperdocumento (Turine et al., 1998; Turine, 1998). As páginas no contexto recuperam um determinado assunto segundo uma certa perspectiva e em um certo nível de conhecimento. Os contextos de navegação podem ser implementados pelas estruturas de acesso (roteiros e índices).

O HMBS também prevê o uso de variáveis, ações e história, definidos no escopo de Statecharts, os quais podem ser utilizados a fim de enriquecer os modelos referentes aos conteúdos educacionais.

Variáveis podem ser utilizadas durante a navegação pelo conteúdo a fim de personalizar e controlar o caminho a ser percorrido pelo aprendiz. Adicionalmente, pode-se especificar o aprendizado programado com base na execução de ações associadas a transições (Turine, 1998). Pode-se, por exemplo, definir em tempo de execução os caminhos mais adequados para um dado aprendiz considerando seu conhecimento e perfil sobre o assunto, o qual pode ser inferido com base nas escolhas do aprendiz durante a navegação pelo conteúdo ou, alternativamente, com base em pesos/notas atribuídas aos caminhos de navegação escolhidos. Alguns desses aspectos foram investigados por Leiva (2003) na proposição do modelo MDE.

O uso de ações proporciona o mecanismo de propagação de eventos (broadcast), explorado, potencialmente, para fornecer suporte à sincronização em diversos tipos de aplicações multimídia. Mecanismos de história, por sua vez, permitem a recuperação de contextos visitados anteriormente.

O HMBS permite ainda explorar aspectos associados à validação do hiperdocumento, possibilitanto identificar inconsistências estruturais e problemas relacionados à visualização e navegação, bem como a análise de algumas propriedades. Essas análises são baseadas essencialmente 
na geração da árvore de alcançabilidade, que fornece subsídios para a detecção de anomalias na especificação. Nesse sentido, algumas propriedades dinâmicas de Statecharts foram definidas e introduzidas no contexto de hiperdocumentos (Turine et al., 1997, 1998; Turine, 1998): alcançabilidade de uma página a partir de uma configuração de contexto qualquer, reiniciabilidade, deadlock durante a navegação, vivacidade de ligações navegacionais e seqüência válida de âncoras.

Por fim, é interessante observar que várias das propriedades e características associadas ao HMBS já vêm sendo exploradas na estruturação de hiperdocumentos educacionais pelo modelo MDE (Leiva et al., 2002b; Leiva, 2003), sobretudo no que se refere à avaliação e acompanhamento do aprendiz.

As principais características do HMBS, analisadas segundo os requisitos e perspectivas para modelagem de conteúdos educacionais, estão sintetizadas na Tabela 3.9.

Tabela 3.9: Síntese das Características do Modelo HMBS.

\begin{tabular}{||l|l|l|l||}
\hline \hline Perspectiva & Requisito & Adequação & Mecanismo \\
\hline \hline \multirow{4}{*}{ Conceitual } & Taxonomia de Conceitos & Não aborda & - \\
\cline { 2 - 4 } & Composição de Conceitos & Não aborda & - \\
\cline { 2 - 4 } & Relacionamentos Específicos & Não aborda & - \\
\cline { 2 - 5 } & Decomposição Hierárquica & Adequado & $\begin{array}{l}\text { Estados, Subestados, Superes- } \\
\text { tados, Mecanismos de Aninha- } \\
\text { mento }\end{array}$ \\
\hline \hline \multirow{3}{*}{ Instrucional } & $\begin{array}{l}\text { Diferenciação entre Categorias de Co- } \\
\text { nhecimento }\end{array}$ & Não Aborda & - \\
\hline \hline \multirow{3}{*}{\begin{tabular}{l} 
Didática \\
\cline { 2 - 4 }
\end{tabular}} & Ordem Pedagógica & $\begin{array}{l}\text { Aborda Indireta- } \\
\text { mente }\end{array}$ & Transições de Statecharts \\
\cline { 2 - 5 } & Contextos de Aprendizado & Adequado & $\begin{array}{l}\text { Estruturas de Acesso, Visões } \\
\text { Hierárquicas }\end{array}$ \\
\cline { 2 - 5 } & História & Adequado & $\begin{array}{l}\text { Estabelecido pela Técnica Sta- } \\
\text { techarts }\end{array}$ \\
\cline { 2 - 4 } & Propagação de Eventos & Adequado & $\begin{array}{l}\text { Estabelecido pela Técnica Sta- } \\
\text { techarts }\end{array}$ \\
\hline \hline
\end{tabular}

Salienta-se que as análises e comparações entre modelos para a representação de conteúdos educacionais estão sintetizadas no relatório técnico Modelos para Representação de Conteúdos Educacionais: Um Estudo Comparativo (Barbosa et al., 2004), que se encontra em fase final de elaboração.

A partir das comparações realizadas, tanto aspectos positivos como fatores limitantes que comprometem a utilização de determinado modelo segundo uma dada perspectiva de modelagem foram identificados. Os aspectos observados motivaram a proposição de uma abordagem de modelagem, ressaltando os pontos fortes e minimizando as limitações identificadas, fornecendo ainda subsídios para que a construção dos modelos associados seja conduzida de forma integrada e consistente. A abordagem proposta é discutida em detalhes na próxima seção. 


\subsection{Abordagem Integrada para Modelagem de Conteú- dos Educacionais}

As avalições e comparações conduzidas na Seção 3.5 permitiram identificar pontos fortes e fracos da aplicação de cada uma das abordagens analisadas com respeito à modelagem de conteúdos educacionais. De modo geral, observou-se que, enquanto algumas abordagens mostram-se particularmente interessantes no tratamento de aspectos conceituais, outras incorporam elementos relevantes sob a perspectiva instrucional e outras, ainda, demonstram grande poder expressivo na representação de aspectos didáticos (e de navegação).

Além de reafirmar a importância do estabelecimento de requisitos e parâmetros de comparação associados à atividade de modelagem de conteúdos educacionais (discutida na Seção 3.3), as análises realizadas também evidenciam a necessidade de abordagens integradas, capazes de reunir, de forma consistente, os diversos aspectos e perspectivas de modelagem observados.

Dentro desse contexto, nesta seção é apresentada a abordagem $\mathcal{A L M}-\mathcal{C I D}$ (Abordagem Integrada de Modelagem - Conceitual, Instrucional e Didática) ou, em inglês, IMA-CID (Integrated Modelling Approach - Conceptual, Instructional and Didactic), cujo propósito é reunir, em uma única proposta, as perspectivas de modelagem conceitual, instrucional e didática discutidas anteriormente. Ressalta-se ainda o caráter iterativo considerado na aplicação da abordagem proposta. A Figura 3.11 sintetiza os principais aspectos da abordagem $\mathcal{A I M}-\mathcal{C I D}$.

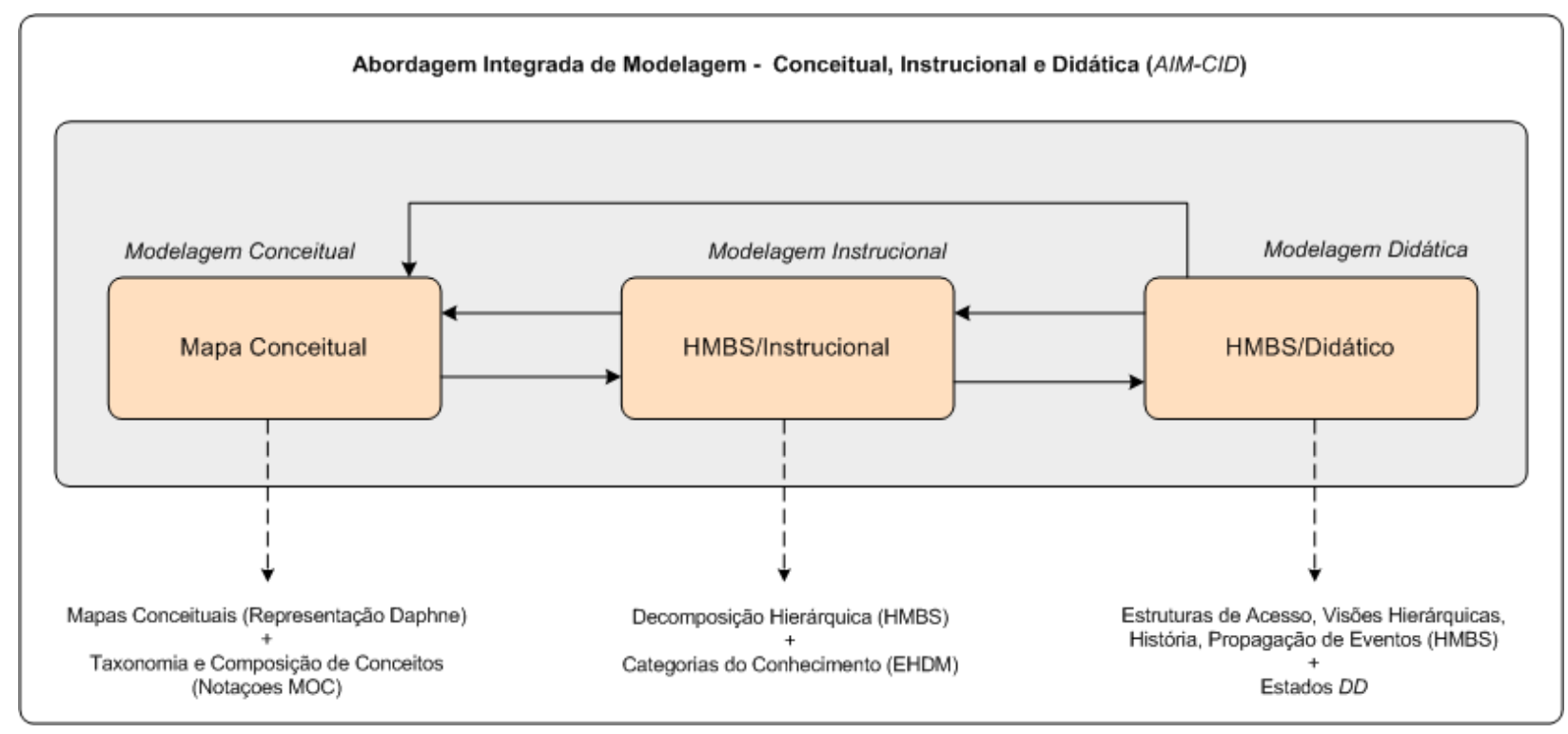

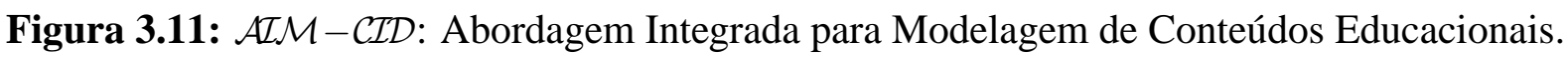

Em linhas gerais, a partir das análises conduzidas, foram selecionados os modelos e mecanismos que se mostraram mais adequados à modelagem de conteúdos educacionais, ressaltando os aspectos positivos identificados. Além disso, a fim de minimizar as limitações observadas, algumas restrições e/ou extensões também foram definidas e incorporadas aos mesmos. 
Na etapa de Modelagem Conceitual, optou-se pela utilização da técnica de Mapas Conceituais (Moreira \& Buchweitz, 1987; Novak, 1981; Novak \& Gowin, 1984; Novak, 1990), com representações e significados semelhantes aos estabelecidos pelo modelo/metodologia Daphne (Kawasaki \& Fernandes, 1996), incluídas algumas notações adicionais herdadas do Modelo Orientado a Conceitos (Pimentel, 1998) do MAPHE (Pimentel, 1997). Dentre os fatores que motivaram a escolha da técnica, destacam-se: (1) sua adequação na representação de conceitos e na estruturação hierárquica do domínio de conhecimento; (2) facilidade de uso, sendo bastante intuitiva mesmo para usuários não familiarizados; (3) fundamentação em princípios educacionais, tais como a Teoria da Aprendizagem Significativa (Ausubel et al., 1978), e grande aceitação por especialistas e profissionais da área de Educação; e (4) adoção da técnica pela maioria das abordagens que envolvem algum tipo de modelagem de conteúdos educacionais (Daphne, EHDM, MAPHE, MDE).

Para a completa adequação da técnica de Mapas Conceituais aos requisitos explorados na perspectiva conceitual, algumas restrições e/ou extensões foram sugeridas:

- Apenas conceitos devem ser representados no mapa conceitual. Essa restrição é justificada pelo fato de que exemplos (além de outras informações associadas) são tratados durante a etapa de Modelagem Instrucional. Observa-se que essa restrição é idêntica à imposta pelo Daphne.

- Além de relacionamentos genéricos, já estabelecidos na definição original da técnica, primitivas para a representação de taxonomia e composição de conceitos, a exemplo das extensões definidas no MOC, também foram incorporadas. Salienta-se, entretanto, que as demais extensões propostas no MOC não foram consideradas a fim de não sobrecarregar o modelo.

Na etapa de Modelagem Instrucional, optou-se pelo uso simplificado do modelo HMBS (Turine et al., 1997, 1998; Turine, 1998) considerando nesse nível somente os aspectos de decomposição hierárquica fornecidos pelo mesmo.

Conforme ressaltado anteriormente, mapas conceituais são fortemente baseados nos princípíos da Teoria da Aprendizagem Significativa (Ausubel et al., 1978), os quais ressaltam a importância da estruturação hierárquica dos conceitos. A utilização do HMBS, com ênfase nos aspectos hierárquicos por ele estabelecidos, pode ser vista como uma "evolução natural" do modelo conceitual para o modelo instrucional. Desse modo, os mecanismos de decomposição hierárquica do HMBS são utilizados para complementar, no nível instrucional, a idéia de estruturação hierárquica já explorada no nível conceitual.

Uma extensão sugerida ao HMBS a fim de garantir sua completa adequação aos aspectos considerados na perspectiva instrucional refere-se à possibilidade de representação de diferentes categorias de conhecimento. Nesse sentido, o modelo deve permitir a representação de itens de informação (por exemplo, considerando a teoria de Merril (1983): fato, conceito, princípio e procedimento) e elementos instrucionais (explanatórios, exploratórios e de avaliação). 
De acordo com a definição formal apresentada na Seção 2.2.9, um hiperdocumento $H$ no HMBS é definido como uma 7-tupla $H=\langle S T, P, m, L, p l$, ae, $N>$, em que $P$ representa o conjunto finito de páginas de informação, definindo o conteúdo do hiperdocumento. Cada página $p \in P$ é definida conceitualmente pela tripla $<c, t, A n c_{p}>$ representando, respectivamente, a porção de informação, o título da página, e a coleção de âncoras contidas na página. A porção de informação $c$ pode ser composta por mídias estáticas (texto, gráfico ou imagem) ou dinâmicas (vídeo, áudio ou animação) (Turine, 1998).

A fim de incorporar a representação de doferentes categorias de conhecimento ao modelo HMBS, redefine-se o conjunto de páginas $P$ para a tripla $<C, t, A n c_{p}>$, onde $C$ representa o conjunto finito de porções de informação, formalizado pela quádrupla $C=<$ $I_{\text {Info }}, E_{\text {Explor }}, E_{\text {Explan }}, E_{\text {Aval }}>$, em que:

- $I_{\text {Info }}$ corresponde ao conjunto finito de itens de informação que compõem o conteúdo da página. $I_{\text {Info }}$ é formalizado pela quádrupla $I_{\text {Info }}=<F$, Conc, Princ, Proc $>$, na qual:

- $F=\left\{f_{1}, f_{2}, \ldots, f_{i}\right\}, i \geq 0$ corresponde ao conjunto finito de fatos associados à página;

- Conc $=\left\{\right.$ conc $_{1}$, conc $_{2}, \ldots$, conc $\left._{j}\right\}, j \geq 0$ corresponde ao conjunto finito de conceitos associados à página;

- Princ $=\left\{\right.$ princ $_{1}$, princ $_{2}, \ldots$, princ $\left._{k}\right\}, k \geq 0$ corresponde ao conjunto finito de princípios associados à página; $\mathrm{e}$

- $\operatorname{Proc}=\left\{\operatorname{proc}_{1}, \operatorname{proc}_{2}, \ldots, \operatorname{proc}_{l}\right\}, l \geq 0$ corresponde ao conjunto finito de procedimentos associados à página.

- $E_{\text {Explan }}$ corresponde ao conjunto finito de elementos explanatórios que compõem o conteúdo da página. $E_{\text {Explan }}$ é formalizado pela tupla $E_{\text {Explan }}=<E x, C o m p l>$, onde:

- $E x=\left\{e x_{1}, e x_{2}, \ldots, e x_{i}\right\}, i \geq 0$ corresponde ao conjunto finito de exemplos associados à página; e

- Compl $=\left\{\operatorname{compl}_{1}, \operatorname{compl}_{2}, \ldots, \operatorname{compl}_{j}\right\}, j \geq 0$ corresponde ao conjunto finito de informações complementares associadas à página.

- $E_{\text {Explor }}$ corresponde ao conjunto finito de elementos exploratórios que compõem o conteúdo da página. $E_{\text {Explor }}$ é formalizado por $E_{\text {Explor }}=<$ Exerc $>$, em que:

- Exer $=\left\{\right.$ exer $_{1}$, exer $_{2}, \ldots$, exer $\left._{i}\right\}, i \geq 0$ corresponde ao conjunto finito de exercícios associados à página.

- $E_{\text {Aval }}$ corresponde ao conjunto finito de elementos de avaliação que compõem o conteúdo da página. $E_{\text {Aval }}$ é formalizado pela tripla $E_{\text {Aval }}=<A D, A F, A S>$, em que: 
- $A D=\left\{a d_{1}, a d_{2}, \ldots, a d_{i}\right\}, i \geq 0$ corresponde ao conjunto finito de avaliações diagnósticas associadas à página.

- $A F=\left\{a f_{1}, a f_{2}, \ldots, a f_{j}\right\}, j \geq 0$ corresponde ao conjunto finito de avaliações formativas associadas à página.

- $A S=\left\{a s_{1}, a s_{2}, \ldots, a s_{k}\right\}, k \geq 0$ corresponde ao conjunto finito de avaliações somativas associadas à página.

O modelo HMBS, desvinculado da representação de transições, eventos e mecanismos de história, e estendido para a representação de diferentes categorias de conhecimento, foi denominado HMBS/Instrucional.

Além dos itens de informação e elementos instrucionais formalizados acima, outros itens e elementos poderiam ter sido incorporados ao modelo. Por exemplo, ao invés da teoria de Merril (1983), poderia ter sido adotada a técnica de Mapeamento de Informações (Horn, 1989), sendo incorporadas como itens de informação as categorias de conhecimento estabelecidas por essa técnica em particular. Outro exemplo refere-se aos elementos exploratórios, definidos formalmente por meio de elementos do tipo exercício. Além de exercício, outros elementos voltados a atividades práticas, tais como experimento, seminário, discussão colaborativa, resumo, entre outros, poderiam ter sido especificados e incorporados ao modelo, de acordo com interesses pedagógicos específicos. A inclusão e a formalização de tais itens e elementos é conduzida de maneira similar à apresentada acima.

Observa-se ainda que a idéia de diferenciação entre categorias do conhecimento foi herdada do método EHDM sem, entretanto, estar vinculada necessariamente à utilização das categorias estabelecidas pelo modelo de Michener (Michener, 1978). De fato, a flexibilidade na escolha das categorias de conhecimento a serem representadas no $\mathcal{H}$ MBS/Instrucional visa a garantir a independência do modelo em relação a teorias e princípios educacionais, os quais devem ser definidos pelo próprio instrutor/mediador.

Na etapa de Modelagem Didática também optou-se pela utilização do modelo HMBS. Nesse nível, além dos aspectos já tratados no $\mathcal{H}$ MBS/Instrucional, elementos associados à navegação e à especificação de aspectos comportamentais do hiperdocumento educacional também foram representados.

Conforme discutido anteriormente, o HMBS permite que aspectos relevantes sob a perspectiva didática, tais como mecanismos de história, propagação de eventos e definição de contextos de aprendizado, sejam tratados. Além disso, a validação do conteúdo educacional também pode ser explorada pela análise de propriedades do statechart subjacente.

O comportamento associado à navegação do usuário (aprendiz ou instrutor/mediador) pelo hiperdocumento também constitui um aspecto essencial sob a perspectiva didática da modelagem de conteúdos educacionais. Por exemplo, com base em informações comportamentais é possível 
personalizar e controlar o caminho a ser percorrido pelo aprendiz em tempo de execução (apresentação do módulo). Tais aspectos são passíveis de modelagem a partir da utilização do HMBS, tendo sido investigados na definição do modelo MDE (Leiva et al., 2002b; Leiva, 2003).

Uma extensão sugerida ao HMBS no nível didático refere-se à idéia de "especificação aberta" dos aspectos de navegação, por meio da qual é possível representar as sequiências de apresentação entre conceitos e informações pertinentes de maneira flexível e personalizada.

Dependendo de fatores como duração do curso, objetivos de aprendizado e público-alvo, maneiras diferenciadas de apresentação e navegação pelo mesmo conteúdo são exigidas. Uma especificação aberta permite que todas as possíveis seqüências de apresentação do conteúdo sejam representadas no mesmo modelo didático. Nesse sentido, a partir de um único modelo, diversas implementações do mesmo conteúdo podem ser geradas em função dos fatores mencionados acima.

A especificação aberta apóia, em nível de modelagem e projeto, o estabelecimento de contextos de aprendizado diferenciados. Além disso, quando fisicamente implementada no módulo educacional ("implementação aberta"), possibilita que a navegação seja definida pelo próprio usuário, em tempo de execução. Em outras palavras, o usuário tem total liberdade para decidir, dinamicamente, quais tópicos devem ser abordados e em que ordem os mesmos devem ser apresentados.

A navegação proporcionada a partir de um modelo especificado de maneira aberta corresponde ao extremo oposto à navegação na qual todas as seqüências de apresentação são previamente estabelecidas. Neste último caso, pode-se considerar a especificação dos aspectos de navegação é como sendo "fechada". As implicações da adoção de especificações abertas, parcialmente abertas ou fechadas na implementação de módulos educacionais são ilustradas e discutidas mais detalhadamente na Seção 5.3.7.

A fim de permitir a representação de especificações abertas no modelo HMBS, é proposta a noção de estados DD (Dynamically Defined - Definido Dinamicamente), os quais apresentam as seguintes propriedades:

1. Apenas um único estado pode estar ativo em um dado momento.

2. Um estado $D D$ não incorpora a representação de estado inicial (default), o qual é definido dinamicamente, em tempo de execução, pelo usuário.

3. Todos os subestados $O R_{D D}$ de um estado $D D$ são totalmente conexos (estão totalmente conectados uns aos outros).

4. A saída de um estado $D D\left(X_{D D}\right)$ pode ativar quaisquer estados $O R_{D D}$ da hierarquia de estados-pai- $D D$ de $X_{D D}$.

É importante observar que as propriedades (1), (2) e (3) de um estado $D D$ não requerem restrições e/ou extensões à sintaxe e à semântica do HMBS. Na verdade, as alterações limitam-se à 
notação gráfica do modelo em que, por questões de clareza e legibilidade, transições e eventos não são explicitamente representados. Considere, por exemplo, um estado $X_{D D}$ e seus subestados $A$, $B, C$ e $D$. Todas as transições possíveis entre $A, B, C$ e $D$ são representadas implicitamente e encontram-se habilitadas, indicando que a partir de qualquer subestado de $X_{D D}$, todos os demais subestados podem ser alcançados. Ressalta-se, entretanto, que a presença de uma transição explícita, por exemplo, do subestado $A$ para o subestado $B$, faz com que todas as demais transições implícitas que partem de $A$ sejam ser desconsideradas. De fato, a transição explícita entre $A$ e $B$ "inibe" as transições implícitas que partem de $A$ para os subestados $C$ e $D$.

Já a hierarquia de estados-pai- $D D$ de um estado $D D$ (Propriedade (4)) requer que a sintaxe e semântica do modelo HMBS (e do statechart subjacente) sejam estendidas como se segue:

- Seja a hierarquia de estados-pai de um estado $X_{D D}$ definida pela seqüência:

$$
\operatorname{SeqPais}\left(X_{D D}\right)=\operatorname{pai}_{S_{1}}, \operatorname{pai}_{S_{2}}, \operatorname{pai}_{S_{3}}, \ldots, \text { pai }_{S_{i}} \text { tal que } p a i_{S_{j-1}} \in \rho\left(\operatorname{pai}_{S_{j}}\right), j=1, \ldots, i-1 .
$$

A hierarquia de estados-pai- $D D$ de $X_{D D}$ é definida pela sequiência:

$$
\begin{gathered}
\operatorname{SeqPais}_{D D}\left(X_{D D}\right)=\operatorname{pai}_{S_{1}}, \text { pai }_{S_{2}}, \text { pai }_{S_{3}}, \ldots, \text { pai }_{S_{n}} \text { tal que } \forall p a i_{S_{k}}, k=1, \ldots, n \text { : } \\
\psi_{\text {est }}\left(\text { pai }_{S_{k}}\right)=O R_{D D} \text { e } p a i_{S_{k-1}} \in \rho\left(\operatorname{pai}_{S_{k}}\right),
\end{gathered}
$$

onde a Função Tipo $\psi_{\text {est }}: S \rightarrow\left\{O R, O R_{D D}, A N D\right\}$ define o tipo de cada estado $O R$.

A Figura 3.12(a) ilustra a representação de um estado $D D X$. A Figura 3.12(b) ilustra o comportamento interno do estado $X$, representando explicitamente suas transições e eventos. A notação $H_{D D}^{*}$ representa a hierarquia de estados-pai- $D D$.

O modelo HMBS, estendido com a representação de estados $D D$, foi denominado $\mathcal{H}$ MBS/Didático. Cabe ressaltar que as extensões propostas para a representação de diferentes categorias de conhecimento, definidas no modelo $\mathcal{H} \mathcal{M B S} /$ Instrucional, foram mantidas no modelo. Além disso, a estruturação hierárquica explorada nos níveis conceitual e instrucional também é preservada. Procura-se, com isso, garantir a uniformidade da abordagem $\mathcal{A} \mathcal{L} M-\mathcal{C L D}$ na construção dos diferentes modelos associados.

É importante destacar que, caso exista uma ferramenta de apoio à edição, interpretação e execução de modelos didáticos segundo o $\mathcal{H} \mathcal{M B S} /$ Didático, especificações “executáveis" também podem ser derivadas e utilizadas como apoio à geração automática de conteúdos educacionais, personalizados de acordo com interesses pedagógicos, perfil do usuário, características do módulo, entre outros aspectos. A Figura 3.13 esquematiza a geração de conteúdos educacionais, conduzida tanto de forma automática como manual. Mecanismos de transformação em dois níveis de abstração distintos são considerados. Na geração manual, mecanismos "tradicionais" de implementação e apresentação, tais como PowerPoint e editores HTML, entre outros, são utilizados. Na geração 

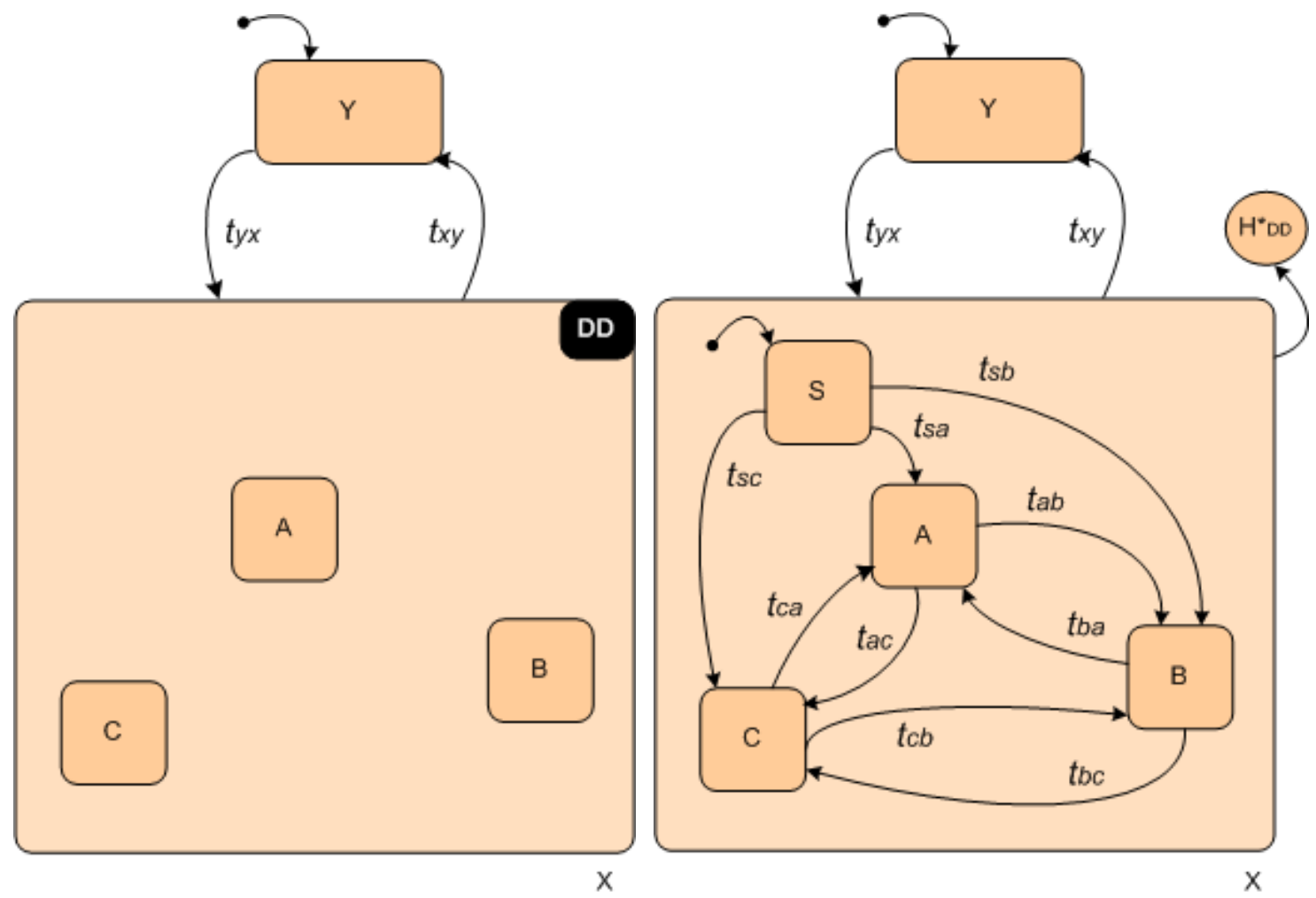

(a) Estado $D D X$ (Transições e Eventos Implícitos). (b) Comportamento Interno de $X$ (Transições e Eventos Explícitos).

Figura 3.12: Representação de um Estado $D D$.

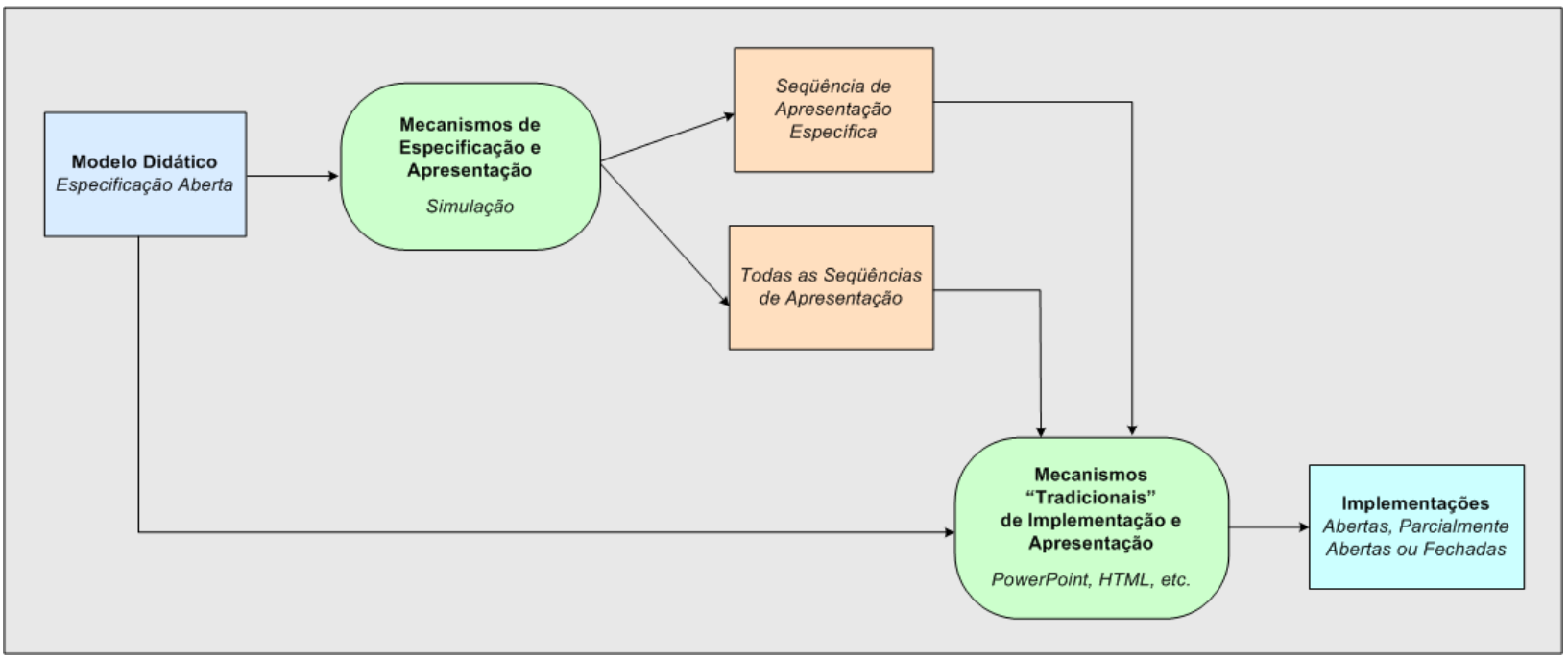

Figura 3.13: Mecanismos de Apoio à Geração de Conteúdos Educacionais.

automática, mecanismos de especificação e apresentação, na forma de ferramentas de simulação, são usados em complemento aos mecanismos tradicionais.

Além da geração automática de material, ferramentas de simulação também podem ser utilizadas como apoio à apresentação dos conteúdos desenvolvidos ou, ainda, na validação das especificações geradas e dos próprios conteúdos associados. 
O estabelecimento de mecanismos automatizados que apóiem a construção e execução de especificações de conteúdos educacionais segundo o modelo $\mathcal{H}$ MBS/Didático é uma das atividades futuras a ser conduzida em decorrência deste trabalho. Além disso, com respeito à abordagem $\mathcal{A L M}-\mathcal{C I D}$, a integração entre os aspectos de modelagem estabelecidos pelo modelo MDE (Leiva et al., 2002b; Leiva, 2003) (que também estende o HMBS para sua aplicação no contexto educacional) e pela abordagem também deve ser investigada posteriormente.

A abordagem e os modelos propostos nesta seção foram considerados na instanciação do processo padrão para a elaboração de módulos educacionais, discutida no Capítulo 4. A aplicação prática da abordagem, incluindo a construção dos modelos conceitual, instrucional e didático associados, é ilustrada no Capítulo 5, no contexto da utilização do processo instanciado.

Nesta seção foi caracterizada a necessidade de integração entre diferentes perspectivas de modelagem, sendo proposta uma abordagem unificada envolvendo tais aspectos. A seguir, a integração de mecanismos de modelagem é discutida sob um ponto de vista específico - a construção de objetos de aprendizado -, considerando aspectos pertinentes à estruturação, armazenamento e recuperação dos componentes internos de tais objetos.

\subsection{Mecanismos de Modelagem: Aplicação no Contexto de Objetos de Aprendizado}

Na Seção 3.2 módulos educacionais foram caracterizados e comparados a objetos de aprendizado (learning objects) (IEEE Learning Technology Standards Committee, 2002; Wiley, 2000, 2001), em termos de características e aspectos de desenvolvimento. Embora o estudo aprofundado envolvendo o desenvolvimento de objetos de aprendizado não seja o objetivo principal deste trabalho, os mecanismos de modelagem identificados podem, sob alguns aspectos, ser investigados como apoio à construção de tais objetos. Nesse sentido, a Figura 3.14 ilustra a estrutura de um objeto de aprendizado, representando itens de informação, elementos instrucionais e perspectivas didáticas segundo a metáfora do átomo, proposta por Wiley (2001).

A idéia básica é investigar a utilização das perspectivas para modelagem de conteúdos educacionais como mecanismos de apoio à estruturação dos componentes internos de um objeto de aprendizado. Desse modo, enquanto prótons correspondem aos conceitos, elétrons e nêutrons são genericamente representados por meio de fatos, princípios, procedimentos, elementos explanatórios, elementos exploratórios, elementos de avaliação e perspectivas didáticas.

A título de ilustração, na Figura 3.15 é apresentada a estrutura interna de um possível objeto de aprendizado associado ao domínio de conhecimento envolvendo o critério Análise de Mutantes (DeMillo et al., 1978). Por exemplo, são abordados os conceitos: Critério Análise de Mutantes, Mutante, Mutante Morto, Mutante Equivalente, Mutante Error-Revealing, Operador de Mutaçãoe Escore de 


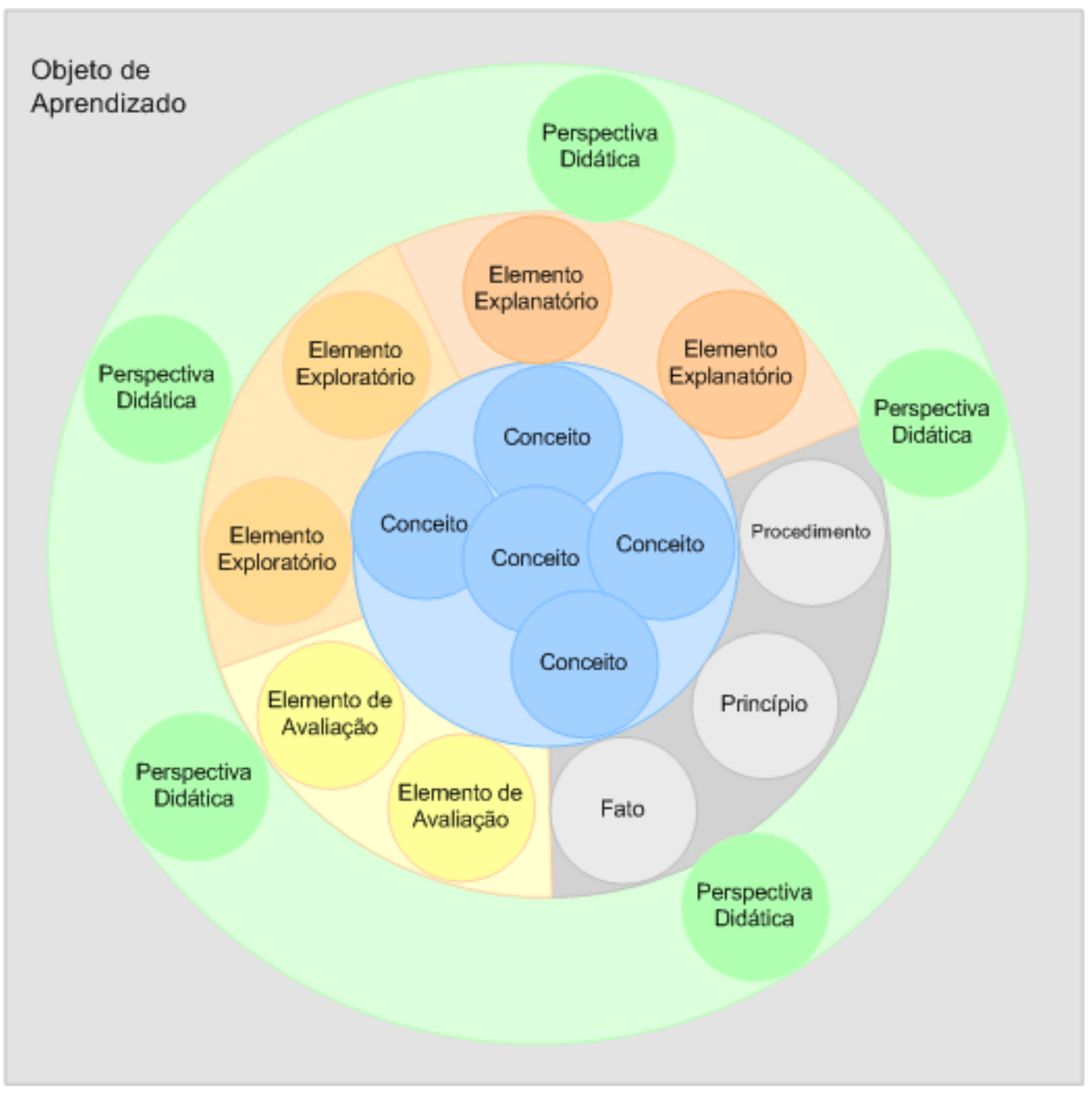

Figura 3.14: Objeto de Aprendizado: Metáfora do Átomo e Perspectivas de Modelagem.

Mutação. Tais conceitos podem ser ilustrados de forma geral - por meio do elemento explanatório Exemplo Identifier -, ou de forma específica - por meio dos elementos Exemplo Mutante e Exemplo Operador de Mutação, os quais ilustram os conceitos Mutante e Operador de Mutação, respectivamente.

Um elemento exploratório - Exercício Fatorial - também foi especificado, tendo como objetivos: praticar os conceitos e estimular discussão e revisão crítica. O elemento de avaliação Experimento Análise de Mutantes, por sua vez, visa a fixar o conhecimento e a avaliar o desempenho dos aprendizes.

Além disso, a fim de fornecer informação adicional sobre o assunto, itens de informação foram especificados: Hipótese do Programador Competente e Efeito de Acoplamento correspondem a princípios; Abordagens Alternativas correspondem a fatos; e Aplicação da Análise de Mutantes representa um procedimento.

É interessante observar que o mapeamento de itens de informação e elementos instrucionais para a estrutura interna dos objetos de aprendizado pode ser útil na definição da granularidade de tais objetos. Tal aspecto foi preliminarmente explorado no artigo Exploring Learning Objects un- 


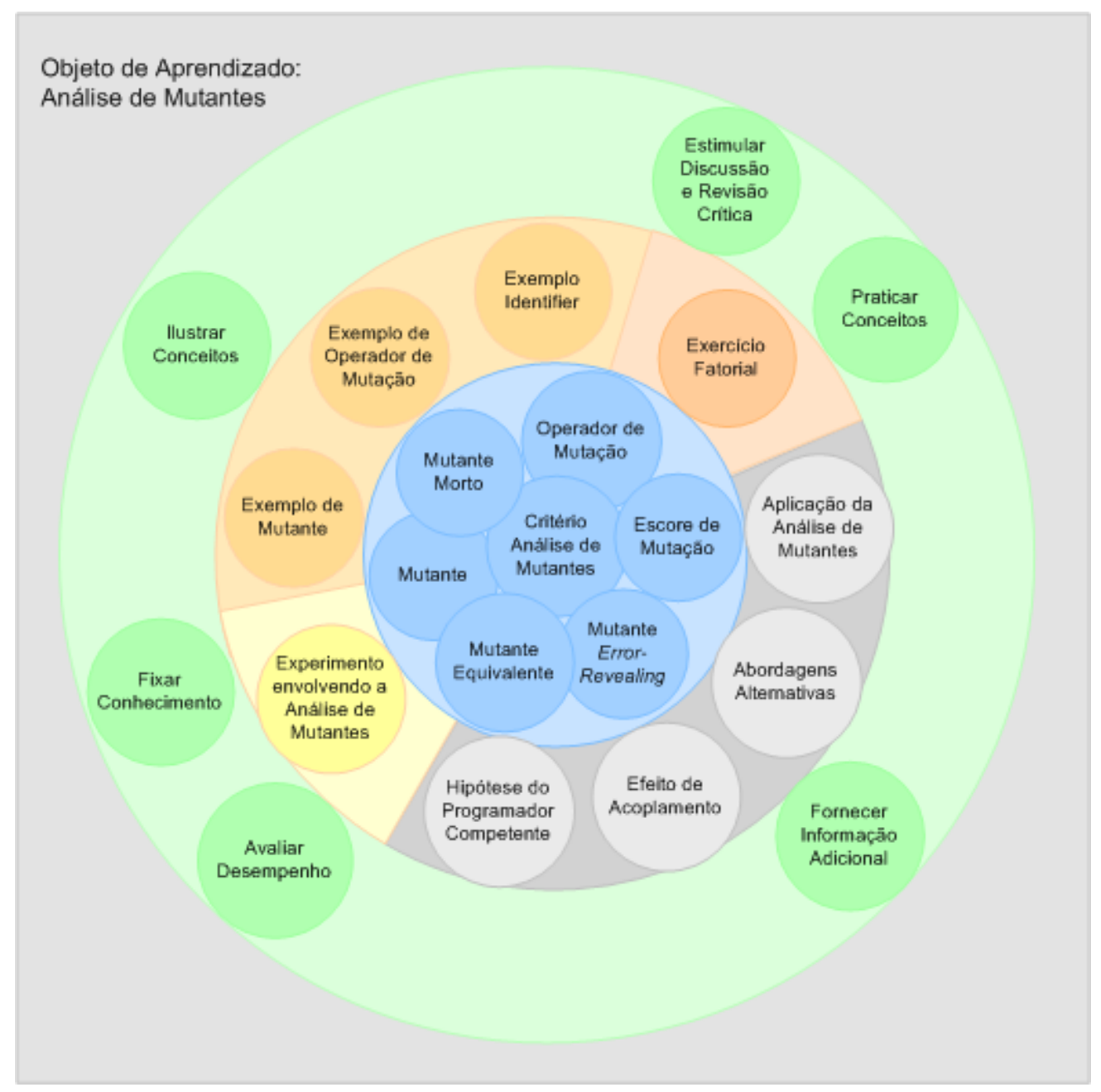

Figura 3.15: Objeto de Aprendizado para o Critério Análise de Mutantes.

der Conceptual, Instructional and Didactic Perspectives (Barbosa et al., 2003d), apresentado na I PGL Data Base Research Conference (PGL DB'2003), devendo ser investigado mais detalhadamente em pesquisas futuras, decorrentes dos desdobramentos do presente trabalho de doutorado.

Ainda no contexto de objetos de aprendizado, mecanismos de modelagem também podem ser investigados no armazenamento e recuperação dos componentes do objeto. Nesse sentido, as perspectivas de modelagem identificadas foram integradas em um meta-modelo ${ }^{3}$ de desenvolvimento, ilustrado na Figura 3.16.

Em linhas gerais, os objetos representados no meta-modelo correspondem a itens de informação - conceitos, fatos, princípios e procedimentos - e elementos instrucionais - exemplos, informações complementares, exercícios e avaliações. Além disso, regras de interação entre os objetos também são representadas. A especificação dos objetos representados no meta-modelo foi feita em RDF (Resource Description Framework) (World Wide Web Consortium (W3C), 2003) - uma infra-estrutura que permite a especificação, troca e reuso de metadados estruturados. Ressalta-se

\footnotetext{
${ }^{3} \mathrm{O}$ meta-modelo foi elaborado em inglês a fim de garantir uniformidade com as especificações de metadados do padrão IEEE LTSC LOM (IEEE Learning Technology Standards Committee, 2002).
} 


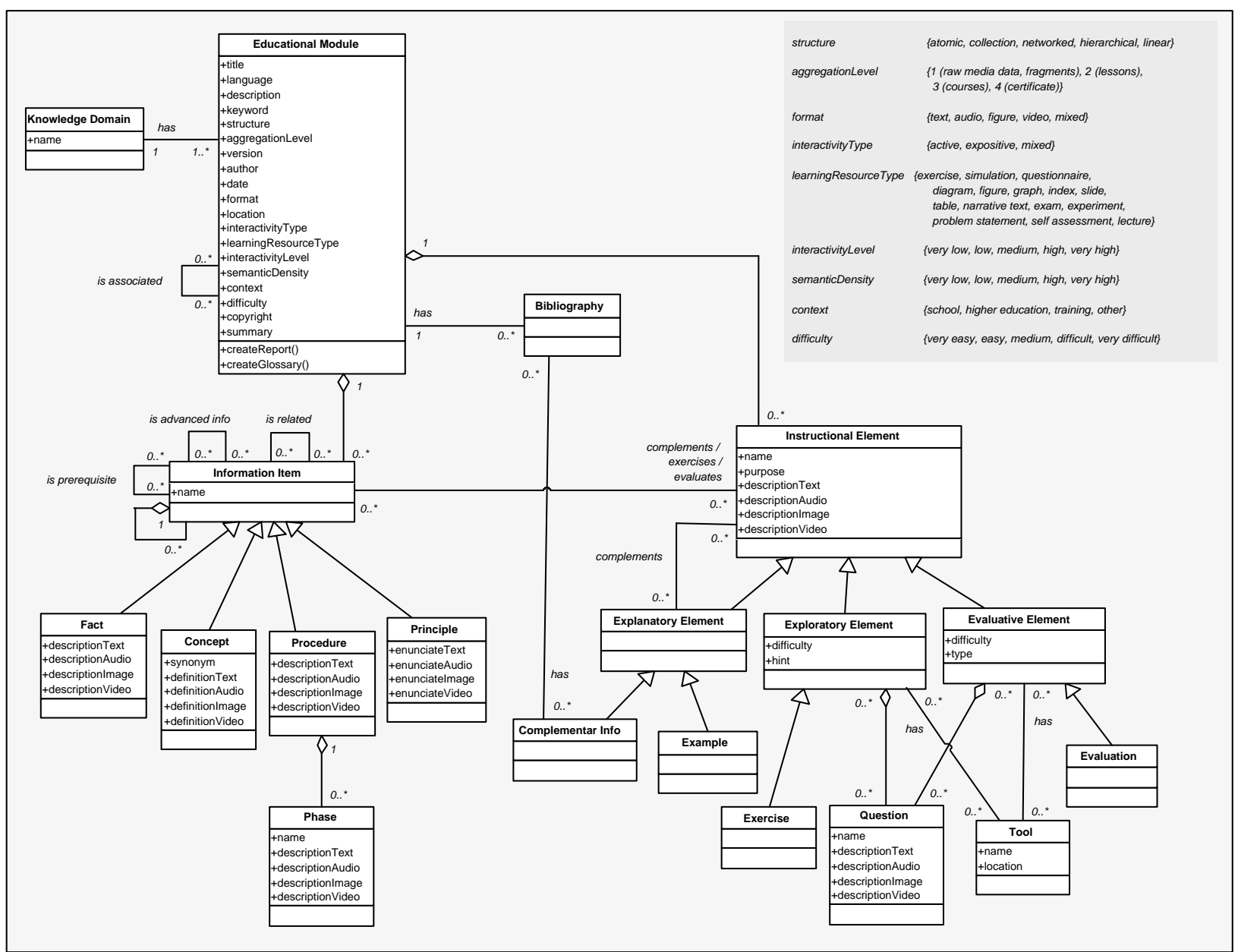

Figura 3.16: Meta-Modelo: Integração das Perspectivas de Modelagem de Conteúdos Educacionais.

ainda que as especificações estão em conformidade com o padrão IEEE LTSC LOM (Learning Objects Metadata) (IEEE Learning Technology Standards Committee, 2002), de modo a facilitar a integração e o reuso dos componentes armazenados em diferentes objetos e contextos de aprendizado.

A aplicação prática do meta-modelo e suas especificações associadas na construção de objetos de aprendizado deve ser investigada futuramente, como parte dos desdobramentos deste trabalho.

Ressalta-se, ainda, que a utilização do meta-modelo proposto não está limitada ao escopo de desenvolvimento de objetos de aprendizado. De fato, o meta-modelo pode ser explorado no projeto e implementação de outras aplicações no contexto educacional. Nessa direção, atualmente vem sendo desenvolvido um sistema para gerenciamento das bases conceituais (Bianchini et al., $2003)^{4}$ visando a apoiar as operações de inserção, remoção, atualização e consulta sobre itens de informação e elementos instrucionais.

\footnotetext{
${ }^{4}$ Trabalho de iniciação científica apoiado pela FAPESP (Processo 03/04271-7), conduzido pelo aluno de graduação Sandro Lopes Bianchini, sob orientação do Prof. José Carlos Maldonado e colaboração da doutoranda.
} 
De modo geral, o objetivo é que tais bases atuem como mecanismos de apoio tanto na definição e estruturação dos módulos, em termos de seus componentes internos, como na integração e reuso com outros módulos já existentes. Adicionalmente, tais bases podem ser utilizadas como dicionários de termos, estabelecendo um vocabulário comum a respeito do domínio de conhecimento, compartilhado entre todos os membros da equipe de desenvolvimento e entre os próprios usuários (instrutores/mediadores e aprendizes) do módulo.

É importante ressaltar que tanto o sistema de gerenciamento como as bases conceituais associadas vêm sendo projetados de forma a possibilitar sua aplicação em quaisquer domínios de conhecimento. Inicialmente, uma base conceitual para o domínio de Teste de Software vem sendo desenvolvida. Ainda, tais mecanismos deverão ser considerados e integrados ao processo instanciado para a elaboração de módulos educacionais (discutido no Capítulo 5), representando aspectos de melhoria do mesmo.

\subsection{Considerações Finais}

Neste capítulo foram discutidos e investigados aspectos pertinentes à modelagem de conteúdos educacionais - uma das atividades relevantes dentro do processo de desenvolvimento de módulos educacionais.

Inicialmente, um conjunto de nove requisitos pertinentes à atividade de modelagem foi proposto: taxonomia de conceitos, composição de conceitos, relacionamentos específicos, decomposição hierárquica, diferenciação entre categorias do conhecimento, ordem pedagógica, contextos de aprendizado, história, e propagação de eventos. Os requisitos foram definidos procurando levar em consideração as perpectivas de desenvolvimento de módulos educacionais - estruturação, evolução, transferência e reuso do conhecimento - também identificadas neste capítulo, tendo como principal objetivo fornecer subsídios à construção, comparação, avaliação e seleção de modelos para representação de conteúdos educacionais. Perspectivas de modelagem, visando a apoiar a caracterização de modelos para representação de conteúdos também foram identificadas.

A partir das perspectivas identificadas e levando em consideração os requisitos de modelagem estabelecidos, um conjunto de modelos genéricos para a representação de conteúdos educacionais foi caracterizado - Modelo Conceitual, Modelo Instrucional e Modelo Didático. Em linhas gerais, o Modelo Conceitual consiste em uma descrição de alto-nível do domínio de conhecimento, sendo responsável pela representação dos conceitos associados e seus inter-relacionamentos. O Modelo Instrucional é responsável pela definição dos itens de informação e elementos instrucionais a serem utilizados no processo de ensino e aprendizado. O Modelo Didático associa os objetos anteriormente modelados, estabelecendo pré-requisitos e seqüências de apresentação entre eles.

A caracterização do estado da arte em termos das abordagens que apóiam a modelagem de conteúdos educacionais também foi conduzida, sendo os requisitos e modelos genéricos propostos aplicados em sua comparação. De modo geral, observou-se que, enquanto algumas abordagens 
são adequadas ao tratamento de aspectos conceituais, outras incorporam elementos relevantes sob a perspectiva instrucional e outras, ainda, demonstram grande poder expressivo na representação de aspectos didáticos (e de navegação).

Os aspectos observados motivaram a proposição de uma abordagem integrada de modelagem, procurando ressaltar os pontos fortes e minimizar as limitações identificadas nas abordagens de modelagem existentes. A abordagem proposta, denominada $\mathcal{A}$ LM-CLD, baseia-se na técnica de Mapas Conceituais e no modelo HMBS, estabelecendo algumas restrições/extensões aos mesmos a fim de permitir que os modelos associados sejam representados com maior riqueza de detalhes. No nível conceitual, mapas conceituais foram estendidos com primitivas específicas para a representação de taxonomia e composição de conceitos. No nível instrucional, foi proposto o modelo $\mathcal{H M B S} /$ Instrucional, estendendo o HMBS a fim de permitir a representação de diferentes categorias de conhecimento. Além disso, apenas os aspectos de decomposição hierárquica foram considerados no modelo. No nível didático, foi proposto o modelo HMBBS/Didático, o qual incorpora ao HMBS original a idéia de estados $D D$, utilizados na especificação dos aspectos de navegação associados ao conteúdo educacional.

Finalmente, a integração dos mecanismos de modelagem identificados neste trabalho também foi analisada como apoio à estruturação, armazenamento e recuperação de componentes internos de objetos de aprendizado. Estudos preliminares conduzidos nessa direção foram discutidos.

No próximo capítulo, a elaboração de módulos educacionais é abordada sob uma perspectiva mais abrangente, envolvendo a padronização, especialização e instanciação de processos para seu desenvolvimento. Além dos aspectos de modelagem discutidos neste capítulo, práticas de projeto instrucional, fatores gerenciais e aspectos organizacionais associados à construção dos módulos são considerados. 



\section{CAPÍTULO}

\section{4}

\section{Padronização de Processos para Elaboração de Módulos Educacionais}

\subsection{Considerações Iniciais}

No Capítulo 3 foi discutida uma atividade específica do processo de desenvolvimento de módulos educacionais - a modelagem de conteúdos educacionais. O desenvolvimento de tais módulos, no entanto, requer que além de aspectos essencialmente técnicos, fatores gerenciais e organizacionais sejam considerados. Questões específicas associadas ao aprendizado, tais como a aplicação de teorias e princípios educacionais e a seleção de ferramentas apropriadas ao ensino e treinamento, também são fundamentais.

Em virtude da diversidade e complexidade dos fatores envolvidos, a elaboração de módulos educacionais demanda tempo e recursos (humanos, técnico-administrativos e econômicos), não podendo ser considerada uma atividade trivial. Nesse sentido, é fundamental a aplicação de práticas sistemáticas e disciplinadas que garantam a produtividade do processo de desenvolvimento e a qualidade dos módulos gerados.

O estabelecimento de um processo padrão insere-se nesse contexto, definindo uma estrutura única de desenvolvimento a ser adotada e respeitada pela organização. Para a aplicação prática do processo padrão estabelecido, é necessário que os processos sejam definidos caso a caso, considerando aspectos específicos da organização e das equipes de desenvolvimento envolvidas, bem como características de cada projeto em particular. De fato, atividades de especialização e instanciação também devem ser conduzidas. 
Este capítulo discute aspectos referentes à padronização de processos para o desenvolvimento de módulos educacionais, sendo estabelecido um processo padrão para a elaboração de tais módulos. Aspectos associados à especialização e instanciação de processos também são abordados e uma instância do processo padrão para módulos educacionais, adequada a projetos em que os módulos desenvolvidos são disponibilizados presencialmente, é estabelecida.

Inicialmente, na Seção 4.2 são sintetizados os principais aspectos considerados no estabelecimento do processo padrão para módulos educacionais. Entre os aspectos discutidos destacam-se práticas de projeto instrucional e questões associadas ao desenvolvimento de produtos livres e ao desenvolvimento colaborativo e distribuído. Na Seção 4.3 é apresentada uma visão geral do processo padrão definido. Como base para o estabelecimento do processo é utilizada a norma ISO/IEC 12207, adaptada ao contexto de produção de módulos educacionais. As atividades do ciclo de vida de um módulo são estabelecidas por meio de três classes de processos: (1) Processos Fundamentais, (2) Processos de Apoio e (3) Processos Organizacionais. A adequação do processo padrão quanto às perspectivas de desenvolvimento consideradas na construção de módulos educacionais - estruturação, evolução, transferência e reuso do conhecimento - é discutida na Seção 4.4. Detalhes sobre os processos definidos, em termos das atividades e tarefas estabelecidas, são descritos na Seção 4.5 .

A Seção 4.6 descreve um modelo para a definição de processos, caracterizando, em linhas gerais, as atividades de definição, especialização e instanciação de processos ${ }^{1}$. Aspectos de especialização do processo padrão para módulos educacionais são tratados na Seção 4.7. Além disso, um modelo de maturidade - o $\mathcal{C M M} /$ Educacional - é proposto e discutido como mecanismo de apoio à especialização do processo padrão em diferentes níveis de maturidade.

Finalmente, na Seção 4.8 são ilustrados aspectos pertinentes à instanciação do processo padrão em um projeto específico. O processo instanciado é descrito em termos dos recursos humanos, métodos e técnicas de desenvolvimento, e recursos tecnológicos e computacionais adotados.

\subsection{Aspectos de Desenvolvimento na Definição do Pro- cesso Padrão}

No estabelecimento do processo padrão para módulos educacionais foram considerados aspectos específicos de desenvolvimento - práticas de projeto instrucional e modelagem de conteúdos educacionais - bem como questões genéricas associadas ao desenvolvimento de produtos livres e ao desenvolvimento colaborativo e distribuído. Aspectos de modelagem de conteúdos educacionais foram abordados no Capítulo 3. Os demais aspectos de desenvolvimento considerados na definição do processo são discutidos nas próximas seções.

\footnotetext{
${ }^{1} \mathrm{O}$ modelo apresentado nessa seção foi proposto por Maidantchik (1999), no contexto de software. Os aspectos abordados no modelo são igualmente válidos no caso de módulos educacionais.
} 


\subsubsection{Projeto Instrucional}

O Projeto Instrucional (Instructional Design) (Clark, 2003; Kruse, 2003; Lee \& Owens, 2000) consiste na aplicação sistemática de princípios científicos sobre como as pessoas aprendem visando ao desenvolvimento de instrução.

Os objetivos do Projeto Instrucional são alcançados por meio de cinco fases - Análise, Projeto, Desenvolvimento, Implementação e Avaliação - referenciadas como modelo ADDIE (Analysis, Design, Development, Implementation, Evaluation). Tais fases são aplicadas iterativamente, sendo que os resultados provenientes de cada fase servem como entrada para a fase subseqüente. Embora vários modelos para o Projeto Instrucional tenham sido desenvolvidos, a maioria deles está baseada no modelo genérico ADDIE:

- Análise: Nesta fase, sub-dividida por alguns autores em Needs for Instruction e Front-End Analysis, determinam-se aspectos tais como as necessidades de aprendizado, níveis atuais e desejados de conhecimento e/ou desempenho, perfil dos aprendizes e metas de aprendizado.

- Projeto: Esta fase é responsável por estabelecer os objetivos de aprendizado a serem atingidos. Conteúdo, atividades práticas e instrumentos de avaliação também são especificados nesta etapa.

- Desenvolvimento: Nesta fase são selecionadas as tecnologias de desenvolvimento adequadas e o módulo educacional propriamente dito é construído. As mídias que compõem o módulo são criadas e as ferramentas e recursos específicos ao domínio de conhecimento em questão são integrados.

- Implementação: Nesta fase o módulo é disponibilizado aos aprendizes.

- Avaliação: Esta fase é responsável por medir a efetividade do aprendizado proporcionado a partir da utilização do módulo, contrapondo-se os resultados de aprendizado obtidos aos objetivos previamente especificados.

É importante ressaltar que a teoria de Projeto Instrucional não trata da estruturação interna do conteúdo educacional, em termos de conceitos e elementos instrucionais associados. Em outras palavras, aspectos pertinentes à modelagem de conteúdos educacionais não são especificados nas práticas de projeto estabelecidas. Indicações sobre como transferir o conhecimento do especialista de domínio (subject matter expert) para o projetista instrucional (instructional designer) também não são fornecidas.

\subsubsection{Desenvolvimento de Produtos Livres}

Nos últimos anos, o movimento de software livre tem sido alvo de grande atenção entre pesquisadores e desenvolvedores, tanto na indústria como em universidades e centros de pesquisa (Feller 
\& Fitzgerald, 2000; McConnell, 1999; O’Reilly, 1999; Raymond, 2003; Zhao \& Elbaum, 2000). Entre as razões que têm impulsionado o interesse por esse tipo de software destacam-se (Davis et al., 2000): estabilidade, portabilidade para várias plataformas, suporte aos usuários por parte dos desenvolvedores, acesso ao código-fonte, e baixo custo (não é preciso pagar pelas licenças).

De modo geral, um software é considerado livre quando é acompanhado de uma permissão para uso, cópia, distribuição e redistribuição, realizando ou não modificações, de forma gratuita ou mediante uma taxa. O código-fonte deve acompanhar o software para que a realização de modificações seja possível. As modificações não precisam ser comunicadas, mas devem ser identificadas e disponibilizadas abertamente (Davis et al., 2000; McConnell, 1999).

A definição de software livre pode ser estendida ao contexto de desenvolvimento de produtos educacionais sob a idéia de um módulo educacional livre (ou mesmo material didático livre). Nesse caso, o módulo possui uma licença de uso e distribuição, sendo permitido a seus usuários realizar alterações nos conteúdos disponibilizados de modo a adequá-los a seus objetivos e necessidades de aprendizado.

Dentro da perspectiva apresentada, o desenvolvimento de módulos educacionais pode ser abordado, sob vários aspectos, em conformidade com as características e princípios do desenvolvimento de software livre. Na verdade, traçando um paralelo entre ambos, uma série de características de desenvolvimento em comum pode ser observada.

A primeira delas refere-se à evolução contínua, em que versões atualizadas do software são lançadas com muito mais freqüência, em resposta às necessidades e opiniões dos usuários. Essa mesma característica também constitui um aspecto essencial no desenvolvimento de módulos educacionais, sobretudo em virtude do caráter dinâmico e evolutivo inerente ao conhecimento, a partir do qual os módulos são constantemente evoluídos como resultado das experiências de aprendizado. A perspectiva de evolução do conhecimento no contexto de módulos educacionais foi discutida na Seção 3.2.

A dispersão geográfica dos desenvolvedores, participando da construção do produto de forma colaborativa e, muitas vezes, voluntária, é outro aspecto identificado tanto no desenvolvimento de software livre como na elaboração de módulos educacionais. A idéia básica é que qualquer desenvolvedor pode contribuir para o produto (software ou módulo educacional) e que as contribuições serão filtradas de forma "darwiniana", ou seja, o melhor código (no caso dos módulos, o melhor conteúdo) sobreviverá, sendo incorporado ao produto em questão. Ressalta-se, nesse caso, a necessidade de intensa coordenação entre desenvolvedores. Considerações pertinentes ao desenvolvimento distribuído e colaborativo são abordadas separadamente, na próxima seção.

Finalmente, o desenvolvimento de produtos livres requer um conjunto de tecnologias colaborativas (correio eletrônico, listas de discussão, web, sistemas de controle de versões, repositórios de informação, entre outros), de modo a garantir a comunicação e a interação entre os vários desenvolvedores. No caso de módulos educacionais, o uso de tecnologias colaborativas é fundamental não apenas no processo de desenvolvimento, mas também durante a disponibilização e utiliza- 
ção do módulo, como forma de viabilizar a condução das atividades e avaliações propostas aos aprendizes.

Em virtude das peculiaridades associadas aos produtos livres, os modelos de desenvolvimento investigados em sua construção também apresentam um conjunto de características bastante diferentes em relação aos modelos de desenvolvimento tradicionais (Feller \& Fitzgerald, 2000; O’Reilly, 1999). Raymond (2003) caracteriza dois tipos de modelos: (1) o modelo Catedral, baseado na concepção tradicional de desenvolvimento de software; e (2) o modelo Bazar, voltado ao desenvolvimento de produtos livres. O modelo Bazar apresenta como principais características: desenvolvimento compartilhado e distribuído, tempo de desenvolvimento curto, e alta qualidade (tanto com respeito à presença de características desejáveis como em relação ao número reduzido de defeitos). Além disso, uma característica marcante é o tempo de resposta para a correção dos defeitos, os quais são corrigidos em um tempo bem menor, se comparado com defeitos de softwares proprietários. O modelo requer ainda uma pessoa (ou grupo de pessoas) que centralize o processo.

É importante salientar que, apesar das pesquisas conduzidas no sentido de entender e sistematizar o processo de desenvolvimento de software livre, este ainda não se encontra definitivamente estabelecido (Davis et al., 2000; Feller \& Fitzgerald, 2000; O’Reilly, 1999). Contudo, é possível identificar algumas atividades principais, ainda que as mesmas não estejam formalmente definidas (Vixie, 1999): especificação de requisitos, projeto e implementação. Na maioria dos projetos de desenvolvimento livre, no entanto, o produto é codificado diretamente, sem que seja dada ênfase às fases de especificação de requisitos e projeto.

Ainda como mecanismos a serem investigados dentro do escopo do desenvolvimento de produtos livres podem-se destacar as metodologias ágeis, as quais têm surgido como uma alternativa aos modelos de processo de desenvolvimento tradicionais. De modo geral, essas metodologias visam a melhorar a eficiência da organização na construção de seus produtos ao mesmo tempo em que procuram diminuir a "burocracia" do desenvolvimento (Maurer \& Martel, 2002). Como exemplos mais significativos dentre as metodologias ágeis estão a eXtremme Programming (XP) (Beck, 1999b,a), a Feature-Driven Development (FDD) (Coad \& Palmer, 2002) e o SCRUM (Rising \& Janoff, 2000).

Apesar dos esforços identificados, ainda não há um consenso a respeito do rigor e formalismo a serem impostos ao processo de desenvolvimento de produtos livres de modo a não restringir suas características fundamentais. De fato, evidencia-se a necessidade de um equilíbrio entre práticas sistemáticas e bem definidas de desenvolvimento e sua aplicação flexível como parte de um processo padrão.

As questões discutidas nesta seção mostram-se extremamente pertinentes quando se tem por objetivo a construção de um módulo educacional livre. Tendo em vista que o processo padrão para elaboração de módulos educacionais pretende ser o mais genérico possível, tais questões também foram consideradas em sua definição. Nesse sentido, a aplicação do processo padrão na construção de um módulo educacional livre pode ser vista como uma possível instância do 
mesmo. Ressalta-se ainda que o estabelecimento de metodologias ágeis para o desenvolvimento de módulos educacionais, baseadas nas atividades e tarefas identificadas no escopo do processo padrão proposto, constitui uma das linhas de pesquisa futura decorrente do presente trabalho de doutorado.

\subsubsection{Desenvolvimento Colaborativo e Distribuído}

Conforme discutido na seção anterior, a presença de desenvolvedores dispersos colaborando entre si para a construção de um determinado produto constitui uma das características fundamentais do desenvolvimento de produtos livres. Ressalta-se, entretanto, que a colaboração e a distribuição de equipes e profissionais de desenvolvimento não são exclusividade de softwares livres, podendo ser observadas no desenvolvimento dos mais variados tipos de produto.

A construção de módulos educacionais, por exemplo, pode envolver desenvolvedores de diversas áreas de conhecimento, trabalhando em equipes multi-disciplinares e heterogêneas, geograficamente dispersas ou não. Tais equipes devem cooperar e interagir entre si, compartilhando dados e informações pertinentes ao projeto - especificações, modelos de domínio, conteúdos, resultados de testes e desempenho dos aprendizes, entre outros. Além disso, a capacidade das equipes de desenvolvimento pode variar, não apenas em função de recursos humanos, mas também quanto a recursos tecnológicos, computacionais e econômicos disponíveis. Por fim, as atividades conduzidas por uma determinada equipe podem ser essenciais para a realização das tarefas de outras equipes, caracterizado relações de dependência entre elas.

Aspectos do desenvolvimento colaborativo e distribuído de software foram enfatizados no trabalho de Maidantchik (1999). Foram identificadas as principais características e problemas do desenvolvimento distribuído de software, a partir dos quais foi estabelecido um processo de software padrão para equipes geograficamente dispersas. Em linhas gerais, Maidantchik (1999) observa que a qualidade dos produtos desenvolvidos por equipes geograficamente dispersas depende de uma comunicação efetiva, da coordenação dos grupos distribuídos, do rastreamento sistemático das atividades e artefatos, e da disponibilidade das informações referentes ao processo de software. De maneira similar, as características e problemas identificados no desenvolvimento distribuído de software também podem ser observados no contexto de desenvolvimento de módulos educacionais:

- Coordenação de equipes: Envolve a interação e a supervisão das equipes de desenvolvimento. O estabelecimento da capacidade de cada equipe e a atribuição de atividades e responsabilidades em função das competências e habilidades de seus membros também deve ser tratado.

- Coordenação das atividades: O fluxo de trabalho deve ser controlado. Identificam-se tarefas concorrentes e que exigem colaboração entre as equipes. A sincronização das tarefas também deve ser considerada. 
- Controle de artefatos (sub-produtos): Envolve problemas de integração dos componentes do módulo (mídias e infra-estrutura), autoria e modelagem distribuídas, visibilidade de avaliações e resultados de desempenho, notificação de modificações, gerência de configuração.

- Apoio à comunicação: Refere-se a todos os aspectos do desenvolvimento que necessitam da troca de informações entre as equipes, a fim de proporcionar a gerência efetiva do processo.

Dentro da perspectiva apresentada, aspectos referentes ao desenvolvimento distribuído, em conformidade com aqueles investigados por Maidantchik (1999) no contexto de produção de software, também foram investigados e incorporados ao processo padrão para módulos educacionais. O processo padrão estabelecido neste trabalho é apresentado nas próximas seções.

\subsection{Visão Geral do Processo Padrão}

Em vários aspectos de desenvolvimento, a produção de módulos educacionais assemelha-se à produção de software. No caso de software, métodos, ferramentas e procedimentos têm sido definidos e integrados visando ao estabelecimento de processos sistemáticos que resultem em produtos confiáveis e eficientes (Pressman, 2001; da Rocha et al., 2001).

A norma internacional ISO/IEC 12207 (International Organization for Standardization, 1995) insere-se nessa perspectiva, visando a definir e a padronizar os processos e as atividades básicas que compõem o processo de desenvolvimento de um software. A padronização de processos resulta em um processo de software padrão responsável por descrever os elementos fundamentais que devem ser incorporados em qualquer processo definido para a organização desenvolvedora. Ainda, atividades de especialização e instanciação do processo padrão também podem ser conduzidas de modo a adequá-lo às características específicas da organização e do projeto sendo executado (da Rocha et al., 2001).

De maneira análoga, a necessidade de práticas sistemáticas e disciplinadas que garantam a produtividade do processo de desenvolvimento e a qualidade dos produtos gerados também pode ser observada no contexto de módulos educacionais. Nesse sentido, procurou-se estabelecer um processo padrão para o desenvolvimento de tais módulos, apoiado na identificação de aspectos e características similares àquelas observadas na produção de software.

O processo padrão definido teve como base a norma ISO/IEC 12207 (International Organization for Standardization, 1995). As atividades do ciclo de vida de um módulo educacional foram estabelecidas por meio de três classes de processos: Processos Fundamentais, Processos de Apoio e Processos Organizacionais. Embora os objetivos e a organização geral de tais classes tenham sido mantidas em relação à norma, foram necessárias adaptações em sua estrutura interna (em termos de processos, atividades e tarefas) de modo a adequá-la à produção de módulos educacionais. Além disso, atividades e tarefas pertinentes ao processo padrão para equipes geograficamente dispersas (Maidantchik, 1999) também foram consideradas. 
A Figura 4.1 ilustra a estrutura geral do processo padrão para a elaboração de módulos educacionais. Processos em laranja foram extraídos da norma ISO/IEC 12207 e adaptados ao contexto de ensino e treinamento. Processos em verde foram extraídos e adaptados a partir do processo padrão para equipes geograficamente dispersas. Processos em azul são específicos ao contexto de módulos educacionais, tendo sido incluídos como resultado do presente trabalho de doutorado.

\begin{tabular}{|c|c|c|}
\hline \multicolumn{2}{|c|}{ Processos Fundamentais } & Processos de Apoio \\
\hline \multicolumn{2}{|c|}{ Aquisição } & Documentação \\
\hline \multicolumn{2}{|c|}{ Definição } & Publicação de Resultados \\
\hline \multicolumn{2}{|c|}{ Fornecimento } & Gerência de Configuração \\
\hline \multicolumn{2}{|c|}{ Planejamento } & Gerência do Conhecimento \\
\hline \multirow{6}{*}{ Desenvolvimento } & \multirow[b]{2}{*}{ Operação } & Garantia da Qualidade \\
\hline & & Verificação \\
\hline & \multirow{2}{*}{ Disponibilização } & Validação \\
\hline & & Revisão Conjunta \\
\hline & \multirow{2}{*}{ Manutenção } & Auditoria \\
\hline & & Resolução de Problemas \\
\hline \multicolumn{3}{|c|}{ Processos Organizacionais } \\
\hline \multicolumn{2}{|c|}{ Capacitação } & Comunicação \\
\hline \multicolumn{2}{|c|}{ Gerência } & Coordenação \\
\hline \multicolumn{2}{|c|}{ Controle de Artefatos } & Infra-Estrutura \\
\hline \multicolumn{2}{|c|}{ Melhoria } & Treinamento \\
\hline & \multicolumn{2}{|c|}{ Copyright e Licença } \\
\hline
\end{tabular}

Figura 4.1: Estrutura Geral do Processo Padrão para Módulos Educacionais.

A Figura 4.2 apresenta uma síntese das categorias de processo estabelecidas pela norma ISO/IEC 12207, pelo processo padrão para equipes geograficamente dispersas e pelo processo padrão para módulos educacionais.

Comparados aos processos fundamentais da norma ISO/IEC 12207, os processos fundamentais para módulos educacionais diferem, sobretudo, com respeito à inclusão do Processo de Disponibilização, que trata das atividades e tarefas do instrutor/mediador do módulo.

Além disso, foram incorporados dois outros processos - Definição e Planejamento - extraídos e adaptados a partir do processo padrão para equipes distribuídas (Maidantchik, 1999). Em seu trabalho, Maidantchik (1999) estabelece tais processos em substituição aos processos de Aquisição 
Norma ISO/IEC 12207

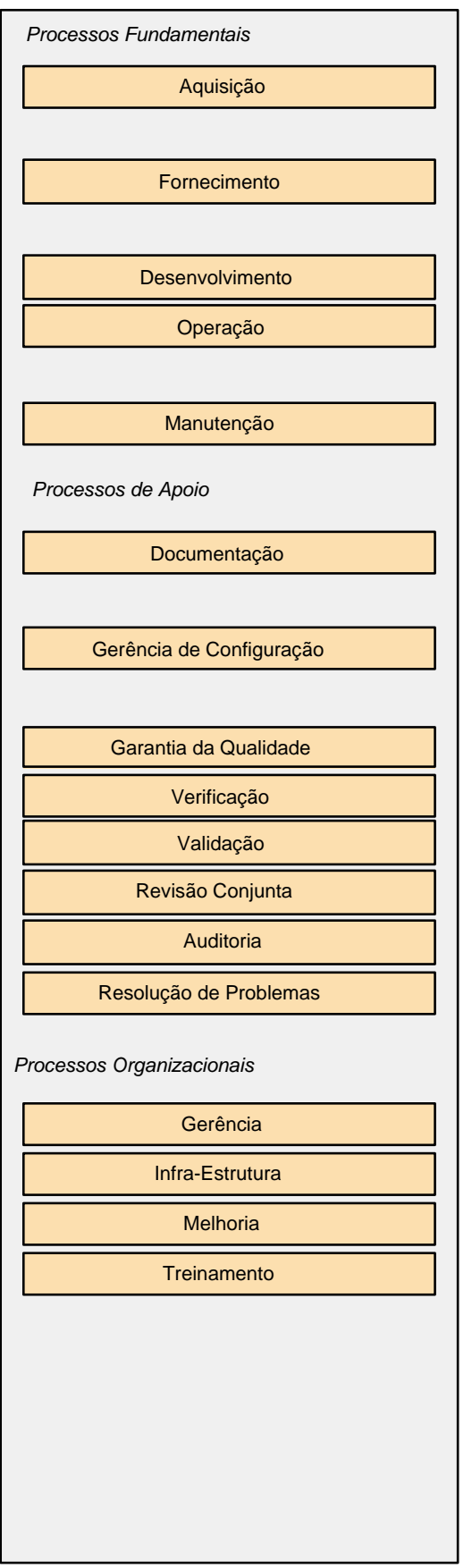

Equipes Geograficamente Dispersas

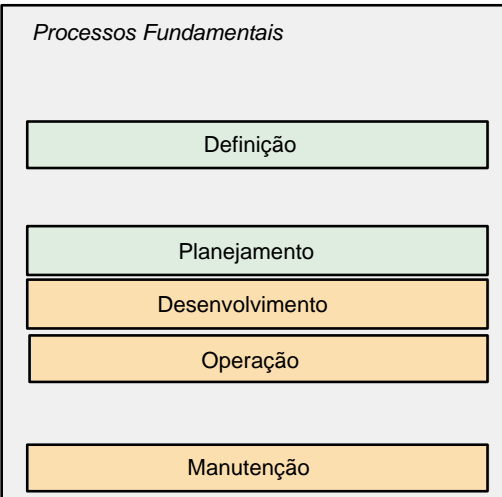

Processos de Apoio

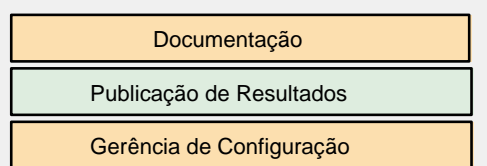

Gerência de Configuração

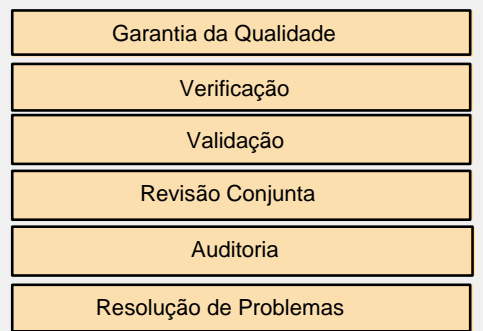

Processos Organizacionais

\begin{tabular}{|c|}
\hline Gerência \\
\hline Infra-Estrutura \\
\hline Melhoria \\
\hline Treinamento \\
\hline Capacitação \\
\hline Comunicação \\
\hline \hline Coordenação \\
\hline Controle de Artefatos \\
\hline
\end{tabular}

Módulos Educacionais

\begin{tabular}{|c|}
\hline Processos Fundamentais \\
\hline Aquisição \\
\hline Definição \\
\hline Fornecimento \\
\hline Planejamento \\
\hline Desenvolvimento \\
\hline Operação \\
\hline Disponibilização \\
\hline Manutenção \\
\hline
\end{tabular}

Processos de Apoio

\begin{tabular}{|c|}
\hline Documentação \\
\hline \hline Publicação de Resultados \\
\hline \hline Gerência de Configuração \\
\hline Gerência do Conhecimento \\
\hline Garantia da Qualidade \\
\hline \hline Verificação \\
\hline \hline Validação \\
\hline \hline Revisão Conjunta \\
\hline Auditoria \\
\hline Resolução de Problemas \\
\hline
\end{tabular}

Processos Organizacionais

\begin{tabular}{|c|}
\hline Gerência \\
\hline \hline Infra-Estrutura \\
\hline Melhoria \\
\hline Treinamento \\
\hline \hline Capacitação \\
\hline \hline Comunicação \\
\hline \hline Coordenação \\
\hline \hline Controle de Artefatos \\
\hline Copyright e Licença \\
\hline
\end{tabular}

Figura 4.2: Norma ISO/IEC 12207 x Processo Padrão para Equipes Geograficamente Dispersas x Processo Padrão para Módulos Educacionais.

e Fornecimento (definidos pela norma ISO/IEC 12207), deixando de abordar aspectos referentes à preparação, atualização, monitoramento e conclusão de contratos de desenvolvimento. Conseqüentemente, as noções de adquirente e fornecedor também não são abordadas. No caso do processo padrão para módulos educacionais, tais aspectos foram preservados e tratados especificamente nos processos de Aquisição e Fornecimento. Optou-se, entretanto, por manter a separação entre questões associadas à aquisição do módulo e aspectos pertinentes à definição do projeto. Da 
mesma forma, aspectos de fornecimento do módulo e de planejamento do projeto também foram abordados separadamente.

Nos demais processos dessa categoria, foram realizadas as alterações necessárias à sua adaptação ao novo contexto de desenvolvimento. Nesse sentido, as práticas de projeto instrucional encontram-se "diluídas" nas atividades e tarefas pertinentes aos processos fundamentais. A Tabela 4.1 ilustra a correspondência entre as fases do modelo ADDIE e as categorias de processos fundamentais definidas. Observa-se que os processos de Aquisição e Fornecimento não foram incluídos na tabela uma vez que o modelo ADDIE não possui fases específicas que tratem tais aspectos.

Tabela 4.1: Correspondência entre as Fases do Modelo ADDIE e os Processos Fundamentais.

\begin{tabular}{||l|l||}
\hline \hline Fases do Modelo ADDIE & Processos Fundamentais \\
\hline \hline Avaliação das Necessidades & Definição \\
\hline Front-End Analysis & Desenvolvimento \\
\hline \hline \multirow{2}{*}{ Projeto } & Planejamento \\
\cline { 2 - 2 } & Desenvolvimento \\
\hline \hline Desenvolvimento & Desenvolvimento \\
\hline \hline \multirow{2}{*}{ Implementação } & Operação \\
\cline { 2 - 2 } & Disponibilização \\
\hline \hline Revisão & Manutenção \\
\hline \hline
\end{tabular}

No caso particular do Processo de Desenvolvimento, além das práticas de projeto instrucional também foram incorporados aspectos específicos referentes à modelagem de conteúdos educacionais, investigados no Capítulo 3.

Os processos de apoio para módulos educacionais diferem daqueles estabelecidos na norma ISO/IEC 12207 pela inclusão do Processo de Publicação de Resultados, extraído de (Maidantchik, 1999), e pela definição do Processo de Gerência do Conhecimento, responsável por tratar os aspectos pertinentes ao gerenciamento e controle do conhecimento sob o qual o módulo está fundamentado. Ressalta-se que o Processo de Gerência do Conhecimento foi estabelecido no contexto de produção de módulos educacionais, não possuindo correspondentes na norma ISO/IEC 12207 e no processo padrão para equipes distribuídas.

Observa-se ainda que, embora o Processo de Auditoria não tenha sido incluído no processo padrão definido por Maidantchik (1999) ${ }^{2}$, este foi preservado no estabelecimento do processo padrão para módulos educacionais.

Quanto aos processos organizacionais, tanto os processos definidos pela norma como os processos estabelecidos para equipes geograficamente dispersas foram considerados. Além disso, foi definido o Processo de Copyright e Licença, tratando aspectos pertinentes aos direitos autorais e termos de uso e distribuição do módulo.

\footnotetext{
${ }^{2}$ Sem a noção de aquisição e fornecimento, aspectos de auditoria também podem ser desconsiderados.
} 
Processos fundamentais, de apoio e organizacionais são descritos mais detalhadamente na Seção 4.5.

\subsection{Adequação do Processo às Perspectivas de Desen- volvimento de Módulos Educacionais}

Nesta seção as atividades e tarefas estabelecidas pelo processo padrão para módulos educacionais são exploradas quanto à sua adequação às perspectivas de desenvolvimento de módulos educacionais - estruturação, evolução, transferência e reuso do conhecimento -, discutidas na Seção 3.2. A Figura 4.3 relaciona os processos definidos a tais perspectivas.

De modo geral, os processos fundamentais relacionam-se às perspectivas de desenvolvimento da seguinte forma:

- O Processo de Definição aborda a estruturação do conhecimento na medida em que estabelece atividades envolvendo a construção de repositórios de terminologias.

- O Processo de Planejamento aborda aspectos pertinentes à transferência, evolução e reuso do conhecimento ao estabelecer atividades envolvendo a determinação de ferramentas educacionais, mecanismos de captura e padrões para especificação de metadados.

- O Processo de Desenvolvimento apóia as perspectivas de estruturação e reuso do conhecimento. A estruturação do conhecimento é enfatizada nas atividades de projeto, envolvendo a construção de modelos conceituais, instrucionais e didáticos, e na atividade de atualização de repositórios de terminologias. Aspectos de reuso do conhecimento são abordados na elaboração de modelos didáticos e na construção e atualização de metadados.

- O Processo de Operação aborda a transferência e a evolução do conhecimento ao estabelecer atividades para o teste e suporte operacional envolvendo a integração de ferramentas de apresentação, de colaboração, de avaliação, de captura e ferramentas específicas ao domínio de conhecimento.

- O Processo de Disponibilização aborda a transferência e a evolução do conhecimento, estabelecendo atividades que apóiam a apresentação de conteúdos e a condução de tarefas e avaliações associadas, e a captura de discussões ocorridas (presenciais ou virtuais).

- O Processo de Manutenção apóia estruturação e o reuso do conhecimento na medida em que define atividades para a manutenção de repositórios de terminologias e manutenção de metadados.

Os processos de apoio, por sua vez, satisfazem as perspectivas de desenvolvimento da seguinte maneira: 


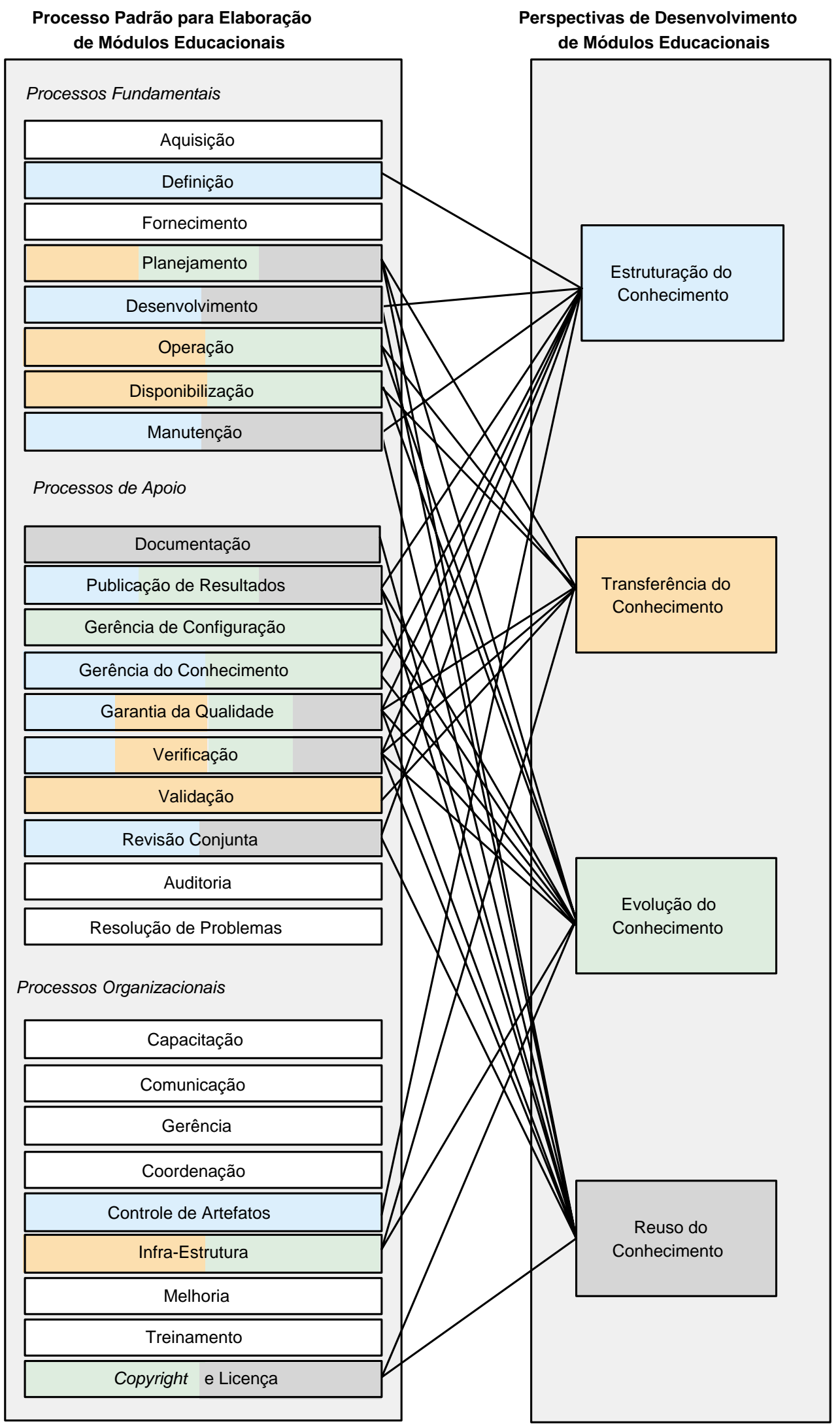

Figura 4.3: Processo Padrão x Perspectivas de Desenvolvimento de Módulos Educacionais. 
- O Processo de Documentação aborda o reuso do conhecimento, estabelecendo documentos para a especificação de metadados.

- O Processo de Publicação de Resultados aborda aspectos de estruturação, evolução e reuso, proporcionando o compartilhamento de informações tais como: modelos para representação dos conteúdos educacionais, dicionários de termos, novos conhecimentos incorporados, resultados sobre o desempenho dos aprendizes e metas de aprendizado alcançadas, metadados, entre outras.

- O Processo de Gerência de Configuração apóia, juntamente com o Processo de Gerência do Conhecimento, a evolução do conhecimento, garantindo o controle sobre os itens de informação e elementos instrucionais alterados/evoluídos. O Processo de Gerência do Conhecimento, em especial, também inclui atividades a fim de preservar a estruturação do conhecimento.

- O Processo de Garantia da Qualidade, por meio das relações estabelecidas com os processos de Verificação, Validação e Revisão Conjunta, trata, indiretamente, as mesmas perspectivas de desenvolvimento abordadas por tais processos.

- O Processo de Verificação aborda, de maneira geral, todas as perspectivas de desenvolvimento consideradas, estabelecendo atividades para verificar os modelos pertinentes aos conteúdos educacionais, a integração entre ferramentas e mecanismos de apoio e os padrões de metadados especificados.

- O Processo de Validação aborda, indiretamente, a transferência do conhecimento, proporcionando mecanismos para a análise dos resultados obtidos a partir da utilização do módulo em relação às metas inicialmente estabelecidas.

- O Processo de Revisão Conjunta aborda a estruturação e o reuso do conhecimento por meio de revisões técnicas conduzidas nos modelos para representação de conteúdos e nas especificações de metadados, entre outros sub-produtos considerados.

Quanto aos processos organizacionais, esses relacionam-se às perspectivas de desenvolvimento como se segue:

- O Processo de Controle de Artefatos apóia a estruturação do conhecimento na medida em que proporciona mecanismos para o planejamento e controle da elaboração e integração dos conteúdos que compõem o módulo.

- O Processo de Infra-Estrutura é relevante sob as perspectivas de transferência e evolução do conhecimento, estabelecendo atividades a fim de manter a infra-estrutura e a integração de ferramentas educacionais, ferramentas específicas ao domínio de conhecimento, ferramentas de captura, entre outras. 
- O Processo de Copyright e Licença aborda, indiretamente, aspectos de evolução e reuso do conhecimento ao estabelecer os termos de modificação e redistribuição do módulo.

Observa-se que nem todos os processos estão relacionados às perspectivas de desenvolvimento de módulos educacionais. De fato, no caso das categorias de processos fundamentais e de apoio, alguns deles são especificamente voltados a aspectos contratuais (Aquisição, Fornecimento, Auditoria). O Processo de Resolução de Problemas, em especial, aborda aspectos envolvendo o próprio processo padrão definido. Quanto à categoria de processos organizacionais, a maioria dos processos estabelecidos tratam aspectos pertinentes à organização e às equipes de desenvolvimento.

\subsection{Processos do Ciclo de Vida de um Módulo Educaci- onal}

Os processos, atividades e tarefas pertinentes às categorias de processos fundamentais, de apoio e organizacionais são descritos a seguir. Quando pertinente, os processos também são analisados quanto à sua adequação em projetos tradicionais e em projetos envolvendo o desenvolvimento de produtos educacionais livres. A título de ilustração, apenas algumas das atividades de cada processo são consideradas. O processo padrão completo, contendo todos os processos, atividades e tarefas estabelecidas, encontra-se disponível no relatório técnico Módulos Educacionais: Definição de um Processo Padrão de Desenvolvimento (Barbosa \& Maldonado, 2004), que se encontra em fase final de elaboração.

\subsubsection{Processos Fundamentais}

Segundo a norma ISO/IEC 12207, os processos fundamentais são responsáveis por estabelecer as principais atividades e tarefas a serem realizadas durante o ciclo de vida do produto. No contexto de produção de software, vários modelos (Cascata, Prototipagem, RAD, Incremental, Espiral, Concorrente, RUP) podem ser utilizados no estabelecimento do ciclo de vida (Pressman, 2001; da Rocha et al., 2001).

Considerando o desenvolvimento de módulos educacionais, aspectos referentes ao projeto instrucional (Clark, 2003; Kruse, 2003; Lee \& Owens, 2000) têm sido investigados. Conforme discutido anteriormente, os objetivos do projeto instrucional são alcançados por meio de cinco fases (Kruse, 2003), correspondendo ao modelo genérico ADDIE. Tal modelo forma a base sob a qual grande parte das abordagens de desenvolvimento instrucional existentes estão fundamentadas (Clark, 2003).

Os processos fundamentais adaptados ao contexto de desenvolvimento de módulos educacionais buscam incorporar, em especial, algumas das principais práticas propostas pelo modelo ADDIE, juntamente com atividades específicas voltadas à modelagem de conteúdos. Oito processos fundamentais foram estabelecidos nesse contexto: (1) Processo de Aquisição; (2) Processo 
de Definição; (3) Processo de Fornecimento; (4) Processo de Planejamento; (5) Processo de Desenvolvimento; (6) Processo de Operação; (7) Processo de Disponibilização; e (8) Processo de Manutenção.

\section{Processo de Aquisição}

O Processo de Aquisição é responsável por estabelecer um contrato para o desenvolvimento e definir as atividades e tarefas a serem realizadas pelo adquirente, ou seja, aquele que tem a necessidade de obter o módulo educacional. Por obtenção entende-se a aquisição, o desenvolvimento ou a melhoria do módulo educacional. Por adquirente entende-se um comprador (irá adquirir o módulo pronto, já desenvolvido), um cliente (irá contratar um serviço terceirizado para o desenvolvimento do módulo), um proprietário (irá desenvolver o módulo) ou um usuário (irá evoluir o módulo já em utilização).

Como atividades pertinentes ao Processo de Aquisição têm-se: (1) preparação do pedido de proposta; (2) preparação e atualização do contrato; (3) monitoramento do fornecedor; (4) documentação do processo de aquisição; e (5) aceitação e conclusão.

As atividades identificadas correspondem àquelas definidas no processo de aquisição da norma ISO/IEC 12207 para tratar o estabelecimento, monitoramento e aprovação do contrato (juntamente com o fornecedor). Atividades relacionadas à definição dos requisitos e às necessidades do adquirente são abordadas, em separado, no Processo de Definição.

Considerando o contexto de desenvolvimento de módulos educacionais livres, embora a idéia de aquisição possa não fazer muito sentido, aspectos referentes a direitos autorais (copyright) e à licença do módulo (termo de distribuição que garante legalmente os direitos de usar, copiar, modificar e redistribuir o módulo ou qualquer sub-produto derivado) podem ser tratados dentro do escopo das atividades que estabelecem o contrato.

\section{Processo de Definição}

O Processo de Definição é responsável por determinar o problema de aprendizado a ser solucionado, identificando as necessidades do adquirente e estabelecendo os requisitos a serem satisfeitos. Dependendo do contexto de desenvolvimento, o Processo de Definição pode ser aplicado isoladamente ou em complemento ao Processo de Aquisição.

Como atividades pertinentes ao Processo de Definição têm-se: (1) definição do problema e das necessidades de aprendizado; (2) definição inicial dos requisitos; (3) análise da viabilidade do projeto; (4) determinação do escopo do módulo; (5) construção do repositório de terminologias; (6) documentação do processo de definição; e (7) revisão e aprovação.

A maioria das atividades identificadas corresponde às atividades pertinentes ao processo de definição, estabelecido no contexto de desenvolvimento distribuído (Maidantchik, 1999). As adaptações mais significativas ocorreram na atividade de definição do problema e das necessidades de 
aprendizado, à qual foram incorporadas algumas das práticas propostas na sub-fase de Avaliação das Necessidades do modelo ADDIE (Clark, 2003; Kruse, 2003; Lee \& Owens, 2000). Entre as tarefas associadas destacam-se:

- Determinação da condição de aprendizado atual: Conhecimento e habilidades ausentes bem como eventuais problemas ocorridos na transferência de conhecimento devem ser identificados.

- Definição das metas de aprendizado e habilidades associadas: Definem-se as metas de aprendizado e o tipo de conhecimento e habilidades requeridas para alcançá-las. A situação ideal de aprendizado é definida e comparada à situação atual.

- Ordenação das metas conforme sua importância: Listam-se, segundo sua relevância, as metas de aprendizado a serem alcançadas, identificando-se ainda os inter-relacionamentos entre elas.

- Identificação de discrepâncias de aprendizado: Diferenças entre o desempenho de aprendizado ideal e o desempenho atual são determinadas. Identificam-se os fatores que levam à necessidade de desenvolvimento instrucional, ou seja, as causas da necessidade.

Ressalta-se ainda a importância da atividade de construção do repositório de terminologias, por meio da qual é elaborado um dicionário de termos sobre o domínio de conhecimento em questão. Essa atividade foi inicialmente estabelecida em (Maidantchik, 1999) e representa um mecanismo de apoio para que as equipes de desenvolvimento distribuídas compartilhem conceitos e informações pertinentes, adotando uma terminologia uniforme e consistente durante todo o projeto. Nesse sentido, a construção de um dicionário de termos é relevante não apenas sob a perspectiva de colaboração e distribuição, mas também quanto ao aspecto de desenvolvimento de produtos livres.

Observa-se, por fim, que tais repositórios podem ser estendidos para mecanismos mais elaborados, como bases conceituais ou mesmo ontologias de domínio, permitindo que todo o conhecimento a partir do qual o módulo está fundamentado seja armazenado e compartilhado entre as equipes de desenvolvimento.

\section{Processo de Fornecimento}

O Processo de Fornecimento é responsável por estabelecer as atividades e tarefas do fornecedor do módulo educacional, em especial aquelas associadas ao estabelecimento do contrato (juntamente com o adquirente) e à execução e controle dos planos de projeto elaborados no Processo de Planejamento.

Como atividades pertinentes ao Processo de Fornecimento têm-se: (1) iniciação; (2) preparação da resposta; (3) contrato; (4) execução e controle; (5) revisão e avaliação; (6) documentação do processo de fornecimento; e (7) entrega e conclusão. 
As atividades identificadas correspondem àquelas definidas no processo de fornecimento da norma ISO/IEC 12207, com exceção da atividade de planejamento, tratada separadamente no Processo de Planejamento, discutido a seguir.

Assim como observado no Processo de Aquisição, ainda que a idéia de fornecimento não pareça muito adequada ao contexto de desenvolvimento de produtos livres, aspectos referentes a (copyright) e licença de uso podem ser abordados durante o estabelecimento do contrato.

\section{Processo de Planejamento}

No Processo de Planejamento é conduzida uma revisão dos requisitos do módulo visando a definir sua estrutura geral e estabelecer os planos a serem utilizados para gerenciar o projeto e garantir a qualidade do módulo.

Como atividades pertinentes têm-se: (1) especificação inicial; (2) determinação dos componentes do módulo educacional; (3) planejamento; (4) determinação de padrões; (5) documentação do processo de planejamento; e (6) revisão e aprovação.

O Processo de Planejamento teve como base o processo de planejamento estabelecido por Maidantchik (1999), ao qual foram incorporadas práticas referentes à fase de Projeto do modelo ADDIE. Considerando a atividade de planejamento, destacam-se as seguintes tarefas associadas:

- Definição da estrutura geral do módulo: Reúnem-se informações gerais sobre o módulo, (necessidades de aprendizado, desempenho atual dos aprendizes e obstáculos ao aprendizado, nível de desempenho desejável e resultados esperados, restrições de projeto, entre outras). É feita uma revisão das metas de aprendizado e dos principais requisitos do módulo educacional. Determinam-se partes relevantes do domínio de conhecimento a serem abordadas e possíveis sub-módulos são identificados. A estrutura geral do módulo é definida.

- Planejamento das equipes de desenvolvimento: Identificam-se e selecionam-se os papéis apropriados à execução do projeto. Cada papel especificado possui um conjunto de responsabilidades e atribuições associado ${ }^{3}$. Definem-se as equipes e seus membros. As atividades dos processos de desenvolvimento, operação, disponibilização e manutenção são atribuídas conforme a capacidade de cada equipe e a partir da estrutura geral do módulo. A eventual necessidade de treinamento dos membros das equipes, seja em aspectos técnicos de desenvolvimento ou em aspectos específicos pertinentes ao domínio de conhecimento em questão, deve ser identificada.

- Determinação da metodologia, padrões e ferramentas: Estabelecem-se os métodos e procedimentos a serem adotados pelas equipes durante o desenvolvimento, operação, disponibili-

\footnotetext{
${ }^{3}$ Em linhas gerais, a equipe de desenvolvimento pode apresentar os seguintes papéis: gerente de projeto, coordenador de equipe, especialista de domínio (subject matter expert), analista, projetista instrucional (instructional designer), implementadores (diretor de criação, projetista gráfico, produtor de vídeo, produtor de áudio, técnico em vídeo, técnico em áudio, editor), operador, mantenedor, administrador de recursos e gerente de versões.
} 
zação e manutenção do módulo. Definem-se padrões de especificação para o módulo educacional. A construção de metadados pode ser considerada. Determinam-se os mecanismos e ferramentas de representação a serem adotados na especificação dos modelos conceitual, instrucional e didático. Padrões de desenvolvimento abordando estilo de escrita e normas de gramática, padrões de edição, padrões de realimentação e interação, tratamento de áudio e vídeo, padrões gráficos e padrões de navegação, entre outros, são especificados. Ferramentas de desenvolvimento, ferramentas educacionais e ferramentas específicas ao domínio de conhecimento são identificadas.

As atividades estabelecidas pelo Processo de Planejamento desempenham um papel importante em projetos de desenvolvimento tradicional, devendo ser executadas e documentadas com certo rigor e formalismo. Além disso, considerando a existência de várias equipes de trabalho distribuídas, tais atividades devem ser estruturadas em dois níveis (Maidantchik, 1999): um referente a cada equipe de trabalho, e outro pertinente ao projeto como um todo.

No caso de desenvolvimento módulos educacionais livres, por outro lado, tais atividades devem ser conduzidas de modo mais flexível, algumas delas podendo inclusive ser suprimidas. Ainda assim, ênfase deve ser dada ao planejamento das equipes, selecionando os desenvolvedores e atribuindo papéis e tarefas adequadas a cada um deles, de acordo com seus próprios interesses e motivações para a participação no projeto.

\section{Processo de Desenvolvimento}

O Processo de Desenvolvimento é responsável por tratar as atividades que compõem o ciclo de vida de desenvolvimento do módulo educacional. Como atividades que compõem o processo têmse: (1) implantação do processo; (2) análise; (3) projeto; (4) implementação e integração; (5) teste; (6) instalação do módulo no ambiente educacional; (7) construção e atualização de metadados; (8) atualização do repositório de terminologias; (9) documentação do processo de desenvolvimento; e (10) apoio à aceitação do módulo.

A análise de requisitos do módulo educacional tem como principal finalidade obter informações detalhadas sobre $o$ quê será desenvolvido. A análise detalhada de cada componente do módulo é realizada a partir das necessidades de aprendizado, identificadas no Processo de Definição, e dos requisitos iniciais e da estrutura geral do módulo educacional, resultantes do Processo de Planejamento. As tarefas pertinentes à análise foram definidas a partir da sub-fase de Front-End Analysis do modelo ADDIE. Entre as tarefas estabelecidas destacam-se:

- Análise de audiência: Determina-se o perfil demográfico da audiência (idade, sexo, nível de escolaridade e conhecimentos gerais). Diferenças culturais entre os aprendizes são identificadas. Coletam-se dados referentes ao tipo e tom de linguagem mais adequados ao públicoalvo. Requisitos especiais em função da condição física do aprendiz bem como aspectos 
ergonômicos devem ser considerados. Determina-se o perfil de aprendizado da audiência. Informações referentes a estilos de aprendizado são coletadas. Identificam-se as motivações e frustrações do aprendiz em relação ao domínio de conhecimento abordado. Determinamse o conhecimento prévio e as habilidades específicas no referido domínio. Interesses e expectativas de aprendizado quanto aos tópicos a serem cobertos são identificados.

- Análise tecnológica: Analisam-se os recursos tecnológicos disponíveis para apoiar o desenvolvimento, operação, disponibilização e manutenção do módulo educacional. Tanto o ambiente do adquirente como o do fornecedor são analisados em relação às suas capacidades tecnológicas. Determinam-se tecnologias colaborativas e de comunicação (correio eletrônico, chat-room, newsgroups, vídeo-conferência), tecnologias para disponibilização (servidores de áudio e vídeo, infra-estrutura para captura de aulas presenciais, CD-ROM, discos, FTP) e tecnologias para a condução das avaliações do aprendiz (mecanismos de autenticação e confidencialidade das informações).

- Análise de tarefas: As tarefas que o aprendiz deve ser capaz de executar como resultado do processo de aprendizado são identificadas e descritas. Determinam-se o conhecimento, as habilidades e o comportamento que o aprendiz deve apresentar visando à execução das tarefas. A frequiência com que as tarefas são executadas, a dificuldade associada e a relevância para a experiência de aprendizado também são determinadas a fim de identificar quais delas são críticas e essenciais para que as metas de aprendizado sejam atingidas.

Além dos tipos de análise descritos acima, também devem ser conduzidas: análise dos objetivos de aprendizado, análise de métodos e mecanismos utilizados na disponibilização do módulo, análise de outros produtos (módulos) existentes, análise circunstancial (estrutura física e aspectos ambientais do local onde o módulo será utilizado) e análise dos custos envolvidos no projeto.

A atividade de projeto do módulo educacional procura estabelecer um guia de desenvolvimento para a fase de implementação e integração. Aspectos específicos abordados nesta atividade referem-se sobretudo ao entendimento e à estruturação das partes relevantes do conteúdo educacional bem como à especificação das atividades práticas e avaliações a serem associadas ao mesmo. As tarefas pertinentes à atividade de projeto estão fundamentadas nos aspectos de modelagem de conteúdos educacionais discutidos no Capítulo 3. Práticas da fase de Projeto do modelo ADDIE também foram consideradas. Entre as tarefas estabelecidas têm-se:

- Modelagem conceitual: Identificam-se os elementos conceituais relevantes do domínio de conhecimento e seus inter-relacionamentos. Relacionamentos estruturais (part-of, type-of) e relacionamentos específicos do domínio são determinados. Os elementos conceituais identificados e seus significados são incluídos e/ou atualizados no repositório de terminologias. Identificam-se possíveis sub-módulos. Modelos conceituais são elaborados tanto para o módulo completo como para cada um dos sub-módulos identificados. 
- Modelagem instrucional: Os elementos conceituais são detalhados e itens de informação associados são identificados. Determinam-se os elementos instrucionais (explanatórios, exploratórios e de avaliação) os quais devem ser associados aos itens de informação. Para cada elemento instrucional especificam-se os objetivos de aprendizado associados. Mídias apropriadas bem como ferramentas e mecanismos de apoio são especificados.

- Modelagem didática: Identificam-se os paradigmas educacionais e as estratégias de motivação a serem exploradas. Estabelecem-se os pré-requisitos e a sequiência em que itens de informação e elementos instrucionais devem ser apresentados. Especifica-se o propósito didático ao qual o elemento instrucional se destina (por exemplo, no caso de elementos de avaliação: avaliação diagnóstica, formativa ou somativa). Diferentes modelos didáticos podem ser construídos para o mesmo esquema conceitual/instrucional expressando, dessa forma, visões didáticas diferenciadas do mesmo domínio de conhecimento.

- Projeto da interface: Responsável pela definição e aplicação de padrões estéticos ao módulo.

A atividade de implementação e integração consiste no uso adequado das tecnologias previamente identificadas para a codificação e integração dos componentes do módulo educacional. Templates e outros mecanismos de apoio devem ser considerados. Mecanismos de armazenamento e manipulação das mídias são especificados e implementados. A atividade de implementação e integração corresponde à fase de Desenvolvimento proposta no modelo ADDIE.

A atividade de teste consiste na avaliação do módulo educacional implementado quanto à correção e à efetividade do aprendizado. Para o estabelecimento das tarefas associadas ao teste foram incorporadas algumas das práticas da fase de Revisão do modelo ADDIE, dentre elas:

- Verificação de padrões: Inspeciona-se o módulo quanto aos padrões de desenvolvimento estabelecidos no processo de fornecimento.

- Verificação editorial: Inspeciona-se o módulo quanto a erros de gramática, ortografia, pontuação.

- Verificação funcional: Inspeciona-se o módulo quanto a erros na lógica de navegação e na composição/sincronização das mídias.

- Validação instrucional: Inspeciona-se o módulo quanto à efetividade do aprendizado. Cursos-piloto podem ser conduzidos. Métricas previamente estabelecidas devem ser empregadas.

- Relatório de problemas: Eventuais problemas técnicos (observados durante a verificação) e problemas instrucionais (observados na validação) são reportados e divulgados às equipes de desenvolvimento. Melhorias no módulo são notificadas para versões futuras. 
Ainda como parte das atividades estabelecidas pelo Processo de Desenvolvimento, destacamse a atividade de construção e atualização de metadados, estabelecendo informações descritivas sobre o módulo, e a atividade de atualização do repositório de terminologias, extraída de (Maidantchik, 1999).

Nos projetos desenvolvidos de forma tradicional, todas as atividades definidas pelo Processo de Desenvolvimento são igualmente relevantes. Além disso, considerando a existência de equipes de trabalho distribuídas, é interessante que tais atividades sejam supervisionadas local e globalmente, ou seja, tanto no âmbito de cada equipe como no contexto geral do projeto.

Sob a perspectiva de desenvolvimento de módulos educacionais livres, a atividade central estabelecida pelo Processo de Desenvolvimento corresponde à implementação e integração do módulo educacional. Apesar disso, embora as atividades de análise e projeto sejam pouco enfatizadas, alguns de seus sub-produtos, tais como os modelos conceituais, instrucionais e didáticos, podem atuar como veículos de cooperação e comunicação entre os diversos desenvolvedores, apoiando a compreensão do domínio de conhecimento associado e a uniformidade na construção do módulo. Atividades relativas à especificação de metadados e à atualização do repositório de terminologias também podem ser executadas com esse propósito.

Com respeito aos testes, esses em geral são realizados separadamente, apenas no âmbito das necessidades e interesses específicos de cada desenvolvedor (ou equipe de desenvolvimento). Ainda assim, é possível derivar um plano integrado de teste, informal, fornecendo indicativos a respeito de quais aspectos devem ser considerados no escopo do projeto como um todo.

\section{Processo de Operação}

O Processo de Operação é responsável por tratar as atividades e tarefas do operador, abrangendo a operação do módulo educacional e o suporte operacional aos usuários (por usuários entendem-se instrutores/mediadores, aprendizes e outros desenvolvedores).

As atividades pertinentes ao Processo de Operação são: (1) implantação do processo; (2) teste operacional; (3) operação do módulo; (4) suporte operacional; (5) identificação de problemas e melhorias; e (6) documentação do processo de operação.

As atividades definidas correspondem essencialmente às estabelecidas pelo processo de operação da norma ISO/IEC 12207, adaptadas à produção de módulos educacionais a partir das práticas estabelecidas na fase de Implementação do modelo ADDIE. A título de ilustração, considere a atividade de teste operacional: ferramentas para captura e apresentação do conteúdo, mecanismos de apoio às atividades práticas (ferramentas colaborativas, de simulação, ferramentas específicas ao domínio de conhecimento) e mecanismos de apoio à avaliação do aprendiz devem ser integrados ao módulo e sua operação testada. Cursos-piloto também podem ser conduzidos.

No contexto de desenvolvimento tradicional, o Processo de Operação é conduzido de maneira centralizada. Os problemas identificados são repassados às equipes de trabalho responsáveis, e as 
melhorias e documentos resultantes das atividades do processo são compartilhados entre todos os participantes.

No caso de projetos envolvendo o desenvolvimento de módulos educacionais livres, o Processo de Operação pode ser executado de duas maneiras: localmente, no ambiente de específico de cada interessado no módulo; ou globalmente, considerando o projeto como um todo. No último caso, o operador pode ser visto como um elemento centralizador, sendo responsável por controlar mudanças e administrar as versões do módulo, e notificar e solucionar os problemas encontrados.

\section{Processo de Disponibilização}

O Processo de Disponibilização trata das atividades e tarefas do instrutor/mediador do módulo educacional. É importante salientar que esse processo foi estabelecido especificamente para o contexto de produção de módulos educacionais, não possuindo atividades e tarefas correspondentes definidas na norma ISO/IEC 12207 ou no processo padrão para equipes distribuídas. Ressalta-se ainda que o estabelecimento das atividades e tarefas associadas ao processo foi baseado nas práticas pertinentes à fase de Implementação do modelo ADDIE.

As atividades pertinentes ao Processo de Disponibilização são: (1) iniciação; (2) disponibilização do módulo; (3) acompanhamento e suporte instrucional; (4) identificação de problemas e melhorias; e (5) documentação do processo de disponibilização.

A atividade de iniciação consiste no estabelecimento das condições de aprendizado necessárias para a apresentação do conteúdo, execução de atividades práticas e avaliação de desempenho dos aprendizes. O instrutor/mediador deve preparar-se para a disponibilização do módulo (por exemplo, estar ciente de estrutura do módulo, das ferramentas educacionais e mecanismos de apoio disponíveis, do perfil dos aprendizes e dos objetivos de aprendizado). Estratégias de motivação visando a despertar a curiosidade dos aprendizes em relação aos tópicos abordados e a motivá-los à execução das atividades propostas devem ser estabelecidas.

A atividade de disponibilização do módulo trata de aspectos referentes à apresentação do conteúdo, à execução de atividades práticas e à avaliação de desempenho dos aprendizes. No caso de aulas presenciais, as discussões e experiências ocorridas em sala podem ser capturadas e armazenadas para possível integração aos conteúdos já desenvolvidos. Para os módulos disponibilizados à distância, ênfase é dada à integração das discussões e atividades ocorridas colaborativamente.

$\mathrm{Na}$ atividade de acompanhamento e suporte instrucional são estabelecidos mecanismos, manuais ou automáticos, para acompanhar e gerenciar o desempenho do aprendiz durante a apresentação do conteúdo e execução das atividades práticas e de avaliação. Realimentação quanto ao desempenho na utilização do módulo deve ser fornecida. O instrutor/mediador também é responsável por oferecer assistência aos aprendizes quanto aos aspectos conceituais e instrucionais tratados no módulo.

$\mathrm{Na}$ atividade de identificação de problemas e melhorias, as dúvidas e dificuldades observadas na utilização do módulo são documentadas e repassadas ao Processo de Manutenção. Metas 
e objetivos de aprendizado não alcançados bem como novos conhecimentos resultantes da utilização do módulo são identificados, documentados e divulgados para sua posterior integração e conseqüente evolução do módulo. Sucessos e recomendações para futuros desenvolvimentos são relatadas.

Cabe ressaltar que o Processo de Disponibilização pode ser suprimido caso o módulo educacional seja disponibilizado simplesmente com o intuito de compartilhar material didático, sem a presença de um instrutor/mediador e sem a preocupação com acompanhamento dos aprendizes, suporte instrucional ou mesmo evolução e melhoria do módulo. Neste caso, a execução das atividades pertinentes ao Processo de Operação já são suficientes.

No contexto de desenvolvimento tradicional, o Processo de Disponibilização deve ser executado de modo centralizado. Já no caso de desenvolvimento de módulos educacionais livres, as atividades estabelecidas pelo processo devem ser conduzidas localmente, no ambiente de específico de cada interessado no módulo. Entretanto, pelas próprias características inerentes a tais projetos, é interessante que os problemas e melhorias identificados durante a disponibilização do módulo sejam divulgados e compartilhados entre os demais desenvolvedores.

\section{Processo de Manutenção}

O Processo de Manutenção é responsável por estabelecer as atividades e tarefas do mantenedor do módulo educacional. A manutenção do módulo, de modo similar ao que ocorre em sistemas de software, é observada em virtude da necessidade de correção de problemas (técnicos e/ou instrucionais), incorporação de novos conhecimentos (resultantes ou não da utilização do módulo) e adaptação do módulo a eventuais mudanças tecnológicas.

Como atividades pertinentes ao processo têm-se: (1) implantação do processo; (2) análise do problema e da modificação; (3) implementação da modificação; (4) revisão/aceitação; (5) manutenção do repositório de terminologias; (6) manutenção de metadados; (7) migração; (8) documentação do processo de manutenção; e (9) descontinuação do módulo.

As atividades estabelecidas no Processo de Manutenção são similares às definidas no contexto de produção de software, sendo necessárias poucas adaptações para o escopo de módulos educacionais. Práticas da fase de Revisão do modelo ADDIE foram consideradas na adaptação do processo. A título de ilustração considere, por exemplo, atividade de implementação da modificação. Nesta atividade o mantenedor deve analisar o pedido de mudança, verificando que componentes do módulo devem ser modificados. Implementam-se as modificações reaplicando as atividades realizadas durante o desenvolvimento. O módulo alterado deve ser testado a fim de identificar e eliminar possíveis problemas técnicos e instrucionais decorrentes das alterações. Aspectos da integração do módulo ao ambiente educacional também devem ser considerados.

Salienta-se ainda que a cada modificação executada é fundamental que o dicionário de termos e os metadados também sejam atualizados e/ou evoluídos. Tais tarefas são tratadas pelas atividades de manutenção do repositório de terminologias e manutenção de metadados, respectivamente. 
Sob a perspectiva de desenvolvimento de módulos livres, o Processo de Manutenção pode ser executado, em geral, de duas formas. Na primeira delas, a manutenção do módulo é feita localmente, no contexto particular de utilização de cada desenvolvedor (ou grupo de desenvolvedores). As alterações e modificações têm caráter local e não são refletidas às demais equipes de desenvolvimento. No segundo caso, ainda que as alterações e modificações sejam executadas localmente, as mesmas são repassadas a todos os membros do projeto. Em ambos os casos, mecanismos para controle de mudanças e gerência de versões devem ser garantidos.

Salienta-se ainda que as alterações devem ser realizadas respeitando os termos de uso e modificação estabelecidos na licença do módulo. Além disso, é fundamental que as versões posteriores do módulo continuem sendo livres, ou seja, não é permitido adicionar restrições de modo a proibir aos outros usuários as liberdades principais do módulo e seus sub-produtos relacionados.

\subsubsection{Processos de Apoio}

Os processos de apoio são responsáveis por estabelecer as atividades e tarefas de suporte aos outros processos do ciclo de vida do módulo educacional, contribuindo para o sucesso e a qualidade do projeto. Dez processos de apoio foram definidos no contexto de produção de módulos educacionais: (1) Processo de Documentação; (2) Processo de Publicação de Resultados; (3) Processo de Gerência de Configuração; (4) Processo de Gerência do Conhecimento; (5) Processo de Garantia da Qualidade; (6) Processo de Verificação; (7) Processo de Validação; (8) Processo de Revisão Conjunta; (9) Processo de Auditoria; e (10) Processo de Resolução de Problemas.

\section{Processo de Documentação}

No Processo de Documentação são estabelecidas as atividades necessárias para o registro das informações produzidas ao longo do ciclo de vida do módulo educacional. Tais atividades são responsáveis por planejar, produzir e manter os documentos necessários aos profissionais de desenvolvimento e demais interessados no módulo.

As atividades associadas ao Processo de Documentação são: (1) implantação do processo; (2) projeto e desenvolvimento; (3) produção; e (4) manutenção. A título de ilustração, considere a implantação do processo. Nessa atividade cria-se um plano de documentação que identifica todos os documentos a serem produzidos durante o ciclo de vida do módulo. Tanto documentos voltados à equipe de desenvolvimento (gerentes, especialistas do domínio, projetistas instrucionais, implementadores web, entre outros) como aos usuários do módulo (instrutores/mediadores, aprendizes) devem ser especificados. Documentos pertinentes à especificação e definição dos metadados associados ao módulo educacional devem ser considerados. Especificam-se ainda os documentos para registro das evoluções decorrentes da utilização do módulo. A forma como um documento se relaciona com os demais bem como os termos para sua referência/indexação também devem ser explicitadas. 
No contexto de desenvolvimento de módulos educacionais livres, mesmo que os documentos existentes sejam simplificados e pouco formais, sua utilização nos projetos pode facilitar o entendimento das características fundamentais do módulo, apoiando ainda o compartilhamento de informações relevantes sobre o desenvolvimento.

Além disso, no caso de equipes de trabalho distribuídas (tanto no desenvolvimento livre como no desenvolvimento tradicional), o Processo de Documentação deve ser apoiado por mecanismos de comunicação, integrando recursos e ferramentas para controle de versões e concorrência. Suporte ao desenvolvimento colaborativo dos documentos também deve ser fornecido.

\section{Processo de Publicação dos Resultados}

Esse processo é responsável pela publicação dos resultados decorrentes das atividades do ciclo de vida do módulo, planejando, projetando e distribuindo informações sobre sub-produtos relacionados e sobre o estado do projeto.

Como atividades pertinentes ao Processo de Publicação de Resultados têm-se: (1) implantação do processo; (2) projeto; e (3) distribuição. Na implantação do processo define-se um plano para publicação dos resultados, identificando quais informações sobre serão publicadas (decisões e restrições de projeto, modelos de desenvolvimento, dicionário de termos, modificações/evoluções). Determina-se ainda em que etapas do ciclo de vida tais informações serão disponibilizadas às equipes de desenvolvimento. $\mathrm{Na}$ atividade de projeto são identificadas as ferramentas de comunicação a serem utilizadas na publicação dos resultados. Na atividade de distribuição, os resultados são publicados por meio das ferramentas definidas.

O Processo de Publicação de Resultados foi originalmente definido por Maidantchik (1999) no contexto de desenvolvimento colaborativo e distribuído de produtos de software. É importante observar que o processo também desempenha um papel relevante no desenvolvimento de produtos livres, uma vez que estabelece mecanismos e recursos visando a facilitar a comunicação e a colaboração entre os diversos participantes do projeto. Neste caso, ênfase é dada às atividades de projeto e distribuição, não sendo necessária a elaboração de um plano formal para publicação de resultados durante a atividade de implantação do processo.

\section{Processo de Gerência de Configuração}

O Processo de Gerência de Configuração é responsável pela aplicação de procedimentos técnicos e administrativos a fim de identificar e definir os itens de configuração do módulo ${ }^{4}$, controlar modificações e versões dos itens, registrar e relatar o estado de cada item e solicitações de modificação, garantir completitude, consistência e corretitude dos itens, e controlar o armazenamento, manipulação e entrega dos mesmos.

\footnotetext{
${ }^{4}$ Um item de configuração do módulo corresponde ao item produzido durante o processo de desenvolvimento do módulo educacional para o qual é importante que seja realizado o controle de alterações. Um conjunto de itens de configuração constitui uma configuração do módulo.
} 
As atividades pertinentes ao Processo de Gerência de Configuração são: (1) implantação do processo; (2) identificação da configuração; (3) determinação de responsabilidades; (4) controle da configuração; (5) avaliação da configuração; e (6) entrega e gerência de configuração. A título de ilustração, considere a atividade de identificação da configuração. Nela definem-se os itens do módulo e suas versões a serem controlados durante o projeto. Devem sofrer gerenciamento de configuração os itens mais utilizados no ciclo de vida, os mais genéricos, os projetados para reutilização e os que podem ser alterados por vários desenvolvedores simultaneamente (da Rocha et al., 2001). Apenas os itens selecionados são controlados, sendo que os demais itens podem ser alterados livremente. O modo como os itens se relacionam também deve ser especificado. Definem-se ainda as regras para o armazenamento e a recuperação dos itens no repositório de itens de configuração (previamente especificado e implementado).

O gerenciamento de configuração é uma atividade relevante sob a perspectiva de desenvolvimento livre visto que os produtos construídos estão em contínua evolução. No caso de software livre, por exemplo, a grande maioria dos projetos emprega alguma forma de gerência de configuração (Asklund \& Bendix, 2001; der Hoek, 2000), sendo a ferramenta CVS (Concurrent Versions System) (Morse, 1996) uma das mais utilizadas.

Além disso, cabe ressaltar que, embora nos processos tradicionais de desenvolvimento a gerência de configuração exija rigor e formalização na execução das tarefas associadas, no caso de desenvolvimento de livre essa atividade pode ser conduzida de modo mais flexível, visando a preservar as características "livres" dos produtos desenvolvidos. Na verdade, a idéia é que sejam estabelecidos mecanismos e ferramentas que proporcionem um certo grau de controle sobre os itens de configuração, sem no entanto restringir as "liberdades" de desenvolvimento.

Caso existam várias equipes de desenvolvimento distribuídas, a gerência de configuração deve ser realizada em duas fases: uma referente aos itens criados por cada equipe de desenvolvimento; outra referente aos artefatos resultantes da integração dos itens.

\section{Processo de Gerência do Conhecimento}

O Processo de Gerência do Conhecimento foi definido no contexto de desenvolvimento de módulos educacionais e é responsável por tratar os aspectos pertinentes ao gerenciamento e controle do conhecimento sob o qual o módulo está fundamentado. De modo geral, as mudanças e evoluções ocorridas no conhecimento devem ser refletidas diretamente no conteúdo educacional, em termos dos itens de conhecimento ${ }^{5}$ associados.

Como atividades pertinentes ao Processo de Gerência do Conhecimento foram estabelecidas: (1) implantação do processo; (2) identificação de itens de conhecimento; (3) determinação dos itens de configuração associados; (4) determinação de responsabilidades; (5) controle de itens de conhecimento; (6) avaliação de itens de conhecimento; e (7) entrega e gerência do conhecimento.

\footnotetext{
${ }^{5}$ No escopo das atividades e tarefas associadas ao Processo de Gerência do Conhecimento, itens de informação (conceitos, fatos, princípios, procedimentos) e objetos instrucionais (exemplos, explicações complementares, exercícios, avaliações, entre outros) serão referenciados, de modo genérico, como itens de conhecimento.
} 
$\mathrm{Na}$ atividade de implantação do processo é elaborado um plano para a gerência do conhecimento, determinando as tarefas para gerenciar o domínio de conhecimento associado ao módulo bem como os procedimentos para sua realização, as responsabilidades das equipes e as relações com os processos de desenvolvimento, disponibilização e manutenção.

A atividade de identificação de itens de conhecimento consiste na determinação dos itens de informação e objetos instrucionais a serem controlados. Tais elementos podem ser agrupados em função das partes específicas do domínio de conhecimento a que estão relacionados. Esta atividade deve ser conduzida em paralelo à atividade de determinação dos itens de configuração associados, responsável por determinar quais itens de configuração deverão ser alterados em função das modificações ocorridas nos itens de conhecimento.

As equipes responsáveis pelo controle de cada grupo de itens de conhecimento são definidas na atividade de determinação de responsabilidades.

A atividade de controle de itens de conhecimento é responsável por gerenciar e registrar as mudanças ocorridas nos itens de informação e objetos conceituais, determinando ainda as versões a eles associadas. Observa-se que esta atividade implica em que o controle dos itens de configuração pertinentes também seja realizado pelo Processo de Gerência de Configuração.

$\mathrm{Na}$ atividade de avaliação de itens de conhecimento verificam-se se as mudanças solicitadas foram respeitadas e se a nova "versão do conhecimento" (conteúdo) está em conformidade com os requisitos definidos anteriormente.

A atividade de entrega e gerência do conhecimento consiste na entrega controlada dos itens de conhecimento, verificando se os mesmos foram armazenados segundo o que foi planejado.

Por fim, ressalta-se que assim como os repositórios de itens de configuração, relevantes no contexto de gerenciamento de configuração, repositórios de itens de conhecimento também podem ser construídos como apoio à gerência de conhecimento. Uma série de mecanismos de controle pode ser especificada a fim de estabelecer um repositório de itens de conhecimento. Tais mecanismos vão desde formatos simplificados, como dicionários de termos, até construções mais elaboradas, como bases conceituais e ontologias.

Observa-se que as atividades do Processo de Gerência de Configuração são bastante semelhantes às definidas pelo Processo de Gerência do Conhecimento. A diferença está no fato de que aquelas são estabelecidas em um contexto mais abrangente, associado ao projeto do módulo educacional como um todo, enquanto estas são definidas em um nível mais específico, em termos do domínio de conhecimento. Além disso, é interessante observar que as alterações ocorridas no nível de conhecimento devem ser propagadas para o nível de projeto. Nesse sentido, a realização de atividades de gerência de conhecimento implicam na condução de atividades de gerenciamento de configuração.

Observa-se que as mesmas considerações sobre o estabelecimento de mecanismos de controle flexíveis no gerenciamento de configuração de produtos livres são válidas no escopo do Processo de Gerência de Conhecimento. 


\section{Processo de Garantia da Qualidade}

O Processo de Garantia da Qualidade é responsável pelas atividades conduzidas a fim de garantir que os processos e produtos do módulo estejam em conformidade com os requisitos especificados e com os planos estabelecidos.

Como atividades associadas ao processo têm-se: (1) implantação do processo; (2) determinação de responsabilidades; (3) projeto; (4) garantia de produtos; (5) garantia de processos. Considere a implantação do processo como exemplo. Nessa atividade são identificados os objetivos do processo de qualidade e determinadas as relações com os processos de Verificação, Validação e Revisão. Define-se um plano de garantia da qualidade incluindo padrões de qualidade, metodologias, procedimentos e ferramentas para a execução das atividades de garantia da qualidade.

Tanto no desenvolvimento tradicional como no desenvolvimento de módulos livres, requisitos e aspectos mínimos de qualidade devem ser especificados e gerenciados, com maior ou menor rigor, por meio de atividades de controle de qualidade. Neste último, tais atividades podem ser conduzidas de maneira integrada, considerando o projeto como um todo, ou localmente, no contexto de desenvolvimento de cada interessado (ou grupo de interessados) no módulo educacional.

Além disso, no caso de equipes de desenvolvimento distribuídas (tanto em projetos tradicionais como livres), para que a garantia da qualidade seja efetiva é fundamental que todas as equipes tenham acesso aos requisitos e planos de qualidade especificados.

\section{Processo de Verificação}

O Processo de Verificação é responsável por estabelecer as atividades para verificação do módulo educacional, sendo utilizado para determinar se os sub-produtos de uma atividade atendem completamente aos requisitos ou às condições impostas em atividades anteriores. Inclui análises, revisões e testes.

Como atividades pertinentes ao Processo de Verificação têm-se: (1) implantação do processo; (2) determinação de responsabilidades; (3) projeto; e (4) verificação. A atividade de verificação, por exemplo, reúne as tarefas para verificar os módulos e os processos. Na verificação de módulos são inspecionados o projeto, os modelos pertinentes ao domínio de conhecimento (conceitual, instrucional e didático), os requisitos, os objetivos e as metas de aprendizado, o conteúdo, a interface, a integração entre sub-módulos, a integração com ambientes e ferramentas educacionais, e a documentação. Na verificação dos processos, inspecionam-se os planos, a implantação dos processos, padrões e equipes de desenvolvimento.

Assim como as atividades de garantia de qualidade, atividades de verificação são relevantes tanto no desenvolvimento tradicional como no desenvolvimento de produtos livres. No desenvolvimento de módulos educacionais livres, a verificação pode ser conduzida de modo integrado, envolvendo todas as equipes desenvolvedoras, ou isoladamente, envolvendo apenas os interessa- 
dos no módulo, os quais verificam aspectos específicos ao seu contexto particular de utilização do mesmo.

No caso de equipes de desenvolvimento distribuídas, a verificação deve ser estruturada em dois níveis, conforme ressaltado por Maidantchik (1999): um referente à verificação dos subprodutos elaborados por cada equipe e outro referente à verificação dos sub-produtos resultantes da integração de resultados parciais.

\section{Processo de Validação}

O Processo de Validação é responsável por estabelecer as atividades para validação do módulo educacional, sendo utilizado para determinar se produto final atingiu os requisitos especificados.

O processo consiste nas seguintes atividades: (1) implantação do processo; (2) determinação de responsabilidades; (3) projeto; e (4) validação. A atividade de validação, por exemplo, é responsável pela análise dos resultados obtidos em relação a um objetivo (ou conjunto de objetivos) específico(s) de aprendizado. Cursos-piloto podem ser conduzidos a fim de apoiar o processo.

As considerações sobre desenvolvimento de produtos livres e equipes distribuídas, discutidas no escopo das atividades do Processo de Verificação, são igualmente válidas no contexto das atividades estabelecidas pelo Processo de Validação.

\section{Processo de Revisão Conjunta}

O Processo de Revisão Conjunta é responsável por avaliar o estado e os sub-produtos de uma atividade de projeto, envolvendo tanto aspectos técnicos como gerenciais.

O processo consiste nas atividades de: (1) implementação do processo; (2) determinação de responsabilidades; (3) projeto; (4) revisões gerenciais; e (5) revisões técnicas.

$\mathrm{Na}$ atividade de revisões gerenciais avalia-se o estado do projeto segundo o que foi estabelecido nos planos. Já na atividade de revisões técnicas são avaliados os sub-produtos e serviços, verificando-se se estão completos, se respeitam os padrões e especificações e se estão prontos para que se possa executar a próxima atividade.

De modo geral, as revisões técnicas são importantes tanto no desenvolvimento tradicional como no desenvolvimento de módulos livres. Revisões gerenciais, por sua vez, mostram-se mais adequadas ao processo tradicional de desenvolvimento.

\section{Processo de Auditoria}

No Processo de Auditoria são definidas as atividades para determinar a adequação do módulo aos requisitos, aos planos e ao contrato, quando apropriado. O processo consiste nas atividades de (1) implantação do processo; e (2) auditoria.

Auditorias são adequadas apenas no contexto de desenvolvimento tradicional, podendo ser desconsideradas no caso de projetos envolvendo o desenvolvimento de produtos livres. 


\section{Processo de Resolução de Problemas}

O Processo de Resolução de Problemas estabelece um processo para analisar e resolver os problemas encontrados durante a execução dos outros processos, identificando-se ainda tendências de novas ocorrências.

Como atividades pertinentes ao processo têm-se: (1) implantação do processo; (2) determinação de responsabilidades; e (3) resolução de problemas. A título de ilustração, considere a atividade de resolução de problemas. Quando um problema é identificado, um relatório contendo sua descrição é preparado. O documento é atualizado durante as tarefas de investigação do problema, análise e resolução.

As atividades estabelecidas pelo Processo de Resolução de Problemas podem ser exploradas no contexto de desenvolvimento de módulos educacionais livres, fornecendo meios que garantam, em tempo adequado, a análise e a resolução dos problemas identificados. Ressalta-se, entretanto, que os aspectos pertinentes à documentação produzida durante o processo devem ser flexibilizados.

\subsubsection{Processos Organizacionais}

Os processos organizacionais referem-se às características, capacitação, recursos e infra-estrutura das organizações que desenvolvem módulos educacionais, sendo empregados a fim de estabelecer e implantar a estrutura necessária para a condução das tarefas estabelecidas pelos demais processos. Além disso, processos organizacionais também são responsáveis por definir atividades para a melhoria dos recursos humanos e do próprio processo de desenvolvimento dos módulos.

Nove processos organizacionais foram definidos para a construção de módulos educacionais: (1) Processo de Capacitação; (2) Processo de Comunicação; (3) Processo de Gerência; (4) Processo de Coordenação; (5) Processo de Controle de Artefatos; (6) Processo de Infra-Estrutura; (7) Processo de Melhoria; (8) Processo de Treinamento e (9) Processo de Copyright e Licença.

\section{Processo de Capacitação}

O Processo de Capacitação é responsável pela determinação e avaliação da capacidade de cada equipe de desenvolvimento por meio da identificação de recursos humanos, computacionais e econômicos.

Como atividades pertinentes ao Processo de Capacitação têm-se: (1) implantação do processo; (2) coleta de dados; e (3) determinação de capacidades. A título de ilustração, considere a atividade de coleta de dados. São coletadas informações referentes ao número de equipes de desenvolvimento, número de membros de cada equipe, formação e experiência de cada membro (tanto em aspectos de desenvolvimento como na familiaridade com o domínio de conhecimento tratado pelo módulo educacional), lista de recursos computacionais (hardware, software - específicos ou não ao domínio de conhecimento), disponibilidade econômica, capacidades técnica e gerencial de cada equipe, entre outras. 
O Processo de Capacitação foi originalmente definido por Maidantchik (1999), no contexto de desenvolvimento de software envolvendo equipes de trabalho geograficamente dispersas. Ressaltase, entretanto, que as atividades estabelecidas pelo processo também podem ser consideradas na construção de produtos livres. De fato, conforme destacado na Seção 4.2.2, um aspecto relevante associado ao desenvolvimento livre diz respeito à seleção dos desenvolvedores e à atribuição de tarefas. Nesse sentido, a determinação e a avaliação da capacidade das equipes de trabalho envolvidas no projeto constituem aspectos importantes a serem explorados, sendo apoiados pelo Processo de Capacitação.

\section{Processo de Comunicação}

No Processo de Comunicação são abordados todos os aspectos do desenvolvimento que requerem a troca de informações entre as equipes de trabalho.

Como atividades pertinentes ao processo têm-se: (1) implantação do processo; e (2) determinação dos meios e protocolos de comunicação. Na atividade de determinação dos meios e protocolos de comunicação, por exemplo, são identificados os métodos e procedimentos, meios tradicionais ou eletrônicos para troca de informações, considerando os recursos técnicos das equipes. Protocolos de comunicação são definidos e implementados (Maidantchik, 1999).

Assim como o Processo de Capacitação, o Processo de Comunicação foi definido por Maidantchik (1999) e estabelece atividades relevantes tanto no contexto de desenvolvimento tradicional como sob a perspectiva de desenvolvimento livre, facilitando a interação entre as várias equipes de trabalho.

\section{Processo de Gerência}

No Processo de Gerência são estabelecidas as atividades genéricas aplicáveis no gerencimento de um dado processo.

Como atividades pertinentes ao Processo de Gerência têm-se: (1) início e definição do escopo; (2) planejamento; e (3) execução e controle. A título de ilustração, considere a atividade de execução e controle. Cabe ao gerente iniciar a implantação do plano de gerência e monitorar a execução do processo, informando o progresso das atividades. O gerente deve ainda investigar, analisar e solucionar problemas, bem como garantir que eventuais modificações não introduzam inconsistências em outras tarefas.

Conforme destacado anteriormente, embora o desenvolvimento de produtos livres apresente características distintas em relação ao desenvolvimento tradicional, ambos necessitam de uma pessoa (ou grupo de pessoas) que centralize o processo de construção dos produtos. Nesse sentido, o Processo de Gerência mostra-se relevante sob ambas as perspectivas de desenvolvimento. Evidentemente, a gerência em um projeto de desenvolvimento livre atua de forma mais flexível e menos rigorosa se comparada à gerência de um projeto de desenvolvimento tradicional. 


\section{Processo de Coordenação}

No Processo de Coordenação são estabelecidas as atividades para coordenar as equipes de desenvolvimento. Um coordenador é responsável por um produto ou tarefa realizada por uma dada equipe.

Compõem o Processo de Coordenação as seguintes atividades: (1) início e definição do escopo; (2) planejamento; e (3) execução e controle. Considere a atividade de início e definição do escopo. Nessa atividade determinam-se os requisitos das atividades a serem executadas e identificam-se as responsabilidades das equipes de desenvolvimento. Cabe à gerência identificar a viabilidade da realização da tarefa, determinando os recursos da equipe e avaliando sua adequação.

O Processo de Coordenação foi estabelecido no contexto de desenvolvimento distribuído (Maidantchik, 1999) e apresenta-se particularmente interessante em projetos de desenvolvimento livre, os quais requerem intensa coordenação entre os diversos desenvolvedores, em geral dispersos geograficamente.

\section{Processo de Controle de Artefatos}

O Processo de Controle de Artefatos refere-se às atividades para controlar a produção e a integração dos artefatos (sub-produtos) elaborados pelas equipes de desenvolvimento.

As atividades estabelecidas pelo processo são: (1) início e definição do escopo; (2) planejamento; e (3) execução e controle. A atividade de planejamento, por exemplo, é responsável pela definição de um plano para a elaboração de artefatos, identificando as interfaces com outros artefatos, produzidos pelas diversas equipes de desenvolvimento.

As atividades pertinentes ao Processo de Controle de Artefatos foram estabelecidas no contexto de desenvolvimento distribuído (Maidantchik, 1999), sendo aplicáveis tanto em projetos tradicionais como em projetos envolvendo o desenvolvimento de produtos livres.

\section{Processo de Infra-Estrutura}

O Processo de Infra-Estrutura é responsável por definir as atividades para estabelecer e manter a infra-estrutura necessária para a execução dos demais processos. A infra-estrutura pode incluir hardware, software, ambientes e ferramentas educacionais, ferramentas específicas do domínio de conhecimento, tecnologias colaborativas, mecanismos de comunicação (síncrona e assíncrona) e quaisquer outros recursos necessários ao desenvolvimento, operação, disponibilização e manutenção do módulo educacional.

Como atividades pertinentes ao Processo de Infra-Estrutura têm-se: (1) implantação do processo; (2) instalação da infra-estrutura; e (3) manutenção da infra-estrutura. Na atividade de instalação da infra-estrutura, por exemplo, a infra-estrutura necessária à execução dos processos é estabelecida. 
As atividades estabelecidas pelo Processo de Infra-Estrutura são relevantes em qualquer projeto de desenvolvimento, seja ele tradicional ou livre. No caso da existência de várias equipes de trabalho distribuídas, ênfase deve ser dada às tecnologias colaborativas e aos mecanismos de comunicação, tais como correio eletrônico, web, listas de discussão, sistemas de controle de versões, ferramentas para gerenciamento de concorrência, repositórios de informação, entre outros.

\section{Processo de Melhoria}

No Processo de Melhoria são estabelecidas as atividades básicas que a organização deve executar a fim de estabelecer, avaliar, medir, controlar e melhorar os processos do ciclo de vida do módulo educacional. Além de mudanças tecnológicas e mudanças no próprio processo, alterações quanto aos paradigmas e princípios educacionais adotados também devem ser consideradas.

Compõem o Processo de Melhoria as atividades de: (1) determinação do processo; (2) avaliação do processo; e (3) melhoria do processo. Considere a atividade de melhoria de processo. A organização deve sugerir mudanças e identificar os pontos fracos a fim de melhorar tanto os processos seguidos pelas equipes como o processo padrão da organização.

Embora a noção de melhoria de processo seja um tanto quanto abstrata no contexto de desenvolvimento de produtos livres, a identificação dos pontos falhos ocorridos durante o projeto pode fornecer indicativos a respeito de quais práticas devem ser reformuladas para a execução, com sucesso, de projetos semelhantes no futuro.

\section{Processo de Treinamento}

O Processo de Treinamento é responsável por estabelecer as atividades referentes à melhoria do conhecimento das equipes de desenvolvimento. Tanto habilidades gerenciais e técnicas como habilidades específicas envolvendo o domínio de conhecimento devem ser consideradas.

Como atividades estabelecidas pelo Processo de Treinamento têm-se: (1) implantação do processo; e (2) treinamento. Na atividade de implantação do processo, por exemplo, é realizada a revisão dos requisitos a fim de determinar os recursos e conhecimentos necessários para a condução das tarefas. Conforme o Processo de Capacitação, identificam-se quais equipes precisam ser treinadas e os tópicos de treinamento. Para cada equipe é estabelecido um plano de treinamento.

Como a maioria dos projetos de desenvolvimento livre envolve participantes voluntários, motivados a participar do projeto em função de interesses/problemas de desenvolvimento em comum, treinamento em técnicas e/ou conhecimentos específicos é, em geral, desnecessário. Na verdade, parte-se do pressuposto de que os participantes já têm a motivação e o conhecimento necessários para ingressarem no projeto. Por outro lado, no desenvolvimento tradicional, tal pressuposição nem sempre é verdadeira, fazendo com que o treinamento dos desenvolvedores seja uma prática fundamental para o sucesso dos projetos. 


\section{Processo de Copyright e Licença}

O Processo de Copyright e Licença é responsável por tratar as atividades que estabelecem a propriedade intelectual sobre o módulo e os detalhes para sua utilização, modificação e distribuição.

Como atividades pertinentes ao Processo de Copyright e Licença foram definidas: (1) início e definição do escopo; (2) atribuição de direitos autorais; e (3) definição dos termos de distribuição.

Na atividade de início e definição do escopo, a necessidade de copyright e de licença é determinada em função da categoria à qual o módulo pertence (proprietário, livre, domínio público). Além disso, o tipo da licença também deve ser especificado, estabelecendo a compatibilidade da licença para a eventual combinação/integração do módulo a outros módulos licenciados.

A atividade de atribuição de direitos autorais é responsável por determinar o proprietário do módulo educacional, ou seja, aquele que tem a propriedade intelectual sobre o mesmo. Um copyright é atribuído ao módulo. A atividade de definição dos termos de distribuição é responsável por estabelecer os direitos de uso, cópia, modificação e redistribuição do módulo ou qualquer sub-produto derivado, atribuindo uma licença de uso e distribuição ao módulo.

\subsection{Modelo para a Definição de Processos}

Na seção anterior foi definido um processo padrão para a elaboração de módulos educacionais, sendo estabelecidas as principais categorias de processo - fundamentais, de apoio e organizacionais - bem como as atividades e tarefas associadas, necessárias à produção sistemática dos módulos.

Embora o processo padrão defina uma estrutura única de desenvolvimento a ser adotada e respeitada pela organização, variações nas políticas e procedimentos organizacionais, nos paradigmas e princípios educacionais, nos requisitos, métodos e estratégias de desenvolvimento, no tamanho e complexidade do projeto, entre outros fatores, impactam a maneira como o produto é adquirido, definido, planejado, desenvolvido, operado, disponibilizado e mantido.

No caso de software, para serem utilizados em um projeto específico, os processos devem ser definidos caso a caso, considerando as particularidades de cada um. A definição de um processo de software deve, portanto, considerar sua adequação às tecnologias envolvidas, ao domínio de aplicação, ao tipo de software em questão, ao grau de maturidade (ou capacitação) da equipe em Engenharia de Software, às características próprias da organização, às características do projeto e da equipe (Maidantchik, 1999; da Rocha et al., 2001).

Dentro desse contexto, Maidantchik (1999) propõe um modelo para a definição de processos de software, formado por três etapas: (1) definição do processo padrão; (2) especialização do processo padrão; e (3) instanciação do processo para projetos específicos. Como resultado de tais etapas, processos de software em diferentes níveis de abstração são produzidos. A Figura 4.4 ilustra esquematicamente o modelo proposto por Maidantchik (1999). 


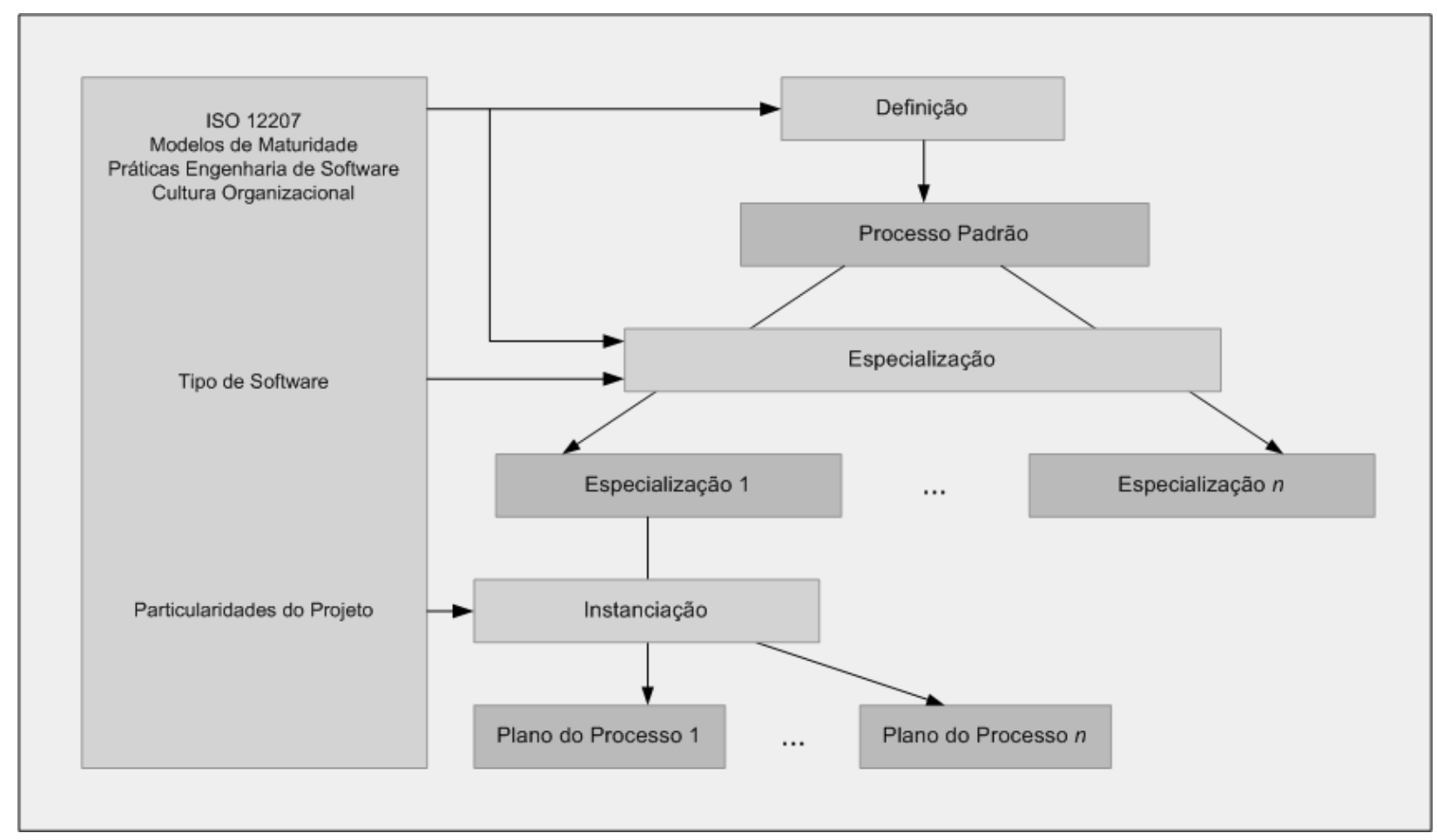

Figura 4.4: Modelo para a Definição de Processos de Software (Maidantchik, 1999; da Rocha et al., 2001).

A definição do processo padrão estabelece uma estrutura comum a ser utilizada pela organização em seus projetos de software, constituindo a base para a definição de todos os processos da mesma (da Rocha et al., 2001). São consideradas a norma ISO/IEC 12207 (International Organization for Standardization, 1995), as características de desenvolvimento na organização e, eventualmente, um modelo de maturidade relacionado à capacitação da organização (por exemplo, CMM (Paulk et al., 1995), CMMI (Software Engineering Institute, 2003), norma ISO/IEC 15504 (International Organization for Standardization, 1998), entre outros).

Diferentes processos de software podem ser especializados a partir do processo padrão definido, conforme as características de cada tipo de software. Segundo da Rocha et al. (2001), considera-se tipo de software uma determinada tecnologia de desenvolvimento (por exemplo, sistemas baseados em conhecimento, sistemas convencionais, etc.) seguindo um paradigma específico (orientado a objetos, estruturado, etc.).

Ainda assim, um dado tipo de software pode ser desenvolvido por meio de modelos de ciclo de vida distintos, utilizando-se diferentes métodos e ferramentas. Nesse sentido, para ser utilizado em um projeto específico, o processo especializado mais adequado para um determinado tipo de software deve ser instanciado a fim de atender às características do projeto. Devem ser consideradas, entre outras peculiaridades do projeto, o tamanho e a complexidade do produto, as características da equipe de desenvolvimento e a expectativa de vida útil do produto (da Rocha et al., 2001).

As considerações feitas nesta seção são igualmente válidas no caso de módulos educacionais. Em especial, as etapas do modelo para a definição de processos de software também são aplicáveis 
no estabelecimento dos processos para a elaboração de tais módulos. De fato, o estabelecimento do processo padrão, discutido na Seção 4.5, corresponde à etapa de definição do modelo proposto por Maidantchik (1999). Aspectos pertinentes à especialização e à instanciação do processo para módulos educacionais são discutidos a seguir, nas seções 4.7 e 4.8 , respectivamente.

\subsection{Aspectos de Especialização do Processo Padrão para Módulos Educacionais}

Nesta seção os aspectos de especialização do processo padrão para módulos educacionais são discutidos tendo como base a especialização do processo padrão para equipes geograficamente dispersas, conduzida por Maidantchik (1999).

Basicamente, visando a atender às diferentes características das equipes de desenvolvimento dispersas, Maidantchik (1999) propôs que o processo padrão fosse especializado de modo a permitir que cada equipe utilize um processo com nível de maturidade compatível à sua capacidade. Para especializar o processo foi estabelecido como referência um modelo, baseado no CMM (Paulk et al., 1995), no qual foram definidos os diferentes níveis de maturidade de um processo e de que forma alcançá-los.

De forma análoga, visando a fornecer subsídios para que o processo padrão para módulos educacionais possa ser especializado segundo as características das equipes envolvidas em sua construção, foi estabelecido um modelo de maturidade para módulos educacionais, a exemplo dos modelos de maturidade existentes no contexto de processos de software (CMM (Paulk et al., 1995), CMMI (Software Engineering Institute, 2003), norma ISO/IEC 15504 (International Organization for Standardization, 1998), entre outros) e do próprio modelo de maturidade de processos para equipes geograficamente dispersas (Maidantchik, 1999).

A estrutura do modelo de maturidade proposto, denominado $\mathcal{C M} /$ Educacional, é apresentada a seguir. Apenas as KPAs especificamente definidas no contexto de desenvolvimento de módulos educacionais são descritas. O modelo completo, incluindo todas as KPAs estabelecidas em cada um dos níveis de maturidade, encontra-se disponível no Apêndice A.

\subsubsection{Estrutura do Modelo de Maturidade para Módulos Educacio- nais}

De modo geral, modelos de maturidade de processos permitem analisar o processo utilizado por uma dada organização com base em um conjunto de critérios. O processo é analisado quanto à sua capacidade em construir os produtos pertinentes em conformidade com os requisitos de qualidade, respeitando os prazos e custos estabelecidos. Os fatores responsáveis pela construção de produtos de baixa qualidade ou que excedam os prazos e orçamentos estipulados também podem ser identificados. 
O modelo de maturidade de processos para elaboração de módulos educacionais - o $\mathcal{C M M} /$ Educacional - foi baseado nos cinco níveis de maturidade definidos pelo modelo CMM (Paulk, 1993; Paulk et al., 1995), adaptando as tarefas e práticas definidas pelo modelo ao contexto de produção de módulos educacionais. Além disso, o modelo de maturidade de processos para equipes geograficamente dispersas (Maidantchik, 1999) também foi utilizado como base para a definição das tarefas e práticas pertinentes.

A Figura 4.5 sintetiza o modelo $\mathcal{C M}$ /Educacional, contrastando-o com o modelo CMM e o modelo de maturidade para equipes geograficamente dispersas. Os modelos são comparados com respeito à estruturação dos níveis de maturidade, considerando as áreas-chave estabelecidas em cada um deles.
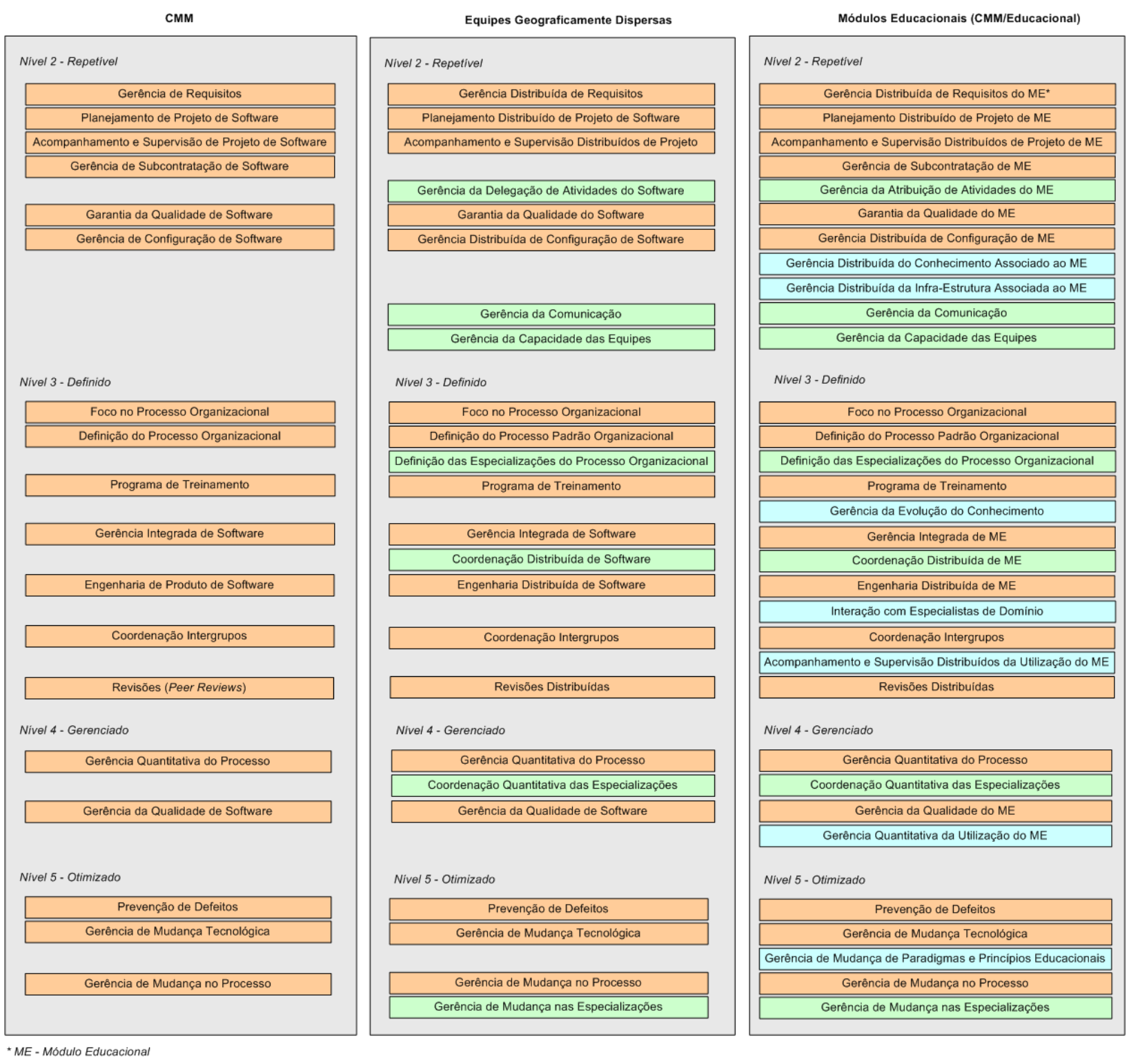

Figura 4.5: Modelo CMM x Modelo de Maturidade para Equipes Geograficamente Dispersas x Modelo $\mathrm{CMM} /$ Educacional. 
No Nível 2, duas novas KPAs foram estabelecidas:

- Gerência Distribuída do Conhecimento Associado ao Módulo Educacional: Responsável por: (1) estabelecer e garantir a integridade dos itens de informação e elementos instrucionais compartilhados pelas equipes de desenvolvimento durante todo o ciclo de vida do módulo educacional; e (2) estabelecer e manter mecanismos de apoio ao compartilhamento do conhecimento (bases conceituais, repositório de terminologias, ontologias, etc.).

- Gerência Distribuída da Infra-Estrutura Associada ao Módulo Educacional: Responsável por definir e manter a infra-estrutura necessária para instalação e utilização distribuída das ferramentas (educacionais, específicas ao domínio de conhecimento, etc.) e mecanismos de apoio (comunicação, colaboração, captura, etc.) por todas as equipes de desenvolvimento.

Além disso, foram mantidas as KPAs estabelecidas no modelo de maturidade para equipes geograficamente dispersas (Maidantchik, 1999), adaptadas ao contexto de desenvolvimento de módulos educacionais: Gerência da Comunicação e Gerência da Capacidade das Equipes.

Ressalta-se ainda que no modelo de maturidade estabelecido por (Maidantchik, 1999), a KPA de Gerência de Subcontratação do Software, definida pelo CMM, foi substituída pela KPA de Gerência da Delegação de Atividades do Software. No caso de módulos educacionais, optou-se por manter ambas as KPAs. De fato, aspectos de subcontratação devem ser considerados tendo em vista que tanto ferramentas e mecanismos de apoio como outros módulos educacionais relacionados podem ser adquiridos e integrados ao módulo em desenvolvimento. Por outro lado, a atribuição das atividades de projeto às equipes mais capacitadas também constitui um aspecto importante a ser considerado na presença de várias equipes de desenvolvimento.

Também é importante observar que, embora a noção de modelos e níveis de maturidade não seja explorada no contexto de desenvolvimento de produtos livres, muitas das práticas estabelecidas no Nível 2, em especial as referentes à gerência (de subcontratação, de configuração, de conhecimento e de infra-estrutura associados ao módulo, de comunicação e de capacidade das equipes), mostram-se particularmente adequadas a esse contexto, podendo ser investigadas ainda que de modo informal dentro de seu processo de desenvolvimento.

No Nível 3, foram estabelecidas as seguintes KPAs:

- Gerência da Evolução do Conhecimento: Responsável por: (1) identificar, selecionar e avaliar novos conhecimentos pertinentes ao domínio do módulo; e (2) estabelecer e manter mecanismos de apoio para integrar, de maneira ordenada, os novos conhecimentos ao módulo.

- Interação com Especialistas de Domínio: Responsável por: (1) estabelecer meios para que as equipes de desenvolvimento interajam ativamente com especialistas do domínio, apresentando e trocando informações sobre o conhecimento ao qual o módulo se destina; e (2) 
coordenar e controlar as interações entre as equipes de desenvolvimento e especialistas de domínio.

- Acompanhamento e Supervisão Distribuídos da Utilização do Módulo Educacional: Responsável por: (1) estabelecer meios para coletar informações a respeito da utilização do módulo educacional (desempenho dos aprendizes, novos conhecimentos produzidos, metas e objetivos de aprendizado atingidos, etc.); e (2) coordenar e controlar as alterações/evoluções ocorridas no módulo em função de sua aplicação no âmbito de ensino e treinamento.

Ainda, as KPAs de Definição das Especializações do Processo Organizacional e Coordenação Distribuída de Software foram extraídas de (Maidantchik, 1999) e adaptadas ao contexto de módulos educacionais.

No Nível 4, foi estabelecida a KPA de Gerência Quantitativa da Utilização do Módulo Educacional, responsável por medir, analisar e controlar quantitativamente o desempenho dos aprendizes ao longo da utilização do módulo educacional.

A KPA de Coordenação Quantitativa das Especializações foi extraída do trabalho de Maidantchik (1999).

No Nível 5, foi definida a KPA de Gerência de Mudança de Paradigmas e Princípios Educacionais, responsável por (1) identificar, selecionar e avaliar outros paradigmas e princípios educacionais quanto ao impacto na qualidade do aprendizado proporcionado; e (2) transferir para a organização, de maneira ordenada, os paradigmas e princípios educacionais vantajosos, integrando-os às especializações do processo padrão.

Do modelo de maturidade para equipes geograficamente dispersas (Maidantchik, 1999) foi incorporada a KPA de Gerência de Mudança das Especializações.

Como observação final sobre o modelo de maturidade para módulos educacionais, é importante ressaltar que as KPAs do $\mathcal{C M M} /$ Educacional também podem ser categorizadas em áreas de processo, a exemplo do que ocorre com as KPAs do CMM em relação às áreas de processo do CMMI (Ahern et al., 2001; Chrissis et al., 2003; Software Engineering Institute, 2003). O estabelecimento de um modelo de maturidade integrado para módulos educacionais, similar ao CMMI no contexto de software, constitui uma das linhas de pesquisa futura associada a este trabalho. Considerações preliminares nessa direção são discutidas no Apêndice A.

\subsubsection{Especialização do Processo Padrão para os Níveis de Maturi- dade}

A principal motivação para a especialização do processo padrão é permitir que gerentes e coordenadores de equipes abstraiam determinados aspectos do processo, concentrando-se em aspectos específicos para atender as áreas-chave de um dado nível de maturidade. Nesse sentido, a especialização requer que seja estabelecida a correspondência entre os diferentes aspectos do processo 
padrão e as áreas-chave do modelo de maturidade. Pode-se, com isso, identificar os aspectos do processo os quais devem ser enfatizados a fim de atender às áreas-chave de um determinado nível de maturidade (Maidantchik, 1999).

As tabelas 4.2, 4.3, 4.4 e 4.5 ilustram a relação das áreas-chave de cada nível de maturidade do modelo $\mathcal{C M M} /$ Educacional (níveis 2, 3, 4 e 5) com os processos estabelecidos pelo processo padrão que melhor atendem aos seus objetivos. Ressalta-se que a maioria das relações identificadas foram adaptadas e estão em conformidade com as relações previamente estabelecidas por Maidantchik (1999) no contexto de equipes geograficamente dispersas. Algumas dessas relações, em especial aquelas estabelecidas especificamente no contexto de produção de módulos educacionais, são discutidas a seguir.

Tabela 4.2: Áreas-Chave (Nível 2) x Processo Padrão.

\begin{tabular}{|c|c|}
\hline Áreas-Chave (Nível 2) & Processo Padrão \\
\hline $\begin{array}{l}\text { Gerência Distribuída de Requisitos do Módulo Edu- } \\
\text { cacional }\end{array}$ & $\begin{array}{l}\text { Definição, Planejamento, Garantia da Qualidade, Au- } \\
\text { ditoria }\end{array}$ \\
\hline $\begin{array}{l}\text { Planejamento Distribuído de Projeto do Módulo Edu- } \\
\text { cacional }\end{array}$ & Planejamento, Gerência \\
\hline $\begin{array}{l}\text { Acompanhamento e Supervisão Distribuídos de } \\
\text { Projeto do Módulo Educacional }\end{array}$ & $\begin{array}{l}\text { Gerência, Coordenação, Desenvolvimento, Operação, } \\
\text { Disponibilização, Manutenção, Publicação de Resul- } \\
\text { tados, Resolução de Problemas }\end{array}$ \\
\hline Gerência de Subcontratação de Módulo Educacional & $\begin{array}{l}\text { Aquisição, Fornecimento, Auditoria, Copyright e Li- } \\
\text { cença, Gerência }\end{array}$ \\
\hline $\begin{array}{l}\text { Gerência da Atribuição de Atividades do Módulo } \\
\text { Educacional }\end{array}$ & Planejamento, Gerência \\
\hline Garantia da Qualidade do Módulo Educacional & $\begin{array}{l}\text { Garantia da Qualidade, Verificação, Validação, Reso- } \\
\text { lução de Problemas }\end{array}$ \\
\hline $\begin{array}{l}\text { Gerência Distribuída de Configuração de Módulo } \\
\text { Educacional }\end{array}$ & $\begin{array}{l}\text { Gerência de Configuração, Planejamento, Controle de } \\
\text { Artefatos }\end{array}$ \\
\hline $\begin{array}{l}\text { Gerência Distribuída do Conhecimento Associado ao } \\
\text { Módulo Educacional }\end{array}$ & $\begin{array}{l}\text { Gerência do Conhecimento, Planejamento, Desenvol- } \\
\text { vimento, Gerência de Configuração }\end{array}$ \\
\hline $\begin{array}{l}\text { Gerência Distribuída da Infra-Estrutura Associada ao } \\
\text { Módulo Educacional }\end{array}$ & Infra-Estrutura, Planejamento \\
\hline Gerência da Comunicação & Comunicação, Documentação \\
\hline Gerência da Capacidade das Equipes & Capacitação, Planejamento, Gerência, Coordenação \\
\hline
\end{tabular}

No Nível 2, com respeito à KPA de Gerência Distribuída do Conhecimento Associado ao Módulo Educacional, o processo padrão apresenta um processo específico para gerenciar, de forma distribuída, o conhecimento associado ao módulo: Processo de Gerência do Conhecimento. O Processo de Planejamento, por meio da atividade de definição da estrutura geral do módulo, estabelece tarefas visando a determinar as partes relevantes do domínio de conhecimento a serem abordadas. O Processo de Desenvolvimento, mais especificamente na atividade de projeto, enfatiza a compreensão e a estruturação do conhecimento, sendo elaborados os modelos conceitual, instrucional e didático associados. Por fim, no Processo de Gerência de Configuração, os itens de conhecimento são incorporados e gerenciados como parte dos itens de configuração do módulo. 
Com relação à KPA de Gerência Distribuída da Infra-Estrutura Associada ao Módulo Educacional, o Processo de Infra-Estrutura estabelece e mantém a infra-estrutura necessária tanto para o desenvolvimento como para a utilização do módulo educacional. O Processo de Planejamento, por meio da atividade de determinação da metodologia, padrões e ferramentas, também é responsável por especificar as ferramentas e recursos tecnológicos e computacionais associados ao módulo.

Tabela 4.3: Áreas-Chave (Nível 3) x Processo Padrão.

\begin{tabular}{||l|l||}
\hline \hline Áreas-Chave (Nível 3) & Processo Padrão \\
\hline \hline Foco no Processo da Organizacional & Melhoria \\
\hline \hline Definição do Processo Padrão Organizacional & $\begin{array}{l}\text { Melhoria, Desenvolvimento, Operação, Disponibili- } \\
\text { zação, Manutenção }\end{array}$ \\
\hline \hline $\begin{array}{l}\text { Definição das Especializações do Processo Organiza- } \\
\text { cional }\end{array}$ & - \\
\hline \hline Programa de Treinamento & Treinamento, Planejamento \\
\hline \hline Gerência da Evolução do Conhecimento & $\begin{array}{l}\text { Gerência do Conhecimento, Desenvolvimento, Dis- } \\
\text { ponibilização, Manutenção }\end{array}$ \\
\hline \hline Gerência Integrada de Módulo Educacional & $\begin{array}{l}\text { Desenvolvimento, Verificação, Validação, Controle } \\
\text { de Artefatos }\end{array}$ \\
\hline \hline Coordenação Distribuída de Módulo Educacional & Gerência, Coordenação \\
\hline \hline Engenharia Distribuída de Módulo Educacional & $\begin{array}{l}\text { Desenvolvimento, Operação, Disponibilização, Ma- } \\
\text { nutenção }\end{array}$ \\
\hline \hline Interação com Especialistas de Domínio & $\begin{array}{l}\text { Desenvolvimento, Resolução de Problemas, Gerência } \\
\text { do Conhecimento, Publicação de Resultados }\end{array}$ \\
\hline \hline Coordenação Intergrupos & $\begin{array}{l}\text { Desenvolvimento, Publicação de Resultados, Resolu- } \\
\text { ção de Problemas }\end{array}$ \\
\hline \hline $\begin{array}{l}\text { Acompanhamento e Supervisão Distribuídos da Uti- } \\
\text { lização do Módulo Educacional }\end{array}$ & $\begin{array}{l}\text { Operação, Disponibilização, Manutenção, } \\
\text { Publicação de Resultados, Resolução de Problemas }\end{array}$ \\
\hline \hline Revisões Distribuídas & $\begin{array}{l}\text { Revisões, Definição, Planejamento, Desenvolvi- } \\
\text { mento, Operação, Disponibilização, Manutenção }\end{array}$ \\
\hline \hline
\end{tabular}

No Nível 3, com respeito à KPA de Gerência da Evolução do Conhecimento, o Processo de Gerência do Conhecimento, por meio da atividade de controle de itens de conhecimento, trata de aspectos referentes às mudanças e evoluções ocorridas no conhecimento e da forma com que essas devem ser refletidas no conteúdo do módulo educacional. Além disso, os processos de Desenvolvimento, Disponibilização e Manutenção contêm atividades específicas que identificam, registram e acompanham as evoluções ocorridas.

Quanto à KPA de Interação com Especialistas de Domínio, os processos de Desenvolvimento e Resolução de Problemas estabelecem atividades conjuntas envolvendo equipes de desenvolvimento e especialistas de domínio. Os processos de Gerência do Conhecimento e Publicação de Resultados também apóiam esta KPA.

A KPA de Acompanhamento e Supervisão Distribuídos da Utilização do Módulo Educacional é apoiada pelos processos de Operação, Disponibilização e Manutenção, contendo atividades que determinam a utilização do módulo e seu acompanhamento. Incorporam-se ainda atividades descritas nos processos de Publicação de Resultados e Resolução de Problemas. 
Tabela 4.4: Áreas-Chave (Nível 4) x Processo Padrão.

\begin{tabular}{||l|l||}
\hline \hline Áreas-Chave (Nível 4) & Processo Padrão \\
\hline \hline Gerência Quantitativa do Processo & $\begin{array}{l}\text { Planejamento, Garantia de Qualidade, Desenvol- } \\
\text { vimento, Operação, Disponibilização, Manutenção, } \\
\text { Documentação, Melhoria }\end{array}$ \\
\hline \hline Coordenação Quantitativa das Especializações & $\begin{array}{l}\text { Planejamento, Garantia de Qualidade, Desenvol- } \\
\text { vimento, Operação, Disponibilização, Manutenção, } \\
\text { Documentação, Melhoria }\end{array}$ \\
\hline \hline Gerência da Qualidade do Módulo Educacional & Garantia da Qualidade, Validação, Melhoria \\
\hline \hline $\begin{array}{l}\text { Gerência Quantitativa da Utilização do Módulo Edu- } \\
\text { cacional }\end{array}$ & $\begin{array}{l}\text { Planejamento, Garantia da Qualidade, Operação, Dis- } \\
\text { ponibilização, Documentação, Validação, Melhoria }\end{array}$ \\
\hline \hline
\end{tabular}

No Nível 4, com respeito à KPA de Gerência Quantitativa da Utilização do Módulo Educacional, os processos de Planejamento e de Garantia da Qualidade contêm atividades para definir os dados a serem coletados. Os processos de Operação e Disponibilização reúnem atividades para a coleta dos dados. As informações coletadas são documentadas pelo Processo de Documentação. O Processo de Validação estabelece atividades para gerenciar quantitativamente a utilização do módulo. O Processo de Melhoria utiliza os dados coletados para analisar e aprimorar o processo.

Tabela 4.5: Áreas-Chave (Nível 5) x Processo Padrão.

\begin{tabular}{||l|l||}
\hline \hline Áreas-Chave (Nível 5) & Processo Padrão \\
\hline \hline Prevenção de Defeitos & Resolução de Problemas, Melhoria \\
\hline \hline Gerência de Mudança Tecnológica & Infra-Estrutura, Melhoria \\
\hline \hline $\begin{array}{l}\text { Gerência de Mudança de Paradigmas e Princípios } \\
\text { Educacionais }\end{array}$ & Melhoria \\
\hline \hline Gerência de Mudança no Processo & Melhoria \\
\hline Gerência de Mudança nas Especializações & Melhoria \\
\hline
\end{tabular}

No Nível 5, a KPA de Gerenciamento de Mudança de Paradigmas e Princípios Educacionais é apoiada pelo Processo de Melhoria, que reúne atividades para o aprimoramento do processo em termos dos paradigmas e princípios educacionais adotados.

A partir da determinação da correspondência entre os aspectos do processo padrão e as áreaschave do modelo de maturidade, é possível gerar as especializações do processo padrão. Segundo Maidantchik (1999), a especialização do processo em um determinado nível de maturidade é gerada excluindo-se as atividades relacionadas aos níveis de maturidade superiores. Desse modo, a especialização do segundo nível de maturidade não contém as atividades referentes ao terceiro, quarto e quinto níveis, incorporando exclusivamente as atividades relacionadas a todas as áreaschave do Nível 2. A especialização do terceiro nível de maturidade incorpora tanto as atividades relacionadas a todas as áreas-chave do Nível 2 como do Nível 3. As especializações do quarto e quinto níveis são geradas de maneira similar.

Por meio de uma avaliação, que pode ser conduzida adaptando-se metodologias tais como o CBA-IPI (CMM-Based Appraisal for Internal Process Improvement) (Dunaway \& Masters, 1996), 
SCAMPI (Standard CMMI Appraisal Method for Process Improvement) (Software Engineering Institute, 2001), entre outras, ao contexto de produção de módulos educacionais, a capacidade de cada equipe de trabalho é determinada. Assim, a especialização mais adequada é designada a cada equipe e instanciada a projetos específicos, envolvendo a construção de diferentes tipos de módulos.

Aspectos associados à instanciação de processos para a elaboração de módulos educacionais são discutidos na próxima seção.

\subsection{Instanciação do Processo Padrão para Módulos Educacionais}

A atividade de instanciação consiste na seleção e alocação de métodos, técnicas de desenvolvimento, recursos humanos e tecnológicos para cada uma das atividades de um projeto particular (Maidantchik, 1999). Em outras palavras, a instância do processo endereça as especificidades (particularidades) de desenvolvimento de cada projeto (da Rocha et al., 2001).

A fim de ilustrar a instanciação do processo padrão para módulos educacionais, nesta seção é considerada sua utilização em uma classe de projetos específica. Basicamente, tais projetos são conduzidos em uma dada instituição de ensino (no caso, o ICMC-USP), envolvendo a elaboração de módulos educacionais a serem aplicados presencialmente, tanto em disciplinas oferecidas aos alunos da instituição como em minicursos, tutoriais e palestras ministradas por seus professores em eventos científicos ou em organizações industriais. No processo instanciado são definidos, entre outros, os recursos humanos e as funções desempenhadas ao longo do processo, os artefatos (sub-produtos) consumidos e gerados, o modelo de ciclo de vida e as técnicas de desenvolvimento adotadas, e as ferramentas e mecanismos de apoio selecionados nesse contexto. Tais aspectos são abordados nas próximas seções.

Ressalta-se, ainda, que a instanciação pode ser conduzida a partir da adaptação de um processo especializado ou diretamente a partir de um processo padrão definido. Considerando o primeiro caso, o processo padrão definido na Seção 4.5 poderia ser especializado em função da capacidade das equipes de desenvolvimento envolvidas, conforme descrito na Seção 4.7, e então instanciado para um projeto específico. No segundo caso, o processo instanciado seria adaptado a partir do processo padrão para módulos educacionais, sem a necessidade de um processo especializado. Qualquer uma das possibilidades de instanciação pode ser utilizada, cabendo à organização a escolha mais adequada às suas necessidades. Na instanciação de processos para a elaboração de módulos educacionais discutida nesta seção foi considerada a segunda possibilidade.

Salienta-se, por fim, que a discussão referente à instanciação é feita de maneira informal e simplificada, tendo como principal objetivo fornecer uma visão geral a respeito do processo instanciado. 


\subsubsection{Recursos Humanos}

Com respeito aos recursos humanos necessários à condução do projeto, foram selecionados para compor a equipe de desenvolvimento os seguintes atores:

- Especialista de Domínio: Detém o conhecimento sobre o domínio ao qual o módulo se destina. É responsável por fornecer apoio e esclarecer dúvidas na determinação dos componentes e partes relevantes do módulo educacional. Desempenha um papel fundamental no modelagem de conteúdos, em especial na construção do modelo conceitual e na determinação das categorias de conhecimento associadas. Atua ainda na validação instrucional do módulo.

- Gerente de Projeto: Atribui atividades e integra resultados. Tem amplo conhecimento a respeito do andamento das atividades executadas e do projeto como um todo. É responsável pela especificação dos metadados associados ao módulo e pela definição dos mecanismos de validação utilizados.

- Coordenador de Equipe: Supervisiona uma equipe de desenvolvimento, representando o principal elo de comunicação entre seus membros e a gerência do projeto.

- Gerente de Versões: É responsável pela manutenção das versões do módulo.

- Desenvolvedor: É responsável pelo desenvolvimento do módulo propriamente dito. Possui vários papéis associados:

- Analista: É responsável pela especificação do módulo e pela determinação e análise dos requisitos. Atua ainda na validação do módulo.

- Projetista Instrucional: Atua na modelagem dos conteúdos educacionais e no projeto da interface do módulo.

- Implementador: Atua na implementação (edição dos conteúdos), integração dos componentes multimídia, verificação e teste do módulo.

- Operador: É responsável pela assistência operacional aos usuários do módulo.

- Mantenedor: É responsável pela manutenção do módulo.

- Técnico: É responsável pelo estabelecimento e gerência dos recursos tecnológicos e computacionais utilizados no projeto. Fornece suporte técnico ao desenvolvimento e à disponibilização do módulo.

- Instrutor: Estabelece as necessidades instrucionais. É responsável pela disponibilização, supervisão e acompanhamento do módulo. Atua na identificação e registro de problemas e melhorias. Pode auxiliar nas atividades de verificação e validação. 
A Figura 4.6 ilustra o relacionamento entre os membros da equipe de desenvolvimento e os principais papéis por eles desempenhados, conforme estabelecido durante a instanciação. Observase que, da maneira como foi definido, nesta instância do processo o instrutor corresponde ao próprio adquirente do módulo, ou seja, aquele que tem a necessidade de desenvolvimento.

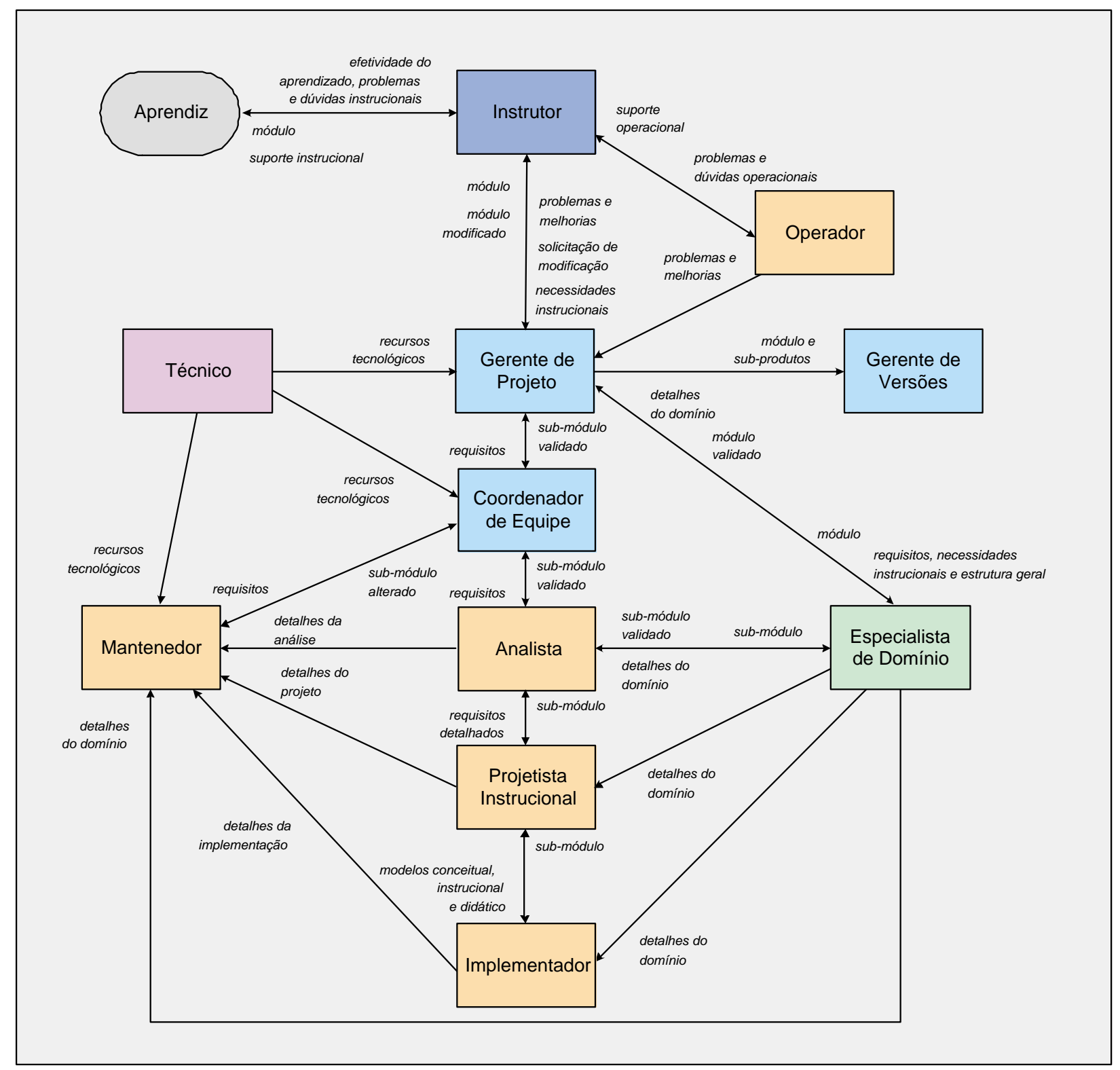

Figura 4.6: Equipe de Desenvolvimento e Papéis Associados.

Ressalta-se ainda que uma mesma pessoa pode acumular dois ou mais dos papéis identificados. Além disso, várias pessoas podem ser alocadas para a mesma função.

\subsubsection{Métodos e Técnicas de Desenvolvimento}

Nesta seção são discutidos os métodos e as técnicas de desenvolvimento selecionadas para a condução do projeto. 
Como modelo de ciclo de vida sob o qual as atividades dos processos fundamentais devem ser baseadas, foi adotado o modelo ADDIE, caracterizado pelas fases de Análise, Projeto, Desenvolvimento, Implementação e Avaliação. A decisão pela adoção do modelo justifica-se pelo fato de que o mesmo é especificamente voltado ao desenvolvimento de produtos educacionais, estabelecendo mecanismos para a aplicação sistemática de práticas e princípios de projeto instrucional (Clark, 2003; Kruse, 2003; Lee \& Owens, 2000).

Para a modelagem dos conteúdos educacionais foi considerada a abordagem $\mathcal{A L M}-\mathcal{C I D}$, discutida na Seção 3.6. De modo geral, tal abordagem é baseada na técnica de Mapas Conceituais (Moreira \& Buchweitz, 1987; Novak, 1981; Novak \& Gowin, 1984; Novak, 1990) e no modelo HMBS (Turine, 1998), estabelecendo algumas restrições/extensões aos mesmos a fim de permitir que os modelos conceitual, instrucional e didático sejam representados com maior riqueza de detalhes. Na modelagem conceitual são construídos mapas conceituais, na modelagem instrucional é utilizado o modelo $\mathcal{H}$ MBS/Instrucional e na modelagem didática é utilizado o HMBSS/Didático.

Além disso, como base para a diferenciação das categorias de conhecimento, exploradas no modelo instrucional, foi adotada a teoria Component Display Theory (Merril, 1983). Tal escolha foi feita em função do caráter genérico da teoria, aplicável em quaisquer domínios de conhecimento. Adicionalmente, o conjunto de elementos nos quais as informações podem ser caracterizadas (fato, conceito, princípio e procedimento) apresenta, ao mesmo tempo: (1) baixa cardinalidade, facilitando a compreensão do modelo e possibilitando maior clareza às páginas/transparências do módulo (diminuição da sobrecarga cognitiva); e (2) abrangência necessária para a representação das informações relevantes sobre o domínio.

Finalmente, também foi adotado um padrão para a especificação de metadados associados ao módulo educacional - o IEEE LTSC LOM (Learning Objects Metadata) (IEEE Learning Technology Standards Committee, 2002). Trata-se de um padrão internacionalmente aceito, estando em conformidade com outras especificações, tais como Dublin Core e vCard, permitindo o eventual intercâmbio e reuso de informações entre diferentes módulos educacionais.

\subsubsection{Recursos Tecnológicos e Computacionais}

Os recursos tecnológicos e computacionais necessários à realização do projeto podem ser genericamente classificados de acordo com os papéis que desempenham dentro do contexto de produção de módulos educacionais. Nesse sentido, três categorias básicas de ferramentas podem ser identificadas:

- Ferramentas de Autoria: Apóiam a elaboração do conteúdo do módulo educacional. São responsáveis por tratar aspectos referentes tanto à representação, integração e gerenciamento do domínio de conhecimento como à modelagem e editoração dos conteúdos associados.

- Ferramentas de Ensino: Constituem a infra-estrutura básica para a integração do material didático elaborado (conteúdos teóricos e práticos) e sua utilização em ambientes reais de 
ensino e treinamento. Abordam aspectos pertinentes à disponibilização dos conteúdos e à condução e acompanhamento das atividades práticas e avaliações propostas.

- Ferramentas Administrativas ${ }^{6}:$ São responsáveis pelo gerenciamento dos cursos nos quais os módulos estão inseridos. Abordam aspectos administrativos tais como proposta e oferecimento do curso, matrícula, aprovação e frequiência dos aprendizes, certificação, entre outros.

Observa-se que as ferramentas de autoria e de ensino podem ser aplicadas tanto no que se refere à automatização dos processos propostos quanto à sua integração como parte do módulo educacional em construção, estando ambas as perspectivas intrinsicamente relacionadas.

A fim de selecionar quais ferramentas irão fazer parte do processo instanciado, é fundamental que as mesmas sejam analisadas com respeito à sua adequação na automatização dos processos e atividades estabelecidas pelo processo padrão e em relação às perspectivas de desenvolvimento de módulos educacionais. Tais aspectos são discutidos a seguir.

\section{Ferramentas de Apoio: Aspectos de Automatização do Processo Padrão}

Nesta seção ferramentas de autoria e de ensino são discutidas e analisadas com respeito à automatização do processo padrão para módulos educacionais. A idéia é discutir como tais ferramentas podem ser utilizadas, dentro do contexto do processo padrão definido, a fim de apoiar a produção dos módulos.

Como ferramentas de autoria, consideram-se: (1) ferramentas para modelagem de conteúdos educacionais; (2) ferramentas para integração do conhecimento; e (3) ferramentas de editoração. Como ferramentas de ensino, são analisadas: (1) ferramentas de apresentação; (2) ferramentas colaborativas; (3) ferramentas de avaliação; e (4) ferramentas de captura.

A Tabela 4.6 ilustra a adequação das categorias de ferramentas consideradas com respeito ao processo padrão proposto. É interessante observar que uma ferramenta específica pode pertencer a diferentes categorias. Por exemplo, dependendo do aspecto considerado, o ambiente ATEnA pode ser utilizado na construção de mapas conceituais, na modelagem de aspectos instrucionais e didáticos, na editoração e apresentação dos conteúdos, e na avaliação dos aprendizes.

Ferramentas para modelagem conceitual podem ser utilizadas na automatização do Processo de Desenvolvimento, em especial nas tarefas e atividades de projeto que envolvem a construção de modelos (mapas) conceituais.

Vários esforços de automatização podem ser identificados no contexto de construção de mapas conceituais. Por exemplo, podem-se citar as ferramentas Inspiration (Inspiration Software Inc., 2003), KMap (Gaines \& Shaw, 2003) e CMap (Coffey et al., 2002), entre outras. Além disso,

\footnotetext{
${ }^{6}$ Ferramentas administrativas não são consideradas visto que aspectos pertinentes ao gerenciamento de cursos não são abordados neste trabalho.
} 
Tabela 4.6: Categorias de Ferramentas de Apoio x Processo Padrão para Módulos Educacionais.

\begin{tabular}{||l|l|l||}
\hline \hline Categorias de Ferramentas & Exemplos de Ferramentas & Processo Padrão \\
\hline \hline $\begin{array}{l}\text { Ferramentas para Modelagem } \\
\text { Conceitual }\end{array}$ & $\begin{array}{l}\text { Inspiration, KMap, CMap, } \\
\text { HLM, ATEnA }\end{array}$ & Desenvolvimento \\
\hline $\begin{array}{l}\text { Ferramentas para Modelagem } \\
\text { Instrucional e Didática }\end{array}$ & HySCharts, ATEnA & $\begin{array}{l}\text { Desenvolvimento, Garantia de Qualidade, } \\
\text { Validação, Verificação }\end{array}$ \\
\hline $\begin{array}{l}\text { Ferramentas para Integração do } \\
\text { Conhecimento }\end{array}$ & $\begin{array}{l}\text { ODEd, ObjectEditor, Protégé, } \\
\text { Ontolingua }\end{array}$ & $\begin{array}{l}\text { Definição, Desenvolvimento, Manutenção, } \\
\text { Gerência do Conhecimento }\end{array}$ \\
\hline Ferramentas de Editoração & $\begin{array}{l}\text { Word, PowerPoint, FrontPage, } \\
\text { Flash, WCC, CyberQ, HLM, } \\
\text { ATEnA }\end{array}$ & Desenvolvimento, Manutenção \\
\hline Ferramentas de Apresentação & $\begin{array}{l}\text { WebCT, AulaNet, ATEnA, } \\
\text { HySCharts, Eureka/WCC, web, }, \\
\text { PowerPoint }\end{array}$ & Disponibilização, Operação, Validação \\
\hline Ferramentas Colaborativas & $\begin{array}{l}\text { correio eletrônico, listas de } \\
\text { discussão, CoWeb, Eureka, } \\
\text { WebCT,AulaNet }\end{array}$ & $\begin{array}{l}\text { Disponibilização, Operação, Validação, } \\
\text { Publicação de Resultados, Comunicação }\end{array}$ \\
\hline Ferramentas de Avaliação & $\begin{array}{l}\text { HLM, CyberQ, WebCT, Aula- } \\
\text { Net,ATEnA }\end{array}$ & $\begin{array}{l}\text { Disponibilização, Operação, Manutenção, } \\
\text { Validação, Melhoria }\end{array}$ \\
\hline Ferramentas de Captura & e-Class & Disponibilização, Operação, Manutenção \\
\hline
\end{tabular}

ambientes como o ATEnA (Leiva et al., 2002a; Leiva, 2003) e o HLM (Menasce, 1998) também incluem em sua arquitetura módulos específicos para a edição de tais mapas. É importante observar, entretanto, que as ferramentas citadas não incorporam ao desenvolvimento dos mapas conceituais associados as restrições/extensões propostas neste trabalho.

Ferramentas para modelagem instrucional e didática são empregadas na automatização do Processo de Desenvolvimento, mais especificamente na atividade de projeto, complementando as ferramentas para construção de mapas conceituais no âmbito da modelagem de conteúdos educacionais. Caso as ferramentas consideradas possibilitem a interpretação e execução dos modelos didáticos elaborados, os processos de Garantia de Qualidade, Validação e Verificação também são beneficiados.

Conforme discutido no Capítulo 3, o modelo HMBS (Turine, 1998) apresenta-se como uma opção interessante no contexto de modelagem de conteúdos educacionais, possuindo características relevantes as quais podem ser exploradas sob as perspectivas instrucional e didática. Dentro desse contexto, o ambiente HySCharts (Turine et al., 1998), o qual permite criar, interpretar e executar especificações formais de aplicações hipermídia segundo o modelo HMBS, representa uma possível ferramenta de apoio à automatização desses aspectos de modelagem.

É importante observar que, caso sejam utilizados os modelos estendidos do HMBS $\mathcal{H}$ MBS/Instrucional e $\mathcal{H}$ MBS/Didático - nenhum suporte automatizado à sua construção é fornecido e, desse modo, as atividades de modelagem instrucional e modelagem didática devem ser conduzidas manualmente. A adequação do ambiente HySCharts aos modelos propostos neste trabalho deve ser investigada futuramente. Conforme discutido na Seção 3.6, uma ferramenta de apoio à criação, interpretação e execução de modelos especificados segundo o HMBS/Didático, além de 
apoiar a atividade de modelagem didática, pode ser utilizada na geração automática dos conteúdos associados.

O ambiente ATEnA (Leiva et al., 2002a; Leiva, 2003), por sua vez, fornece suporte à edição e execução de modelos segundo o MDE (Leiva et al., 2002b; Leiva, 2003), que estende o HMBS para o tratamento de hiperdocumentos educacionais, com ênfase nos aspectos de avaliação do aprendiz. Nesse sentido, o ambiente pode ser utilizado especificamente no apoio à modelagem de elementos instrucionais de avaliação (avaliação diagnóstica, avaliação formativa e avaliação somativa).

Ferramentas para integração do conhecimento mostram-se particularmente adequadas à automatização do Processo de Desenvolvimento, apoiando a integração dos componentes do conteúdo (itens de informação e elementos instrucionais) e o estabelecimento de uma base conceitual associada (ou um dicionário de termos, considerando sua utilização de forma simplificada). Sob essa perspectiva, as atividades de construção e manutenção de repositórios de terminologias, tratadas respectivamente nos processos de Definição e Manutenção, também podem ser automatizadas a partir da utilização de tais ferramentas. Ressalta-se ainda que, na medida em que apóiam o compartilhamento e o gerenciamento dos conceitos e informações pertinentes ao domínio, tais ferramentas também podem ser exploradas no contexto do Processo de Gerência do Conhecimento.

Como mecanismos de apoio à integração do conhecimento destacam-se as ferramentas para construção de ontologias: ODEd (Mian \& Falbo, 2002), ObjectEditor (Beck, 2003), Protégé (Grosso, 1999), Ontolingua (Knowledge Systems Laboratory, 2003), entre outras.

Ferramentas de editoração são responsáveis pela construção propriamente dita dos conteúdos do módulo educacional. Podem ser utilizadas como apoio aos processos de Desenvolvimento e Manutenção, contribuindo para a automatização das atividades de implementação e integração, e implementação da modificação, respectivamente.

Tanto ferramentas de editoração genéricas (tais como Word, PowerPoint, Visio, FrontPage, Photoshop, Dreamweaver, Flash, LaTeX, etc.) como ferramentas específicas (tais como WCC (Pacheco et al., 1999a,b), CyberQ (Tucker, 1995), HLM (Menasce, 1998), ATEnA (Leiva, 2003)) podem ser consideradas.

Ferramentas de apresentação podem ser utilizadas como apoio ao Processo de Disponibilização, em especial na atividade de disponibilização do módulo. Além disso, também podem ser inseridas no escopo do Processo de Operação, apoiando a automatização das atividades de teste operacional e operação do módulo. Por fim, ainda que indiretamente, o Processo de Validação também pode ser beneficiado com a utilização dessas ferramentas, as quais possibilitam que cursos-piloto sejam conduzidos antes da liberação final do módulo.

A maioria dos sistemas educacionais existentes inclui, como requisito essencial dentro do conjunto de suas funcionalidades, mecanismos de suporte à apresentação do material didático elaborado. Dentre esses sistemas podem-se citar, por exemplo, o WebCT (Goldberg et al., 1996), o AulaNet (Lucena et al., 1998), o ATEnA (Leiva, 2003), o HySCharts (Turine et al., 1998) e o Eureka/WCC (Eberspächer et al., 1999; Pacheco et al., 1999a,b). Recursos genéricos, tais como a 
própria infra-estrutura web e a infra-estrutura de apresentação do PowerPoint, também podem ser utilizados com esse propósito.

Ferramentas colaborativas podem ser utilizadas como apoio aos processos de Disponibilização (atividades de disponibilização do módulo, e acompanhamento e suporte instrucional) e Operação (atividades de teste operacional, operação do módulo e suporte operacional). O Processo de Validação também pode ser indiretamente apoiado. Além disso, tais ferramentas podem apoiar o projeto como um todo, sendo utilizadas como mecanismos de comunicação entre desenvolvedores, fornecendo suporte aos processos de Publicação de Resultados e Comunicação, entre outros.

Várias tecnologias colaborativas podem ser adotadas no contexto de ensino e treinamento, desde as mais simples, como correio eletrônico e listas de discussão, até sistemas integrados e mais elaborados, tais como o Eureka (Eberspächer et al., 1999) e a CoWeb (Guzdial et al., 2002). Grande parte dos sistemas educacionais existentes, tais como WebCT e AulaNet, também dispõem de recursos e tecnologias colaborativas próprias em sua arquitetura.

Ferramentas de avaliação podem ser aplicadas como apoio aos processos de Disponibilização (atividades de disponibilização do módulo, acompanhamento e suporte instrucional, e identificação de problemas e melhorias), Operação (atividades de teste operacional, operação do módulo, e identificação de problemas e melhorias) e Manutenção (atividade de análise do problema e da modificação). Além disso, assim como ferramentas colaborativas e de apresentação, quando utilizadas na implantação de cursos-piloto tais ferramentas também podem apoiar o Processo de Validação. Ressalta-se ainda que os resultados obtidos a partir da aplicação das ferramentas de avaliação podem ser utilizados a fim de medir e controlar os processos do ciclo de vida do módulo, apoiando dessa forma o Processo de Melhoria.

Em geral, ferramentas de avaliação são incorporadas como parte dos sistemas educacionais existentes, como é o caso dos ambientes WebCT, AulaNet e ATEnA ou, ainda, desenvolvidas como ambientes específicos de avaliação - HLM (Menasce, 1998), CyberQ (Tucker, 1995), entre outros.

No contexto de cursos presenciais, ferramentas de captura vêm sendo investigadas e incorporadas como infra-estrutura de apoio ao ensino e treinamento, possibilitando a captura automática de transparências, áudio, vídeo e anotações durante as aulas. Sob a perspectiva do processo padrão estabelecido, tais ferramentas podem ser utilizadas, de modo geral, como suporte à automatização dos processos de Disponibilização, Operação e Manutenção. Como exemplo de ferramenta de captura destaca-se o ambiente e-Class (Pimentel et al., 2002).

\section{Ferramentas de Apoio: Adequação às Perspectivas de Desenvolvimento de Módu- los Educacionais}

Ferramentas de autoria e de ensino também podem ser analisadas quanto às perspectivas de desenvolvimento de módulos educacionais - estruturação, transferência, evolução e reuso do conhecimento -, discutidas na Seção 3.2. 
De modo geral, a maior parte das ferramentas de autoria enfatizam aspectos pertinentes à estruturação do conhecimento, podendo, em algumas situações, atuar como mecanismos de apoio à evolução e ao reuso. Ferramentas de ensino, por sua vez, têm como foco principal a transferência do conhecimento. No entanto, tendo em vista a diversidade de características e funcionalidades que cada ferramenta pode apresentar e o fato de que a mesma ferramenta pode pertencer a diferentes categorias, é interessante que as análises e comparações também sejam realizadas separadamente. A Tabela 4.7 sintetiza os resultados observados a partir de análises conduzidas nessa direção. Por limitações de espaço, somente algumas ferramentas foram consideradas.

Tabela 4.7: Ferramentas de Apoio x Perspectivas de Desenvolvimento de Módulos Educacionais.

\begin{tabular}{||c|c|c|c|c||}
\hline \hline \multirow{2}{*}{ Ferramentas } & \multicolumn{3}{|c||}{ Perspectivas de Desenvolvimento de Módulos Educacionais } \\
\cline { 2 - 5 } & Estruturação & Transferência & Evolução & Reuso \\
\hline \hline KMap & Parcialmente Adequado & Não Aborda & Não Aborda & Não Aborda \\
\hline HySCharts & Parcialmente Adequado & Adequado & Não Aborda & Não Aborda \\
\hline ODEd & Parcialmente Adequado & Não Aborda & Adequado & Adequado \\
\hline PowerPoint & Não Aborda & Satisfatório & Não Aborda & Pouco Satisfatório \\
\hline WebCT & Pouco Satisfatório & Adequado & Não Aborda & Pouco Satisfatório \\
\hline CoWeb & Não Aborda & Parcialmente Adequado & Satisfatório & Satisfatório \\
\hline HLM & Pouco Satisfatório & Parcialmente Adequado & Não Aborda & Não Aborda \\
\hline$e$-Class & Não Aborda & Pouco Satisfatório & Adequado & Satisfatório \\
\hline \hline
\end{tabular}

De acordo com a tabela, tem-se que:

- A ferramenta KMap (Gaines \& Shaw, 2003) aborda aspectos pertinentes à estruturação do conhecimento sob a perspectiva de modelagem conceitual, apoiando a identificação, organização e modularização dos conceitos associados.

- O ambiente HySCharts (Turine et al., 1998) pode ser utilizado no tratamento de aspectos relativos à estruturação do conhecimento, sob as perspectivas de modelagem instrucional e didática. No entanto, o ambiente não apóia a automatização dos modelos $\mathcal{H} M \mathcal{B B S} /$ Instrucional e $\mathcal{H} \mathcal{M B S} /$ Didático, não permitindo a representação de categorias do conhecimento diferenciadas nem a especificação aberta dos aspectos de apresentação e navegação do conteúdo. Aspectos de transferência do conhecimento, no que se refere à apresentação dos conteúdos modelados, também podem ser apoiados pelo ambiente.

- A ferramenta $O D E d$ (Mian \& Falbo, 2002) apóia a construção de ontologias, fornecendo recursos para a integração, gerência e compartilhamento do conhecimento. No contexto de desenvolvimento de módulos educacionais, a ferramenta pode ser utilizada como mecanismo sistemático para apoiar a evolução e o reuso do conhecimento. A estruturação do conhecimento também pode ser indiretamente beneficiada. Entretanto, nenhum suporte à modelagem de aspectos conceituais, instrucionais e didáticos é oferecido. 
- A ferramenta PowerPoint apóia de forma satisfatória a transferência do conhecimento. Mecanismos simplificados de reuso, possibilitando a integração com outras apresentações, documentos e programas executáveis, também podem ser identificados.

- O WebCT (Goldberg et al., 1996) apresenta um bom nível de adequação no tratamento de questões associados à transferência do conhecimento, sobretudo quanto aos mecanismos disponíveis para a apresentação de módulo, condução de atividades práticas e avaliação e acompanhamento do aprendiz. Quanto à estruturação do conhecimento, embora seja possível definir seqüências hierárquicas ou lineares para a apresentação do módulo, nenhum recurso para identificação e modelagem dos conceitos e relacionamentos pertinentes é disponibilizado pela ferramenta. $\mathrm{O}$ ambiente permite ainda que conteúdos de outros módulos sejam reutilizados. No entanto, não dispõe de mecanismos para integração e gerência de conhecimento, implicando que o reuso seja conduzido de forma manual e sem suporte à eventual evolução dos conhecimentos (conteúdos) compartilhados.

- A CoWeb (Guzdial et al., 2002) fornece recursos para a transferência do conhecimento, mostrando-se especialmente adequada à condução de atividades instrucionais, sobretudo aquelas envolvendo cooperação entre aprendizes e entre aprendizes e instrutores/mediadores. Aspectos pertinentes à evolução e ao reuso do conhecimento também podem ser indiretamente apoiados, em especial quando a ferramenta é integrada a ambientes de captura, tais como o e-Class.

- O ambiente HLM (Menasce, 1998) apóia a transferência do conhecimento, sobretudo no que se refere à condução de avaliações e acompanhamento do aprendiz. Além disso, pode ser utilizado como um mecanismo simplificado no apoio à estruturação e à criação de questões e exercícios.

- O e-Class (Pimentel et al., 2002) é especialmente adequado no tratamento de aspectos pertinentes à evolução do conhecimento, fornecendo recursos para captura e integração de novos conteúdos àqueles previamente elaborados e disponibilizados ao aprendiz. Aspectos de reuso também podem ser indiretamente apoiados quando o ambiente é utilizado em conjunto com ferramentas colaborativas, tais como a CoWeb. Quanto ao aspecto de transferência do conhecimento, apenas a apresentação dos conteúdos do módulo é apoiada.

Em linhas gerais, é possível observar que a maioria das ferramentas, ao mesmo tempo em que se mostram adequadas a uma determinada perspectiva, deixam de abordar outros aspectos de desenvolvimento relevantes. De fato, tais resultados, somados àqueles já observados com respeito à automatização do processo padrão, evidenciam a importância do estabelecimento e utilização integrada de ferramentas de autoria e de ensino na construção de módulos educacionais.

Finalmente, é importante ressaltar que os fatores considerados na análise das ferramentas podem constituir um conjunto preliminar de requisitos e/ou critérios de avaliação, utilizados como 
apoio na seleção de ferramentas adequadas à automatização das atividades e tarefas do processo padrão (especializado e/ou instanciado) e, conseqüentemente, ao desenvolvimento de módulos educacionais.

\section{Ferramentas de Apoio: Processo Instanciado}

A seguir, são identificadas as ferramentas a serem utilizadas a fim de apoiar o processo instanciado para a elaboração de um dado tipo de módulo educacional. A seleção das ferramentas teve como base as análises conduzidas e as características específicas do projeto a ser desenvolvido.

Como ferramentas de apresentação foram adotados o WebCT (Goldberg et al., 1996), nos casos em que se deseja incorporar os módulos desenvolvidos a um ambiente educacional específico; e ferramentas genéricas, tais como PowerPoint e a própria infra-estrutura web, em situações nas quais o uso de ambientes educacionais não se faz necessário.

A escolha pelo WebCT justifica-se por vários fatores, entre eles: (1) trata-se de uma iniciativa internacional, amplamente utilizada por instrutores e aprendizes nos mais variados domínios de aplicação; (2) oferece interface amigável, tanto no que se refere à incorporação dos módulos ao ambiente como na apresentação dos mesmos aos aprendizes; (3) oferece documentação (tutoriais) e suporte técnico aos usuários; (4) toda infra-estrutura necessária à instalação, gerenciamento e manutenção é centralizada e fornecida pela USP, que detém a licença de uso e os termos para distribuição do ambiente às suas instituições. Dentro desse contexto, o WebCT pode ser particularmente interessante na utilização dos módulos desenvolvidos em disciplinas tanto do ICMC como de outras instituições da USP.

A adoção de ferramentas genéricas, por outro lado, permite flexibilidade na disponibilização dos módulos visto que, em geral, tais ferramentas fazem parte da infra-estrutura básica de qualquer instituição/organização em que os mesmos venham a ser utilizados.

Ainda com respeito à apresentação dos módulos, como infra-estrutura para a captura das aulas presenciais foi adotado o e-Class (Abowd et al., 1996; Pimentel, 2001). Trata-se de uma experiência bem sucedida em outras instituições de ensino (Georgia Institute of Technology), já incorporada ao ICMC-USP, que possui salas de aula instrumentadas com os recursos e mecanismos necessários à sua aplicação. A instituição também dispõe de recursos integrando o $e$-Class à CoWeb.

Como ferramenta colaborativa foi adotada a CoWeb (Guzdial et al., 2002). Além de estar integrada à "rotina" de ensino de instrutores e aprendizes do ICMC-USP, a possibilidade de usos diferenciados da ferramenta (distribuição das informações, criação colaborativa, discussão e revisão, integração com mecanismos de captura, entre outros) justificam sua seleção. Além disso, a ferramenta pode ser acessada via web, viabilizando sua utilização mesmo em apresentações externas ao ICMC-USP. Ressalta-se que, caso o WebCT seja utilizado na apresentação dos módulos, os próprios mecanismos de colaboração disponíveis no ambiente também podem ser considerados. 
Como apoio à autoria dos módulos, optou-se basicamente pela utilização de ferramentas de editoração genéricas, de amplo conhecimento pela comunidade de desenvolvedores: Word, PowerPoint, Visio, FrontPage, Photoshop, Dreamweaver, Flash, LaTeX ${ }^{7}$, entre outras.

Como apoio à comunicação entre os membros da equipe de desenvolvimento, facilitando a coordenação e a publicação dos resultados pertinentes ao projeto, optou-se pela utilização de correio eletrônico. Visto que, a princípio, o desenvolvimento ocorre apenas localmente (não são consideradas equipes distribuídas, externas ao ICMC-USP), reuniões de projeto podem ser agendadas pessoalmente, sem a necessidade de recursos mais elaborados.

Finalmente, como suporte ao gerenciamento de configuração foi selecionada a ferramenta $C V S$ (Concurrent Versions System) (Morse, 1996). Trata-se de um software bastante utilizado para implantação de repositórios de controle de versões, possibilitando, entre outras facilidades, o registro das modificações, data e responsáveis pelas alterações.

\subsubsection{Restrições Impostas ao Processo Instanciado}

Nesta seção são discutidas as principais restrições impostas ao processo instanciado. Ressalta-se que tais restrições constituem aspectos de melhoria do processo e deverão ser consideradas em suas próximas versões.

A primeira restrição refere-se ao fato das equipes de desenvolvimento não poderem estar geograficamente dispersas. A título de ilustração, na presença de equipes distribuídas, recursos mais elaborados para comunicação síncrona e assíncrona devem ser tratados e incorporados como parte da infra-estrutura necessária ao projeto.

Outra restrição diz respeito à construção manual dos modelos conceituais (mapas estendidos), instrucionais (HMBSS/Instrucional) e didáticos (HMBBS/Didático) durante a modelagem dos conteúdos educacionais. Conforme ressaltado anteriormente, as ferramentas existentes nesse contexto (KMap, HySCharts, ATEnA, entre outras) não incorporam as extensões propostas para a construção de tais modelos. Nesse sentido, aspectos relevantes, em especial os associados à validação dos modelos didáticos, não foram abordados. Ressalta-se, por exemplo, a impossibilidade de execução do statechart subjacente ao modelo e de análise automática das propriedades dinâmicas associadas. Atividades envolvendo o estabelecimento de mecanismos automatizados que apóiem a construção dos modelos propostos, em especial o modelo $\mathcal{H} \mathcal{M} B S /$ Didático, estão previstas como parte dos desdobramentos deste trabalho.

Finalmente, ferramentas automatizadas para a integração e gerência do conhecimento também não foram consideradas. A decisão de não utilizar, por exemplo, ferramentas para construção de ontologias como apoio automatizado à integração do conhecimento nessa instância do processo foi tomada a fim de evitar que tanto desenvolvedores como especialistas fossem sobrecarregados

\footnotetext{
${ }^{7}$ A princípio, tanto pacotes proprietários como soluções livres podem ser utilizadas. A decisão fica a cargo da equipe de desenvolvimento, levando em consideração a habilidade no uso das ferramentas associadas bem como os custos envolvidos.
} 
com a definição de axiomas - uma tarefa trabalhosa, que demanda tempo e habilidade específica em aspectos matemáticos.

\subsection{Considerações Finais}

Neste capítulo foi discutida a padronização de processos para o desenvolvimento de módulos educacionais, tendo como principal objetivo o estabelecimento de diretrizes para elaboração e evolução sistemática dos mesmos. A norma ISO/IEC 12207 serviu como base para o estabelecimento das categorias de processo e atividades associadas, sendo adaptada ao contexto de ensino e treinamento sobretudo por meio da incorporação de práticas de projeto instrucional e modelagem de conteúdos educacionais.

Comparados aos processos fundamentais da norma ISO/IEC 12207, os processos fundamentais para módulos educacionais diferem, sobretudo, com respeito à inclusão do Processo de Disponibilização, que trata das atividades e tarefas do instrutor/mediador do módulo educacional. Com respeito à categoria de processos de apoio, foi estabelecido o Processo de Gerência do Conhecimento, responsável por tratar os aspectos pertinentes ao gerenciamento e controle do conhecimento sob o qual o módulo está fundamentado. Quanto aos processos organizacionais, foi definido o Processo de Copyright e Licença, tratando aspectos pertinentes aos direitos autorais e termos de uso e distribuição do módulo.

Além da definição do processo padrão, aspectos de especialização também foram investigados. Nesse sentido, foi estabelecido um modelo de maturidade de processos para elaboração de módulos educacionais - $\mathcal{C M M} /$ Educacional -, o qual pode ser utilizado como apoio à especialização do processo padrão em diferentes níveis de maturidade. O $\mathcal{C M M} /$ Educacional foi baseado nos cinco níveis de maturidade definidos pelo modelo CMM e no modelo de maturidade de processos para equipes geograficamente dispersas. As tarefas e práticas definidas por tais modelos foram adaptadas ao contexto de produção de módulos educacionais e, além disso, sete novas KPAs foram definidas. O $\mathcal{C M M} /$ Educacional é apresentado em detalhes no Apêndice A. Além disso, as KPAs do modelo proposto também foram categorizadas em áreas de processo, a exemplo do que ocorre com as KPAs do CMM em relação às áreas de processo do CMMI. Uma definição preliminar do $\mathcal{C M N}$ I/Educacional também pode ser encontrada nesse apêndice.

Por fim, aspectos de instanciação do processo padrão também foram discutidos, sendo ilustrado o estabelecimento de um processo instanciado para um projeto específico. A determinação e seleção de recursos humanos, métodos e técnicas de desenvolvimento, e ferramentas e mecanismos de apoio pertinentes ao processo foram abordados. Em especial, na seleção das ferramentas e mecanismos de apoio, uma série de ferramentas educacionais foi caracterizada e analisada em termos de sua adequação à automatização das atividades e tarefas estabelecidas pelo processo padrão e em relação às perspectivas de desenvolvimento de módulos educacionais. De fato, tal caracterização é fundamental para a escolha de ferramentas adequadas ao processo instanciado. 
Além disso, ressalta-se que os fatores considerados nas análises conduzidas podem constituir um conjunto preliminar de requisitos e/ou critérios de avaliação nesse contexto.

No próximo capítulo, a aplicação prática do processo instanciado é ilustrada por meio da elaboração de um módulo educacional específico envolvendo o domínio de conhecimento sobre Teste de Software. 


\section{Estudo de Caso: Um Módulo Educacional no Domínio de Teste de Software}

\subsection{Considerações Iniciais}

No Capítulo 4 foi definido um processo padrão para elaboração de módulos educacionais, estabelecendo os processos, atividades e tarefas necessárias à produção sistemática dos mesmos. Além disso, aspectos associados à especialização e instanciação de processos também foram abordados e uma instância do processo padrão definido, adequada a projetos em que os módulos desenvolvidos são disponibilizados presencialmente, foi estabelecida.

É importante observar, no entanto, que o processo instanciado no contexto particular desse tipo de módulo pode ser refinado em função de fatores ainda mais específicos como, por exemplo, o domínio de conhecimento associado ao módulo. A título de ilustração, considere as áreas pertinentes à Ciência da Computação. Poderiam ser construídos módulos educacionais voltados ao ensino de Computação Gráfica, Sistemas Operacionais, Sistemas Distribuídos, Banco de Dados, Engenharia de Software, entre outros. Além disso, dentro de cada uma dessas áreas específicas, poderiam ser consideradas as sub-áreas relacionadas. Assim, no caso de Engenharia de Software, poderiam ser elaborados módulos sobre Especificação e Análise de Requisitos, Projeto e Desenvolvimento de Software, Verificação, Validação e Teste de Software, Manutenção, Gerenciamento de Configuração, Modelos de Qualidade de Software, entre outros. 
Dentro desse contexto, neste capítulo é ilustrada a aplicação prática do processo instanciado na elaboração de um módulo educacional específico, envolvendo o domínio de conhecimento sobre Teste de Software. Na Seção 5.2, é dada uma visão geral a respeito do módulo educacional desenvolvido. A aplicação do processo instanciado é ilustrada na Seção 5.3, discutindo aspectos pertinentes às atividades e tarefas conduzidas durante a construção do módulo. Por limitações de espaço, são consideradas apenas as atividades e tarefas mais relevantes pertinentes aos processos fundamentais do ciclo de vida, dando-se ênfase aos aspectos de estruturação e modelagem dos conteúdos educacionais.

\subsection{Aspectos Gerais do Módulo Teste de Software: Teo- ria e Prática}

Conforme discutido na Seção 3.2, módulos educacionais correspondem a unidades de estudo, compostas essencialmente por conteúdos teóricos integrados a atividades práticas e avaliações, cuja disponibilização aos aprendizes é apoiada por meio de recursos tecnológicos e computacionais.

O módulo educacional Teste de Software: Teoria e Prática, desenvolvido a partir da aplicação do processo instanciado estabelecido no Capítulo 4, insere-se nesse contexto. Conceitos, fatos, princípios, procedimentos, exemplos, informações complementares e exercícios pertinentes ao domínio de Teste de Software foram estruturados, modelados e implementados na forma de um conjunto de transparências, ao qual foram integradas páginas HTML, documentos-texto, ferramentas específicas do domínio de conhecimento e ferramentas educacionais. A transparência principal do módulo, ilustrando a integração entre seus diversos componentes, é apresentada na Figura 5.1.

De modo geral, foram consideradas no processo de desenvolvimento do módulo as perspectivas de estruturação, transferência, evolução e reuso do conhecimento. Em especial, aspectos de estruturação foram enfatizados, sendo construídos modelos conceituais, instrucionais e didáticos para a representação dos conteúdos educacionais pertinentes.

Quanto ao aspecto de transferência do conhecimento, além da incorporação de ferramentas educacionais ao módulo, é importante ressaltar a integração de ferramentas de teste, as quais atuam como mecanismos de apoio à condução das atividades instrucionais propostas, possibilitando a aplicação prática dos conceitos e demais informações teóricas associadas.

Tais ferramentas também são relevantes no que diz respeito à evolução do conhecimento, apoiando a condução de estudos teóricos e empíricos, caracterizados no contexto do módulo educacional como elementos instrucionais na forma de exercícios. Nesse sentido, pretende-se que, à medida que o módulo seja disponibilizado no escopo de disciplinas sobre Teste de Software, os resultados obtidos a partir dos estudos teóricos e empíricos conduzidos sejam utilizados como base para a evolução dos conteúdos educacionais associados.

Ainda no que diz respeito à evolução do conhecimento, o módulo também deve ser disponibilizado, a curto prazo, em ambientes instrumentados com recursos para a captura das aulas 


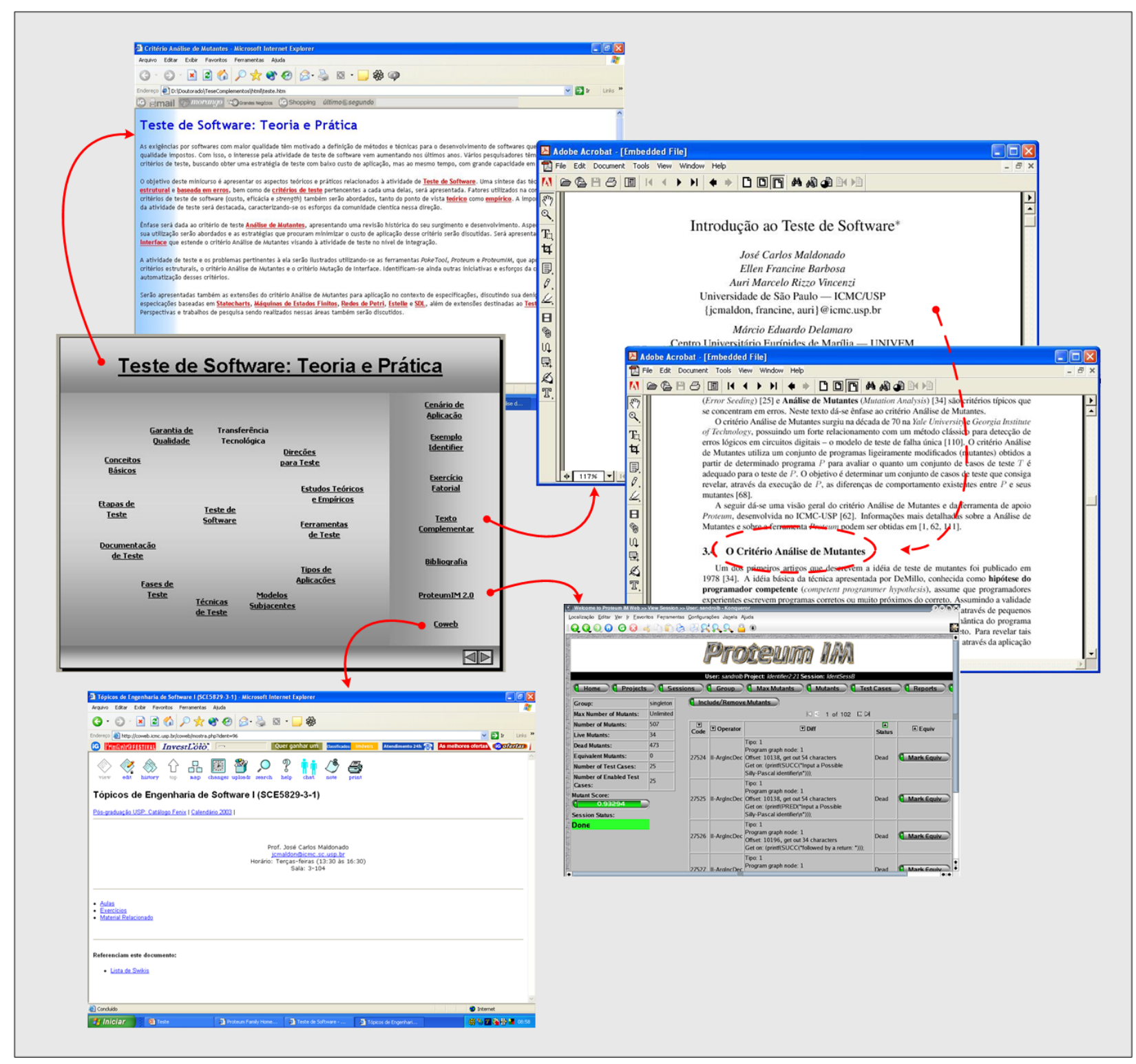

Figura 5.1: Transparência Principal do Módulo Teste de Software: Teoria e Prática: Integração entre Transparências, Documentos-Texto, Ferramentas de Teste e Ferramentas Educacionais.

presenciais. Desse modo, as discussões ocorridas em aula (na forma de áudio, vídeo e anotações) também serão utilizadas como apoio à evolução dos conteúdos pertinentes.

Por fim, salienta-se que o módulo apresenta características de especificação e implementação abertas, discutidas na Seção 3.6. Em outras palavras, o usuário tem total liberdade para decidir, em tempo de execução (apresentação), quais tópicos e assuntos devem ser tratados e em sequiência apresentá-los. Com isso, permite-se que o módulo seja personalizado em função de aspectos tais como tempo de apresentação, objetivos e metas de aprendizado, público-alvo, entre outros.

A seguir, características e particularidades referentes ao módulo educacional Teste de Software: Teoria e Prática são apresentadas e discutidas no contexto das principais atividades e tarefas conduzidas durante sua construção. 


\subsection{Aplicação do Processo Padrão Instanciado no Domí- nio de Teste de Software}

Esta seção tem como propósito ilustrar a aplicação do processo instanciado, discutido no Capítulo 4, no desenvolvimento do módulo educacional Teste de Software: Teoria e Prática. Nesse sentido, algumas das principais atividades e tarefas conduzidas durante sua elaboração são descritas.

Do Processo de Definição, no contexto da atividade de Definição do Problema e das Necessidades de Aprendizado, foram consideradas as tarefas de Determinação da Condição de Aprendizado Atual e Definição das Metas de Aprendizado e Habilidades Associadas.

Do Processo de Planejamento, no contexto da atividade de Planejamento, foram consideradas as tarefas de Definição da Estrutura Geral do Módulo, Planejamento das Equipes de Desenvolvimento e Determinação da Metodologia, Padrões e Ferramentas.

Considerando o Processo de Desenvolvimento, no contexto da atividade de Análise, foi considerada a tarefa de Análise de Audiência. No contexto da atividade de Projeto foram consideradas as tarefas de Modelagem Conceitual, Modelagem Instrucional, Modelagem Didática e Projeto da Interface. Foram consideradas ainda, de maneira geral, as tarefas pertinentes às atividades de Implementação, Integração e Testes.

Do Processo de Disponibilização, foram consideradas, de modo geral, as tarefas pertinentes às atividades de Disponibilização do Módulo e Identificação de Problemas e Melhorias.

\subsubsection{Determinação da Condição de Aprendizado Atual}

A primeira tarefa conduzida para a construção do módulo educacional Teste de Software: Teoria e Prática foi a identificação de conhecimentos e habilidades ausentes observados no aprendizado do domínio de teste. A tarefa foi conduzida junto a um especialista de domínio que, no caso específico deste projeto, era o próprio professor interessado no desenvolvimento do módulo. De modo geral, entre os aspectos identificados destacam-se:

- Visão equivocada em relação aos objetivos e limitações da atividade de teste.

- Problemas na caracterização da atividade de teste, em termos das etapas e fases associadas, planejamento e projeto de casos de teste, técnicas de teste e estratégias de aplicação.

- Dificuldade na caracterização de critérios de teste, sobretudo quanto aos requisitos de teste associados.

- Visão essencialmente teórica, com dificuldade na aplicação prática de critérios básicos de teste, tais como critérios funcionais e critérios baseados em fluxo de controle. 
- Problemas no entendimento e aplicação de critérios mais "fortes", tais como critérios baseados em fluxo de dados e em mutação.

- Pouca ou nenhuma experiência na utilização de ferramentas de teste e na condução de estudos comparativos entre critérios.

- Visão limitada das áreas em que a atividade de teste pode ser aplicada.

É interessante observar que os problemas listados durante essa atividade foram identificados, sobretudo, a partir da experiência acadêmica prévia do especialista/professor na condução de disciplinas, minicursos, tutoriais e palestras na área.

\subsubsection{Definição das Metas de Aprendizado e Habilidades Associa- das}

A partir dos problemas e das necessidades de aprendizado identificadas, foram estabelecidos os principais objetivos a serem atingidos em decorrência da aplicação do módulo de teste:

- Proporcionar uma visão clara a respeito dos objetivos da atividades de teste, discutindo aspectos teóricos, práticos e limitações associadas.

- Fornecer uma visão abrangente da área, discutindo os principais conceitos e a terminologia associada. Situar a atividade de teste dentro do contexto da Engenharia de Software.

- Proporcionar uma visão abrangente das principais técnicas, estratégias, métodos e critérios de teste. Discutir fatores para comparação de critérios, tanto do ponto de vista teórico como empírico.

- Proporcionar habilidade na aplicação prática de critérios de teste por meio da utilização de ferramentas de suporte. Aspectos de projeto e desenvolvimento de ferramentas de teste também devem ser abordados.

- Discutir os possíveis cenários de desenvolvimento os quais podem ser beneficiados com a aplicação da atividade de teste. Por exemplo, o teste e a validação de sistemas reativos, o teste de sistemas distribuídos e o teste de software orientado a objeto, em nível de implementação e em nível de especificação, devem ser abordados.

\subsubsection{Definição da Estrutura Geral do Módulo}

A definição da estrutura geral do módulo envolveu, inicialmente, o levantamento dos materiais didáticos sobre Teste de Software existentes. Foram considerados: (1) materiais elaborados pelo especialista/professor, utilizados em disciplinas, minicursos, tutoriais e palestras sobre o assunto; 
(2) materiais elaborados por outros professores do ICMC-USP, envolvendo aspectos pertinentes à área; e (3) materiais de outras instituições (Georgia Institute of Technology, UNICAMP, CenPRA (Centro de Pesquisas Renato Archer), entre outras).

O modelo de currículo para Computação (Computing Curricula 2001) (IEEE Computer Society and Association for Computing Machinery, 2001) e a proposta de currículo para Engenharia de Software (Computing Curricula - Software Engineering) (IEEE Computer Society and Association for Computing Machinery, 2003), resultados do esforço conjunto da IEEE e da ACM, também foram investigados quanto aos tópicos envolvendo Teste de Software. Currículos de Engenharia de Software/Teste de Software de outras instituições de ensino, tanto no contexto nacional como internacional, também foram analisados com respeito aos tópicos de interesse cobertos.

Por fim, salienta-se que as recomendações do SWEBOK (Software Engineering Body of Knowledge $^{1}$ (Bourque et al., 1999; IEEE Computer Society, 2001) para a área de Teste de Software também foram consideradas.

A partir do levantamento conduzido e visando a atingir os objetivos e metas de aprendizado previamente definidos, um conjunto de 16 sub-módulos foi especificado. A Figura 5.2 ilustra a estrutura do módulo, em termos de seus sub-módulos. Observa-se que a figura representa um mapa conceitual geral para o domínio de Teste de Software. Os sub-módulos definidos enfatizam os seguintes aspectos da atividade de teste:

- Teste de Software: Caracteriza a atividade de teste em função de seus objetivos e limitações.

- Garantia de Qualidade: Situa a atividade de teste dentro do contexto de Engenharia de Software, em especial com relação às atividades de Garantia de Qualidade.

- Conceitos Básicos: Introduz os principais termos e conceitos pertinentes à area - engano, defeito, erro e falha, caso de teste, critério de adequação, critério de seleção.

- Etapas de Teste: Caracteriza a atividade de teste em termos de suas etapas de aplicação planejamento, projeto, execução e análise dos resultados.

- Documentação de Teste: Possui caráter gerencial, apresentando e discutindo os tipos de documentos pertinentes a cada etapa da atividade de teste.

- Fases de Teste: Caracteriza a atividade de teste quanto às suas fases principais - teste de unidade, teste de integração e teste de sistema.

- Técnicas de Teste: Caracteriza as técnicas de teste funcional, estrutural e baseada em erros. Critérios de teste associados também são ilustrados e discutidos.

\footnotetext{
${ }^{1} \mathrm{O}$ projeto SWEBOK tem como objetivo principal definir e caracterizar o conteúdo relativo à Engenharia de Software, promovendo uma visão consistente da área e fornecendo subsídios para o desenvolvimento de currículos e material de certificação associados.
} 


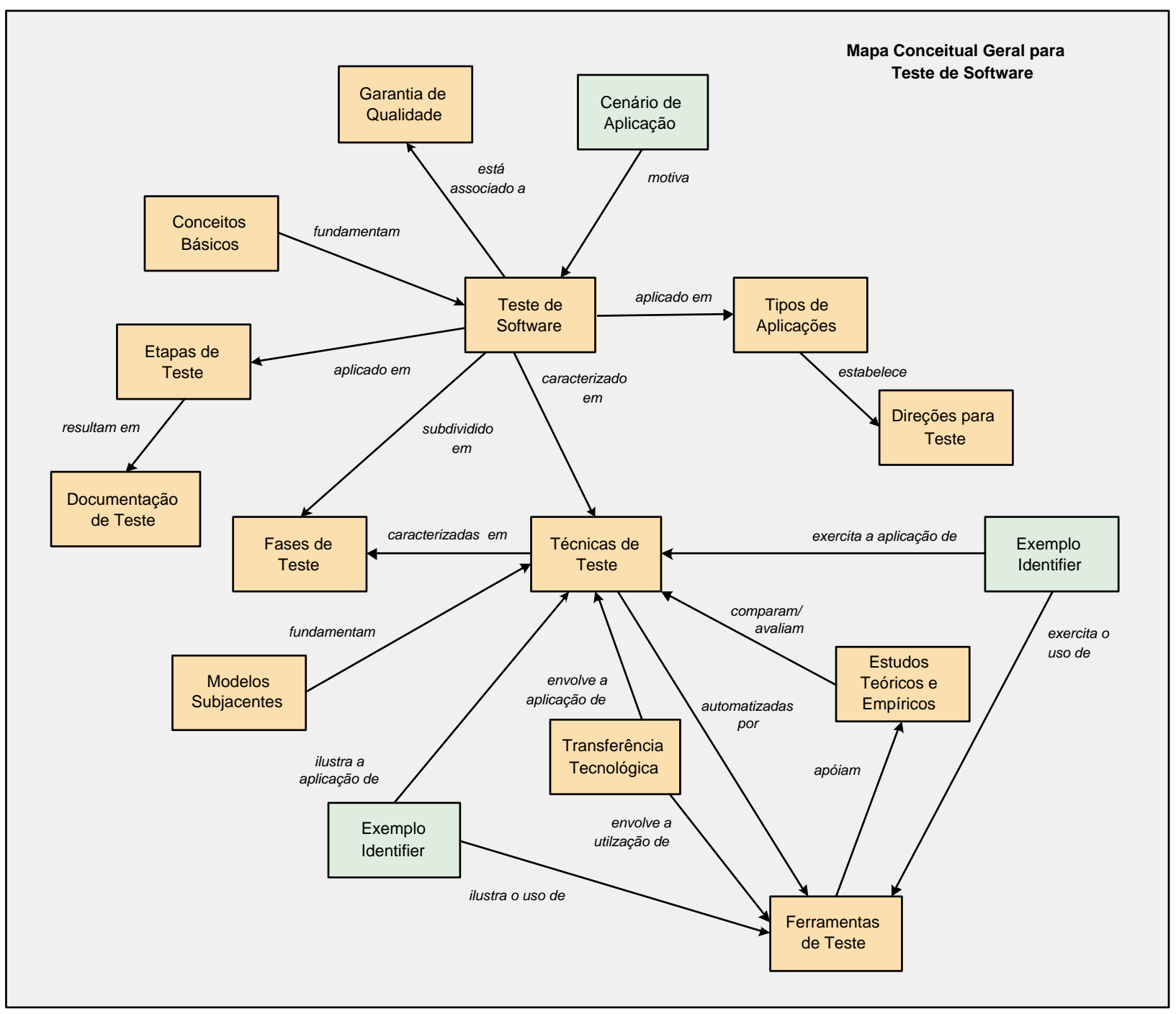

Figura 5.2: Estrutura Geral do Módulo Teste de Software: Teoria e Prática.

- Modelos Subjacentes: Apresenta os modelos que fundamentalmente são utilizados na definição dos requisitos de teste.

- Tipos de Aplicações: Discute a atividade de teste em termos dos produtos/aplicações testados - teste de máquinas de estado finito, teste de Statecharts, teste de programas concorrentes, teste de programas orientados a objeto, teste de componentes, entre outros.

- Ferramentas de Teste: Discute aspectos de automatização da atividade de teste.

- Estudos Teóricos e Empíricos: Discute aspectos teóricos e práticos envolvendo a comparação entre técnicas e critérios de teste.

- Direções para Teste: Ilustra tendências e direções de pesquisa na área.

- Transferência Tecnológica: Discute aspectos envolvendo a transferência tecnológica dos conceitos e práticas de teste entre universidade e indústria. 
- Cenário de Aplicação: Ilustra possíveis situações e cenários em que a atividade de teste pode ser aplicada. Atua como um elemento de motivação ao estudo dos tópicos associados ao domínio de Teste de Software.

- Exemplo Identifier: Ilustra a aplicação prática de critérios e ferramentas associadas no teste de um programa específico.

- Exercício Fatorial: Explora a aplicação prática de critérios e ferramentas associadas no teste de um programa específico.

Observa-se que os sub-módulos Cenário de Aplicação, Exemplo Identifier e Exercício Fatorial representam elementos instrucionais com o propósito motivar, ilustrar e praticar determinados tópicos abordados dentro do contexto geral do módulo.

Além disso, é importante ressaltar que, embora os sub-módulos tenham sido projetados a fim de possibilitar sua utilização de forma independente, caracterizando unidades coesivas de estudo, relacionamentos entre conceitos de sub-módulos diferentes também podem ser estabelecidos. De fato, enquanto aspectos específicos de teste são abordados em cada sub-módulo separadamente, uma visão geral do domínio de conhecimento é obtida a partir da forma com que os sub-módulos se inter-relacionam.

A Figura 5.3 ilustra a correspondência dos tópicos associados à area de Teste de Software, estabelecidos pelo SWEBOK, em relação os sub-módulos projetados ${ }^{2}$.

De acordo com a figura, com exceção do tópico C1.5-Usage-Based, todos os tópicos estabelecidos pelo SWEBOK têm ao menos um de seus itens coberto pelo módulo Teste de Software: Teoria e Prática. De fato, a correspondência ilustrada na figura não significa que todos os itens definidos em um dado tópico do SWEBOK estejam sendo cobertos pelo sub-módulo associado. Por exemplo, o tópico A3-Relationships of testing to other activities estabelece que o teste seja contextualizado em relação à depuração, garantia de qualidade, certificação, entre outros aspectos. A atividade de garantia de qualidade representa apenas um desses itens e, dentro do contexto do módulo educacional desenvolvido, é tratada no sub-módulo Garantia de Qualidade.

Além disso, um mesmo sub-módulo pode incorporar itens de diferentes tópicos. É o caso, por exemplo, do sub-módulo Conceitos Básicos, que engloba itens tanto do tópico A1-Testing-related terminology como do tópico A2-Theoretical foundations.

Finalmente, cabe ressaltar que os aspectos pertinentes à automatização da atividade de teste, abordados nos sub-módulos Ferramentas de Teste e Transferência Tecnológica, são tratados pelo SWEBOK dentro da área de Software Engineering Tools and Methods.

\footnotetext{
${ }^{2}$ Os tópicos estabelecidos pelo SWEBOK não foram traduzidos de modo a preservar sua definição original.
} 


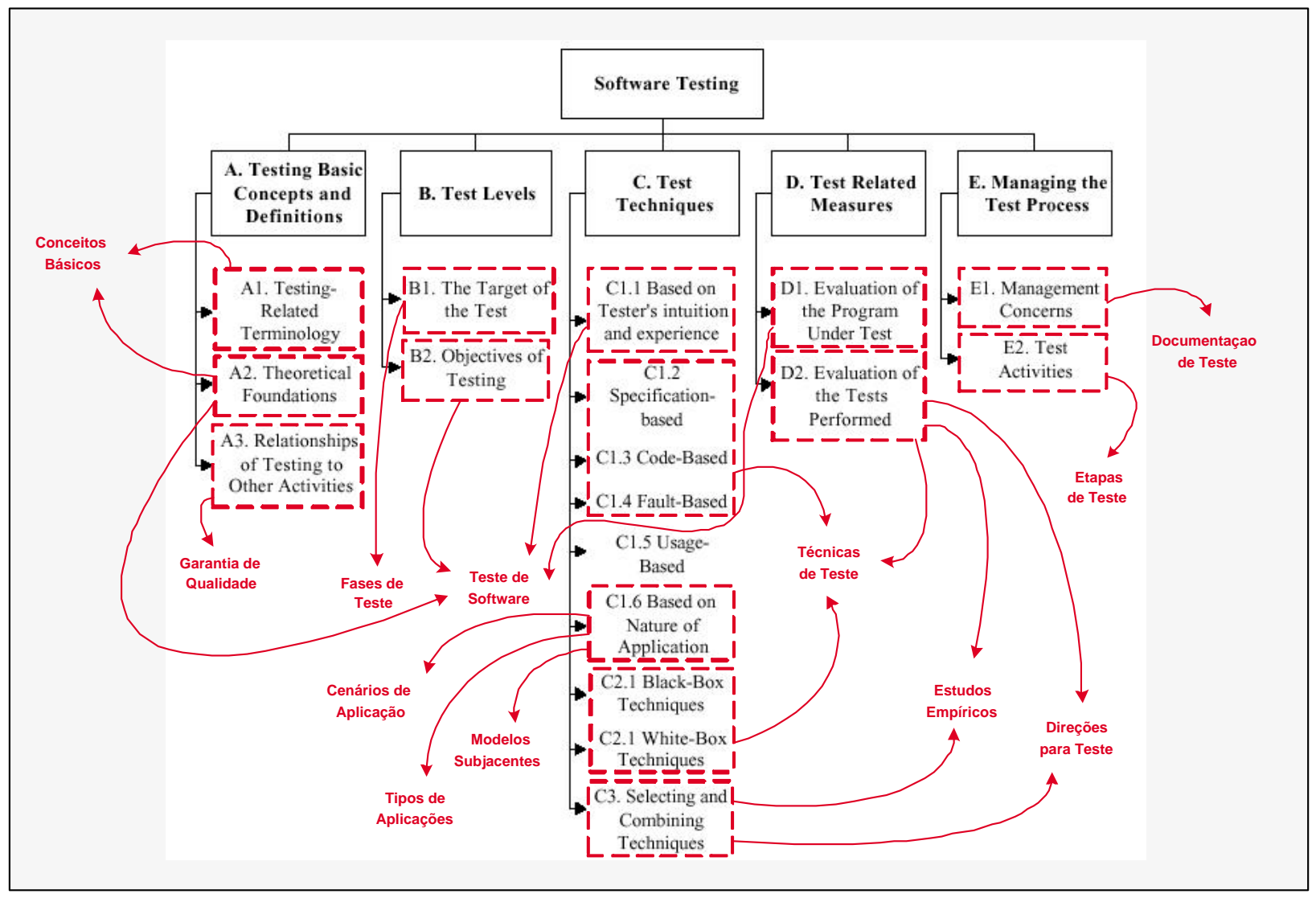

Figura 5.3: Tópicos do SWEBOK (Área de Teste de Software) x Sub-Módulos.

\subsubsection{Planejamento da Equipe de Desenvolvimento}

A equipe de desenvolvimento foi composta por três participantes: (1) o professor responsável pelo módulo, atuando como especialista de domínio e instrutor; (2) um aluno de pós-graduação, com conhecimento sobre a área de Teste de Software, acumulando os papéis de gerente de projeto, gerente de versões, coordenador e desenvolvedor; e (3) um aluno de graduação, desempenhando os papéis de desenvolvedor e técnico em recursos computacionais.

Observa-se que os papéis desempenhados pelos participantes da equipe de desenvolvimento foram estabelecidos previamente pelo processo instanciado, na definição dos recursos humanos envolvidos no projeto.

\subsubsection{Determinação da Metodologia, Padrões e Ferramentas}

A metodologia, os padrões e as ferramentas adotadas no desenvolvimento do módulo estão em conformidade com o que foi estabelecido durante a instanciação do processo, discutida na Seção 4.8. Nesse sentido, como métodos e técnicas de desenvolvimento foram selecionados o modelo ADDIE (Clark, 2003; Kruse, 2003; Lee \& Owens, 2000), a abordagem integrada $\mathcal{A I M}$ - CID (envolvendo a aplicação de mapas conceituais estendidos e dos modelos HMBS/Instrucional e HMBSS/Didático), e a teoria de Merril (1983). Como padrão para a especificação de metadados 
foi adotado o IEEE LTSC LOM (Learning Objects Metadata) (IEEE Learning Technology Standards Committee, 2002).

Quanto ao suporte automatizado, foram selecionadas ferramentas de editoração genéricas (Word, PowerPoint, Visio, FrontPage, Photoshop, Dreamweaver, Flash, LaTeX), o WebCT (Goldberg et al., 1996), a CoWeb (Guzdial et al., 2002) e o e-Class (Abowd et al., 1996; Pimentel, 2001). Observa-se que, neste projeto em particular, não foram utilizadas ferramentas para o controle de versões, embora o processo instanciado tenha estabelecido a ferramenta CVS (Morse, 1996) com essa finalidade.

Além das ferramentas de apoio estabelecidas pelo processo instanciado, ferramentas específicas no contexto do domínio de conhecimento ao qual o módulo se destina também devem ser selecionadas. No caso do módulo Teste de Software: Teoria e Prática, tendo em vista os objetivos e as metas de aprendizado estabelecidas, sobretudo com respeito à aplicação prática de técnicas e critérios de teste, foram selecionadas as seguintes ferramentas:

- PokeTool (Chaim, 1991): Apóia a aplicação de critérios estruturais, tanto baseados em fluxo de controle como baseados em fluxo de dados, em programas procedimentais.

- PROTEM/IM2.0 - versão web (Bianchini et al., 2003; Maldonado et al., 2000b): Apóia a aplicação de critérios de teste baseados em mutação, tanto em nível de unidade como em nível de integração, em programas procedimentais.

- JaBUTi (Vincenzi et al., 2003b): Apóia a aplicação de critérios estruturais em programas orientados a objeto.

A decisão pelas ferramentas acima justifica-se em função dos aspectos de aprendizado proporcionados, os quais podem ser explorados na condução das atividades e tarefas propostas no contexto do módulo. Por exemplo, tais ferramentas possibilitam, entre outros aspectos: (1) a aplicação prática tanto de critérios básicos como de critérios mais elaborados; (2) o estabelecimento de estratégias de teste levando em consideração diferentes critérios e fases de teste; (3) a aplicação dos mesmos conceitos de teste em paradigmas de desenvolvimento distintos.

\subsubsection{Análise de Audiência}

O público-alvo do módulo de teste é formado por alunos de graduação e pós-graduação, tanto do ICMC-USP como de outras instituições, e profissionais da área de computação. Embora cada grupo de aprendizes exija uma maneira diferenciada de apresentação e navegação pelos conceitos, informações e elementos instrucionais associados, o conteúdo educacional é essencialmente o mesmo. Nesse sentido, o módulo deve ser flexível o suficiente de modo que seja possível adequá-lo às características do público-alvo sem maiores alterações em sua estrutura. 
Como pré-requisitos, são necessários conhecimentos básicos em estruturas de dados e linguagens de programação, além de noções gerais sobre técnicas, metodologias e paradigmas de desenvolvimento de software. Além disso, os aprendizes devem estar motivados à realização de trabalhos práticos em cooperação com outros participantes, à apresentação e discussão de suas idéias por meio de ferramentas colaborativas e à pesquisa de assuntos e tópicos relacionados via web.

\subsubsection{Modelagem de Conteúdos Educacionais}

A modelagem dos conteúdos educacionais relativos ao módulo foi conduzida de acordo com a abordagem integrada $\mathcal{A L M}$ - CID , resultando na construção de modelos conceituais, instrucionais e didáticos pertinentes ao domínio de Teste de Software. A fim de ilustrar os modelos resultantes dessa atividade, foi selecionado um tópico específico desse domínio de conhecimento - o critério Análise de Mutantes (DeMillo et al., 1978) -, pertencente ao sub-módulo Técnicas de Teste.

Com o propósito de facilitar a compreensão dos modelos elaborados e analisar suas implicações na maneira como o módulo foi construído, alguns aspectos de implementação também são discutidos nesta seção, quando pertinente. Cabe ressaltar, no entanto, que as atividades de modelagem e implementação foram conduzidas separadamente.

\section{Modelagem Conceitual}

A Figura 5.4 ilustra o modelo conceitual construído para o domínio de conhecimento envolvendo o critério Análise de Mutantes. Conforme destacado anteriormente, o modelo conceitual estabelecido pela abordagem $\mathcal{A} I M$ - CLD corresponde a um mapa conceitual restrito à representação de conceitos e estendido com notações de taxonomia e composição de conceitos. Fazendo uma leitura do modelo elaborado, tem-se que:

- A Análise de Mutantes é um dos Critérios de Teste pertencentes à Técnica Baseada em Erros. Outros critérios representantes dessa técnica são: Error Guessing, Error Seedinge Teste de Perturbação.

- A Análise de Mutantes assume a validade da Hipótese do Programador Competente e do Efeito de Acoplamento. O critério utiliza informações sobre Erros Típicos para derivar casos de teste e possui um Escore de Mutação associado.

- Erros Típicos são modelados por meio de Operadores de Mutação, dando origem a programas Mutantes.

- Mutantes caracterizam Transformações Sintáticas de Programas, podendo ser classificados em Mutantes Mortos, Mutantes Equivalentes e Mutantes Error-Revealing. 
- Transformações Sintáticas podem resultar na Equivalência de Programas, caracterizando um Mutante Equivalente.

- Mutação Aleatória, Mutação Seletiva e Mutação Restrita representam sub-tipos do critério Análise de Mutantes.

- A Mutação Restrita pode ser utilizada no estabelecimento de Conjuntos Essenciais de Operadores, caracterizando subconjuntos de Operadores de Mutação.

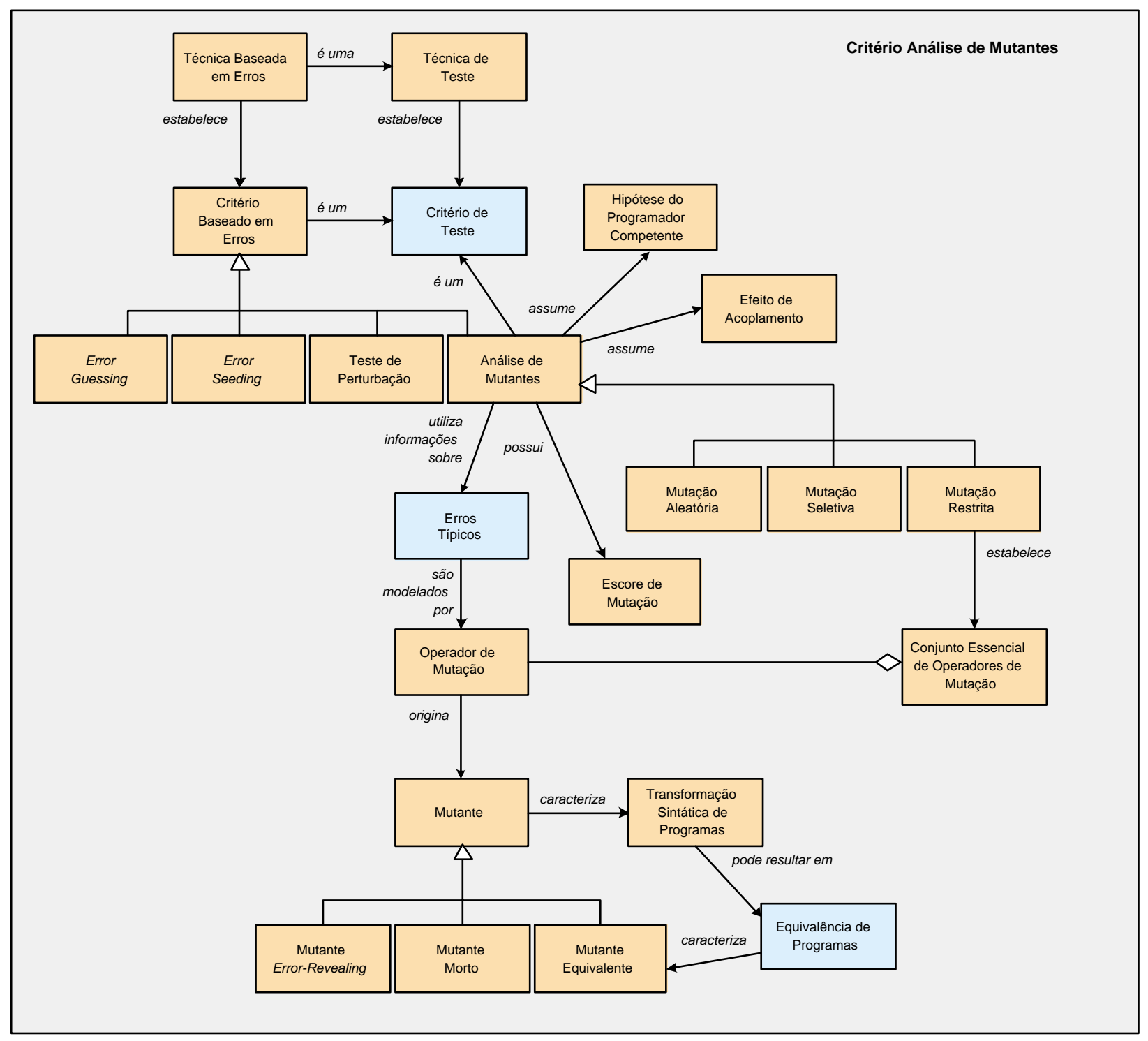

Figura 5.4: Critério Análise de Mutantes: Modelo (Mapa) Conceitual.

Observa-se que o modelo construído satisfaz os requisitos e aspectos identificados como relevantes sob a perspectiva conceitual: relações de taxonomia e composição de conceitos, relacionamentos específicos ao domínio e modularização (decomposição hierárquica). A Figura 5.5 apresenta uma visão parcial do modelo elaborado, ilustrando alguns desses aspectos e o modo como 
foram representados. Por exemplo, existe uma relação de taxonomia entre os conceitos Mutante, Mutante Morto, Mutante Equivalente e Mutante Error-Revealing. De forma análoga, os conceitos Conjunto Essencial de Operadores de Mutação e operador de Mutação estão associados por meio de uma relação de composição. Já a associação entre Mutante Equivalente e Equivalência de Programas caracteriza um relacionamento específico, com um significado particular dentro do contexto da Análise de Mutantes.

Por fim, conceitos externos ao sub-módulo em questão também foram representados no modelo. Correspondem a conceitos externos: Equivalência de Programas, definido no submódulo Teste de Software; e Erros Típicos e Critério de Teste, ambos definidos no sub-módulo Conceitos Básicos.

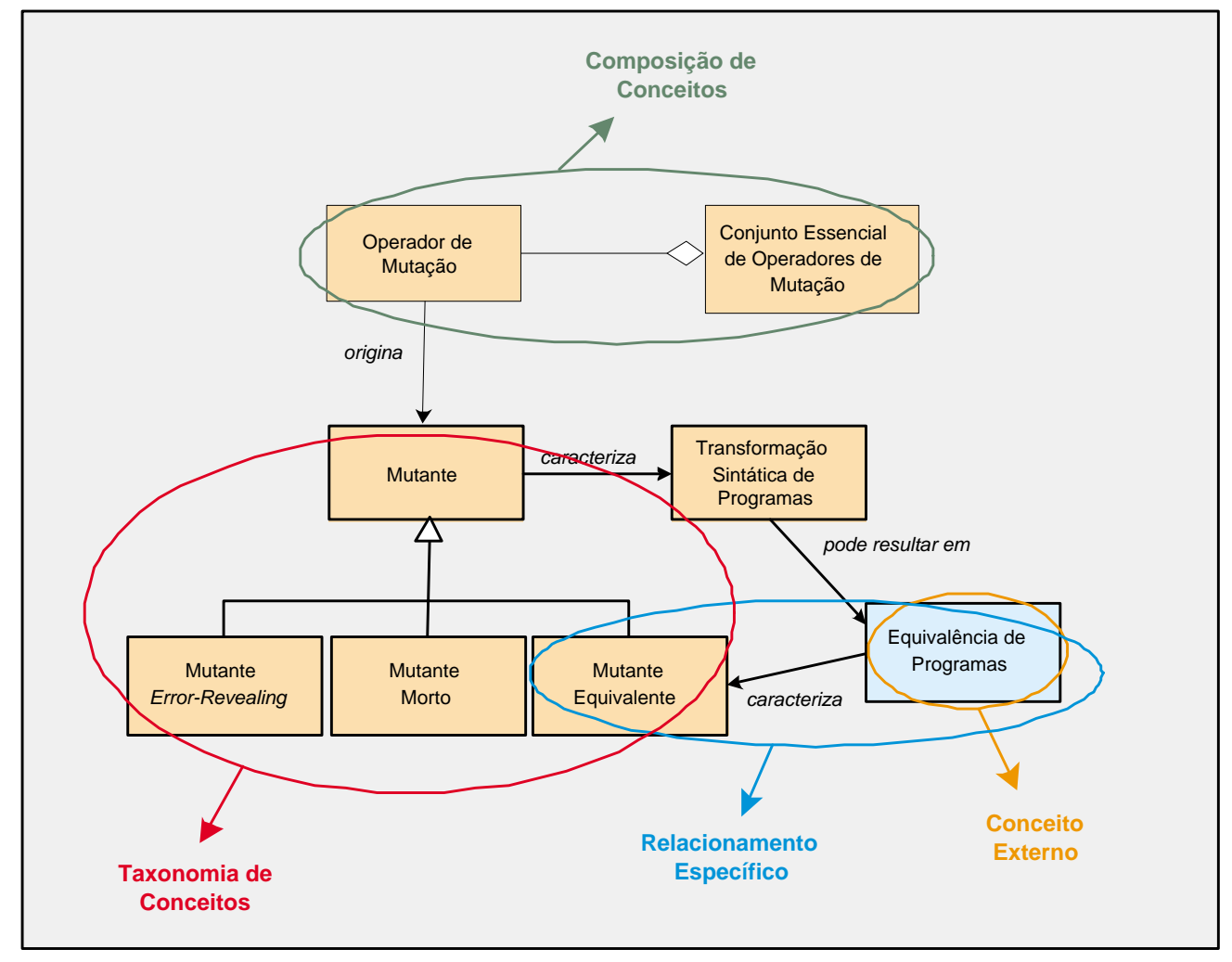

Figura 5.5: Requisitos Associados à Perspectiva Conceitual Representados no Modelo.

Embora o módulo educacional não seja diretamente derivado a partir do modelo conceitual, vários aspectos modelados podem ser visualizados nas páginas/transparências implementadas. Por exemplo, a Figura 5.6 ilustra as transparências referentes a Mutante Equivalente e Equivalência de Programas. No frame esquerdo da transparência sobre Mutante Equivalente está representada a idéia de taxonomia associada ao conceito. Além disso, o link para a transparência Equivalência de Programas implementa um relacionamento externo, levando o usuário ao sub-módulo Teste de Software, no qual o conceito está definido.

Relacionamentos externos devem ser tratados em ambos os modelos considerados. Em termos práticos, isso significa que no modelo conceitual em que o conceito Equivalência de 


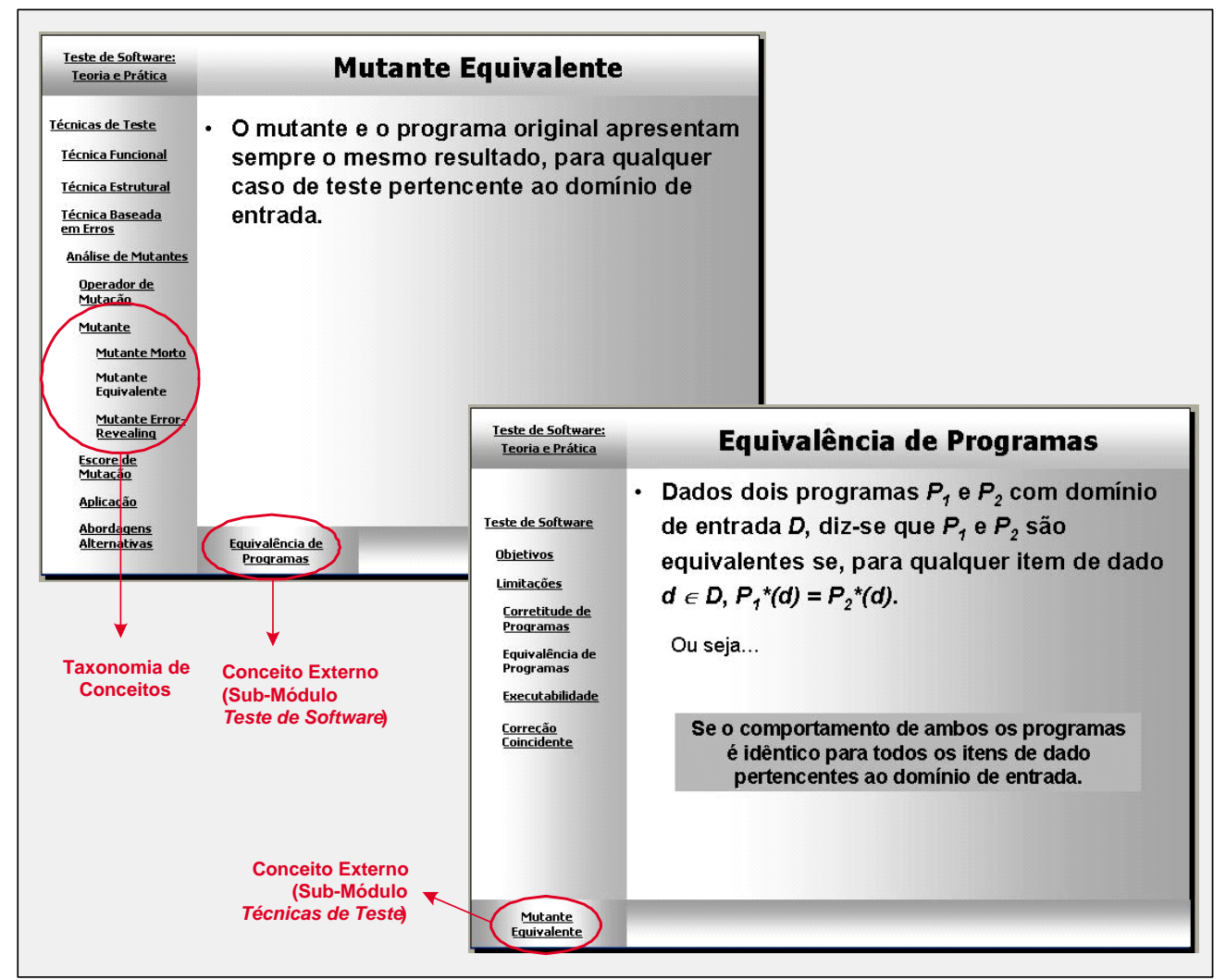

Figura 5.6: Transparências referentes a Mutante Equivalente e Equivalência de Programas.

Programas é definido, o conceito Mutante Equivalente deve ser modelado como um conceito externo. Conseqüentemente, na transparência sobre Equivalência de Programas deve haver um link direcionando o usuário à transparência Mutante Equivalente.

Salienta-se ainda que nem todos os conceitos representados no modelo conceitual precisam estar necessariamente implementados no módulo educacional. Os critérios Error Guessing, Error Seeding e Teste de Perturbação, apesar de estarem representados no modelo da Figura 5.4, não foram considerados na versão atual do módulo. Sua representação, no entanto, além de melhor contextualizar a Análise de Mutantes em relação a outros critérios da técnica baseada em erros, fornece sugestões para futura implementação e, conseqüentemente, para a evolução do módulo.

Finalmente, é importante ressaltar o caráter subjetivo da modelagem conceitual. De fato, diversos outros modelos representando o mesmo conhecimento poderiam ter sido elaborados dependendo do especialista e/ou projetista envolvido em sua construção.

\section{Modelagem Instrucional}

A Figura 5.7 apresenta o modelo instrucional elaborado para o critério Análise de Mutantes. Conforme estabelecido na abordagem $\mathcal{A L M}-\mathcal{C} \mathcal{L} D$, aspectos instrucionais são modelados segundo o $\mathcal{H M B S} /$ Instrucional, que restringe o HMBS à representação dos aspectos de decomposição hierárquica, incorporando ainda mecanismos de apoio à diferenciação entre categorias do conhecimento. 


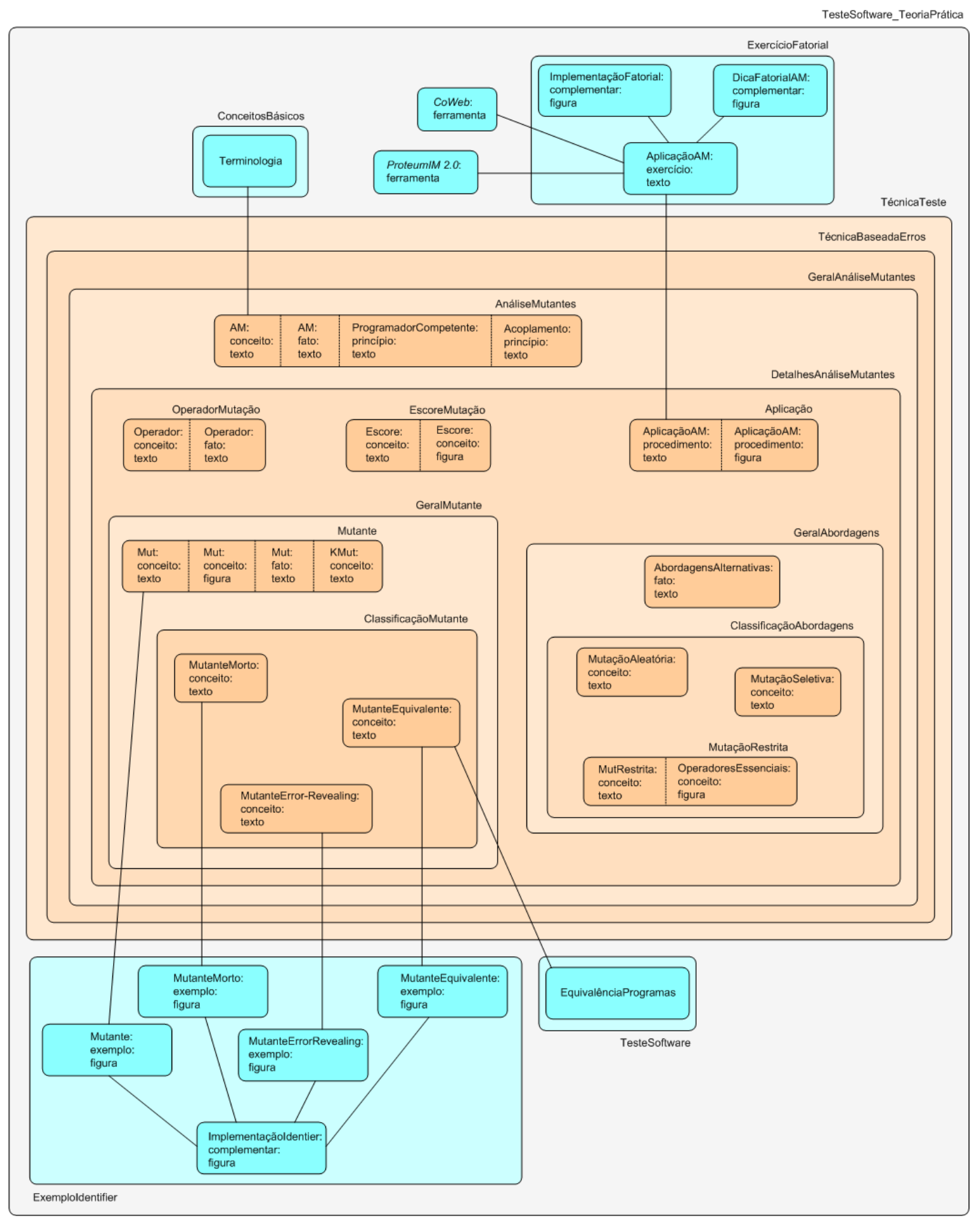

Figura 5.7: Critério Análise de Mutantes: Modelo Instrucional (HMMBS/Instrucional).

A primeira etapa para a construção do modelo instrucional consistiu na identificação de outras informações relevantes que pudessem ser associadas aos conceitos representados no modelo conceitual da Figura 5.4. Conforme estabelecido no processo instanciado, o mecanismo utilizado para a diferenciação das categorias do conhecimento foi baseado na teoria de Merril (1983), estabelecendo quatro tipos básicos de informação: fato, conceito, princípio e procedimento. Por exemplo, de acordo com a Figura 5.7, a página/transparência referente ao estado Análisemutantes deve conter, além de sua definição (AM:conceito:texto), fa- 
tos (AM: fato:texto) e princípios (ProgramadorCompetente:princípio:texto e Acoplamento:princípio:texto) associados. Conceitos e informações mais detalhadas sobre o critério foram modelados em estados separados: OperadorMutação, Mutante, EscoreMutação, Aplicação, AbordagensAlternativas, entre outras.

Os tipos de mídia associados às informações que compõem as páginas/transparências também foram representados. Por exemplo, a página/transparência referente ao estado Aplicação é composta por informações da categoria procedimento, representadas na forma de textos (AplicaçãoAM:procedimento:texto) e figuras (AplicaçãoAM: procedimento: figura).

As figuras 5.8 e 5.9 ilustram as implicações da diferenciação das categorias de conhecimento representadas no modelo instrucional na implementação das transparências referentes à Análise de Mutantes e à Aplicação da Análise de Mutantes, respectivamente. De modo geral, tem-se que:

- A definição associada ao critério Análise de Mutantes representa o conceito propriamente dito.

- Aspectos relacionados à construção de casos de teste a partir da Análise de Mutantes exemplificam um dos fatos associados ao critério.

- A Hipótese do Programador Competente e o Efeito de Acoplamento correspondem aos princípios associados ao critério.

- Os passos para a aplicação da Análise de Mutantes estabelecem um procedimento sistematizando sua utilização. Tanto elementos textuais como gráficos são considerados.

Observe que na Figura 5.8 foram apresentadas duas transparências referentes à Análise de Mutantes, enquanto no modelo instrucional associado subentende-se que todas as informações são apresentadas simultaneamente na mesma página/transparência (estados AND). De maneira análoga, as informações associadas à aplicação do critério foram apresentadas em três transparências (Figura 5.9), enquanto no modelo instrucional uma única página/transparência foi representada.

Tal "quebra" justifica-se em virtude da limitação de espaço imposta às transparências elaboradas no PowerPoint. De fato, essa é uma limitação dependente do formato escolhido para a apresentação do módulo e da própria ferramenta de editoração utilizada. Por exemplo, caso o módulo fosse implementado como um conjunto de páginas HTML, uma única página com barras de rolagem seria suficiente para conter todas as informações relativas à Análise de Mutantes. Na tentativa de resolver essa limitação, botões de ação à direita das transparências foram incluídos com o propósito de indicar que o mesmo item de informação possui mais de uma transparência associada. Além disso, o título da transparência só é alterado quando ocorre mudança no item de informação apresentado.

A segunda etapa na construção do modelo instrucional consistiu em identificar os elementos instrucionais a serem associados aos itens de informação. Basicamente, dois tipos de elementos 


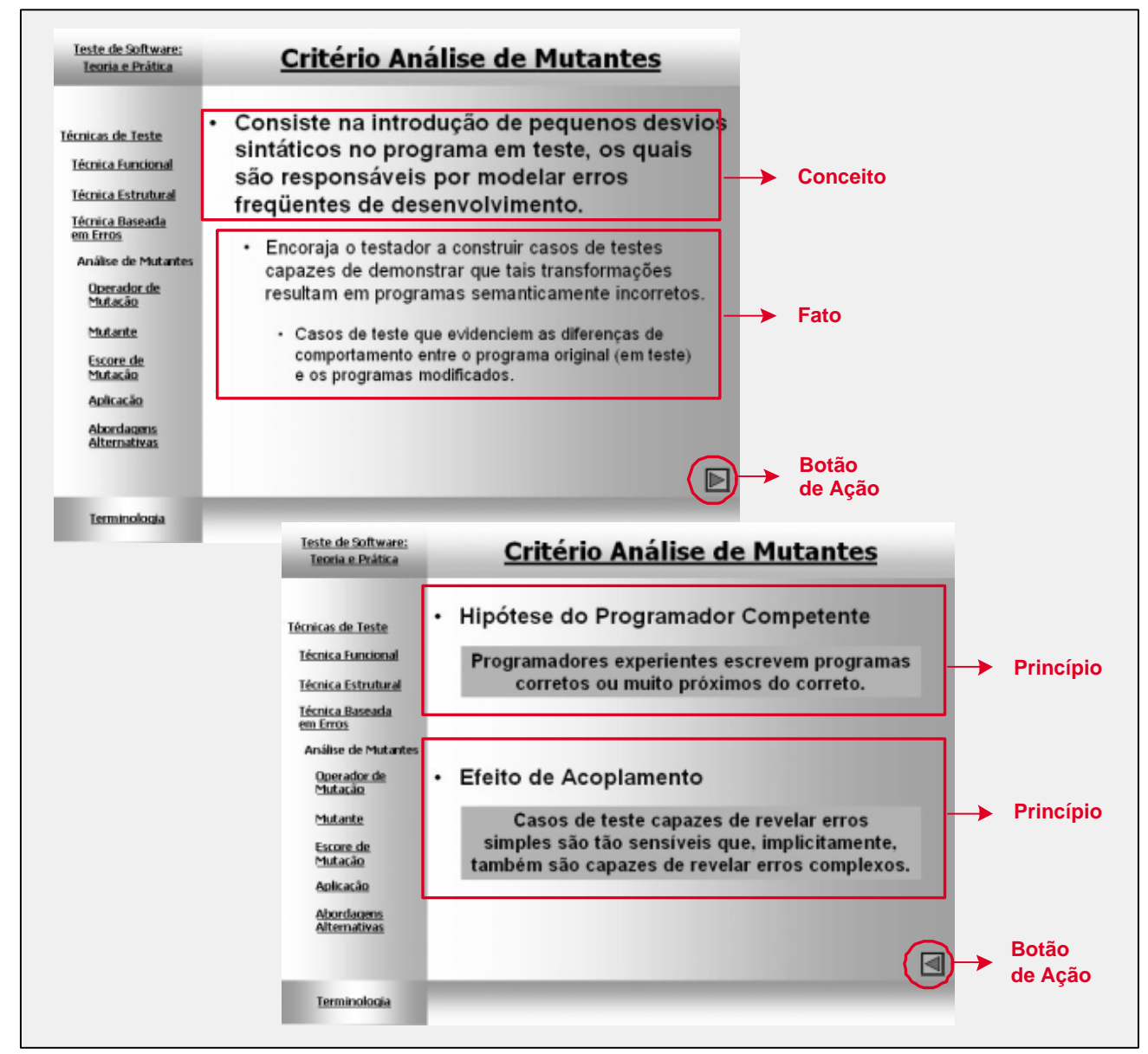

Figura 5.8: Transparências referentes à Análise de Mutantes.

instrucionais foram representados no modelo da Figura 5.7: (1) explanatórios, na forma de exemplos e informações complementares; e (2) exploratórios, na forma de exercícios.

Considere inicialmente apenas os elementos explanatórios.

Os conceitos pelos estados Mut:conceito:texto, MutanteMorto:conceito:texto, MutanteEquivalente:conceito:texto e Mutante Error-Revealing:conceito:texto foram associados, cada um deles, a exemplos pertinentes representados pelos estados Mutante:exemplo:figura, MutanteMorto:exemplo:figura, MutanteEquivalente:exemplo:figura e MutanteError-Revealing:exemplo:figura, respectivamente. Tais exemplos, por sua vez, possuem informações complementares, sendo associados ao elemento explanatório representado por ImplementaçãoIdentifier:complementar:figura. Tem-se, desse modo, elementos explanatórios complementando outros elementos explanatórios.

É importante ressaltar que os exemplos discutidos fazem parte de um elemento explanatório mais abrangente (ExemploIdentifier) no qual também são exemplificadas outras técnicas e critérios de teste. Por limitações de espaço, apenas elementos explanatórios pertinentes ao critério Análise de Mutantes foram representados no modelo da Figura 5.7. 


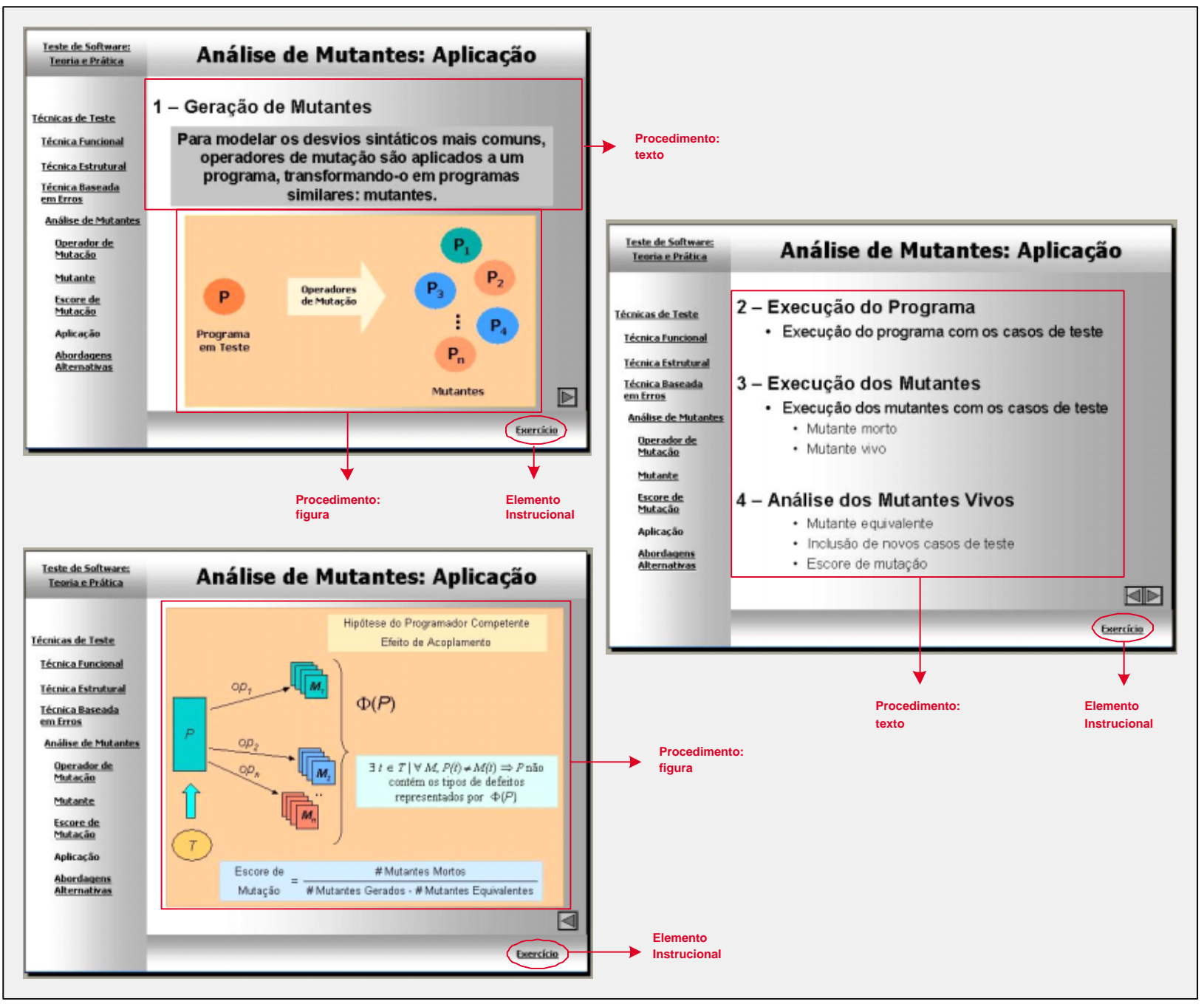

Figura 5.9: Transparências referentes à Aplicação da Análise de Mutantes.

Quanto aos elementos exploratórios, foi modelado um exercício, representado por AplicaçãoAM:exercício:texto, envolvendo a aplicação do critério Análise de Mutantes no teste de um programa que calcula o fatorial de um número. $\mathrm{O}$ exercício foi associado ao item de informação dado pelo estado Aplicação. Elementos explanatórios fornecendo informações complementares a fim de apoiar sua resolução do exercício também foram considerados: ImplementaçãoFatorial:complementar:figura e DicaFatorialAM: complementar: figura. Além disso, as ferramentas utilizadas na condução do exercício (ProteumIM 2 . 0 : ferramenta e CoWeb : ferramenta) também foram representadas. Observa-se ainda que o exercício envolvendo a aplicação da Análise de Mutantes também faz parte de um elemento exploratório mais abrangente (ExercícioFatorial) no qual são exploradas outras técnicas e critérios de teste.

Na Figura 5.9 é ilustrado o link que ativa o exercício proposto a partir das transparências referentes à Aplicação da Análise de Mutantes. A Figura 5.10 ilustra a transparência contendo o exercício e as transparências referentes às informações complementares, juntamente com as telas 
das ferramentas associadas à condução do exercício. Links para outras transparências que compõem o "exercício completo" também são apresentados.

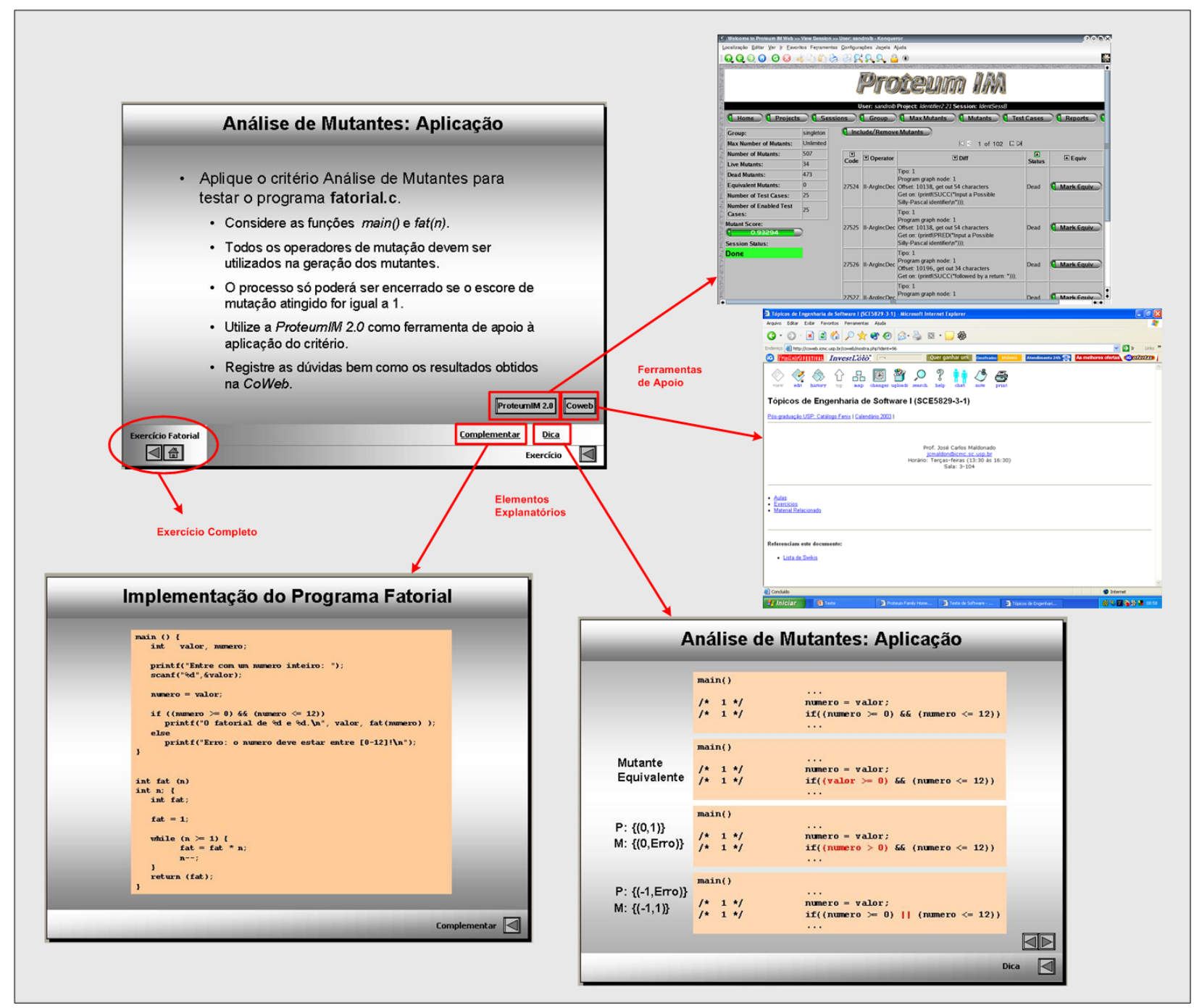

Figura 5.10: Transparências referentes ao Exercício Proposto para a Aplicação da Análise de Mutantes.

Além de elementos instrucionais pertencentes a outros sub-módulos, itens de informação externos ao sub-módulo Técnicas de Teste também foram representados: Terminologia e Equivalência de Programas. Procura-se, com isso, preservar a idéia de conceitos externos explorada no modelo conceitual. Salienta-se entretanto que apenas os itens e elementos externos especificamente relacionados ao critério Análise de Mutantes foram representados no modelo.

Por fim, visto que não compete ao modelo instrucional o estabelecimento de seqüências de apresentação entre seus objetos, apenas indicativos sobre as associações existentes entre eles são fornecidos. No caso de relacionamentos envolvendo itens de informação e elementos instrucionais, linhas simples (sem setas indicando ordem ou direção) visam a representar a existência de uma associação entre tais objetos, sem no entanto fornecer indícios a respeito da seqüência de apre- 
sentação envolvida. Quanto aos relacionamentos entre itens de informação, apenas os aspectos de estruturação hierárquica são considerados.

\section{Modelagem Didática}

Conforme ressaltado anteriormente, diversos modelos didáticos podem ser derivados a partir de um único modelo instrucional. Nesse sentido, a título de ilustração, três modelos didáticos (figuras 5.11, 5.12 e 5.13), elaborados segundo o $\mathcal{H}$ MBSS/Didático, foram construídos a partir do modelo instrucional da Figura 5.7.

O modelo didático da Figura 5.11 consiste em uma especificação aberta dos aspectos de navegação, na qual estão representadas todas as possíveis seqüências de apresentação entre os objetos modelados.

Conforme definido na Seção 3.6, as propriedades (3) e (4) de um estado $D D$ estabelecem que:

3. Todos os subestados $O R_{D D}$ de um estado $D D$ são totalmente conexos.

4. A saída de um estado $D D\left(X_{D D}\right)$ pode ativar quaisquer estados $O R_{D D}$ da hierarquia de estados-pai- $D D$ de $X_{D D}$.

Considere, por exemplo, o estado $D D$ DetalhesAnáliseMutantes. De acordo com a Propriedade (3), todos subestados de DetalhesAnáli seMutantes - OperadorMutação, EscoreMutação, Aplicação, GeralMutante e GeralAbordagens - estão conectados entre si por meio de transições implícitas, as quais estabelecem a navegação entre eles $^{3}$. Desse modo, a partir de operadorMutação, por exemplo, pode-se atingir os estados EscoreMutação, Aplicação, GeralMutante e GeralAbordagens.

Considere agora o estado Mutante. A partir de Mutante é possível alcançar o estado ClassificaçãoMutante (e vice-versa). De fato, Mutante e ClassificaçãoMutante são subestados do estado $D D$ GeralMutante e, desse modo, estão conectados entre si por meio de transições implícitas, as quais estabelecem a navegação entre eles.

Além disso, de acordo com a Propriedade (4) e considerando a sequiência (GeralMutante, DetalhesAnáliseMutantes, GeralAnáliseMutantes, TécnicaBaseadaErros, TécnicaTeste, TesteSoftware_TeoriaPratica) como sendo a hierarquia de estadospai- $D D$ de Mutante, tem-se, por exemplo, que a partir de Mutante podem ser atingidos todos os estados $O R_{D D}$ de Detal hesAnáli seMutantes: OperadorMutação, EscoreMutação, Aplicação, GeralMutante e GeralAbordagens. Para definir o conjunto completo de estados que podem ser atingidos a partir do estado Mutante, a mesma análise deve ser realizada para todos os estados da hierarquia de estados-pai- $D D$ de GeralMutante ${ }^{4}$.

\footnotetext{
${ }^{3}$ Para garantir clareza e legibilidade ao modelo e facilitar sua compreensão, no esquema gráfico de um estado $D D$ não são representadas as transições entre seus subestados. Tais transições ficam implícitas, uma vez que as propriedades de um estado $D D$ estabelecem que todos os seus subestados são totalmente conexos.

${ }^{4}$ Por limitações de espaço, apenas estados relativos ao critério Análise de Mutantes foram representados nos modelos didáticos ilustrados nesta seção.
} 
TesteSoftware_TeoriaPrática

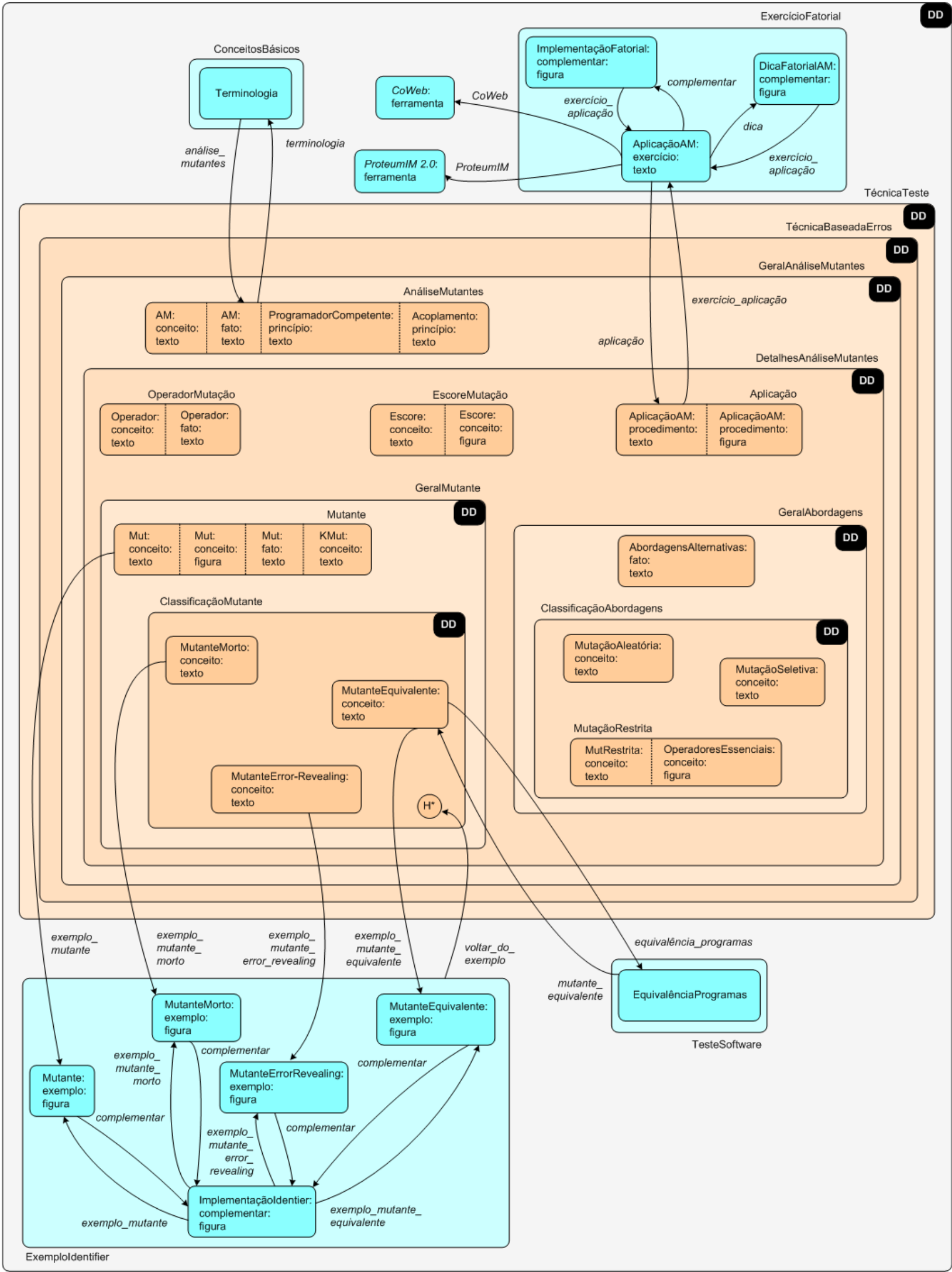

Figura 5.11: Critério Análise de Mutantes: Modelo Didático (HMMBS/Didático) - Especificação Aberta. 
É interessante observar que os estados AbordagensAlternativas e ClassificaçãoAbordagens não podem ser alcançados a partir de Mutante, visto que o estado GeralAbordagens não pertence à hierarquia de estados-pai- $D D$ de GeralMutante.

O segundo modelo didático, representado na Figura 5.12, consiste em uma especificação parcialmente aberta, na qual algumas das possibilidades de navegação foram desconsideradas.

Observe que o estado GeralAnáli seMutantes deixou de ser um estado DD. Além disso, o estado DetalhesAnáliseMutantes possui agora transições explícitas entre seus subestados. Desse modo, a partir do estado GeralMutante apenas o estado EscoreMutação pode ser atingido. De fato, a transição entre GeralMutante e EscoreMutação "inibe" as transições implícitas que partem de Geralmutante para os demais subestados $O R_{D D}$ de DetalhesAnáliseMutantes, fazendo com que tais possibilidades de navegação sejam desconsideradas.

Considerando novamente o estado Mutante, tem-se então que, além do estado ClassificaçãoMutante (Propriedade (3)), apenas os estados EscoreMutação e AnáliseMutantes (transições explícitas) podem ser atingidos.

O terceiro modelo, representado na Figura 5.13, consiste em uma especificação fechada, na qual os aspectos de navegação são pré-determinados, ou seja, a ordem de apresentação dos objetos é fixa, devendo ser previamente definida pelo especialista e/ou instrutor responsável pelo módulo. Nesse sentido, a partir do estado Mutante, por exemplo, apenas os estados MutanteMorto e EscoreMutação podem ser atingidos.

Nos três modelos ilustrados, além da sequiência de apresentação entre itens de informação, a associação entre tais itens e os respectivos elementos instrucionais pertinentes também foi estabelecida. Por exemplo, nas três situações, a partir de Mutante também é possível atingir o estado Mutante:exemplo:figura, que representa um exemplo associado, dentro do contexto de ExemploIdentifier. A utilização do mecanismo de história no retorno do exemplo também deve ser ressaltada.

É interessante observar que as seqüências de apresentação representadas nos modelos das figuras 5.12 e 5.13 correspondem a subconjuntos das possíveis sequiências de apresentação estabelecidas pelo modelo da Figura 5.11. De maneira similar, as sequiências representadas no modelo da Figura 5.13 correspondem a um subconjunto das seqüências estabelecidas pelo modelo da Figura 5.12. De fato, o modelo didático especificado da forma aberta corresponde à base a partir da qual todas as possíveís seqüências de apresentação podem ser derivadas.

Conforme ressaltado anteriormente, utilizando-se o $\mathcal{H}$ MBS/Didático na modelagem dos aspectos didáticos do conteúdo educacional, é possível construir um único modelo didático, especificado de maneira aberta, a partir do qual diversas implementações distintas do mesmo conteúdo podem ser obtidas. Tal característica é de fundamental importância na geração de conteúdos personalizados, cujos tópicos e a ordem em que os mesmos devem ser apresentados é estabelecida em função de fatores tais como tempo de apresentação, objetivos de aprendizado e público-alvo. 
TesteSoftware_TeoriaPrática

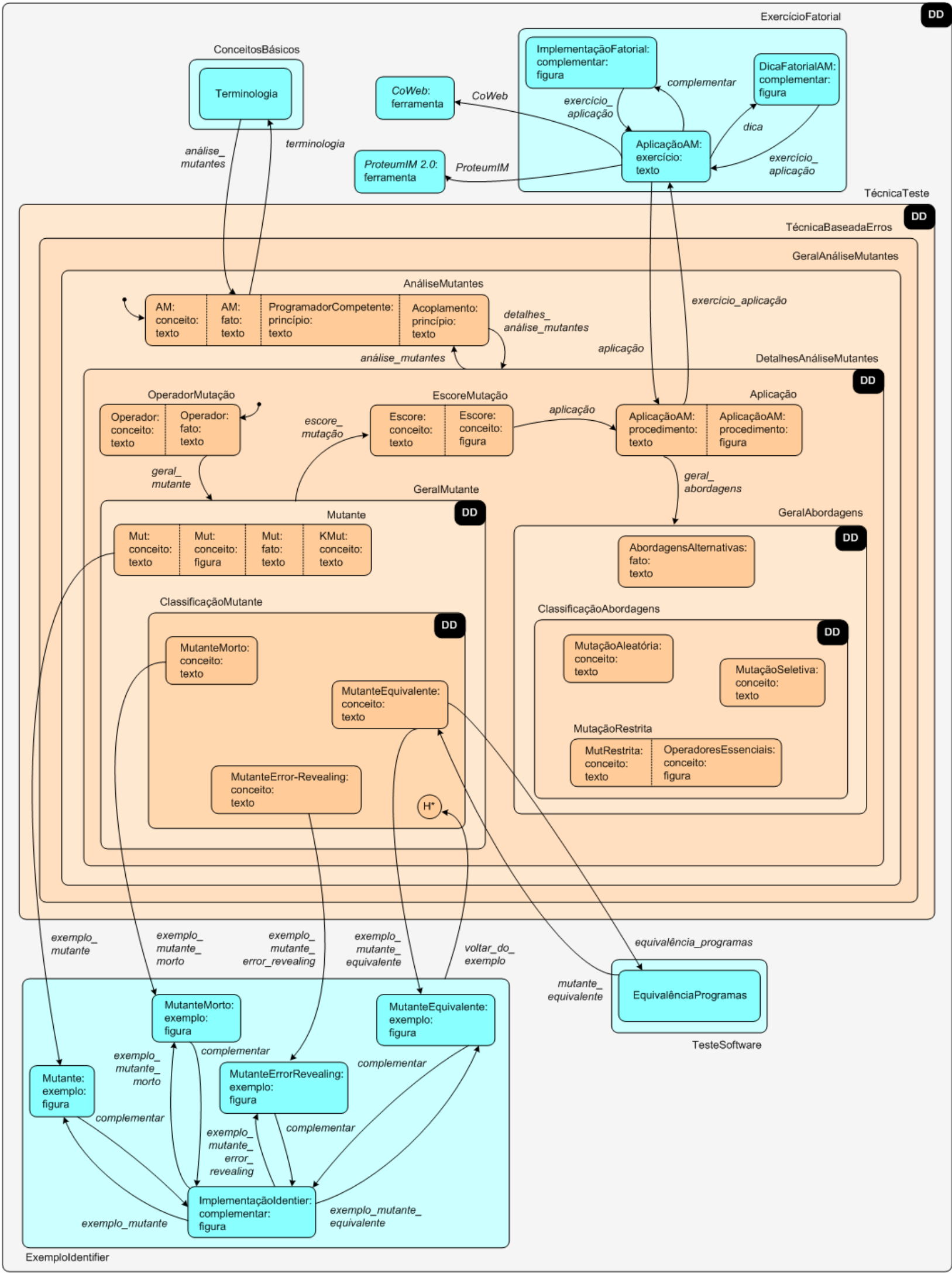

Figura 5.12: Critério Análise de Mutantes: Modelo Didático (HMMBS/Didático) - Especificação Parcialmente Aberta. 


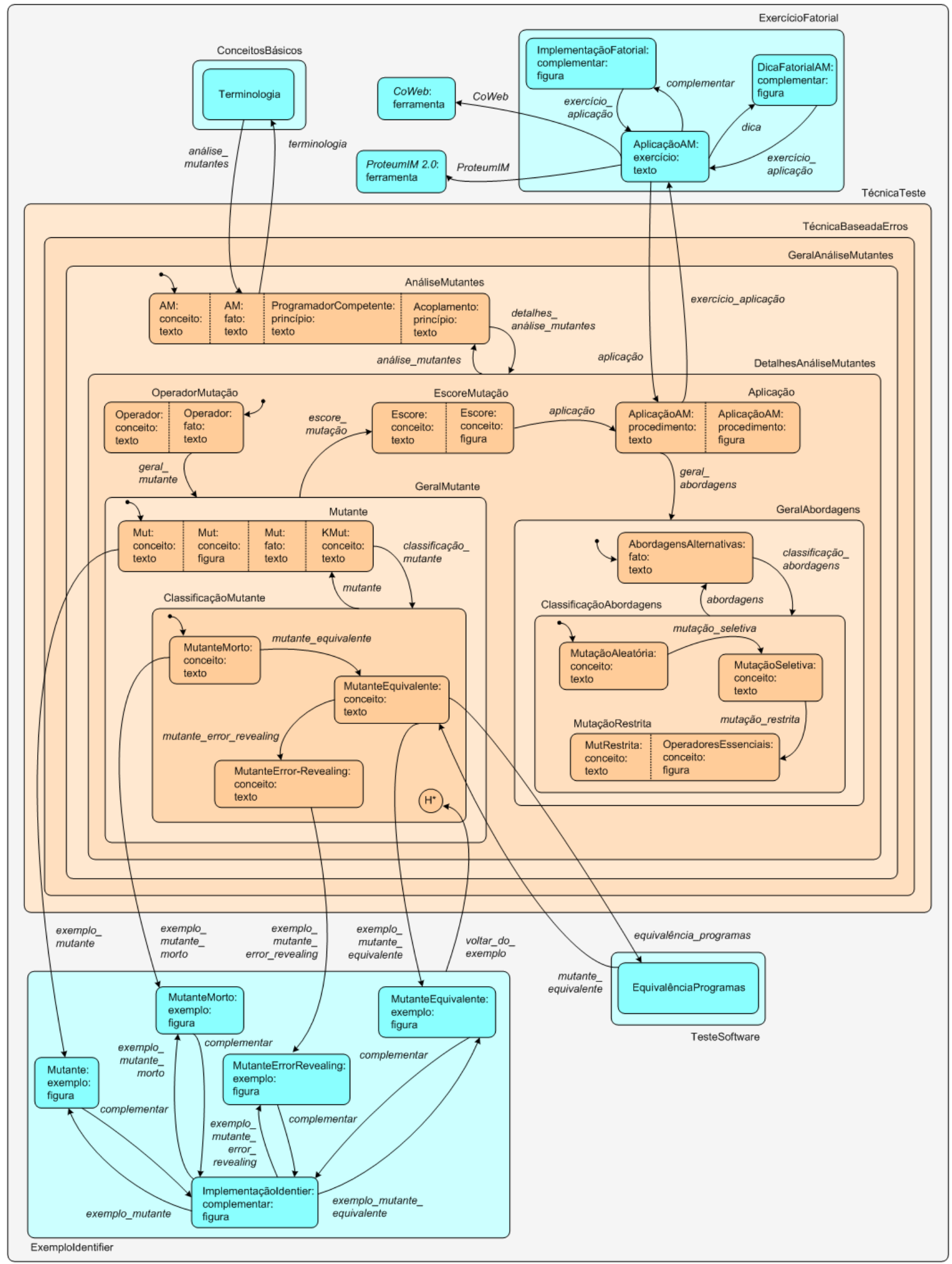

Figura 5.13: Critério Análise de Mutantes: Modelo Didático (HMMBS/Didático) - Especificação Fechada. 
A título de comparação, três versões para a transparência referente a Mutante foram implementadas: uma considerando a especificação aberta, outra a especificação parcialmente aberta, e outra a especificação fechada. A Figura 5.14 ilustra as transparências resultantes para cada umas das especificações consideradas.

De modo geral, a implementação aberta mostrou-se totalmente flexível quanto à escolha, em tempo de execução, dos assuntos a serem abordados e dos caminhos de navegação. Observa-se, no entanto, que a grande quantidade de opções de navegação oferecida pode aumentar a sobrecarga cognitiva imposta ao aprendiz.

Em relação à implementação aberta, na implementação parcialmente aberta a sobrecarga cognitiva imposta ao aprendiz foi menor, tendo em vista o número reduzido de opções de navegação representadas. Além disso, a implementação parcialmente aberta impôs que o contexto no qual as informações estavam inseridas fosse sempre retomado antes que outro contexto fosse apresentado. Nesse sentido, estando dentro de algum tópico pertinente à Análise de Mutantes (Operador de Mutação, Mutante, Escore de Mutação, Aplicação ou Abordagens Alternativas) e desejando explorar outros critérios de teste pertencentes à Técnica Baseada em Erros, o usuário precisa, necessariamente, retornar à transparência referente ao critério Análise de Mutantes. Se, por um lado, tal característica pode auxiliar na compreensão geral dos assuntos vistos, por outro lado, pode tornar a apresentação dos tópicos cansativa e extremamente repetitiva.

Quanto à implementação fechada, a sobrecarga cognitiva é ainda menor em relação às demais versões implementadas. Entretanto, as informações são apresentadas de forma específica e pontual, muitas vezes desconexa do contexto global em que a informação está inserida. Além disso, nenhum tipo de personalização do conteúdo, em tempo de execução é permitido.

A decisão sobre qual tipo de especificação utilizar deve ser baseada nos perfis dos aprendizes e do próprio instrutor, bem como nas características esperadas do módulo. No caso do módulo Teste de Software: Teoria e Prática, tendo em vista que o mesmo deve ser reutilizado em contextos distintos de ensino e treinamento, com objetivos e públicos variados, optou-se pela especificação e implementação abertas. Desse modo, o instrutor tem total liberdade para decidir dinamicamente quais informações e em que seqüência as mesmas devem ser apresentadas. As outras especificações, em especial a especificação fechada, não foram consideradas em virtude dos aspectos restritivos impostos, os quais poderiam limitar as características dinâmicas pretendidas à apresentação do módulo.

Como consideração final, observa-se que, pela limitação de espaço imposta às transparências elaboradas no PowerPoint, os links para os sub-módulos que compõem o módulo educacional (subestados $O R_{D D}$ do estado $D D$ TesteSoftware_TeoriaPrática) não foram implementados em cada uma das transparências elaboradas, conforme estabelecido no modelo da Figura 5.11. Como alternativa, foi implementado o link Teste de Software: Teoria e Prática, direcionando o usuário à página principal do módulo, de onde é possível atingir todos os sub-módulos associados. Ressalta-se que essa é uma limitação dependente do formato escolhido para a apresentação 


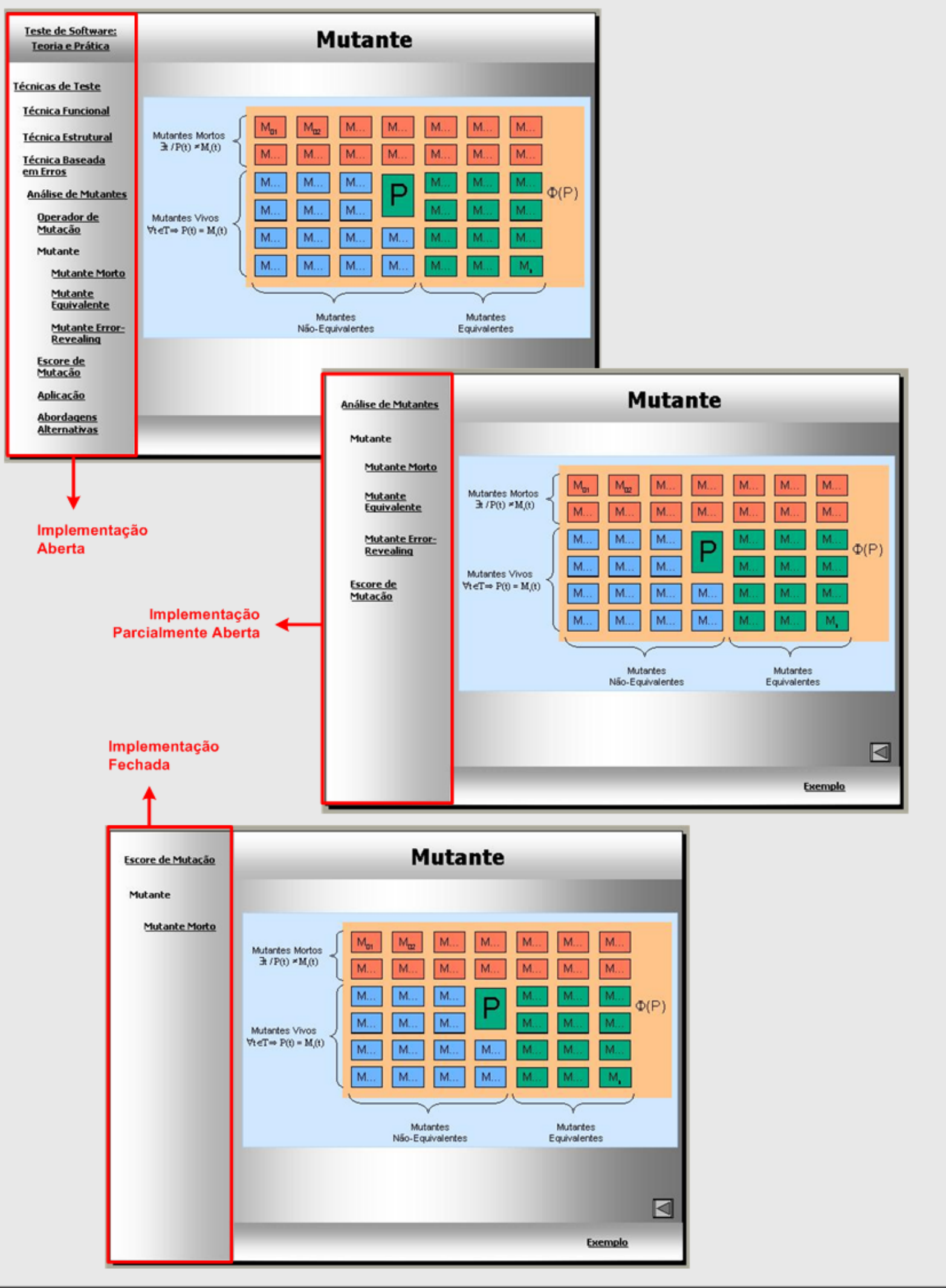

Figura 5.14: Transparências referentes a Mutante - Versão Aberta, Parcialmente Aberta e Fechada. 
do módulo e da própria ferramenta de editoração utilizada. Páginas HTML, por exemplo, não apresentariam esse tipo de limitação.

\subsubsection{Projeto da Interface}

Na especificação da interface gráfica e definição de padrões estéticos associados às transparências do módulo foram utilizados ADVs (Abstract Data Views), propostos pelo OOHDM (Schwabe \& Rossi, 1995). Na Figura 5.15(a) é apresentado o $A D V$ de mais alto nível para o módulo. Esse $A D V$ é uma composição de diversos outros $A D V s$, incluindo: Apresentação (Figura 5.15(b)), Informações Adicionais (Figura 5.15(c)), Tela Principal (Figura 5.15(d)), Item de Informação (Figura 5.15(e)) e Elemento Instrucional (Figura 5.15(f)).

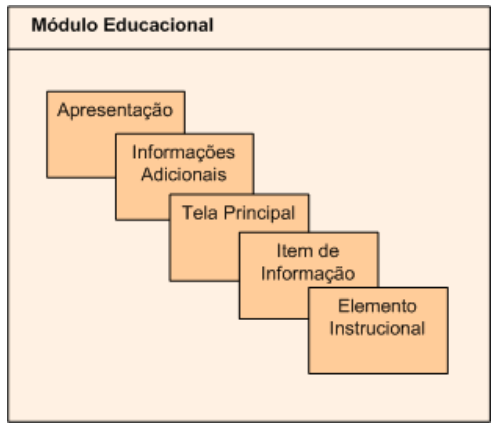

(a) $A D V$ Módulo Educacional.

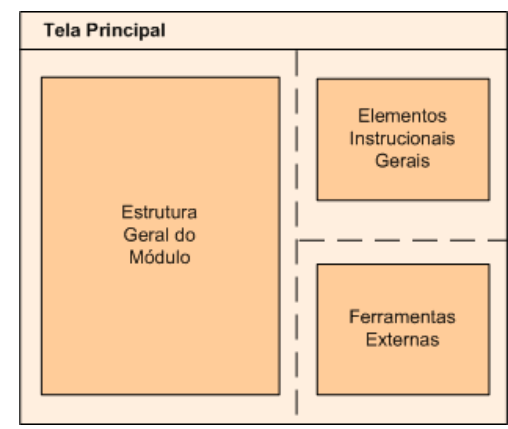

(d) $A D V$ Tela Principal.

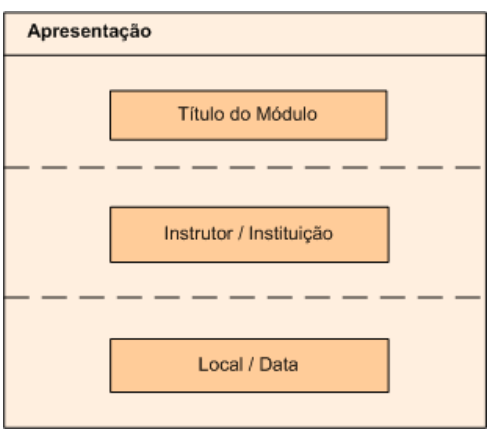

(b) $A D V$ Apresentação.

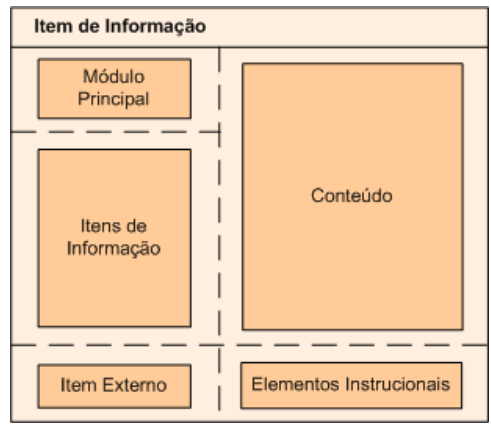

(e) $A D V$ Item de Informação.

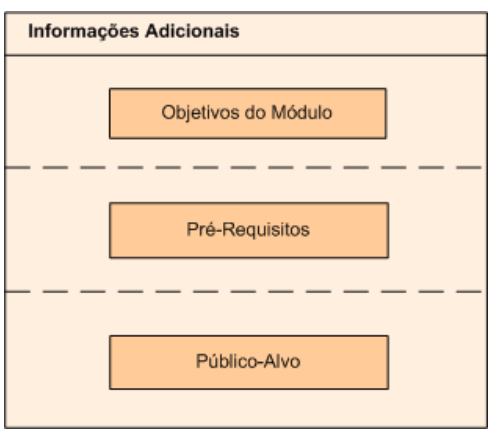

(c) $A D V$ Informações Adicionais.

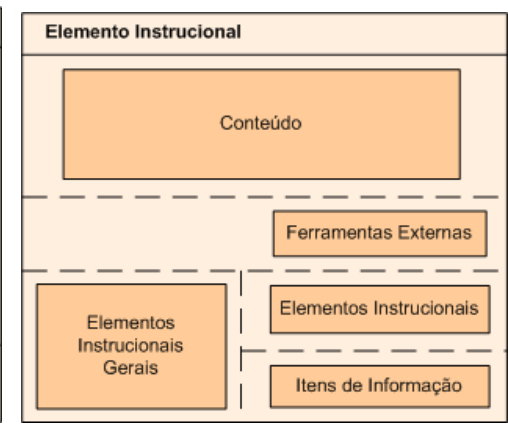

(f) $A D V$ Elemento Instrucional.

Figura 5.15: $A D V s$ das Transparências do Módulo Teste de Software: Teoria e Prática.

Os aspectos dinâmicos da aplicação foram especificados por meio de $A D V$ Charts, expressando as transformações no nível de interface do módulo e seu impacto na apresentação dos itens de informação e elementos instrucionais. A título de ilustração, a Figura 5.16 apresenta o ADV Chart correspondente ao $A D V$ Item de Informação.

É importante observar que os modelos didáticos desenvolvidos durante a fase de modelagem especificam os aspectos dinâmicos do módulo educacional com um alto nível de detalhamento, em termos de cada item de informação e/ou elemento instrucional. Os ADV Charts, por outro lado, especificam aspectos dinâmicos em um nível mais abstrato, estabelecendo um padrão de comportamento geral para as transparências do módulo. 


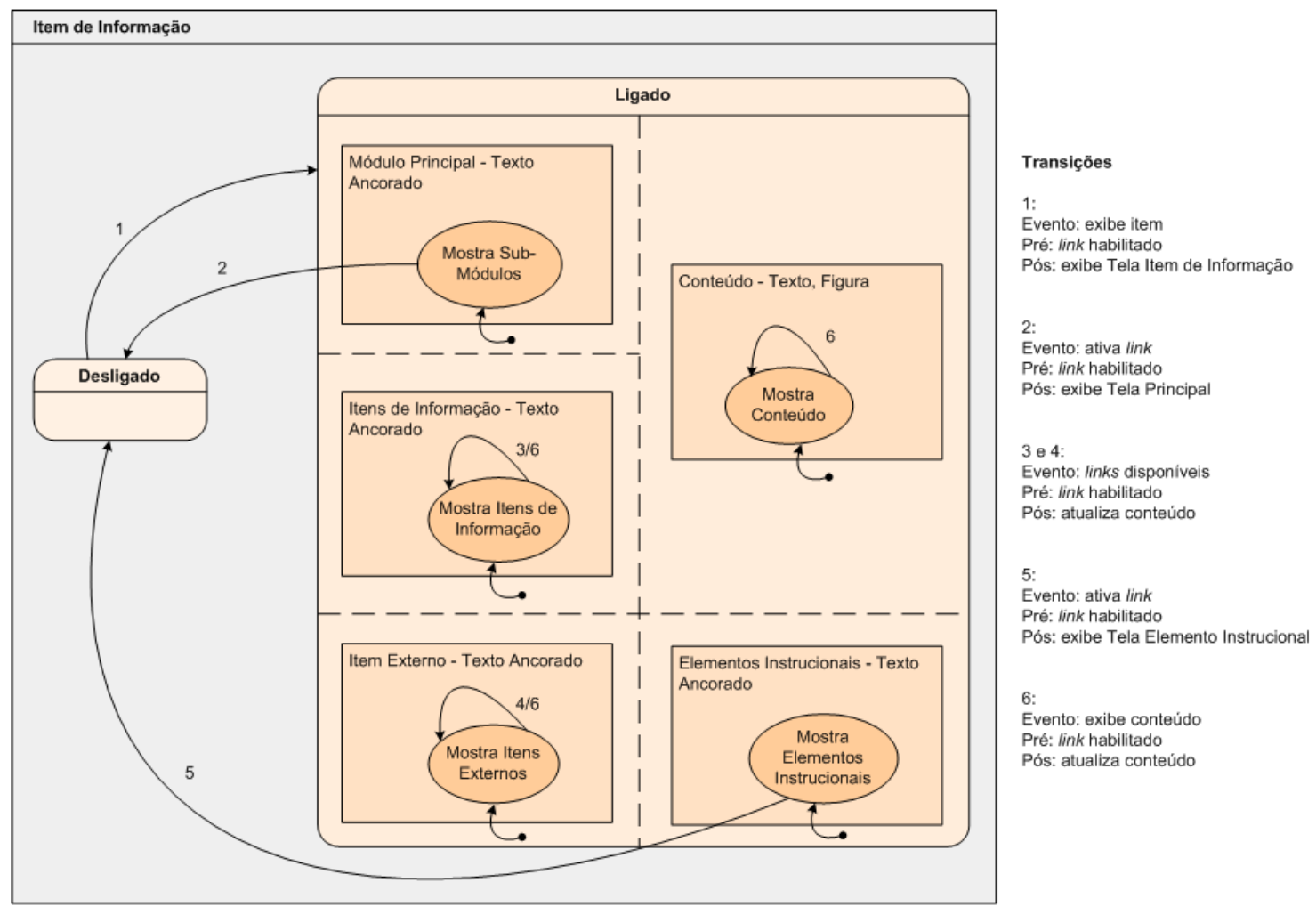

Figura 5.16: $A D V$ Chart Item de Informação.

\subsubsection{Implementação, Integração e Testes}

Na etapa de Implementação e Integração, os modelos construídos durante a modelagem de conteúdos educacionais e o projeto da interface são traduzidos para um ambiente de implementação, produzindo o módulo educacional a ser disponibilizado.

O módulo educacional para o domínio de Teste de Software foi implementado a partir do modelo didático da Figura 5.11, de acordo com os padrões de interface especificados pelos $A D V s$ da Figura 5.15, utilizando as ferramentas de editoração genéricas (PowerPoint, Visio, FrontPage, Photoshop, entre outras) estabelecidas pelo processo instanciado.

O resultado dessa etapa do desenvolvimento foi uma implementação aberta, na qual todas as possíveis seqüências de apresentação entre os elementos do módulo encontram-se implementadas, fornecendo ao usuário total liberdade na escolha dos tópicos a serem abordados e dos caminhos de navegação a serem seguidos. Aspectos mais detalhados discutindo a especificação aberta e suas implicações na forma como o módulo educacional foi implementado foram abordadas na Seção 5.3.7.

Além da elaboração dos conteúdos principais, construídos essencialmente na forma de transparências, conteúdos complementares, no formato de páginas HTML e documentos-texto, também foram desenvolvidos e integrados ao módulo. Ferramentas educacionais e ferramentas específicas ao domínio de conhecimento sobre Teste de Software também foram integradas. 
Na Figura 5.1 (Seção 5.2) foi apresentada a transparência principal do módulo, ilustrando, de maneira geral, a integração entre os vários elementos que o compõem. De acordo com a figura, a partir da transparência principal, o usuário é direcionado a um texto introdutório sobre Teste de Software, abordando os tópicos contidos no módulo, entre eles o critério Análise de Mutantes. Devido a decisões de implementação, optou-se pela integração de um único documento-texto, abrangendo de forma geral a maioria dos assuntos relacionados. Ressalta-se, entretanto, que vários documentos menores, específicos, poderiam ter sido associados a cada transparência (ou grupo de transparências).

Além do documento-texto, uma página HTML contendo informações gerais sobre o módulo e seus sub-módulos associados também foi integrada à transparência principal. Ainda a partir da mesma transparência, o usuário também tem acesso à ferramenta colaborativa CoWeb, que possibilita sua interação com os demais usuários do módulo (instrutor e aprendizes), e à ferramenta de teste $\mathcal{P R O T E M} / \mathcal{I M} 2.0$, que apóia a condução de atividades práticas envolvendo a aplicação do critério Análise de Mutantes ${ }^{5}$.

A integração entre transparências e páginas HTML é ilustrada de modo mais detalhado na Figura 5.17. De acordo com a figura, a partir da transparência sobre Análise de Mutantes é possível atingir uma página HTML referente ao mesmo assunto. As linhas pontilhadas denotam a similaridade dos conteúdos. Além disso, os links para itens de informação implementados na transparência possuem links correspondentes implementados na página HTML, de modo que também seja possível ao usuário navegar por tais itens a partir de suas páginas associadas.

As páginas HTML também podem conter informações adicionais, não incluídas nas transparências. Por exemplo, a partir da página HTML referente à Análise de Mutantes é possível obter informações sobre o "pai” do critério (Richard DeMillo), suas principais publicações e o primeiro artigo discutindo a idéia de mutantes no teste de programas procedimentais.

O conjunto completo de páginas HTML referentes ao módulo sobre Teste de Software vem sendo desenvolvido de maneira semelhante à construção das transparências, com base nos modelos conceitual, instrucional e didático previamente discutidos.

Por fim, na etapa de Testes, o módulo educacional implementado foi avaliado a partir das seguintes atividades: (1) verificação de padrões, inspecionando o módulo quanto aos padrões de interface estabelecidos; (2) verificação editorial, inspecionando o módulo quanto a erros de gramática, ortografia e pontuação; e (3) verificação funcional, inspecionando o módulo quanto a erros de lógica na navegação. A atividade de validação instrucional foi conduzida de modo informal, em paralelo à disponibilização do módulo.

\subsubsection{Disponibilização do Módulo}

O módulo Teste de Software: Teoria e Prática foi inicialmente disponibilizado em uma palestra, de mesmo nome, apresentada pelo Prof. Dr. José Carlos Maldonado no II Simpósio Brasileiro de

\footnotetext{
${ }^{5} \mathrm{~A}$ integração entre transparências e ferramentas de apoio também foi ilustrada na Figura 5.9 (Seção 5.3.7).
} 


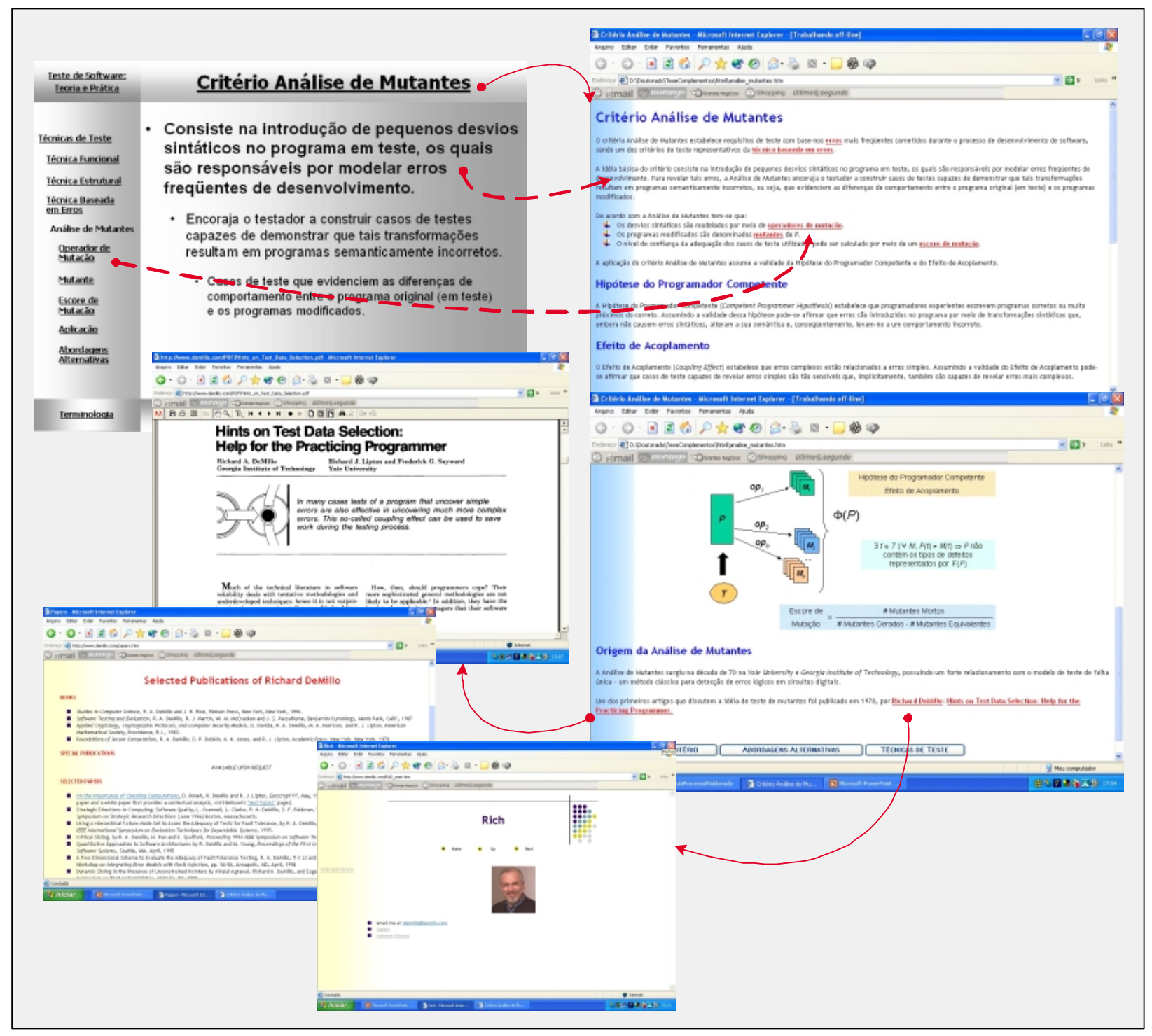

Figura 5.17: Integração entre Transparências e Páginas HTML.

Qualidade de Software (SBQS 2003), realizado em Fortaleza. A palestra teve uma hora e meia de duração, sendo proferida à uma platéia heterogênea, reunindo profissionais, professores, pesquisadores e estudantes de diversas áreas, interessados em questões relativas à Qualidade de Software. Foram abordados aspectos gerais da atividade de teste, com ênfase às principais tendências e direções de pesquisa na área.

Em seguida, o módulo foi disponibilizado em dois minicursos, com características similares. O primeiro minicurso ocorreu em Manaus, durante o XVII Simpósio Brasileiro de Engenharia de Software (SBES 2003). O minicurso foi ministrado pela doutoranda Ellen Francine Barbosa (ICMC-USP), com duração de quatro horas. O público-alvo foi de aproximadamente 80 pessoas, em sua grande maioria alunos de graduação, com conhecimentos prévios em Engenharia de Software. O módulo foi disponibilizado no formato de transparências, sem nenhum mecanismo de captura ou colaboração associados. Foi dada ênfase a aspectos teóricos de teste, com caráter introdutório sobre o assunto. Alguns aspectos práticos foram ilustrados sem envolver, entretanto, a 
participação direta dos aprendizes. Nenhum tipo de avaliação sobre o módulo foi realizado, embora tenha sido possível observar, ainda que informalmente, um impacto positivo da utilização do mesmo sobre os alunos.

O segundo minicurso ocorreu em Belém, na V Escola de Informática Norte (ERI - Norte), promovida pela Sociedade Brasileira de Computação. O minicurso, ministrado pelo Prof. Dr. José Carlos Maldonado (ICMC-USP), teve três horas de duração, com participação de cerca de 60 alunos de graduação. Assim como no minicurso anterior, ênfase foi dada a aspectos teóricos, possibilitando uma visão geral da área aos participantes. Uma avaliação informal, referente às características técnicas e pedagógicas do módulo, foi conduzida.

O questionário de avaliação aplicado aos alunos foi elaborado com base no trabalho de Gladcheff (2000), adaptado ao contexto do módulo desenvolvido. As questões foram divididas em quatro seções: (1) usabilidade, em termos da interface do módulo; (2) conteúdo, referente aos conceitos, exemplos, exercícios e informações complementares utilizadas no módulo; (3) navegação; e (4) aspectos gerais sobre o módulo. As três primeiras seções foram compostas por questões objetivas, de múltipla escolha. A quarta seção consistiu em questões subjetivas. O questionário de avaliação, juntamente com uma síntese dos resultados obtidos a partir de sua aplicação, encontram-se disponíveis no Apêndice B.

De modo geral, a partir da disponibilização do módulo nos dois minicursos citados e, sobretudo, por meio da aplicação do questionário de avaliação, foram observados os seguintes aspectos:

- No que se refere à usabilidade do módulo, o esquema de cores, a disposição das informações nas transparências e as representações das funções de interface (ícones, links) foram, em geral, aprovadas pelos alunos. Comentários específicos, entretanto, apontaram certo desconforto em relação ao tamanho das fontes e das figuras utilizadas.

- Quanto ao conteúdo, os alunos salientaram como aspectos positivos a estruturação e a abrangência dos assuntos abordados. A conexão entre os conceitos envolvidos também foi observada, juntamente com a adequação dos exemplos e informações complementares associadas. Com respeito aos exercícios propostos, observou-se a expectativa por problemas e situações práticas em que os alunos estivessem ativamente envolvidos. É importante ressaltar que, embora exercícios práticos abordando a utilização de ferramentas de teste tenham sido integrados ao módulo, o pouco tempo disponível para a realização do minicurso inviabilizou sua utilização. De fato, tais observações apontam para a necessidade de inclusão de exercícios práticos mais concisos e objetivos, que possam ser explorados em situações nas quais o tempo de apresentação do módulo seja pequeno.

Além disso, comentários específicos indicaram certa repetição de tópicos, podendo resultar em cansaço durante a apresentação. A necessidade de inclusão dos pré-requisitos considerados no módulo também foi apontada. 
- No que diz respeito à navegação, foi ressaltada a flexibilidade na escolha das sequiências de apresentação dos tópicos. Além disso, apesar da grande quantidade de informações disponibilizada, os alunos, de modo geral, não se sentiram "perdidos" no módulo.

Adicionalmente, além das características específicas do módulo, aspectos tais como velocidade de apresentação, dinamismo, objetividade e entusiasmo do instrutor também foram observados pelos alunos.

É importante ressaltar que o questionário foi elaborado e aplicado de maneira informal, sem o intuito de abranger todos os aspectos necessários à avaliação de módulos educacionais. De fato, trata-se de uma versão bastante preliminar, à qual devem ser incluídos outros fatores, tanto técnicos como pedagógicos, de modo a torná-la adequada e completa à avaliação dos módulos. Apesar disso, a avaliação conduzida, mesmo que informalmente, foi importante na identificação de aspectos positivos, problemas e melhorias pertinentes ao módulo desenvolvido.

\subsubsection{Identificação de Problemas e Melhorias}

Além dos problemas discutidos na seção anterior, outros aspectos também devem ser considerados para a melhoria do módulo educacional desenvolvido. Por exemplo, questões relacionadas à maior integração do módulo com ferramentas de apoio e à sua disponibilização em ambientes e sistemas educacionais precisam ser enfatizadas.

Nesse contexto, atualmente vem sendo conduzida a disponibilização do módulo dentro do ambiente WebCT. A Figura 5.18 ilustra a tela inicial do curso Verificação, Validação e Teste de Software, sendo desenvolvido. No link Conteúdo é possível ter acesso às transparências do módulo. Destacam-se as ferramentas de colaboração fornecidas pelo ambiente, as quais deverão ser utilizadas de maneira integrada junto ao módulo disponibilizado.

Além disso, a disponibilização do módulo a partir da infra-estrutura do $e$-Class, integrado à CoWeb, também vem sendo investigada. Pretende-se, com isso, possibilitar a captura das aulas e discussões ocorridas, utilizando as informações capturadas na evolução dos conteúdos já desenvolvidos.

Como melhorias ao processo instanciado, ênfase deve ser dada à utilização de ferramentas automatizadas, sobretudo no que se refere à construção dos modelos para representação de conteúdos educacionais e à integração e gerência do conhecimento.

\subsection{Considerações Finais}

Neste capítulo foi ilustrada a aplicação prática de um processo instanciado para o desenvolvimento de módulos educacionais disponibilizados presencialmente. O processo foi aplicado no contexto de um projeto específico, envolvendo a construção de um módulo educacional no domínio de conhecimento de Teste de Software. Basicamente, o módulo foi desenvolvido como um conjunto de 


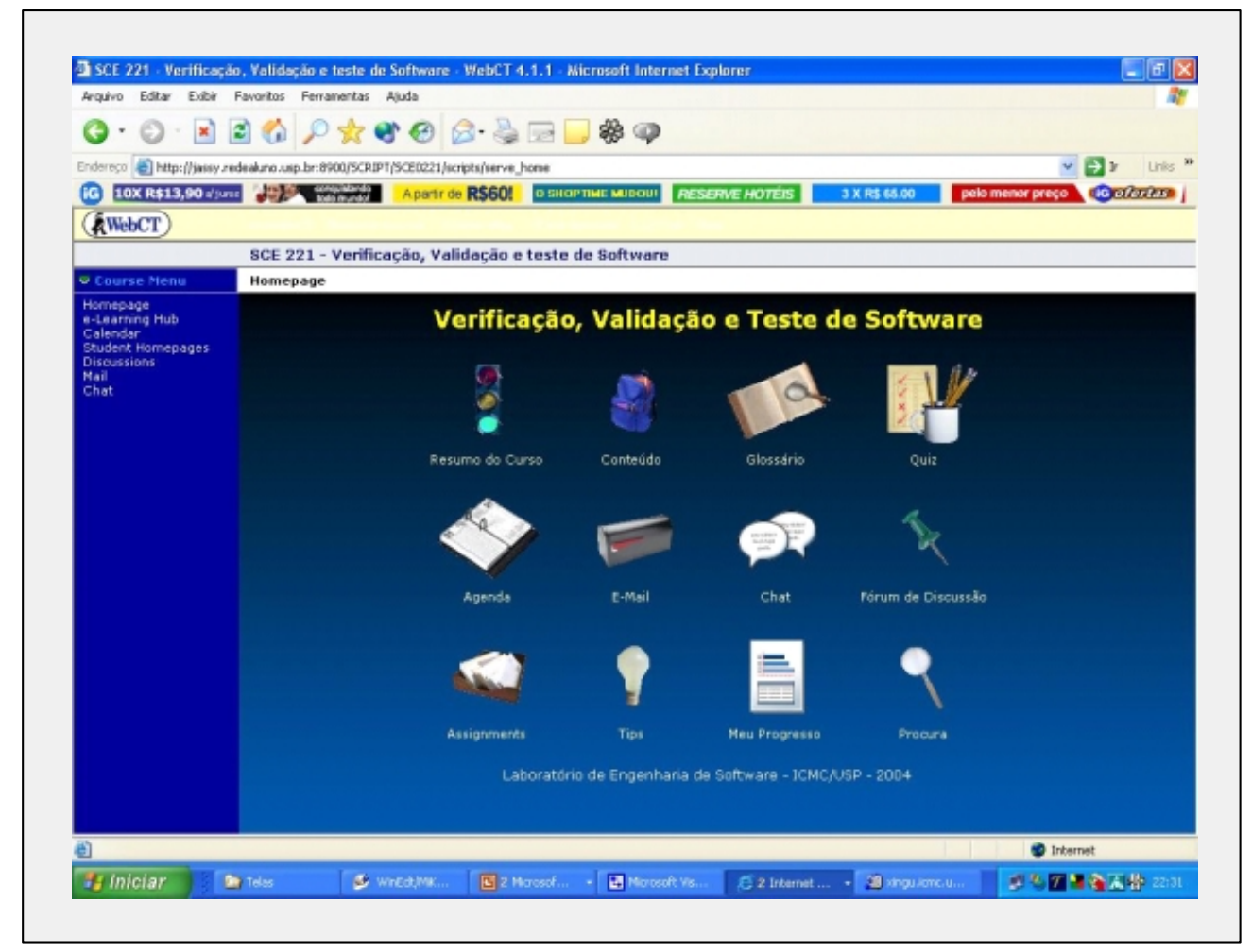

Figura 5.18: Página do WebCT referente ao Curso Verificação, Validação e Teste de Software.

transparências, ao qual também foram integradas páginas HTML, documentos-texto, ferramentas educacionais e ferramentas específicas ao domínio de Teste de Software.

A aplicação do processo foi ilustrada em termos gerais, discutindo aspectos relacionados à definição, planejamento, desenvolvimento e disponibilização do módulo. Ênfase foi dada à modelagem dos conteúdos educacionais, a qual foi conduzida com base nos modelos para representação de conteúdos estabelecidos pela abordagem $\mathcal{A} I \mathcal{M}-\mathcal{C L D}$. Foram elaborados: (1) mapas conceituais, incluindo primitivas específicas para a representação de relacionamentos de taxonomia e composição de conceitos; (2) modelos instrucionais, construídos segundo o HMBBS/Instrucional, incorporando a representação de categorias de conhecimento diferenciadas; e (3) modelos didáticos, construídos segundo o $\mathcal{H}$ MBS/Didático, incorporando a representação de estados $D D$ e a noção de "especificação aberta" dos aspectos de navegação.

De modo geral, os aspectos observados a partir da elaboração do módulo Teste de Software: Teoria e Prática evidenciam a viabilidade de aplicação dos mecanismos de apoio propostos neste trabalho, tanto no que se refere à Modelagem de Conteúdos Educacionais como no contexto de Padronização de Processos para a Elaboração de Módulos Educacionais. Ressalta-se, entretanto, a necessidade de aplicação e avaliação dos mecanismos propostos em projetos mais abrangentes e com características diferenciadas.

No próximo capítulo é apresentada uma visão geral da pesquisa conduzida, sendo sintetizadas as principais contribuições deste trabalho e as linhas para pesquisa futura, decorrentes de sua realização. 

CAPÍTULO

6

Conclusão

Neste capítulo é dada uma visão geral do trabalho realizado, descrevendo suas principais contribuições em função das linhas básicas de pesquisa investigadas - Modelagem de Conteúdos Educacionais e Padronização de Processos para a Elaboração de Módulos Educacionais. Perspectivas futuras de pesquisa também são evidenciadas.

\subsection{Visão Geral da Pesquisa Realizada}

Nos últimos anos, temas relacionados ao ensino e treinamento têm sido bastante discutidos e investigados pela comunidade científica, em diversas áreas de atuação. De modo geral, a definição de mecanismos adequados à elaboração e disponibilização de material didático, incluindo ainda recursos para avaliação e acompanhamento do aprendiz e apoio à condução de atividades práticas, têm sido explorados a fim de fornecer subsídios ao estabelecimento de ambientes de ensino e treinamento efetivos quanto aos objetivos e metas de aprendizado especificados. Módulos educacionais inserem-se nessa perspectiva, correspondendo a unidades concisas de estudo, compostas essencialmente por conteúdos teóricos e práticos, integrados e disponibilizados aos aprendizes por meio de recursos tecnológicos e computacionais.

Dentro do contexto de desenvolvimento de módulos educacionais, a modelagem de conteúdos apresenta-se como uma das atividades relevantes a ser considerada, sendo fundamental para a estruturação do conhecimento que se deseja ensinar. No entanto, apesar de sua importância no processo ensino e treinamento, poucos são os modelos especificamente voltados à modelagem de conteúdos educacionais (Kawasaki \& Fernandes, 1996; Leiva et al., 2002b; Leiva, 2003; Pansanato \& Nunes, 1999; Pimentel, 1997, 1998). Além disso, como não há um conjunto pré-estabelecido 
de requisitos associados à atividade, cada um dos modelos existentes aborda aspectos distintos, os quais podem ser adequados a um determinado cenário e inadequado para outros.

Tais limitações evidenciam fatores importantes a serem considerados em relação à atividade de modelagem de conteúdos. O primeiro deles refere-se à necessidade de determinação de requisitos de modelagem, fundamentais à construção, análise e seleção de modelos para a representação de conteúdos educacionais. O segundo diz respeito à necessidade de estabelecimento de uma abordagem capaz de integrar os diferentes aspectos e perspectivas de modelagem, fornecendo subsídios para que a construção e aplicação dos modelos associados seja conduzida de modo consistente e abrangente.

Além da estruturação e modelagem dos conteúdos, o desenvolvimento de módulos educacionais requer ainda que outros aspectos técnicos, somados a fatores gerenciais e organizacionais, também sejam considerados. Em decorrência da diversidade e complexidade dos aspectos envolvidos, a construção de tais módulos exige tempo e recursos (técnicos, administrativos, financeiros, humanos), não podendo ser considerada uma atividade trivial. Nesse sentido, a exemplo do que já ocorre no contexto de produção de software, a definição e a padronização de práticas sistemáticas e disciplinadas de desenvolvimento também são necessárias na construção de módulos educacionais, garantindo, com isso, produtividade ao processo de desenvolvimento e qualidade aos módulos elaborados.

Considerando os aspectos e limitações discutidos, neste trabalho foram investigados e estabelecidos mecanismos de apoio ao desenvolvimento de módulos educacionais, caracterizados em função de duas linhas básicas de pesquisa: Modelagem de Conteúdos Educacionais e Padronização de Processos para a Elaboração de Módulos Educacionais.

Na linha de Modelagem de Conteúdos Educacionais, inicialmente foi estabelecido um conjunto de requisitos de modelagem, visando a fornecer subsídios para a construção, comparação, avaliação e seleção de modelos para representação de conteúdos. Além disso, procurando caracterizar tais modelos, algumas perspectivas de modelagem também foram identificadas. A perspectiva conceitual aborda a modelagem dos conceitos relevantes do domínio de conhecimento e o modo como os mesmos estão relacionados. A perspectiva instrucional refere-se à modelagem de informações adicionais e elementos complementares sobre o domínio. A perspectiva didática é responsável por associar os objetos anteriormente modelados, estabelecendo uma seqüência de apresentação entre eles.

Com base nos requisitos e perspectivas de modelagem identificadas, foi caracterizado um conjunto de modelos genéricos para a representação de conteúdos educacionais - Modelo Conceitual, Modelo Instrucional e Modelo Didático -, cada um deles abordando aspectos distintos da atividade de modelagem. Em linhas gerais, o Modelo Conceitual consiste em uma descrição de alto-nível do domínio de conhecimento, na qual são representados os conceitos associados e seus interrelacionamentos. O Modelo Instrucional é responsável pela definição dos itens de informação e elementos instrucionais a serem utilizados no processo de ensino e aprendizado. Finalmente, no 
Modelo Didático são estabelecidos pré-requisitos e seqüências de apresentação envolvendo itens de informação e elementos instrucionais. Tais seqüências devem ser definidas de acordo com os objetivos do curso, a estratégia pedagógica do professor e o perfil de cada aprendiz, entre outros aspectos.

A caracterização do estado da arte em termos das abordagens que apóiam a modelagem de conteúdos educacionais também foi conduzida, sendo os requisitos e modelos genéricos propostos aplicados em sua comparação. Tanto abordagens específicas, envolvendo o projeto e desenvolvimento de aplicações hipermídia educacionais (Daphne (Kawasaki \& Fernandes, 1996), EHDM (Pansanato \& Nunes, 1999), MAPHE (Pimentel, 1997, 1998) e MDE (Leiva et al., 2002b; Leiva, 2003)), como abordagens para a construção de hiperdocumentos genéricos (HDM (Garzotto et al., 1993), RMM (Isakowitz et al., 1995), OOHDM (Schwabe \& Rossi, 1995), EORM Lange (1994), Trellis (Stotts \& Furuta, 1989) e HMBS (Turine, 1998)) foram analisadas. De modo geral, observou-se que, enquanto algumas abordagens mostram-se adequadas ao tratamento de aspectos conceituais, outras incorporam elementos relevantes sob a perspectiva instrucional e outras, ainda, demonstram grande poder expressivo na representação de aspectos didáticos (e de navegação).

Os aspectos observados resultaram na proposição de uma abordagem integrada de modelagem, envolvendo as perspectivas conceitual, instrucional e didática: $\mathcal{A L M}-\mathcal{C I D}$ (Abordagem Integrada de Modelagem - Conceitual, Instrucional e Didática) ou, em inglês, IMA-CID (Integrated Modelling Approach - Conceptual, Instructional and Didactic). A idéia fundamental consiste em ressaltar os pontos fortes e minimizar as limitações identificadas nas abordagens existentes, fornecendo ainda subsídios para que a construção dos modelos associados seja conduzida de forma única e abrangente.

A abordagem proposta foi baseada na técnica de Mapas Conceituais (Moreira \& Buchweitz, 1987; Novak, 1981; Novak \& Gowin, 1984; Novak, 1990) e no modelo HMBS (Turine, 1998), estabelecendo algumas restrições/extensões aos mesmos a fim de permitir que os modelos conceitual, instrucional e didático fossem representados com maior riqueza de detalhes. Mapas conceituais foram estendidos com primitivas para a representação de taxonomia e composição de conceitos. O modelo HMBS foi estendido considerando diferentes níveis de abstração. No nível instrucional, foram considerados apenas os aspectos de decomposição hierárquica fornecidos pelo HMBS, acrescidos da possibilidade de representação de diferentes categorias de conhecimento. $\mathrm{O}$ HMBS estendido no nível instrucional foi denominado $\mathcal{H}$ MBSS/Instrucional. No nível didático, foi incorporada ao modelo HMBS original a idéia de estados DD (Dynamically Defined - Definido Dinamicamente), utilizados como apoio à especificação e implementação abertas dos aspectos de navegação. As extensões estabelecidas no nível instrucional também foram mantidas no nível didático. O modelo HMBS estendido no nível didático foi denominado HMBSS/Didático.

Quanto à linha de Padronização de Processos para Elaboração de Módulos Educacionais, foi definido um conjunto de processos, atividades e tarefas específicas para a elaboração de tais módulos, identificando mecanismos de apoio à sua realização e sistematizando sua aplicação por 
meio de um processo padrão. A definição do processo padrão teve como base a norma ISO/IEC 12207 (International Organization for Standardization, 1995), adaptando-a ao contexto de ensino e treinamento por meio da inclusão de práticas e aspectos específicos pertinentes ao projeto instrucional (Clark, 2003; Kruse, 2003; Lee \& Owens, 2000) e à modelagem de conteúdos educacionais. O desenvolvimento de produtos livres e desenvolvimento colaborativo e distribuído também foram considerados.

Além da definição do processo padrão, investigaram-se ainda aspectos associados à especialização do processo. Nesse sentido, foi proposto um modelo de maturidade de processos para a elaboração de módulos educacionais - o $\mathcal{C M M} /$ Educacional - visando a apoiar a especialização do processo padrão em diferentes níveis de maturidade. O $\mathcal{C M M} /$ Educacional foi baseado nos cinco níveis de maturidade definidos pelo modelo CMM (Paulk, 1993; Paulk et al., 1995) e em suas práticas-chave associadas. O modelo de maturidade de processos para equipes geograficamente dispersas estabelecido em (Maidantchik, 1999) também foi utilizado na definição das tarefas e práticas pertinentes à elaboração distribuída e colaborativa dos módulos. Ressalta-se ainda que as KPAs do $\mathcal{C M M} /$ Educacional também foram categorizadas em áreas de processo, a exemplo do que ocorre com as KPAs do CMM em relação às áreas de processo do CMMI, procurando com isso estabelecer uma definição preliminar do $\mathcal{C M} \mathcal{M} \mathbb{L} /$ Educacional.

Finalmente, aspectos de instanciação do processo padrão foram discutidos, sendo ilustrado o estabelecimento de um processo instanciado para um projeto específico. A determinação e seleção de recursos humanos, métodos e técnicas de desenvolvimento, e ferramentas e mecanismos de apoio pertinentes ao processo foram abordados. Ainda no escopo da atividade de instanciação, uma série de ferramentas educacionais foi caracterizada em termos de sua adequação à automatização do processo padrão, evidenciando a importância do estabelecimento e utilização integrada de tais ferramentas na construção de módulos educacionais. A aplicação prática do processo instanciado foi ilustrada por meio da elaboração de um módulo educacional específico envolvendo o domínio de conhecimento sobre Teste de Software.

\subsection{Contribuições de Pesquisa}

Dentro do contexto apresentado na seção anterior, podem-se destacar como principais contribuições deste trabalho:

\section{- Na linha de Modelagem de Conteúdos Educacionais:}

- Proposição de um conjunto de requisitos para a modelagem de conteúdos educacionais e identificação de perspectivas de modelagem associadas.

- Proposição de um conjunto de modelos genéricos - Modelo Conceitual, Modelo Instrucional e Modelo Didático - para a representação de conteúdos educacionais. 
- Caracterização do estado da arte quanto às abordagens para modelagem de conteúdos educacionais existentes e aplicação dos requisitos e modelos genéricos propostos na análise e comparação das mesmas.

- Proposição da abordagem $\mathcal{A} \mathcal{L}$ M - CID (Abordagem Integrada de Modelagem - Conceitual, Instrucional e Didática).

- Proposição do modelo $\mathcal{H}$ MBS/Instrucional, aplicado no nível instrucional da abordagem $\mathcal{A L M}-\mathcal{C L D}$, estendendo o modelo HMBS para a representação de diferentes categorias de conhecimento.

- Proposição do modelo $\mathcal{H}$ MBSS/Didático, aplicado no nível didático da abordagem $\mathcal{A L M}-\mathcal{C} \mathcal{L D}$, incorporando ao modelo HMBS a representação de estados $D D$.

- Na linha de Padronização de Processos para Elaboração de Módulos Educacionais:

- Definição de um processo padrão para a elaboração de módulos educacionais, adaptado a partir da norma ISO/IEC 12207. Incorporação de práticas de projeto instrucional, modelagem de conteúdos educacionais, aspectos de desenvolvimento livre e desenvolvimento colaborativo e distribuído.

- Definição do $\mathcal{C M M} /$ Educacional - um modelo de maturidade de processos para a elaboração de módulos educacionais. Definição preliminar do modelo $\mathcal{C M} \mathcal{M} \mathcal{T} /$ Educacional.

- Instanciação do processo padrão definido e aplicação prática do processo instanciado no desenvolvimento de um módulo educacional específico no domínio de conhecimento sobre Teste de Software.

\subsection{Trabalhos Futuros}

Dando continuidade às atividades conduzidas durante o trabalho de doutorado, podem-se destacar como perspectivas futuras de pesquisa as seguintes linhas de atuação:

- Explorar o desenvolvimento de objetos de aprendizado (learning objects) (IEEE Learning Technology Standards Committee, 2002; Wiley, 2000, 2001) sob a perspectiva de módulos educacionais.

- Estabelecer mecanismos e ferramentas de apoio à construção de modelos instrucionais e didáticos segundo o HMBSS/Instrucional e o HMBBS/Didático. Em especial, mecanismos automatizados apoiando a interpretação e a execução de modelos didáticos também devem ser definidos e investigados como suporte à geração automática de conteúdos educacionais.

- Investigar a integração entre os aspectos de modelagem estabelecidos pelo modelo MDE (Leiva, 2003) e a abordagem $\mathcal{A L M}-$ CID. 
- Investigar as atividades e tarefas identificadas no escopo do processo padrão proposto no estabelecimento de metodologias ágeis para o desenvolvimento de módulos educacionais. Aspectos pertinentes à construção de módulos educacionais livres, em conformidade com a metodologia ágil estabelecida, também deverão ser considerados. Ainda, os aspectos estabelecidos pelo processo também poderão ser considerados e explorados sob as perspectivas de reengenharia e engenharia reversa de módulos educacionais.

- Aplicar o processo padrão no contexto de desenvolvimento colaborativo e distribuído, especializando o processo em função da capacidade das diversas equipes de desenvolvimento envolvidas. A especialização do processo deverá ser conduzida utilizando como apoio o modelo $\mathcal{C M M} /$ Educacional.

- Evoluir o processo padrão instanciado, aplicado na construção do módulo educacional para Teste de Software, incorporando aspectos de automatização, em especial no que se refere à definição e utilização de ferramentas de apoio à modelagem, integração do conhecimento e captura de aulas presenciais. A aplicação completa do processo instanciado evoluído também deverá ser conduzida.

- Instanciar o processo padrão e/ou os processos especializados na construção de outros tipos de módulos educacionais. Outras instâncias do processo, envolvendo, por exemplo, a construção de módulos educacionais a serem disponibilizados em cursos à distância, deverão ser estabelecidas.

- Investigar a adequação de modelos conceituais como apoio à construção de ontologias de domínio. Os modelos conceituais elaborados no domínio de Teste de Software poderão ser utilizados no desenvolvimento de uma ontologia nesse domínio.

- Aplicar os mecanismos de apoio identificados neste trabalho em outros domínios da Engenharia de Software.

Atualmente, os mecanismos investigados vêm sendo aplicados como apoio ao desenvolvimento de módulos educacionais associados ao ensino integrado de Teste de Software e Fundamentos Básicos de Programação (trabalho de mestrado em andamento - Processo FAPESP 03/04567-3). Pretende-se ainda que os mesmos sejam utilizados no contexto de experimentação (condução e replicação de experimentos), apoiando a elaboração de materiais de treinamento incorporados a pacotes de laboratório (lab packages).

Além de Teste de Software, os mecanismos investigados também deverão ser aplicados em outras sub-áreas da Engenharia de Software, resultando na reestruturação dos materiais didáticos associados e no desenvolvimento de módulos educacionais pertinentes. Por exemplo, podem-se destacar as sub-áreas de Gerenciamento de Configuração, Garantia de Qualidade, Revisão de Software, Manutenção de Software, Padrões de Desenvolvimento e Documentação de Software, entre outras. 


\subsection{Produção Científica}

Uma síntese das publicações decorrentes deste trabalho e de seus possíveis desdobramentos futuros é apresentada a seguir.

\subsubsection{Publicações Relacionadas}

Como principais publicações resultantes das atividades realizadas durante o trabalho de doutorado nas linhas de atuação discutidas, podem-se destacar:

- Barbosa, E. F.; Maldonado, J. C.; Maidantchik, C. L. L. Padronização de processos para o desenvolvimento de módulos educacionais. In: XXIX Latin-American Conference on Informatics (CLEI 2003), La Paz, Bolívia, 2003c.

- Barbosa, E. F.; Maldonado, J. C.; Ricarte, I. L. M. Exploring learning objects under conceptual, instructional and didactic perspectives. In: I PGL Data Base Research Conference (PGL DB 2003), Rio de Janeiro, RJ, 2003d.

- Barbosa, E. F.; LeBlanc, R.; Guzdial, M.; Maldonado, J. C. Introducing testing practices into objects and design course. In: 16th Conference on Software Engineering Education and Training (CSEET 2003), Madrid, Spain, $2003 \mathrm{~b}$.

- Barbosa, E. F.; LeBlanc, R.; Guzdial, M.; Maldonado, J. C. The challenge of teaching software testing earlier into design courses. In: II Workshop on the Teaching of Software Testing (WTST 2003), Melbourne, FL, 2003a.

- Barbosa, E. F.; Maldonado, J. C.; Ricarte, I. L. M. Learning materials: Towards the establishment of guidelines for domain modeling. In: Informatics Curricula, TEaching Methods and best practice Working Conference (ICTEM 2002), Florianópolis, SC, 2002.

- Barbosa, E. F.; Adriano, C. M.; Maldonado, J. C.; Ricarte, I. L. M.; Jino, M. Fostering theoretical, empirical and tool specific knowledge in a software testing learning scenario. In: International Conference on Engineering and Computer Education (ICECE 2000), São Paulo, SP, 2000.

\subsubsection{Publicações Esperadas}

Em função dos resultados já obtidos, somados àqueles esperados a partir da condução das atividades discutidas na Seção 6.3, um conjunto de artigos deverá ser submetido a periódicos internacionais. Assim, como publicações esperadas podem-se destacar: 
- Artigo estendido ilustrando o estabelecimento dos modelos conceitual, instrucional e didático, a definição das guidelines associadas e sua utilização na avaliação de abordagens para modelagem de conteúdos educacionais.

- Periódicos Pertinentes: (1) International Journal of Human-Computer Studies (IJHCS); (2) Journal of Computer Science Education; (3) Journal of the Learning Sciences.

- Artigo descrevendo a abordagem $\mathcal{A L M}-\mathcal{C D D}$ e os modelos HMBS/Instrucional e $\mathcal{H}$ MBS/Didático. A aplicação da abordagem e os modelos elaborados para a representação de conteúdos educacionais no domínio de Teste de Software também deve ser tratada.

- Periódicos Pertinentes: (1) Journal of Educational Resources in Computing (JERIC/ACM); (2) International Journal of Human-Computer Studies (IJHCS).

- Artigo estendido discutindo a definição e aplicação de mecanismos para modelagem de conteúdos educacionais na definição, estruturação, armazenamento e recuperação dos componentes internos de objetos educacionais.

- Periódicos Pertinentes: (1) Journal of Educational Resources in Computing (JERIC/ACM); (2) Journal of the Learning Sciences; (3) Cognitive Science.

- Artigo descrevendo o estabelecimento do processo padrão para a elaboração de módulos educacionais, incluindo aspectos de especialização e instanciação do processo.

- Periódicos Pertinentes: (1) Journal of the Learning Sciences; (2) Cognitive Science.

- Artigo descrevendo a aplicação dos mecanismos de apoio ao desenvolvimento de módulos educacionais na elaboração de materiais de treinamento incorporados a pacotes de laboratório.

- Periódicos Pertinentes: (1) Empirical Software Engineering; (2) ACM Transactions on Software Engineering and Methodology (TOSEM).

- Artigo ilustrando o desenvolvimento e a utilização de um módulo educacional no domínio de Teste de Software. A análise dos resultados obtidos quanto ao aprendizado dos alunos também deve ser abordada.

- Periódicos Pertinentes: (1) Journal of Computer Science Education; (2) Journal of College Science Teaching. 


\section{Referências Bibliográficas}

Aвowd, G. D. Classroom 2000: An experiment with the instrumentation of a living educational environment. IBM Systems Journal, v. 38, n. 4, p. 508-530, 1999.

Abowd, G. D.; Atkeson, C. G.; Brotherton, J.; Enqvist, T.; Gully, P.; Lemon, J. Classroom 2000: A system for capturing and accessing multimedia classroom experiences. In: CHI 98, New York, USA, 1998a.

Abowd, G. D.; Atkeson, C. G.; Brotherton, J. A.; EnQvist, T.; Gully, P.; Lemon, J. Investigating the capture, integration and access problem of ubiquitous computing in an educational setting. In: CHI 98, New York, USA, 1998b, p. 440-447.

Abowd, G. D.; Atkeson, C. G.; Feinstein, A.; Hmelo, C.; Kooper, R.; Long, S.; SAWHNEY, N.; TANI, M. Teaching and learning as multimedia authoring: The Classroom 2000 project. In: Fourth ACM International Multimedia Conference (Multimedia 96), 1996, p. 187-198.

Abowd, G. D.; Pimentel, M. G. C.; Kerimbaev, B.; Ishiguro, Y.; Guzdial, M. Anchoring discussions in lecture: An approach to collaboratively extending classroom digital media. In: Computer Supported Collaborative Learning, 1999, p. 11-19.

Acree, A. T.; Budd, T. A.; DeMillo, R. A.; Lipton, R. J.; Sayward, F. G. Mutation analysis. Relatório Técnico GIT-ICS-79/08, Georgia Institute of Technology, Atlanta, GA, 1979.

Adriano, C. M.; Delgado, A. L. N.; Silveira JR., L. G.; Bosnardo, R. C.; Ricarte, I. L. M.; MAGAlhães, L. P. Inquiring the course paradigm with CALM. In: International Conference on Engineering and Computer Education (ICECE 99), Rio de Janeiro, RJ, 1999.

Advanced Distributed Learning Initiative SCORM Specifications. Página Web. Disponível em http://www.adlnet.org/, Último acesso: 02/2004, 2004.

Agrawal, H.; Alberi, J.; Horgan, J. R.; Li, J.; London, S.; Wong, W. E.; Ghosh, S.; WILDE, N. Mining system tests to aid software maintenance. IEEE Computer, p. 64-73, 1998.

Agrawal, H.; DeMillo, R. A.; Hathaway, R.; Hsu, W.; Hsu, W.; Krauser, E. W.; Martin, R. J.; MAThur, A. P.; SpAFford, E. H. Design of mutant operators for the c programming language. Relatório Técnico SERC-TR41-P, Software Engineering Research Center, Purdue University, West Lafayette, IN, 1989. 
Ahern, D. M.; Turner, R.; Clouse, A. CMMI Distilled: A practical introduction to integrated process improvement. Addison-Wesley, 2001.

Asklund, U.; BendiX, L. Configuration management for open source software. In: 1st Workshop on Open Source Software Development (ICSE 2001), Toronto, Canada, 2001.

AssociaÇÃo BRASILEIRA DE NORMAS TÉCNICAS Tecnologia da Informação - Processo de Ciclo de Vida do Software. Padrão NBR ISO/IEC 12207, ABNT, 1998.

Ausubel, D. P.; Novak, J. D.; Hanesian, H. Educational psychology: a cognitive view. 2 ed. New York: Hold, Rinehart \& Winston, 1978.

BARBOSA, E. F. Uma contribuição para a determinação de um conjunto essencial de operadores de mutação no teste de programas $C$. Dissertação de Mestrado, ICMC-USP, São Carlos, SP, 1998.

Barbosa, E. F.; Adriano, C. M.; Maldonado, J. C.; Ricarte, I. L. M.; Jino, M. Fostering theoretical, empirical and tool specific knowledge in a software testing learning scenario. In: International Conference on Engineering and Computer Education (ICECE 2000), São Paulo, SP, 2000.

Barbosa, E. F.; LeBlanc, R.; Guzdial, M.; Maldonado, J. C. The challenge of teaching software testing earlier into design courses. In: II Workshop on the Teaching of Software Testing (WTST 2003), Melbourne, FL, 2003a.

Barbosa, E. F.; LeBlanc, R.; Guzdial, M.; Maldonado, J. C. Introducing testing practices into objects and design course. In: 16th Conference on Software Engineering Education and Training (CSEET 2003), Madrid, Spain, 2003b.

Barbosa, E. F.; Maldonado, J. C. Módulos educacionais: Definição de um processo padrão de desenvolvimento. Relatório Técnico, ICMC-USP, São Carlos, SP, (em elaboração), 2004.

Barbosa, E. F.; Maldonado, J. C.; Maidantchik, C. L. L. Padronização de processos para o desenvolvimento de módulos educacionais. In: XXIX Latin-American Conference on Informatics (CLEI 2003), La Paz, Bolívia, 2003c.

Barbosa, E. F.; Maldonado, J. C.; Ricarte, I. L. M. Learning materials: Towards the establishment of guidelines for domain modeling. In: Informatics Curricula, TEaching Methods and best practice Working Conference (ICTEM 2002), Florianópolis, SC, 2002.

Barbosa, E. F.; Maldonado, J. C.; Ricarte, I. L. M. Exploring learning objects under conceptual, instructional and didactic perspectives. In: I PGL Data Base Research Conference (PGL DB 2003), Rio de Janeiro, RJ, 2003d.

Barbosa, E. F.; Maldonado, J. C.; Ricarte, I. L. M. Modelos para a representação de conteúdos educacionais: um estudo comparativo. Relatório Técnico, ICMC-USP, São Carlos, SP, (em elaboração), 2004.

Barbosa, E. F.; Maldonado, J. C.; Vincenzi, A. M. R. Towards the determination of sufficient mutant operators for C. Software Testing, Verification and Reliability, v. 11, n. 2, p. 113-136, 2001. 
Barbosa, E. F.; Vincenzi, A. M. R.; Maldonado, J. C. Uma contribuição para a determinação de um conjunto essencial de operadores de mutação no teste de programas C. In: XII Simpósio Brasileiro de Engenharia de Software (SBES 98), Maringá, PR, 1998, p. 103-120.

Baruque, L. B.; Porto, F.; Melo, R. N. Towards an instructional design methodology based on learning objects. In: International Conference on Computers and Advanced Technology in Education (CATE 2003), 2003.

BECK, H. Fine-grained representation of educational content based on ontologies. In: I PGL DB Research Conference (PGL DB 2003), Rio de Janeiro, RJ, 2003, p. 105-110.

BECK, K. Embracing change with extreme programming. IEEE Computer, v. 32, n. 10, p. 7077, 1999a.

BECK, K. Extreme programming explained: Embrace change. Addison Wesley, 1999b.

BEIZER, B. Software testing techniques. 2nd ed. New York: Van Nostrand Reinhold Company, 1990.

Bianchini, S. L.; Barbosa, E. F.; Maldonado, J. C. Disponibilização de ferramentas de teste de software via web. Trabalho de Iniciação Científica, ICMC-USP, 2003.

Bieman, J. M.; Ghosh, S.; Alexander, R. T. A technique for mutation of java objects. In: 16th IEEE Internation Conference on Automated Software Engineering, San Diego, CA, 2001, p. 23-26.

BInder, R. V. Modal testing strategies for OO software. Computer, v. 29, n. 11, p. 97-99, 1996.

BINDER, R. V. Testing object-oriented systems: Models, patterns, and tools, v. 1. Addison Wesley Longman, Inc., 1999.

Bloom, B. S.; Mesia, B. B.; KRAthwohl, D. R. Taxonomy of educational objectives. New York: David McKay, 1964.

Bourque, P.; Dupuis, R.; Abran, A.; Moore, J. W.; Tripp, L. L. The Guide to the Software Engineering Body of Knowledge. IEEE Software, v. 16, p. 35-44, 1999.

BRITAIN, S. A framework for pedagogical evaluation of virtual learning environments. Relatório Técnico 31, Bangor University Centre for Learning Technology, 1999.

Brotherton, J. A.; Abowd, G. D. Rooms take note: Room takes notes! In: Working Papers of AAAI 98 Spring Symposium, 1998.

Brotherton, J. A.; Bhalodia, J.; Abowd, G. D. Automated capture, integration and visualization of multiple media streams. In: IEEE Conference on Multimedia and Computing Systems, 1998, p. 54-63.

BudD, T. A. Mutation analysis: Ideas, example, problems and prospects, cáp. Computer Program Testing North-Holand Publishing Company, 1981.

Budd, T. A.; DeMillo, R. A.; Lipton, R. J.; SAyward, F. G. Theoretical and empirical studies on using program mutation to test the functional correctness of programs. In: 7 th ACM Symposium on Principles of Programming Languages, New York, NY, 1980, p. 220-233. 
CAmpos, F. C. A. Hipermídia na educação: Paradigmas e avaliação da qualidade. Dissertação de Mestrado, COPPE - UFRJ, Rio de Janeiro, RJ, 1994.

Campos, F. C. A.; Rocha, A. R. C.; Campos, G. H. B. Qualidade de software educacional: Uma proposta. In: Workshop de Qualidade de Software (WQS 99), Simpósio Brasileiro de Engenharia de Software, Florianópolis, SC, 1999.

CARVAlho, M. R. HMBS/M - um método orientado a objetos para o projeto e o desenvolvimento de aplicações hipermídia. Dissertação de Mestrado, ICMC-USP, São Carlos, SP, 1998.

Carvalho, M. R.; Oliveira, M. C. F.; Masiero, P. C. HMBS/M - an object oriented method for hypermedia design. In: V Simpósio Brasileiro de Multimídia e Sistemas Hipermídia (SBMIDIA 99), Goiânia, GO, 1999, p. 43-62.

CASAGRANDE, L. M. Um método para análise e projeto de sistemas de workflow administrativo com interface para a web. Dissertação de Mestrado, ICMC-USP, São Carlos, SP, 2001.

CHAIM, M. L. POKE-TOOL - Uma ferramenta para suporte ao teste estrutural de programas baseado em análise de fluxo de dados. Dissertação de Mestrado, DCA/FEEC/UNICAMP, Campinas, SP, 1991.

Choi, B. J.; DeMillo, R. A.; Krauser, E. W.; Mathur, A. P.; Martin, R. J.; Offutt, A. J.; PAN, H.; SPAfFOrd, E. H. The mothra toolset. In: Twenty-Second Annual Hawaii International Conference on System Sciences, HI, 1989a.

Choi, B. J.; Mathur, A. P. High-performance mutation testing. The Journal of Systems and Software, v. 1, n. 20, p. 135-152, 1993.

Choi, B. J.; Mathur, A. P.; Pattison, A. P. pMothra: Scheduling mutants for execution on a hypercube. In: 3rd Symposium on Software Testing, Analysis and Verification, Key West, FL, 1989 b, p. 58-65.

Chrissis, M. B.; Konrad, M.; Shrum, S. CMMI: Guidelines for process integration and product improvement. Addison-Wesley, 2003.

Cisco Systems, Inc. Reusable learning object strategy: Definition, creation process, and guidelines for building. CISCO Systems, disponível em http://www.cisco.com/warp/public/10/wwtraining/elearning/implement/rlo_strategy_v3-1.pdf, Último acesso: 12/2003, 2000.

Cisco Systems, InC. Reusable learning object strategy: Designing information and learning objects through concept, fact, procedure, process and principle templates. CISCO Systems, disponível em http://business.cisco.com/servletwl3/FileDownloader/iqprd/86575/86575_kbns.pdf, Último acesso: 12/2003, 2001.

CLARK, D. Introduction to Instructional Design. Página Web. Disponível em http://www.nwlink.com/ donclark/hrd/, Último acesso: 12/2003, 2003.

Coad, P.; Palmer, S. Feature-driven development: Guide. Página Web. Disponível em http://www.nebulon.com/articles/fdd/latestfdd.html/, Último acesso: 12/2003, 2002. 
Coffey, J. W.; Hoffman, R.; CAÑAs, A. J.; Ford, K. M. A concept map-based knowledge modeling approach to expert knowledge sharing. In: The IASTED International Conference on Information and Knowledge Sharing (IKS 2002), Virgin Islands, 2002.

Davis, M.; O’Donovan, W.; Fritz, J. Linux and open source in the academic enterprise. In: 28th SIGUCCS Conference on User Services, Richmond, VA, 2000.

Delamaro, M. E. Proteum: Um ambiente de teste baseado na análise de mutantes. Dissertação de Mestrado, ICMC-USP, São Carlos, SP, 1993.

Delamaro, M. E. Mutação de interface: Um critério de adequação inter-procedimental para o teste de integração. Tese de Doutoramento, IFSC-USP, São Carlos, SP, 1997.

Delamaro, M. E.; Maldonado, J. C. Proteum - a tool for the assessment of test adequacy for C programs. In: Conference on Performability in Computing Systems (PCS 96), Brunswick, NJ, 1996, p. 79-95.

Delamaro, M. E.; Maldonado, J. C. Interface mutation: An approach to integration testing. In: Workshop do Projeto de Validação e Teste de Sistemas de Operação, Águas de Lindóia - SP, 1997.

Delamaro, M. E.; Maldonado, J. C.; Mathur, A. P. Interface mutation: An approach for integration testing. IEEE Transactions on Software Engineering, v. 27, n. 3, p. 228-247, 2001a.

Delamaro, M. E.; Maldonado, J. C.; Vincenzi, A. M. R. Proteum/IM 2.0: An integrated mutation testing environment. In: Mutation 2000 Symposium, San Jose, CA: Kluwer Academic Publishers, 2000, p. 91-101.

Delamaro, M. E.; Pezzè, M.; Vincenzi, A. M. R.; Maldonado, J. C. Mutant operators for testing concurrent Java programs. In: Simpósio Brasileiro de Engenharia de Software (SBES 2001), Rio de Janeiro, RJ, 2001 b.

DEMILlo, R. A. Mutation analysis as a tool for software quality assurance. In: COMPSAC80, Chicago, IL, 1980.

Demillo, R. A. Software testing and evaluation. The Benjamin/Cummings Publishing Company Inc., 1987.

DeMillo, R. A.; Gwind, D. S.; King, K. N.; McKraken, W. N.; Offutt, A. J. An extended overview of the mothra testing environment. In: Software Testing, Verification and Analysis, Banff, Canada, 1988, p. 142-151.

DeMillo, R. A.; Lipton, R. J.; Sayward, F. G. Hints on test data selection: Help for the practicing programmer. IEEE Computer, v. 11, n. 4, p. 34-43, 1978.

DoOng, R. K.; FrankL, P. G. The ASTOOT approach to testing object-oriented programs. ACM Transactions on Software Engineering Methodology, p. 101-130, 1994.

DOWNES, S. Learning objects: Resources for distance education worldwide. International Review of Research in Open and Distance Learning, v. 2, n. 1, 2001. 
DSI/CGSA Qualidade e produtividade no setor de software brasileiro: 2001. Revista do SEPIN/MCT, 2002.

DUNAWAY, D. K.; MASTERS, S. CMM based appraisal for internal process improvement (CBA-IPI): Method description. Relatório Técnico CMU/SEI-96-TR-007, Carnegie Mellon University, Software Engineering Institute, Pittsburgh, PA, 1996.

Dupuis, R.; Bourque, P.; Abran, A.; Moore, J. W.; Tripp, L. L. The SWEBOK Project: Guide to the software engineering body of knowledge. Stone Man Trial Version 1.00, Disponível em http://www.swebok.org/, Último acesso: 12/2003, 2001.

Dustin, E.; RAshKa, J.; PAul, J. Automated software testing: Introduction, management, and performance. Addison Wesley Longman, 1999.

Eberspächer, H. F.; VAsconcelos, C. D.; Jamur, J. H.; Eleutério, M. A. M. Eureka: Um ambiente de aprendizagem cooperativa baseado na web para educação à distância. In: $X$ Simpósio Brasileiro de Informática na Educação (SBIE 99), Curitiba, PR, 1999.

ElmasRi, R.; NAVATE, S. Fundamental of database systems. 2 ed. The Benjamim/Cummings Publishing Company, 1990.

FABBRI, S. C. P. F. A análise de mutantes no contexto de sistemas reativos: Uma contribuição para o estabelecimento de estratégias de teste e validação. Tese de Doutoramento, IFSC-USP, São Carlos - SP, 1996.

Fabbri, S. C. P. F.; Maldonado, J. C.; Delamaro, M. E.; Masiero, P. C. Proteum/FSM: A tool to support finite state machine validation based on mutation testing. In: XIX International Conference of the Chilean Computer Science Society (SCCC 99), Talca, Chile, 1999, p. 96-104.

Fabbri, S. C. P. F.; Maldonado, J. C.; Masiero, P. C.; Delamaro, M. E. Análise de mutantes baseada em máquinas de estado finito. In: XI Simpósio Brasileiro de Redes de Computadores (SBRC 93), Campinas, SP, 1993, p. 407-425.

Fabbri, S. C. P. F.; Maldonado, J. C.; Masiero, P. C.; Delamaro, M. E. Mutation analysis testing for finite state machines. In: 5th International Symposium on Software Reliability Engineering (ISSRE 94), Monterey, CA, 1994, p. 220-229.

Fabbri, S. C. P. F.; Maldonado, J. C.; Masiero, P. C.; Delamaro, M. E. Mutation analysis applied to validate specifications based on petri nets. In: 8th IFIP Conference on Formal Descriptions Techniques for Distribute Systems and Communication Protocols (FORTE 95), Montreal, Canada, 1995, p. 329-337.

FALBO, R. A. Integração de conhecimento em um ambiente de desenvolvimento de software. Tese de Doutoramento, COPPE/UFRJ, Rio de Janeiro, RJ, 1998.

Falbo, R. A.; Menezes, C. S.; Rocha, A. R. A systematic approach for building ontologies. In: VI Ibero-American Conference on AI (IBERAMIA 98), Lisboa, Portugal, 1998.

FARIA, W. Aprendizagem e planejamento de ensino. 1 ed. São Paulo: Ática, 1989. 
Feller, J.; FitzGerald, B. A framework analysis of the open source software development paradigm. In: 21st International Conference of Information Systems, Brisbane, Austrália, 2000, p. 58-69.

FRANKL, F. G. The use of data flow information for the selection and evaluation of software test data. Tese de Doutoramento, University of New York, NY, 1987.

Frankl, F. G.; Weyuker, E. J. Data flow testing tools. In: Softfair II, San Francisco, CA, 1985, p. 46-53.

Frankl, P. G.; Weyuker, E. J. An applicable family of data flow testing criteria. IEEE Transactions on Software Engineering, v. 14, n. 10, p. 1483-1498, 1988.

Frankl, P. G.; WeyUKer, E. J. A formal analysis of the fault-detecting ability of testing methods. IEEE Transactions on Software Engineering, v. 19, n. 3, p. 202-213, 1993a.

Frankl, P. G.; Weyuker, E. J. Provable improvements on branch testing. IEEE Transactions on Software Engineering, v. 19, n. 10, p. 962-975, $1993 \mathrm{~b}$.

FrankL, P. G.; WeyUKer, E. J. Testing software to detect and reduce risk. The Journal of Systems and Software, 2000.

Friedman, A. D. Logical design of digital systems. Computer Science Press, 1975.

FuKs, H. Aprendizagem e trabalho cooperativo no ambiente AulaNet. Revista Brasileira de Informática na Educação, v. 1, n. 6, p. 53-73, 2000.

Gaines, B. R.; Shaw, M. L. G. WebMap: Concept mapping on the web. Disponível em http://www.w3j.com/1/gaines.134/paper/134.html, Último acesso: 12/2003, 2003.

Garzotto, F.; Schwabe, D.; Paolini, P. HDM - a model based approach to hypertext application design. ACM Transactions on Information Systems, v. 11, n. 1, p. 1-26, 1993.

GLADCHEFF, A. P. Um instrumento de avaliação da qualidade para software educacional de matemática. Dissertação de Mestrado, IME-USP, São Paulo, SP, 2000.

GoldberG, M.; SAlari, S.; Swoboda, P. World Wide Web - Course Tool: An environment for building WWW-based courses. In: V International World Wide Web Conference, Paris, France, 1996.

Grosso, W. Knowledge modeling at the milennium (the design and evolution of Protégé-2000). In: Knowledge Acquisition Workshop, Banff, Canada, 1999.

GRUBER, T. R. Towards principles for the design of ontologies used for knowledge sharing. Int. Journal Human-Computer Studies, v. 43, n. 5/6, 1995.

GUARINO, N. Understanding, building and using ontologies. Int. Journal Human-Computer Studies, v. 45, n. 2/3, 1997.

Guizzardi, G.; Falbo, R. A.; Filho, J. G. P. Using objects and patterns to implement domain ontologies. Journal of the Brazilian Computer Society, v. 8, n. 1, 2002. 
GUZDIAL, M. Information ecology of collaborations in educational settings: Influence of a tool. In: Computer-Supported Colaborative Learning (CSCL 1997), Toronto, Ontario, Canadá, 1997, p. 83-90.

Guzdial, M. Supporting learners as users. The Journal of Computer Documentation, v. 23, n. 2, p. 3-13, 1999.

GuZDiAL, M. Use of collaborative multimedia in computer science classes. In: 6th Annual Conference on Innovation and Technology in Computer Science Education (ACM ITICSE 2001), Canterbury, United Kingdom, 2001, p. 17-20.

Guzdial, M.; Kehoe, C. Apprenticeship-based learning environments: A principled approach to providing software-realized scaffolding through hypermedia. Journal of Interactive Learning Research, v. 9, n. 3/4, 1998.

Guzdial, M.; Rick, J.; Kehoe, C. Beyond adoption to invention: Teacher-created collaborative activities in higher education. Journal of the Learning Sciences, 2002.

Haley, A.; ZweBEn, S. Development and application of a white box approach to integration testing. The Journal of Systems and Software, v. 4, p. 309-315, 1984.

HAMEL, C. J.; RYAN-JONES, D. Designing instruction with learning objects. International Journal of Educational Technology, v. 3, n. 1, 2002.

Hamlet, D.; TAYlor, R. Partition testing does not inspire confidence. In: II Workshop on Software Testing, Verification and Analysis, Banff, Canadá, 1998, p. 206-215.

HAREL, D. Statecharts: A visual formalism for complex systems. Science of Computer Programming, v. 8, p. 231-274, 1987.

Harrold, M. J. Testing: A roadmap. In: 22th International Conference on Software Engineering, 2000.

Harrold, M. J.; Soffa, M. L. Selecting and using data for integration test. IEEE Software, v. 8, n. 2, p. 58-65, 1991.

Herman, P. M. A data flow analysis approach to program testing. Australian Computer Journal, v. 8, n. 3, 1976.

Hodgins, H. W. The future of learning objects. In: The Instructional Use of Learning Objects: Online Version, D. A. Wiley, ed., 2000.

DER HoEK, A. V. Configuration management and open source projects. In: 3nd Workshop on Software Engineering over the Internet at ICSE 2000, Limerick, Ireland, 2000.

Horgan, J. R.; Mathur, P. Assessing testing tools in research and education. IEEE Software, v. 9, n. 3, p. 61-69, 1992.

HORN, R. E. Mapping hypertext. Lexington: Lexington Institute, 1989.

HowdEn, W. E. Theoretical and empirical studies of program testing. IEEE Transactions on Software Engineering, v. 4, n. 4, p. 293-298, 1978.

Howden, W. E. Functional program testing and analysis. New York: McGrall-Hill, 1987. 
IEEE IEEE Standard Glossary of Software Engineering Terminology. Standard 610.12, IEEE Press, 1990.

IEEE COMPuter Society Guide to the Software Engineering Body of Knowledge: Trial version (1.0). Disponível em http://www.swebok.org/, Último acesso: 12/2003, 2001.

IEEE COMPUTER SOCIETy AND Association FOR COMPUTING Machinery Computing Curricula - Computer Science Volume, Final Report. Disponível em http://www.computer.org/education/cc2001/, Último acesso: 12/2003, 2001.

IEEE COMPUTER SOCIETy AND ASSOCIATION FOR COMPUTING MACHINERY Computing Curricula - Software Engineering, Draft Version. Disponível em http://www.computer.org/education/cc2001/, Último acesso: 12/2003, 2003.

IEEE Learning Technology Standards Committee Learning Object Metadata (LOM). 2002.

IMS Global Learning Consortium IMS Project. Página na Web. Disponível em http://www.imsproject.org/, Último acesso: 12/2003, 2004.

InSPIRATION SOFTWARE INC. Inspiration tool. Página Web. Disponível em http://www.inspiration.com/vlearning, Último acesso: 12/2003, 2003.

InTERnATIONAL ORgANIZATION FOR STANDARDIZATION Information Technology - Software Life Cycle Processes. Padrão ISO/IEC 12207, ISO/IEC, 1995.

INTERNATIONAL ORGANIZATION FOR STANDARDIZATION Information Technology - Software Process Assessment. Padrão ISO/IEC 15504, ISO/IEC, 1998.

Isakowitz, T.; Stohr, E.; Balasubramanian, P. RMM: A methodology for structured hypermedia design. Communications of the ACM, p. 34-44, 1995.

JIN, Z.; OfFuT, A. J. Integration testing based on software couplings. In: X Annual Conference on Computer Assurance (COMPASS 95), Gaithersburg, Maryland, 1995, p. 13-23.

JORGE, R. F. Teste de mutação: Subsídios para a redução do custo de aplicação. Qualificação de Mestrado - ICMC-USP., 2000.

Jorge, R. F.; Vincenzi, A. M. R.; Delamaro, M. E.; Maldonado, J. C. Teste de mutação: Estratégias baseadas em equivalência de mutantes para redução do custo de aplicação. In: XXVII Latin-American Conference on Informatics (CLEI 2001), Merida, Venezuela, 2001.

Kawasaki, E. I.; Fernandes, C. T. Modelo para projeto de cursos hipermídia. In: VII Simpósio Brasileiro de Informática na Educação (SBIE 96), Belo Horizonte, MG, 1996, p. 227240.

KIM, S.; ClARK, J. A.; MCDERMID, J. A. The rigorous generation of Java mutation operators using HAZOP. Relatório Técnico, Department of Computer Science - University of York, Heslington, York, Disponível em http://www-users.cs.york.ac.uk/ jac/, Último acesso: 12/2003, 1999.

Kim, S.; Clark, J. A.; MCDermid, J. A. Class mutation: Mutation testing for objectoriented programs. In: FMES, Disponível em http://www-users.cs.york.ac.uk/ jac/, Último acesso: $12 / 2003,2000$ a. 
Kim, S.; Clark, J. A.; MCDERMID, J. A. Investigating the effectiveness of object-oriented testing strategies with the mutation method. In: Symposium on Mutation Testing, San Jose, CA: Kluwer Academic Publishers, 2000b, p. 4.

Knowledge Systems Laboratory Ontolingua server. Página Web. Disponível em http://www.ksl.stanford.edu/software/ontolingua, Último acesso: 12/2003, 2003.

Krauser, E. W.; Mathur, A. P.; Rego, V. J. High performance software testing on simd machines. IEEE Transactions on Software Engineering, v. SE-17, n. 5, p. 403-422, 1991.

KRUSE, K. Introduction to Instructional Design and the ADDIE Model. Página Web. Disponível em http://www.e-learningguru.com/articles/art2_1.htm, Último acesso: 12/2003, 2003.

LANGE, D. B. An object-oriented design method for hypermedia information systems. In: International Conference on System Sciences, New York, NY, 1994, p. 366-375.

LASKI, J. W.; Korel, B. A data flow oriented program testing strategy. IEEE Transactions on Software Engineering, v. 9, n. 3, 1983.

LeE, W. W.; OWens, D. L. Mutimedia-based instructional design: Computer-based training, web-based training, distance broadcast training. San Francisco, CA: Pfeiffer, 384 p., 2000.

LEIVA, W. D. Um modelo de hipertexto para apoio ao ensino mediado pela web. Tese de Doutoramento, ICMC-USP, São Carlos, SP, 2003.

Leiva, W. D.; Oliveira, M. C. F.; Masiero, P. C.; Fortes, R. P. M. ATEnA: Adaptive tutorial environment with support for assessment. In: Simpósio Brasileiro de Multimídia e Sistemas Hipermídia (SBMIDIA 2002), Fortaleza, 2002a, p. 399-406.

Leiva, W. D.; Oliveira, M. C. F.; Masiero, P. C.; Fortes, R. P. M. MDE: A hypertext model for online courses. In: Simpósio Brasileiro de Multimídia e Sistemas Hipermídia (SBMIDIA 2002), Fortaleza, 2002b, p. 333-340.

Linnenkugel, U.; Müllerburg, M. Test data selection criteria for (software) integration testing. In: First International Conference on Systems Integration, Morristown, NJ, 1990, p. 709-717.

Longmire, W. A primer on learning objects. Informania's Learning Without Limit, v. 3, Disponível em http://www.informania.com/, Último acesso: 12/2003, 2000.

Lucena, C. J. P.; Fuks, H.; Laufer, C.; Ribeiro, M. B.; Choren, R.; Silva, V. T.; Assis, R. L.; Ferraz, F.; Carvalho, G. R. Appying digital information technology to education: a web-based course. In: International Conference on Engineering and Computer Education (ICECE 2000), São Paulo, SP, 2000.

Lucena, C. J. P.; Fuks, H.; Milidiu, R.; Laufer, C.; Ribeiro, M. B.; Noya, R. C.; Silva, V. T.; Ferraz, F.; Carvalho, G. R.; Daflon, L. AulaNet-ajudando os professores a fazerem seu dever de casa. In: XXVI Seminário Integrado de Software e Hardware (SEMISH 99), Rio de Janeiro, RJ, 1999, p. 105-117. 
Lucena, C. J. P.; Fuks, H.; Milidiu, R.; Macedo, L.; Santos, N.; Laufer, C.; RiBeiro, M. B.; Fontoura, M. F.; Noya, R. C.; Crespo, S.; Torres, V.; Daflon, L.; LUKOWIECKI, L. AulaNet - an environment for the development and maintenance of courses on the web. In: International Conference on Engineering in Education (ICECE 98), Rio de Janeiro, RJ, 1998.

MA, Y. S.; KwON, Y.-R.; OfFutT, J. Inter-class mutation operators for java. In: 13th International Symposium on Software Reliability Engineering (ISSRE 2002), Annapolis, MD, 2002, p. 352-366.

MAIDANTCHIK, C. L. L. Gerência de processos de software para equipes geograficamente dispersas. Tese de Doutoramento, COPPE/Universidade Federal do Rio de Janeiro, Rio de Janeiro, RJ, 1999.

Maldonado, J. C. Critérios potenciais usos: Uma contribuição ao teste estrutural de software. Tese de Doutoramento, DCA/FEEC/UNICAMP, Campinas, SP, 1991.

Maldonado, J. C.; Barbosa, E. F.; Vincenzi, A. M. R.; Delamaro, M. E. Evaluating N-selective mutation for $\mathrm{C}$ programs: Unit and integration testing. In: Mutation 2000 Symposium, San Jose, CA: Kluwer Academic Publishers, 2000a, p. 22-33.

Maldonado, J. C.; Barbosa, E. F.; Vincenzi, A. M. R.; Delamaro, M. E.; Souza, S. R. S.; Jino, M. Teste de software: Teoria e prática. Minicursos - XVII Simpósio Brasileiro de Engenharia de Software (SBES 2003), 2003.

Maldonado, J. C.; Delamaro, M. E.; Fabbri, S. C. P. F.; Simão, A. S.; Sugeta, T.; Vincenzi, A. M. R.; MASiero, P. C. Proteum: A family of tools to support specification and program testing based on mutation. In: Mutation 2000 Symposium - Tool Session, San Jose, CA: Kluwer Academic Publishers, 2000b, p. 113-116.

Maldonado, J. C.; Vincenzi, A. M. R.; Barbosa, E. F.; Souza, S. R. S.; Delamaro, M. E. Aspectos teóricos e empíricos de teste de cobertura de software. Relatório Técnico 31, Instituto de Ciências Matemáticas e de Computação - ICMC-USP, 1998.

Marshall, A. C.; Hedley, D.; Riddell, I. J.; Hennell, M. A. Static dataflow-aided weak mutation analysis (sdawm). Information and Software Technology, v. 32, n. 1, 1990.

Martinez, M. Designing learning objects to personalize learning. In: The Instructional Use of Learning Objects: Online Version, D. A. Wiley, ed., 2000.

Mathur, A. P. On the relative strengths of data flow and mutation testing. In: Ninth Annual Pacific Northwest Software Quality Conference, Portland, OR, 1991, p. 165-181.

Mathur, A. P.; KRAUSER, E. W. Modeling mutation on vector processor. In: X International Conference on Software Engineering, Singapore, 1988, p. 154-161.

Mathur, A. P.; Wong, W. E. Evaluation of the cost of alternative mutation strategies. In: VII Simpósio Brasileiro de Engenharia de Software (SBES 93), Rio de Janeiro, RJ, 1993, p. 320-335.

Mathur, A. P.; Wong, W. E. An empirical comparison of data flow and mutation based test adequacy criteria. The Journal of Software Testing, Verification, and Reliability, v. 4, n. 1, p. 9-31, 1994. 
MAurer, F.; MARTEL, S. Extreme programming: Rapid development for web-based applications. IEEE Internet Computing, v. 6, n. 1, p. 86-90, 2002.

Mayorga, J. I.; Verdejo, M. F.; Rodríguez-Artacho, M.; Calero, M. Y. Domain modelling to support educational web-based authoring. In: TET 99 Congress, Norway, 1999.

MCCOnnell, S. Open-source methodology: Ready for prime time? IEEE Software, v. 16, n. 4, p. 6-8, 1999.

Melo, R. N.; Baruque, C. B.; Baruque, L. B.; Pereira, L. A. Instructional design: Desenvolvimento de módulos de e-learning baseados em objetos de aprendizado (learning objects). Curso oferecido pelo Departamento de Informática da PUC-RIO, junho a agosto, 2003.

MENASCE, D. A. Educational challenges and opportunities in the web era. In: VI Workshop sobre Educação em Informática, Belo Horizonte, MG, 1998, p. 433-444.

Merril, M. D. Component display theory. In: Instructional Design Theories and Models: An Overview of their Current States, Hillsdale, NJ: Lawrence Erlbaum, 1983.

MERRILL, M. D. Knowledge objects and mental models. In: The Instructional Use of Learning Objects: Online Version, D. A. Wiley, ed., 2000.

Mian, P. G.; FAlBO, R. A. Supporting ontology development with ODEd. In: 2nd IberoAmerican Symposium on Software Engineering and Knowledge Engineering, Salvador, BA, 2002.

Michener, E. R. Understanding understanding mathematics. Cognitive Science, v. 2, n. 4, 1978.

Moreira, M. A.; BuchweITZ, B. Mapas conceituais: Instrumentos didáticos, de avaliação e de análise de currículo. São Paulo: Editora Moraes Ltda., 1987.

MoRSE, T. CVS: Version control beyond RCS. Linux Journal, 1996.

Mresa, E.; Bottaci, L. Efficiency of mutation operators and selective mutation strategies: an empirical study. The Journal of Software Testing, Verification and Reliability, v. 9, n. 4, p. 205-232, 1999.

Murata, T. Modeling and analysis of concurrent systems. In: Handbook of Software Engineering, New York: Van Nostrand Reinhold Electrical, 1984.

Murata, T. Petri nets: Properties, analysis and applications. Proceedings of the IEEE, v. 77, n. 4 , p. 541-580, 1989.

Muzio, J.; Heins, T.; Mundell, R. Experiences with reusable e-learning objects: From theory to practice. The Internet and Higher Education, v. 5, n. 1, p. 21-34, 2002.

MYERS, G. J. The art of software testing. Wiley, New York, 1979.

NAKagawa, E. Y. Software livre: Processo e produto livres no desenvolvimento de aplicações web. Tese de Doutoramento, ICMC-USP, São Carlos, SP, (exame de qualificação), 2002.

NovaK, J. D. Uma teoria de educação. São Paulo: Editora Pioneira, 1981. 
NovaK, J. D. Concept mapping: A useful tool for science education. Journal of Research in Science Teaching, v. 27, p. 937-949, 1990.

NovaK, J. D.; Gowin, D. B. Learning how to learn. New York: Cambridge University Press, 1984.

NtAfos, S. C. On required element testing. IEEE Transactions on Software Engineering, v. SE-10, p. 795-803, 1984.

NTAFos, S. C. A comparison of some structural testing strategies. IEEE Transactions on Software Engineering, v. 14, n. 6, p. 868-873, 1988.

OfFutT, A. J.; HAYES, J. H. A semantic model of program faults. In: ISSTA 96, San Diego, CA, 1996, p. 195-199.

Offutt, A. J.; Lee, A.; Rothermel, G.; Untch, R. H.; ZAPF, C. An experimental determination of sufficient mutant operators. ACM Transactions on Software Engineering Methodo$\log y$, v. 5, n. 2, p. 99-118, 1996.

Offutt, A. J.; Rothermel, G.; ZAPF, C. An experimental evaluation of selective mutation. In: 15th International Conference on Software Engineering (ICSE 93), Baltimore, MD, 1993, p. 100-107.

Oliveira, K. M.; Rocha, A. R. C.; Travassos, G. H.; Menezes, C. S. Using domainknowledge in software development environments. In: Software Engineering and Knowledge Engineering, Kaiserlautern, Alemanha, 1999.

O’REILly, T. Lessons from open-source software development. Communications of the ACM, v. 42, n. 4, 1999.

Ostrand, T. J.; Weyuker, E. J. Using data flow analysis for regression testing. In: Sixth Annual Pacific Northwest Software Quality Conference, Portland, OR, 1988.

Pacheco, E. J.; De Marco, G. A.; Eberspächer, H. F. WCC - Web Course Creator: um framework para a criação de ambientes de aprendizado para a web. In: XXV Latin-American Conference on Informatics (CLEI 99), Assunción, Paraguay, 1999a.

Pacheco, E. J.; de Marco, G. A.; Eberspächer, H. F. WCC - Web Course Creator: Um sistema tutor inteligente para a geração de ambientes de aprendizado. In: V Workshop de Informática na Escola (WIE 99), Rio de Janeiro, RJ, 1999b.

PaIVA, D. M. B. Proposta e avaliação de um conjunto de requisitos para sistemas de autoria hipermídia educacional. Dissertação de Mestrado, ICMC-USP, São Carlos, SP, 2001.

Pansanato, L. T. E.; Nunes, M. G. V. Autoria de aplicações hipermídia para ensino. Revista Brasileira de Informática na Educação, v. 1, n. 5, p. 103-124, 1999.

Papatheodorou, T. S.; Styliaras, G. D.; Christodoulou, S. P. Evaluation of hypermedia application development and management systems. In: The Ninth ACM Conference on Hypertext and Hypermedia, Pittsburgh, 1998, p. 1-10.

PaulK, M. C. Capability Maturity Model for Software - Version 1.1. Relatório Técnico CMU/SEI-93-TR-24, Carnegie Mellon University, Software Engineering Institute, Pittsburgh, PA, 1993. 
Paulk, M. C.; Weber, C. V.; Curtis, B.; Chrissis, M. B. The Capability Maturity Model: Guidelines for improving the software process. Massachusetts: Addison-Wesley Publishing Company, the SEI Series in Software Engineering, 1995.

Peterson, J. L. Petri nets. ACM Computing Surveys, v. 9, n. 3, p. 223-252, 1977.

Peterson, J. L. Petri net theory and the modeling of systems. New Jersey: Prentice-Hall, Englewood Cliffs, 1981.

Pimentel, M. G. MAPHE: Metodologia de apoio a projetos de hipertextos educacionais. In: VIII Simpósio Brasileiro de Informática na Educação (SBIE 97), São José dos Campos, SP, 1997, p. 351-368.

Pimentel, M. G. Modelo orientado a conceitos (MOC). In: IX Simpósio Brasileiro de Informática na Educação, Fortaleza, CE, 1998.

Pimentel, M. G.; Ishiguro, Y.; Kerimbaev, B.; Abowd, G. D.; Guzdial, M. Supporting long-term educational activities through dynamic web interfaces. Journal Interacting with Computers, p. 353-374, 2001.

Pimentel, M. G. C. Hiperdocumentos estruturados abertos \& Hipermídia em ambientes com computação ubíqua. Concurso de Livre Docência - ICMC-USP, 2001.

Pimentel, M. G. C.; Abowd, G.; Brotherton, J. Requirements for capture-based support to learning. Communications of the ACM, (Accepted), 2002.

PRESSMAN, R. S. Software engineering - a practitioner's approach. 5 ed. McGraw-Hill, 2001.

Probert, R. L.; Guo, F. Mutation testing of protocols: Principles and preliminary experimental results. In: Third International Workshop on Protocol Test Systems (IFIP TC6), NorthHolland, 1991, p. 57-76.

RAPPS, S.; WEYUKER, E. J. Data flow analysis techniques for program test data selection. In: 6th International Conference on Software Engineering, Tokio, Japan, 1982, p. 272-278.

RAPPS, S.; WeyUKer, E. J. Selecting software test data using data flow information. IEEE Transactions on Software Engineering, v. SE-11, n. 4, p. 367-375, 1985.

RAYMOND, E. S. The cathedral and the bazaar. Disponível em http://www.tuxedo.org/ esr/writings/cathedral-bazaar/, Último acesso: 12/2003, 2003.

RISING, L.; JANOFF, N. S. The SCRUM software development process for small teams. IEEE Software, v. 17, n. 4, p. 26-32, 2000.

Da Rocha, A. R. C.; Maldonado, J. C.; Weber, K. C. Qualidade de software: Teoria e prática. São Paulo, SP: Prentice Hall, 2001.

Rumbaugh, J.; Blaha, M.; Premerlani, W.; Eddy, F.; Lorensen, W. Object-oriented modeling and design. Englewood Cliffs, New Jersey, USA: Prentice Hall International, 1991.

Schwabe, D.; Rossi, G. The object-oriented hypermedia design model. Communications of the ACM, v. 38, n. 8, p. 45-46, 1995. 
Seels, B.; Glasgow, Z. Making instructional design decisions. 2 ed. Columbus: PrenticeHall, Inc., 1998.

Simão, A. S.; Maldonado, J. C. Geração de seqüências para redes de Petri baseadas em mutação. In: III Workshop de Métodos Formais, João Pessoa, 2000.

Simão, A. S.; Maldonado, J. C. MuDeL: A language and a system for describing and generating mutants. In: XIV Simpósio Brasileiro de Engenharia de Software (SBES 2001), Rio de Janeiro, Brasil, 2001.

Simão, A. S.; Maldonado, J. C.; Fabbri, S. C. P. F. Proteum-RS/PN: A tool to support edition, simulation and validation of petri nets based on mutation testing. In: XIII Simpósio Brasileiro de Engenharia de Software (SBES 2000), João Pessoa, 2000.

SofTwARE ENGINEERING INSTITUTE Standard CMMI appraisal method for process improvement (SCAMPI), version 1.1: Method definition document. Handbook, 2001.

SofTwARE ENGINEERING InSTITUTE CMMI: Capability maturity model integrated. Disponível em http://www.sei.cmu.edu/cmmi/, Último acesso: 12/2003, 2003.

Sosteric, M.; Hesemeier, S. When is a learning object not an object: A first step towards a theory of learning objects. International Review of Research in Open and Distance Learning, Disponível em http://www.irrodl.org, Último acesso: 12/2003, 2002.

SouzA, S. R. S. Avaliação do custo e eficácia do critério análise de mutantes na atividade de teste de programas. Dissertação de Mestrado, ICMC-USP, São Carlos, SP, 1996.

Souza, S. R. S.; Maldonado, J. C.; Fabbri, S. C. P. F.; Lopes de Souza, W. Mutation testing applied to Estelle specifications. In: 33rd Hawaii International Conference on System Sciences, Mini-Tracks: Distributed Systems Testing, Maui, Havaí, 2000.

Sridhanan, B.; Mundkur, S.; Mathur, A. P. Non-intrusive testing, monitoring and control of distributed CORBA objects. In: 33rd International Conference on Technology of ObjectOriented Languages (TOOLS 33), Mont-saint-Michel, France, 2000, p. 195-206.

Stotts, P. D.; Furuta, R. Petri Net based hypertext: Document structure with browsing semantics. ACM Transactions on Information Systems, v. 7, n. 1, p. 03-29, 1989.

Stotts, P. D.; Furuta, R. Dynamic adaptation of hypertext structure. In: Third ACM Conference on Hypertext (Hypertext 91), San Antonio,Texas, 1991, p. 219-231.

Sugeta, T. Proteum-RS/ST : Uma ferramenta para apoiar a validação de especificações statecharts baseada na análise de mutantes. Dissertação de Mestrado, ICMC-USP, São Carlos, SP, 1999.

Thüring, M.; Hannemann, J.; HaAke, J. M. Hypermedia and cognition: Designing for comprehension. Communications of the ACM, v. 38, n. 8, p. 57-66, 1995.

TUCKER, R. W. Assessing the virtual classrooms: a progress report. Assessment and Accountability Forum, v. 5, n. 2, 1995.

TURINE, M. A. S. HMBS: Um modelo baseado em statecharts para a especificação formal de hiperdocumentos. Tese de Doutoramento, IFSC-USP, São Carlos, SP, 1998. 
Turine, M. A. S.; Oliveira, M. C. F.; Masiero, P. C. Designing structured hypertext with HMBS. In: VIII International ACM Hypertext Conference (Hypertext 97), Southampton, UK, 1997, p. 241-256.

Turine, M. A. S.; Oliveira, M. C. F.; Masiero, P. C. HySCharts: Um ambiente de autoria e navegação baseado no modelo HMBS. In: IV Simpósio Brasileiro de Multimídia e Sistemas Hipermídia (SBMIDIA 98), Rio de Janeiro, RJ, 1998.

URAL, H.; YANG, B. A structural test selection criterion. Information Processing Letters, v. 28, p. 157-163, 1988.

VERGILIO, S. R. Critérios restritos: Uma contribuição para aprimorar a eficácia da atividade de teste de software. Tese de Doutoramento, DCA/FEEC/UNICAMP, Campinas, SP, 1997.

Vergílio, S. R.; MALdonado, J. C.; Jino, M. Caminhos não-executáveis na automação das atividades de teste. In: VI Simpósio Brasileiro de Engenharia de Software (SBES 92), Gramado, RS, 1992, p. 343-356.

VIlela, P. R. S. Critérios potenciais usos de integração: Definição e análise. Tese de Doutoramento, DCA/FEEC/UNICAMP, Campinas, SP, 1998.

VincenZI, A. M. R. Subsídios para o estabelecimento de estratégias de teste baseadas na técnica de mutação. Dissertação de Mestrado, ICMC-USP, São Carlos, SP, 1998.

VINCENZI, A. M. R. Orientação a objetos: Definição e análise de recursos de teste e validação. Tese de Doutoramento, ICMC-USP, São Carlos, SP, (exame de qualificação), 2000.

Vincenzi, A. M. R.; Maldonado, J. C.; Barbosa, E. F.; Delamaro, M. E. Operadores essenciais de interface: Um estudo de caso. In: XIII Simpósio Brasileiro de Engenharia de Software (SBES 99), Florianópolis, SC, 1999, p. 373-391.

Vincenzi, A. M. R.; Maldonado, J. C.; Barbosa, E. F.; Delamaro, M. E. Unit and integration testing strategies for $\mathrm{C}$ programs using mutation-based criteria. Software Testing, Verification and Reliability, v. 11, n. 4, 2001.

Vincenzi, A. M. R.; Maldonado, J. C.; Delamaro, M. E.; Spoto, E. S.; Wong, W. E. Component-based software: An overview of testing. In: Component-Based Software Quality: Methods and Techniques, New York, NY: Springer-Verlag, lecture Notes in Computer Science, v. 2693, 2003a, p. 99-127.

Vincenzi, A. M. R.; Wong, W. E.; Delamaro, M. E.; Maldonado, J. C. JaBUTi: A coverage analysis tool for java programs. In: XVII Simpósio Brasileiro de Engenharia de Software (SBES 2003), Manaus, AM, 2003b.

VIXIE, P. Open sources: Voices of the open source revolution, cáp. Software Engineering. 1 ed O’Reilly \& Associates, p. 91-100, 1999.

WEYUKER, E. J. The cost of data flow testing: an empirical study. IEEE Transactions on Software Engineering, v. SE-16, n. 2, p. 121-128, 1990.

WEYUKER, E. J. Testing component-based software: A cautionary tale. IEEE Software, v. 15, n. 5 , p. 54-59, 1998. 
WeyUKeR, E. J.; JENG, B. Analyzing partition testing strategies. IEEE Transactions on Software Engineering, v. 17, n. 7, p. 703-711, 1991.

WILEY, D. A. Learning object design and sequencing theory. Tese de Doutoramento, Brigham Young University, 2000.

WILEY, D. A. Connecting learning objects to instructional design theory: A definition, a metaphor, and a taxonomy. In: The Instructional Use of Learning Objects, Bloomington, IN: Association for Educational Communications and Technology, disponível em http://reusability.org/read/chapters/wiley.doc, Último acesso: 12/2003, 2001.

Wong, W.; Maldonado, J.; Delamaro, M.; Souza, S. A comparison of selective mutation in $\mathrm{C}$ and fortran. In: Workshop do Projeto Validação e Teste de Sistemas de Operação, Águas de Lindóia, SP, 1997, p. 71-80.

Wong, W.; Sugeta, T.; Li, J. J.; Maldonado, J. C. Coverage testing software architectural design in SDL. Journal of Computer Networks, v. 42, n. 3, p. 359-374, 2003.

Wong, W. E. On mutation and data flow. Tese de Doutoramento, Department of Computer Science, Purdue University, W. Lafayette, IN, 1993.

Wong, W. E.; Maldonado, J. C.; Delamaro, M. E.; Mathur, A. P. Constrained mutation in C programs. In: VIII Simpósio Brasileiro de Engenharia de Software (SBES 94), Curitiba, PR, Brazil, 1994, p. 439-452.

World Wide Web Consortium (W3C) RDF Suite. Página Web. Disponível em http://139.91.183.30:9090/RDF/publications/index.html, Último acesso: 12/2003, 2003.

Zhao, L.; Elbaum, S. A survey on quality related activities in open source. ACM Sigsoft, v. 25, n. 5, p. 54-57, 2000.

ZHU, H. A formal analysis of the subsume relation between software test adequacy criteria. IEEE Transactions on Software Engineering, v. SE-22, n. 4, p. 248-255, 1996. 

APÊNDICE

$A$

\section{Modelo de Maturidade de Processos para Elaboração de Módulos Educacionais}

Neste apêndice são discutidos aspectos referentes ao modelo de maturidade de processos para elaboração de módulos educacionais - o $\mathcal{C M M} /$ Educacional. A estrutura básica do modelo é descrita na Seção A.1. Questões associadas ao estabelecimento de um modelo de maturidade integrado no contexto de módulos educacionais, nos moldes do CMMI (Software Engineering Institute, 2003), são abordadas na Seção A.2.

\section{A.1 Níveis de Maturidade}

A estrutura do modelo $\mathcal{C M M} /$ Educacional foi baseada nos cinco níveis de maturidade definidos pelo CMM (Paulk, 1993; Paulk et al., 1995), adaptando as tarefas e práticas definidas pelo modelo ao contexto de processos para elaboração de módulos educacionais. O modelo de maturidade de processos para equipes geograficamente dispersas (Maidantchik, 1999) também foi utilizado na definição das tarefas e práticas pertinentes à elaboração distribuída e colaborativa dos módulos. Os níveis de maturidade e suas áreas-chave associadas são descritos a seguir. 


\section{A.1.1 Nível 1 - Inicial (Organizações Caóticas)}

As organizações no Nível 1 caracterizam-se pela ausência de quaisquer tipos de processos definidos, ou pelo não seguimento de tais processos, caso existam. Organizações neste nível podem desenvolver módulos educacionais de qualidade, mas seu desempenho é dependente da competência das pessoas envolvidas. Mudando as pessoas, a qualidade pode cair. Os maiores problemas são de ordem gerencial e não de ordem técnica. Não há áreas-chave associadas a este nível.

\section{A.1.2 Nível 2 - Repetível (Organizações Disciplinadas)}

No Nível 2, políticas organizacionais orientam os projetos, estabelecendo processos de gerenciamento. Práticas bem-sucedidas podem ser repetidas em novos projetos. Existe um sistema de gerenciamento vigente, garantindo o cumprimento de custos e prazos em projetos similares já desenvolvidos anteriormente.

\section{Gerência Distribuída de Requisitos do Módulo Educacional}

Esta área-chave tem como principais objetivos:

- Definir e garantir que os requisitos do módulo educacional, sobretudo em termos das metas de aprendizado, sejam respeitados por todas as equipes ao longo do processo de desenvolvimento.

- Garantir que o módulo resultante da integração de seus componentes (conteúdos teóricos, conteúdos práticos, ferramentas educacionais e mecanismos de apoio), desenvolvidos e/ou estabelecidos por diferentes equipes, respeite os requisitos previamente definidos.

\section{Planejamento Distribuído de Projeto do Módulo Educacional}

Esta área-chave tem como principais objetivos:

- Estabelecer estimativas (custo, tempo, recursos) e planos razoáveis para a condução das atividades técnicas e gerenciais de cada equipe de desenvolvimento.

- Estabelecer planos razoáveis para a realização das atividades de integração e coordenação dos trabalhos conduzidos pelas equipes e gerenciamento global do projeto.

Cabe ressaltar que, além de gerentes e desenvolvedores, especialistas do domínio de conhecimento ao qual o módulo se destina também devem participar das atividades de planejamento. 


\section{Acompanhamento e Supervisão Distribuídos de Projeto de Módulo Educacional}

Esta área-chave tem como principal objetivo:

- Estabelecer a visibilidade adequada sobre o progresso das atividades de cada equipe e do projeto como um todo, de modo que seja possível tomar decisões efetivas quando desvios significativos com relação ao planejado são identificados.

\section{Gerência de Subcontratação de Módulo Educacional}

Esta área-chave tem como principal objetivo:

- Selecionar subcontratados qualificados, gerenciando-os de modo efetivo.

\section{Gerência da Atribuição de Atividades do Módulo Educacional}

Esta área-chave tem como principal objetivo:

- Selecionar profissionais (gerentes, especialistas de domínio, desenvolvedores) aptos à condução das atividades e aspectos pertinentes ao projeto de um módulo educacional.

- Identificar as equipes mais adequadas ao desenvolvimento de cada um dos componentes pertinentes ao módulo.

\section{Garantia da Qualidade do Módulo Educacional}

Esta área-chave tem como principal objetivo:

- Realizar revisões e auditorias nos produtos parciais (sub-módulos e/ou componentes pertinentes), no produto final integrado (módulo educacional) e nas atividades referentes ao ciclo de vida, a fim de assegurar que estes encontram-se em conformidade com os padrões e procedimentos de qualidade previamente estabelecidos.

\section{Gerência Distribuída de Configuração de Módulo Educacional}

Esta área-chave tem como principal objetivo:

- Estabelecer e manter a integridade e rastreabilidade dos produtos parciais (sub-módulos e/ou componentes pertinentes) construídos por cada equipe e do produto final integrado (módulo educacional) ao longo de todo o ciclo de vida. 


\section{Gerência Distribuída do Conhecimento Associado ao Módulo Educacional}

Esta área-chave tem como principais objetivos:

- Estabelecer e garantir a integridade dos itens de informação e elementos instrucionais compartilhados pelas equipes de desenvolvimento durante todo o ciclo de vida do módulo educacional.

- Estabelecer e manter mecanismos de apoio ao compartilhamento do conhecimento (bases conceituais, repositório de terminologias, ontologias, etc.).

\section{Gerência Distribuída da Infra-Estrutura Associada ao Módulo Educacional}

Esta área-chave tem como principal objetivo:

- Definir e manter a infra-estrutura necessária para instalação e utilização distribuída das ferramentas (educacionais, específicas ao domínio de conhecimento, etc.) e mecanismos de apoio (comunicação, colaboração, captura, etc.) por todas as equipes de desenvolvimento.

\section{Gerência da Comunicação}

Esta área-chave tem como principal objetivo:

- Definir e garantir a comunicação entre as equipes de desenvolvimento.

\section{Gerência da Capacidade das Equipes}

Esta área-chave tem como principal objetivo:

- Identificar habilidades e restrições de cada equipe visando a definir e a garantir que as atividades a serem delegadas sejam adequadas à sua capacidade.

\section{A.1.3 Nível 3 - Definido (Organizações Padronizadas)}

No Nível 3, a organização possui um processo de desenvolvimento de módulos educacionais definido. Existe a preocupação com um processo padronizado para a organização e personalizado para cada projeto. Todos os projetos utilizam uma versão aprovada do processo padrão para desenvolver e manter o módulo, adequando-a às necessidades do projeto. O processo deve ser definido, documentado e compreendido. Existe ainda a preocupação com a coleta e a disseminação de lições aprendidas em um dado projeto para os demais. 


\section{Foco no Processo Organizacional}

Esta área-chave tem como principais objetivos:

- Determinar a responsabilidade organizacional pelas atividades referentes aos processos para elaboração de módulos educacionais, definindo as capacidades dos processos especializados.

- Coordenar atividades que melhorem a capacidade do processo padrão da organização.

\section{Definição do Processo Padrão Organizacional}

Esta área-chave tem como principais objetivos:

- Desenvolver e manter um processo padrão para elaboração de módulos educacionais.

- Coletar informações sobre como especializar o processo padrão e utilizá-lo em outros projetos de modo a fornecer uma base para benefícios cumulativos e de longo prazo para a organização.

\section{Definição das Especializações do Processo Organizacional}

Esta área-chave tem como principal objetivo:

- Desenvolver e manter as especializações do processo padrão da organização para cada nível de maturidade.

\section{Programa de Treinamento}

Esta área-chave tem como principal objetivo:

- Desenvolver a capacidade e o conhecimento dos membros das equipes de desenvolvimento da organização (considerando suas habilidades e restrições) de modo que os mesmos possam desempenhar suas funções de maneira eficaz e eficiente.

\section{Gerência da Evolução do Conhecimento}

Esta área-chave tem como principais objetivos:

- Identificar, selecionar e avaliar novos conhecimentos pertinentes ao domínio do módulo.

- Estabelecer e manter mecanismos de apoio para integrar, de maneira ordenada, os novos conhecimentos ao módulo. 


\section{Gerência Integrada de Módulo Educacional}

Esta área-chave tem como principal objetivo:

- Integrar atividades técnicas e gerenciais em um modelo definido e coerente de processo para elaboração de módulos educacionais, correspondendo ao processo padrão da organização.

\section{Coordenação Distribuída de Módulo Educacional}

Esta área-chave tem como principal objetivo:

- Coordenar as atividades técnicas e gerenciais de cada equipe de desenvolvimento de acordo com o processo padrão da organização.

\section{Engenharia Distribuída de Módulo Educacional}

Esta área-chave tem como principal objetivo:

- Estabelecer e executar consistentemente um processo de engenharia bem definido, que integre todas as atividades de desenvolvimento de módulos educacionais de modo eficiente $\mathrm{e}$ eficaz.

\section{Interação com Especialistas de Domínio}

Esta área-chave tem como principais objetivos:

- Estabelecer meios para que as equipes de desenvolvimento interajam ativamente com especialistas do domínio, apresentando e trocando informações sobre o conhecimento ao qual o módulo se destina.

- Coordenar e controlar as interações entre as equipes de desenvolvimento e especialistas de domínio.

\section{Coordenação Intergrupos}

Esta área-chave tem como principais objetivos:

- Estabelecer meios para que as equipes de desenvolvimento interajam ativamente umas com as outras, apresentando e trocando informações sobre as atividades do projeto em andamento.

- Coordenar e controlar as interações entre as equipes de desenvolvimento. 
Apêndice A. Modelo de Maturidade de Processos para Elaboração de Módulos Educacionais 241 Acompanhamento e Supervisão Distribuídos da Utilização do Módulo Educacional

Esta área-chave tem como principais objetivos:

- Estabelecer meios para coletar informações a respeito da utilização do módulo educacional (desempenho dos aprendizes, novos conhecimentos produzidos, metas e objetivos de aprendizado atingidos, etc.).

- Coordenar e controlar as alterações/evoluções ocorridas no módulo em função de sua utilização no âmbito de ensino e treinamento.

\section{Revisões Distribuídas}

Esta área-chave tem como principal objetivo:

- Examinar sistematicamente os produtos parciais (sub-módulos e/ou componentes pertinentes) a fim de prevenir possíveis falhas.

\section{A.1.4 Nível 4 - Gerenciado (Organizações Previsíveis)}

No Nível 4, o processo é medido e gerenciado quantitativamente, o que possibilita prever seu desempenho dentro de limites quantificados.

\section{Gerência Quantitativa do Processo}

Esta área-chave estabelece como principal objetivo:

- Controlar quantitativamente o desempenho do processo. O foco é identificar causas especiais de variação dentro de um processo estável que possa ser medido, corrigindo, quando necessário, as circunstâncias que fazem com que a variação transiente ocorra.

\section{Coordenação Quantitativa das Especializações}

Esta área-chave estabelece como principal objetivo:

- Controlar quantitativamente o desempenho das especializações do processo para um determinado projeto.

\section{Gerência da Qualidade do Módulo Educacional}

Esta área-chave estabelece como principal objetivo: 
- Desenvolver um entendimento quantitativo da qualidade do módulo e definir atributos de qualidade específicos a serem respeitados.

- Realizar uma análise qualitativa de cada sub-módulo e/ou componentes pertinentes e do próprio módulo educacional integrado (em termos de conteúdos teóricos e práticos, ferramentas e mecanismos de apoio) com relação às metas de aprendizado estabelecidas.

\section{Gerência Quantitativa da Utilização do Módulo Educacional}

Esta área-chave estabelece como principal objetivo:

- Medir, analisar e controlar quantitativamente o desempenho dos aprendizes ao longo da utilização do módulo educacional.

\section{A.1.5 Nível 5 - Otimizado (Organizações com Melhoria Contínua)}

O Nível 5 refere-se à melhoria contínua. As mudanças de tecnologia, as mudanças de paradigmas e princípios educacionais e as mudanças no próprio processo devem ser gerenciadas de modo a não causarem impacto na qualidade do módulo educacional desenvolvido.

\section{Prevenção de defeitos}

Esta área-chave tem como principais objetivos:

- Identificar possíveis causas de defeitos, priorizá-las e eliminá-las sistematicamente.

- Alterar as especializações do processo para prevenir erros e modificar o processo padrão para evitar a recorrência das falhas em projetos futuros.

\section{Gerência de Mudança Tecnológica}

Esta área-chave tem como principais objetivos:

- Identificar, selecionar e avaliar novas tecnologias (ferramentas educacionais, ferramentas específicas ao domínio de conhecimento, recursos computacionais, métodos e processos) quanto ao impacto na qualidade dos módulos e produtividade do processo de desenvolvimento.

- Transferir para a organização, de maneira ordenada, as tecnologias que se mostrarem adequadas, integrando-as às especializações do processo padrão. 


\section{Gerência de Mudança de Paradigmas e Princípios Educacionais}

Esta área-chave tem como principais objetivos:

- Identificar, selecionar e avaliar outros paradigmas e princípios educacionais quanto ao impacto na qualidade do aprendizado proporcionado.

- Transferir para a organização, de maneira ordenada, os paradigmas e princípios educacionais vantajosos, integrando-os às especializações do processo padrão.

\section{Gerência de Mudança no Processo}

Esta área-chave tem como principal objetivo:

- Melhorar continuamente os processos utilizados na organização com o objetivo de melhorar a qualidade do módulo educacional desenvolvido, aumentando a produtividade das equipes e diminuindo o tempo gasto na elaboração do produto.

\section{Gerência de Mudança nas Especializações}

Esta área-chave tem como principal objetivo:

- Melhorar continuamente as especializações do processo utilizado na organização.

\section{A.2 CMMI para Módulos Educacionais}

As KPAs do modelo $\mathcal{C M M} /$ Educacional também podem ser categorizadas em áreas de processo, a exemplo do que ocorre com as KPAs do modelo CMM em relação às áreas de processo do CMMI.

A adequação do CMMI ao contexto de processos para elaboração de módulos educacionais - o $\mathcal{C M N}$ T/Educacional - constitui uma das linhas de pesquisa futura associada a este trabalho e estudos preliminares nessa direção já vêm sendo conduzidos. A Figura A.1 sugere uma possível estrutura para o modelo integrado, procurando estabelecer a correspondência entre as áreas-chave do modelo $\mathcal{C M M} /$ Educacional e as áreas de processo do $\mathcal{C M N} \mathbb{L} /$ Educacional.

De modo geral, no Nível 2, as KPAs de Gerência Distribuída do Conhecimento Associado ao Módulo Educacional e Gerência Distribuída da Infra-Estrutura Associada ao Módulo Educacional, estabelecidas especificamente no contexto de módulos educacionais, foram mapeadas para áreas de processo de mesmo nome e incluídas na categoria de Gerência de Projeto. A KPA de Gerência da Atribuição de Atividades do Módulo Educacional, extraída de (Maidantchik, 1999) e adaptada ao contexto de desenvolvimento de módulos educacionais, também foi mapeada e incluída na mesma categoria. As demais KPAs extraídas de (Maidantchik, 1999) - Gerência de Comunicação e Gerência da Capacidade das Equipes - foram incorporadas à categoria de Apoio. 


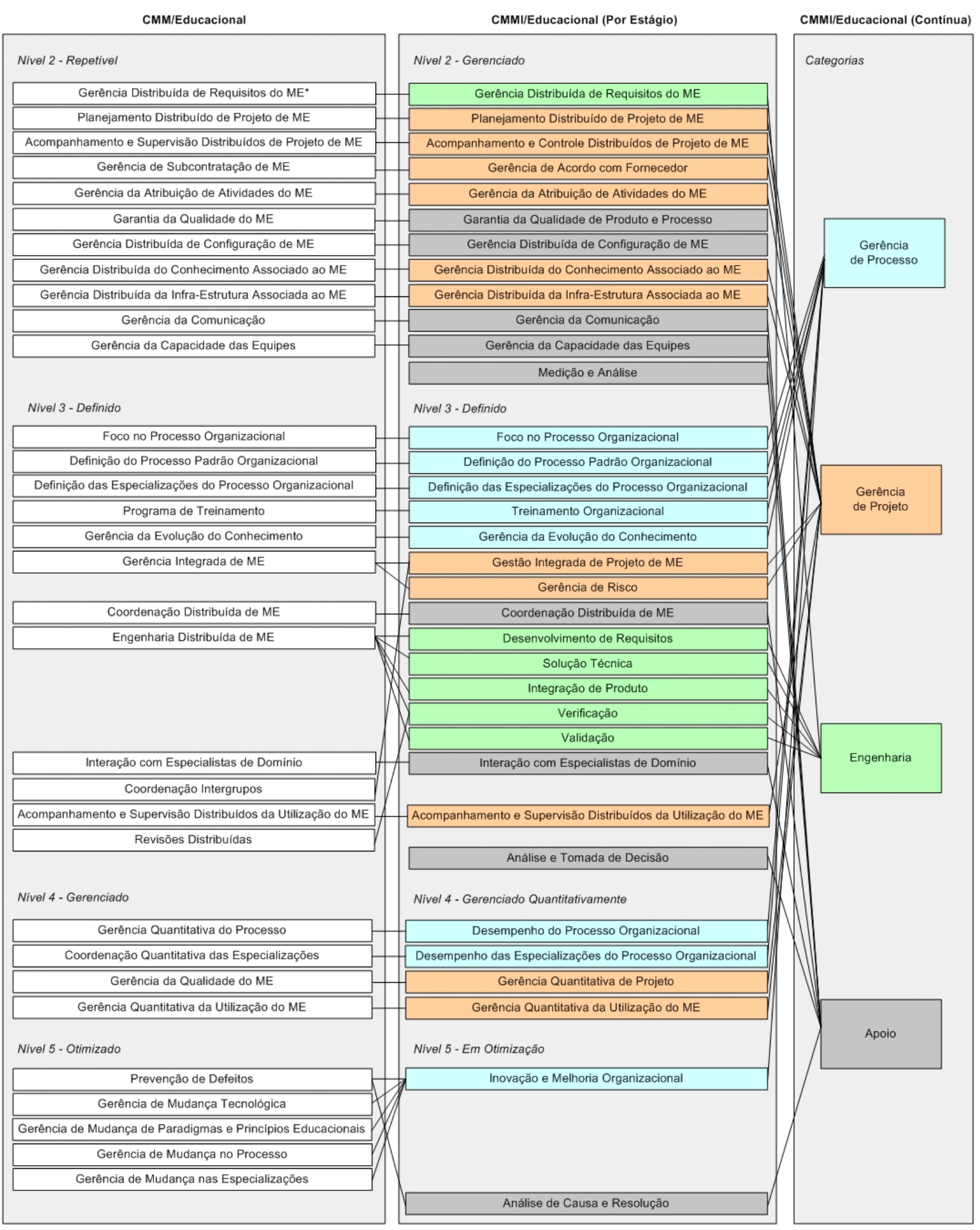

*ME - Módulo Educacional

Figura A.1: $\mathcal{C M M} /$ Educacional x $\mathcal{C M N} /$ Educacional.

No Nível 3, as KPAs de Gerência da Evolução do Conhecimento, Interação com Especialistas de Domínio e Acompanhamento e Supervisão Distribuídos da Utilização do Módulo Educacional foram mapeadas e incorporadas às categorias de Gerência de Processo, Apoio e Gerência de 
Projeto, respectivamente. As KPAs de Definição das Especializações do Processo Organizacional e Coordenação Distribuída de Módulo Educacional, extraídas e adaptadas a partir de (Maidantchik, 1999), também foram mantidas, sendo incorporadas às categorias de Gerência de Processo e Apoio, respectivamente.

No Nível 4, a KPA de Gerência Quantitativa da Utilização do Módulo Educacional foi mapeada e incluída na categoria de Gerência de Projeto. A KPA de Coordenação Quantitativa das Especializações, extraída de (Maidantchik, 1999) foi mapeada e renomeada para Desempenho das Organizações do Processo Organizacional, fazendo parte da categoria de Gerência de Processo.

Finalmente, no Nível 5, a KPA de Gerência de Mudança de Paradigmas e Princípios Educacionais foi mapeada como parte de uma área de processo mais abrangente - Inovação e Melhoria Organizacional -, pertencente à categoria de Gerência de Processo. O mesmo ocorreu com a KPA de Gerência de Mudança nas Especializações, extraída e adaptada a partir de (Maidantchik, 1999).

Salienta-se que essa é apenas uma sugestão para a estruturação e o estabelecimento de um modelo de maturidade integrado no contexto de processos para elaboração de módulos educacionais. Estudos mais detalhados são necessários e deverão ser conduzidos em curto prazo. 



\section{Avaliação de Módulos Educacionais: Questionário e Síntese dos Resultados}

Este apêndice apresenta o questionário utilizado na avaliação das características técnicas e pedagógicas do módulo educacional Teste de Software: Teoria e Prática, disponibilizado na V Escola de Informática Norte (ERI - Norte), em Belém.

O questionário de avaliação aplicado aos alunos foi elaborado com base no trabalho de Gladcheff (2000), adaptado ao contexto do módulo desenvolvido. As questões foram divididas em quatro seções: (1) usabilidade, em termos da interface do módulo; (2) conteúdo, referente aos conceitos, exemplos, exercícios e informações complementares utilizadas no módulo; (3) navegação; e (4) aspectos gerais. As três primeiras seções foram compostas por questões objetivas, de múltipla escolha. A quarta seção consistiu em questões subjetivas.

Uma síntese dos resultados obtidos, em termos do número de alternativas selecionadas para cada questão, também é apresentada. Do total de 60 avaliações conduzidas, três foram descartadas: os alunos envolvidos tiveram uma interpretação equivocada do objetivo da avaliação, considerando não apenas o minicurso sobre Teste de Software, mas também os demais minicursos ocorridos durante o evento. Além disso, para cada um dos três primeiros grupos de questões (objetivas), optou-se por desconsiderar avaliações em que: (1) não foi selecionada alternativa alguma; e (2) mais de uma alternativa foi escolhida. Nesse sentido, para o grupo de questões pertinentes à usabilidade, todas as 57 avaliações foram consideradas; para o grupo de questões associadas ao conteúdo do módulo, 53 avaliações foram válidas; e para o grupo de questões referentes à navegação, 55 avaliações foram consideradas. 
É importante ressaltar que o questionário foi elaborado e aplicado de maneira informal, sem o intuito de abranger todos os aspectos necessários para a avaliação de módulos educacionais. De fato, trata-se de uma versão bastante preliminar, à qual devem ser incluídos outros fatores, tanto técnicos como pedagógicos, de modo a torná-la adequada e completa à avaliação dos módulos.

O questionário de avaliação, juntamente com a síntese dos resultados obtidos a partir de sua aplicação, são apresentados a seguir. Na Seção B.1 são apresentadas as questões pertinentes à usabilidade. Na Seção B.2 são ilustradas as questões relacionadas ao conteúdo do módulo. A Seção B.3 apresenta as questões referentes à navegação. Na Seção B.4 são abordadas questões gerais sobre o módulo. A síntese dos resultados observados é apresentada na Seção B.5.

\section{B.1 Usabilidade - Interface}

As questões de 1 a 6 referem-se à usabilidade do módulo em termos de sua interface, ou seja, a "aparência" das transparências elaboradas:

1. O tipo de interface utilizado no módulo educacional é adequado ao público-alvo do minicurso?
(a) SIM
(b) NÃO

2. As representações das funções da interface (ícones, links, etc.) são fáceis de serem reconhecidas/entendidas?
(a) SIM
(b) QUASE INTEIRAMENTE
(c) POUCO
(d) $\mathrm{NÃO}$

3. A quantidade de informação colocada em cada transparência é adequada?
(a) SIM
(b) QUASE INTEIRAMENTE
(c) POUCO
(d) NÃO

4. O módulo oferece uma linguagem sintaticamente homogênea, ou seja, de forma padronizada?
(a) SIM
(b) $\mathrm{N} \tilde{\mathrm{A} O}$

5. O módulo possui comportamento semelhante em situações semelhantes, ou seja, solicita do usuário ações similares para tarefas similares?
(a) SIM
(b) NÃO

6. As cores são utilizadas com equilíbrio, ou seja, são bem distribuídas evitando assim poluição visual?
(a) SIM
(b) QUASE INTEIRAMENTE
(c) POUCO
(d) NÃO

A Figura B.1 sintetiza os resultados obtidos, em termos das alternativas selecionadas, para as questões de 1 a 6 . 


\section{Usabilidade - Interface}

(57 avaliações válidas)

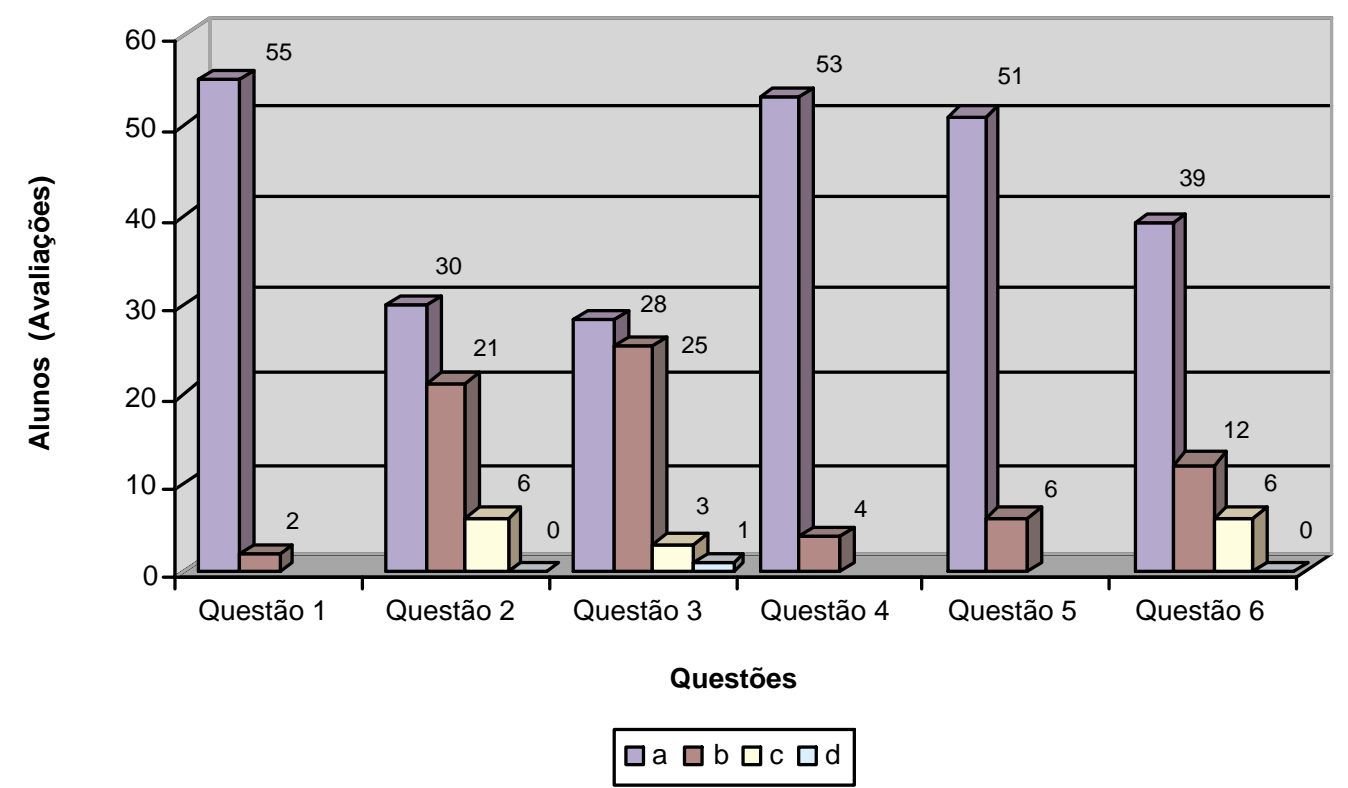

Figura B.1: Usabilidade: Alternativas Selecionadas para cada Questão.

\section{B.2 Conteúdo: Conceitos, Exemplos, Exercícios e Infor- mações Complementares}

As questões de 7 a 15 referem-se ao conteúdo do módulo educacional:

7. O módulo explicitou os conceitos com que se propõe a trabalhar?
(a) SIM
(b) NÃO

8. Todos os conceitos que você desejava trabalhar foram abordados no módulo?
(a) SIM
(b) QUASE INTEIRAMENTE
(c) POUCO
(d) NÃO

9. Existem conceitos abordados pelo módulo que você não desejava trabalhar ao utilizá-lo?
(a) SIM
(b) $\mathrm{NÃO}$

10. Se você respondeu SIM à questão anterior, o módulo permite que o conteúdo a ser abordado seja limitado de forma a incluir apenas o que se deseja trabalhar?
(a) SIM
(b) NÃO

11. O módulo explora, internamente, a conexão entre conceitos?
(a) SIM
(b) QUASE INTEIRAMENTE
(c) POUCO
(d) NÃO 
12. A forma com que os conceitos são abordados permite sua compreensão de forma adequada?
(a) SIM
(b) QUASE INTEIRAMENTE
(c) POUCO
(d) NÃO

13. Os exemplos apresentados pelo módulo são representativos dos conceitos a que se referem?
(a) SIM
(b) QUASE INTEIRAMENTE
(c) POUCO
(d) NÃO

14. Há equilíbrio entre o conteúdo exposto e os exercícios propostos?
(a) SIM
(b) QUASE INTEIRAMENTE
(c) POUCO
(d) NÃO

15. As informações complementares apresentadas pelo módulo são úteis no contexto a que se referem?
(a) SIM
(b) QUASE INTEIRAMENTE
(c) POUCO
(d) NÃO

A Figura B.2 ilustra os resultados obtidos para cada questão referente ao conteúdo do módulo. É importante observar que a Questão 10 é vinculada à Questão 9: o número de avaliações consideradas para a Questão 10 corresponde ao total de avaliações para a Questão 9 cuja alternativa selecionada foi (a), isto é, 26 avaliações.

\section{Conteúdo}

(53 avaliações válidas)

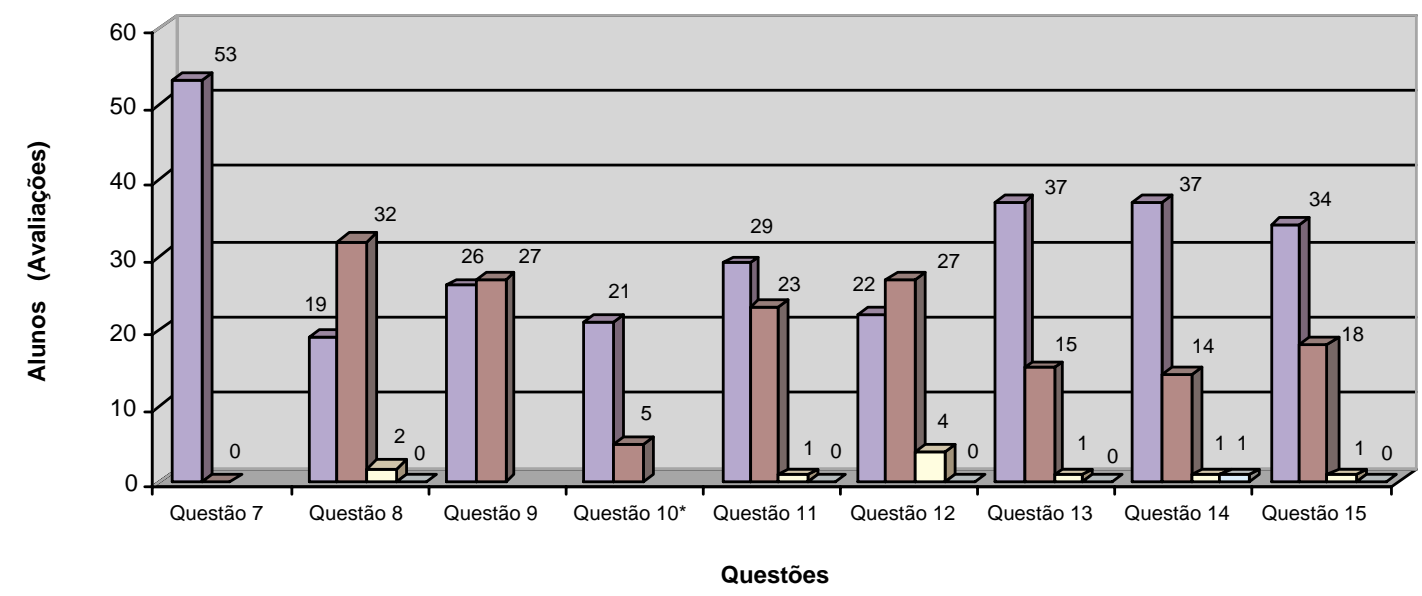

$\square a a^{b} \square c a d$

Questão 10 vinculada à Questão 9

Figura B.2: Conteúdo: Alternativas Selecionadas para cada Questão.

\section{B.3 Navegação}

Aspectos referentes às características de navegação do módulo foram abordados nas questões de 16 a $21:$ 
16. O módulo é objetivo, ou seja, possui um caminho objetivo que direciona para onde o aluno deve ir após a etapa em que se encontra, fazendo com que ele não se perca?
(a) SIM
(b) QUASE INTEIRAMENTE
(c) POUCO
(d) NÃO

17. O módulo apresenta facilidade de navegação?
(a) SIM
(b) QUASE INTEIRAMENTE
(c) POUCO
(d) NÃO

18. A quantia de links oferecida pelo módulo é adequada?
(a) SIM
(b) QUASE INTEIRAMENTE
(c) POUCO
(d) NÂO

19. O módulo possui modularidade das informações, ou seja, as informações são separadas por grupos?
(a) SIM
(b) QUASE INTEIRAMENTE
(c) POUCO
(d) $\mathrm{NÃO}$

20. O módulo contém um mapa de sua estrutura, de forma que o aluno saiba onde está e para onde pode ir?
(a) SIM
(b) $\mathrm{NÃO}$

21. Se você respondeu SIM à questão anterior, o mapa realmente auxilia na navegação?
(a) SIM
(b) QUASE INTEIRAMENTE
(c) POUCO
(d) $\mathrm{NÂO}$

A Figura B.3 ilustra os resultados obtidos para as questões de 16 a 21 . Observa-se que a Questão 21 é vinculada à Questão 20. Desse modo, para a Questão 21, 49 avaliações foram consideradas, o que representa o total de avaliações para a Questão 20 cuja alternativa escolhida foi (a).

\section{B.4 Aspectos Gerais}

Aspectos gerais referentes à utilização do módulo são tratados nas questões de 22 a 25:

22. Você recomendaria o minicurso? Por quê?

23. Quais aspectos do módulo educacional você considera como "pontos fortes"?

24. Quais aspectos do módulo educacional você considera como "pontos fracos"?

25. Sugestões para o melhoramento do módulo educacional e do minicurso associado. 


\section{Navegação}

(55 avaliações)

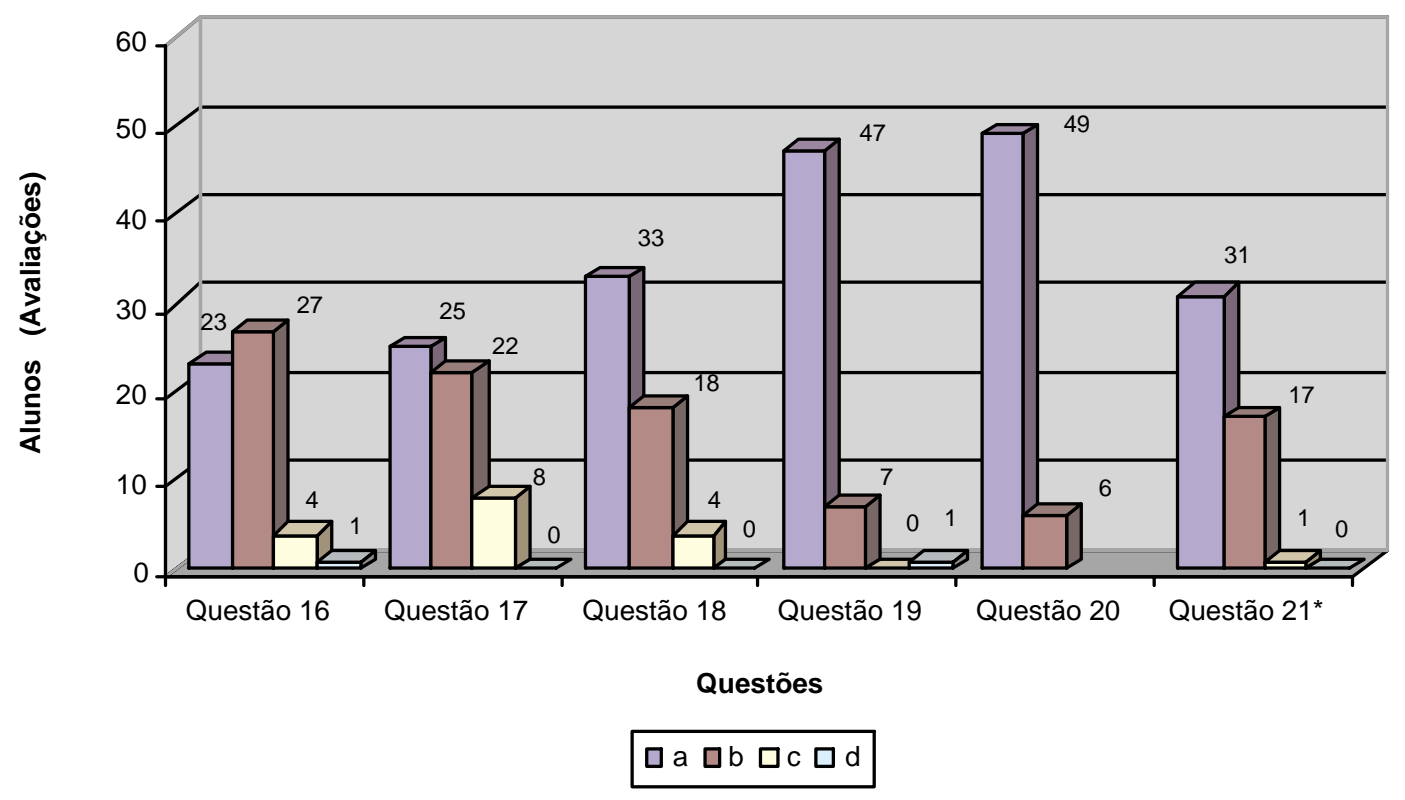

Questão 21 vinculada à Questão 20

Figura B.3: Navegação: Alternativas Selecionadas para cada Questão.

\section{B.5 Síntese dos Resultados Obtidos}

De modo geral, a partir da aplicação do questionário de avaliação foram observados os seguintes aspectos:

- No que se refere à usabilidade do módulo, o esquema de cores, a disposição das informações nas transparências e as representações das funções de interface (ícones, links) foram, em geral, aprovadas pelos alunos. Comentários específicos, entretanto, apontaram certo desconforto em relação ao tamanho das fontes e das figuras utilizadas.

- Quanto ao conteúdo, os alunos salientaram como aspectos positivos a estruturação e a abrangência dos assuntos abordados. A conexão entre os conceitos envolvidos também foi observada, juntamente com a adequação dos exemplos e informações complementares associadas. Com respeito aos exercícios propostos, observou-se a expectativa por problemas e situações práticas em que os alunos estivessem ativamente envolvidos. É importante ressaltar que, embora exercícios práticos abordando a utilização de ferramentas de teste tenham sido integrados ao módulo, o pouco tempo disponível para a realização do minicurso inviabilizou sua utilização. De fato, tais observações apontam para a necessidade de inclusão de exercícios práticos mais concisos e objetivos, que possam ser explorados em situações nas quais o tempo de apresentação do módulo seja pequeno. 
Além disso, comentários específicos indicaram certa repetição de tópicos, podendo resultar em cansaço durante a apresentação. A necessidade de inclusão dos pré-requisitos considerados no módulo também foi apontada.

- No que diz respeito à navegação, foi ressaltada a flexibilidade na escolha das seqüências de apresentação dos tópicos. Além disso, apesar da grande quantidade de informações disponibilizada, os alunos, de modo geral, não se sentiram "perdidos" no módulo.

Adicionalmente, além das características específicas do módulo, aspectos tais como velocidade de apresentação, dinamismo, objetividade e entusiasmo do instrutor também foram observados pelos alunos. 